\title{
Making Valuable Measurements
}

\section{Proceedings of the 1968 Standards Laboratory Conference}

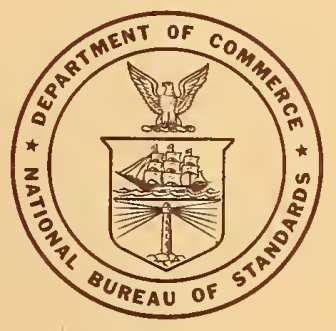

QC 100 457

1313 1969
United States Department of Commerce National Bureau of Standards Special Publication 313 


\section{PERIODICALS}

JOURNAL OF RESEARCH reports National Bureau of Standards research and development in physics, mathematics, chemistry, and engineering. Comprehensive scientific papers give complete details of the work, including laboratory data, experimental procedures, and theoretical and mathematical analyses. Illustrated with photographs, drawings, and charts.

Published in three sections, available separately:

\section{- Physics and Chemistry}

Papers of interest primarily to scientists working in these fields. This section covers a broad range of physical and chemical research, with major emphasis on standards of physical measurement, fundamental constants, and properties of matter. Issued six times a year. Annual subscription: Domestic, \$6.00; foreign, $\$ 7.25^{*}$.

\section{- Mathematical Sciences}

Studies and compilations designed mainly for the mathematician and theoretical physicist. Topics in mathematical statistics, theory of experiment design, numerical analysis, theoretical physics and chemistry, logical design and programming of computers and computer systems. Short numerical tables. Issued quarterly. Annual subscription: Domestic, $\$ 2.25$; foreign, $\$ 2.75^{*}$.

\section{- Engineering and Instrumentation}

Reporting results of interest chiefly to the engineer and the applied scientist. This section includes many of the new developments in instrumentation resulting from the Bureau's work in physical measurement, data processing, and development of test methods. It will also cover some of the work in acoustics, applied mechanics, building research, and cryogenic engineering. Issued quarterly. Annual subscription: Domestic, $\$ 2.75$; foreign, $\$ 3.50^{*}$.

\section{TECHNICAL NEWS BULLETIN}

The best single source of information concerning the Bureau's research, developmental, cooperative and publication activities, this monthly publication is designed for the industry-oriented individual whose daily work involves intimate contact with science and technology-for engineers, chemists, physicists, research managers, product-development managers, and company executives. Annual subscription: Domestic, $\$ 3.00$; foreign, $\$ 4.00^{*}$.

-Difference in price is due to extra cost of foreign mailing.

\section{NONPERIODICALS}

Applied Mathematics Series. Mathematical tables, manuals, and studies.

Building Science Series. Research results, test methods, and performance criteria of building materials, components, systems, and structures.

Handbooks. Recommended codes of engineering and industrial practice (including safety codes) developed in cooperation with interested industries, professional organizations, and regulatory bodies.

Special Publications. Proceedings of NBS conferences, bibliographies, annual reports, wall charts, pamphlets, etc.

Monographs. Major contributions to the technical literature on various subjects related to the Bureau's scientific and technical activities.

National Standard Reference Data Series. NSRDS provides quantitative data on the physical and chemical properties of materials, compiled from the world's literature and critically evaluated.

Product Standards. Provide requirements for sizes, types, quality and methods for testing various industrial products. These standards are developed cooperatively with interested Government and industry groups and provide the basis for common understanding of product characteristics for both buyers and sellers. Their use is voluntary.

Technical Notes. This series consists of communications and reports (covering both other agency and NBS-sponsored work) of limited or transitory interest.

Federal Information Processing Standards Publications. This series is the official publication within the Federal Government for information on standards adopted and promulgated under the Public Law 89-306, and Bureau of the Budget Circular A-86 entitled, Standardization of Data Elements and Codes in Data Systems.

\section{CLEARINGHOUSE}

The Clearinghouse for Federal Scientific and Technical Information, operated by NBS, supplies unclassified information related to Governmentgenerated science and technology in defense, space, atomic energy, and other national programs. For further information on Clearinghouse services, write:

\section{Clearinghouse \\ U.S. Department of Commerce Springfield, Virginia 22151}




\title{
Making Valuable Measurements
}

\section{Proceedings of the 1968 Standards \\ Laboratory Conference}

\author{
H. L. Mason, Editor \\ Presented by the National Conference of Standards Laboratories \\ August 26-29, 1968 \\ National Bureau of Standards \\ Boulder, Colorado 80302
}

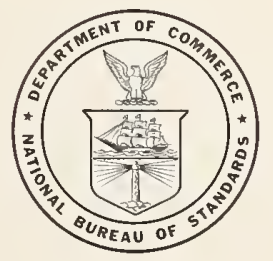

t.

NBS Special Publication 313 ,

Nat. Bur. Stand. (U.S.), Spee. Publ. 313, 177 pages (May 1969)

CODEN : XNBSA

Issued May 1969 


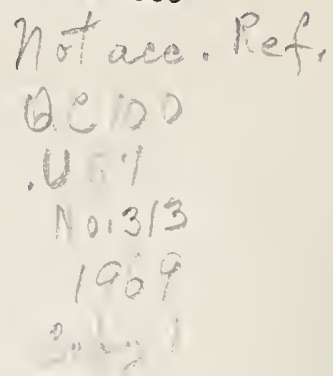

\begin{abstract}
The National Conference of Standards Laboratories is a nonprofit, laboratory-oriented organization whose purpose is to promote cooperative efforts toward solving the common problems faced by standards laboratories in their organization and operation. Established in 1961 under the sponsorship of the National Bureau of Standards, NCSL has a membership of more than 200 organizations. Three biennial national meetings have been held previously as well as a number of specialized regional workshops.

The theme of the 1968 Standards Laboratory Conference is "Making Valuable Measurements." The papers presented will attempt to answer the Who? When? Where? How? and Why? of making valuable measurements. The conference provides an opportunity for discussion of problems confronting laboratory managers and calibration personnel.

Representatives of member organizations of the National Conference of Standards Laboratories met at the Boulder facility of the National Bureau of Standards August 25-29, 1968. Major addresses were given by A. V. Astin and J. L. Sloop. Reports and discussions at eight sessions covered the management of valuable measurements : the management of equipment and data, measurement agreement comparisons, international practices, Defense Department activities, NBS activities, NCSL liaison, and NCSL committee work.
\end{abstract}

Key Words: Metrology management; National Conference of Standard Laboratories; physical measurement.

Library of Congress Cata log Card No. 63-60068 


\section{CHAIRMAN}

C. E. White

Aveo/MSD

\section{VICE CHAIRMEN}

E. J. Arsenaulit

General Electric Company

J. L. HAYES

Navy MEC-Pomona

H. W. LANCE

National Bureau of Standards

O. L. JINEBRINK

Battelle Memorial Institute

\section{SECRETARY}

J. F. HADLEY

Bendix Corporation

\section{TREASURER}

D. I. HERVIG

U.S. Army Sentinel System

\section{THE NATIONAL CONFERENCE OF STANDARDS LABORATORIES}

\section{SPONSOR'S DELEGATE}

E. AMBLER

National Bureau of Standards

\section{DELEGATE MEMBERS}

M. T. ANGELo

Lockheed-California Corporation

R. Y. BaIle Y

Newark Air Force Station

R. B. ERNST

North American Rockwell Corporation

R. H. VERITY

Leeds and Northrup Company

A. J. WOODINGTON

General Dynamies/Convair

\section{PAST CHAIRMAN}

J. R. VAN De Houten

Bell Aerosystems Company

1968 STANDARDS LABORATORY CONFERENCE

\section{CONFERENCE COORDINATOR}

E. J. Arsenault

General Electric Company

\section{TECHNICAL PROGRAM CHAIRMAN}

J. L. HAYES

Navy MEC-Pomona

COMMITTEE REPORTS CHAIRMAN

W. L. VANDAL

McDonnell-Douglas Corporation

LOCAL ARRANGEMENTS

George Goulette

University of Colorado

\section{PUBLIC RELATIONS CHAIRMAN}

J. F. HADLEY

Bendix Corporation

\section{PROCEEDINGS CHAIRMAN}

R. B. ERNST

North American Rockwell Corporation

\section{PROCEEDINGS EDITOR}

H. L. MASON

National Bureau of Standards

\section{LUNCHEON CHAIRMAN}

O. L. LINEBRINK

Battelle Memorial Institute 


\section{Foreword}

The National Conference of Standards Laboratories provides a means by which the country's standards laboratories may cooperate in generating and disseminating useful information relating to calibration techniques and to the operation of standards laboratories. NBS has therefore encouraged the organization and activities of the Conference, and will continue to provide assistance in mutually useful activities, as valuable supplements to the Bureau's work in disseminating accuracy of measurement throughout science and industry. The publication of the Proceedings of this Conference, containing papers presented at the national meeting, is one example of the Bureau's cooperation.

Most of the papers presented at the meeting are published in this volume. Primary responsibility for their technical content must rest, of course, with the individual authors and their organizations.

A. V. Astin, Director. 
NCSL 68

\section{Contents}

Foreword, A. V. Astin

On the Conference Theme, C. E. White

Keynote Address, A. V. Astin

Measurements for Society, J. L. Sloop

Session 1: DOD Activities, J. L. Hayes, Chairman

Activities of the DOD Calibration Coordination Group, R. Y. Bailey

Metrology and Calibration in DOD Quality and Reliability Operations, M. L. Fruechtenicht_.....- 11

Metrology and Calibration Considerations in Integrated Logistic Support Plans, S. Crandon_._... 14

Session 2. NCSL Liaison Delegate Reports, J. L. Hayes, Chairman

The Instrumentation and Measurement Group of the Institute of Electrical and Electronic Engineers,

F. L. Hermach $\ldots \ldots$

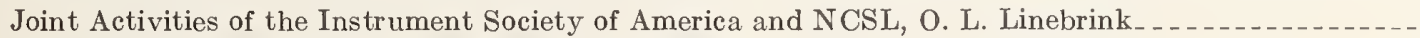

The Precision Measurements Association, R. B. Ernst_.

The American Ordnance Association, J. A. Mallison

Report of the Calibration and Standards Project of the Aeropsace Industries Association Quality

Assurance Committee, N. D. Smith

Session 3. NBS Activities, J. L. Hayes, Chairman

The Economic Value of Making Measurements, H. E. Morgan_

Maximum Use of Existing Accuracy in Measurements, R. S. Powers

New Directions for NBS Outputs, E. C. Wolzien

Highlights of the NBS Boulder Laboratories, T. M. Flynn

Session 4. International Measurements, H. W. Lance, Chairman

Measurement Control as a Valuable National Asset, C. E. White

Legal Metrology and Establishment of Metrology Centres in India, V. B. Mainkar........

Progress of the British Calibration Service, H. E. Barnett

Some Reflections Upon Common Measurement Systems, H. F. Monaghan_.

Progress in Adopting the Metric System in the United Kingdom, A. H. A. Wynn

Ireland and the Metric System, M. E. O'Hagan

The Value of International Measurements, R. H. C. Foxwell

Large Problems of Small Countries, L. Frank

Developments in the Canadian Measurement System, J. G. Cameron__._.

The Advantages and Disadvantages of Industrialized Nations Developing and Supporting A Dual

System of Weights and Measures, J. S. Weber

Session 5. NCSL Committee Reports, W. L. Vandal, Chairman

Information Committee A-6, P. H. Hunter and J. H. Blount

Recommended Practices Committee A-9, W. R. Holmes

Statistical Procedures Committee C-7, D. B. Sharp

Calibration Procedures Committee C-6, A. R. Baughman

Measurement Agreement Comparison Committee C-5, H. S. Ingraham, Jr

Procurement Regulations Committee B-7, F. J. Dyce.

Workload Control Committee B-1, D. J. Greb

Adjusting Calibration Intervals, R. H. Johnson_.

Session 6. The Value of Measurement Agreement Comparison, H. S. Ingraham., Jr, Chairman

An International Comparison of Power Standards at $3 \mathrm{GHz}, \mathrm{P}$. A. Hudson and G. F. Engen

Some U.S./U.K. Calibration Laboratory Measurement Comparisons, F. E. Parr

The NCSL Interlaboratory Comparison of 1965, H. L. Mason

The Interservice Measurement Audit Program, G. G. May 
Session 7. The Management of Equipment and Data, J. C. Shackelford, Chairman

An Information System for Standards Laboratories, W. J. Anson

Administrative Problems in the Introduction of an Automatic Measuring System, G. W. Pentico. . - 129

Processing Technical and Administrative Data within the Standards Laboratory, L. Darling -

Is There a Figure of Merit for the Measurement Process? L. Julie

Total Instrument Control, L. M. Auxier and L. A. Micco

Management Measurement Techniques for Calibration Laboratories, E. J. Arsenault_..... 146

Detecting Economic Obsolescence in Measurement Equipment, C. R. Duda

Calibration Data Collection and Utilization, W. L. Bates_.

Session 8. The Management of Valuable Measurements, A. J. Woodington, Chairman

Value Engineering Techniques-A Way of Managing Valuable Measurements, P. I. Harr

Government's View of Contractor's Management of Valuable Measurements, H. B. Berkowitz _._._. 165

Some Developments in the Management of Standards Activities in the NBS Institute for Basic Standards,

B. W. Birmingham _.

Weapon System User Management of Measurements, R. Y. Bailey

1967-1968 Report of the Chairman, C. E. White 


\section{NCSL 68}

\section{ON THE CONFERENCE THEME}

\section{E. White, NCSL Chairman}

Today we are gathered together in this wonderful bulwark of protection for, and sustainment of, our profession. The facilities and people of the National Bureau of Standards represent, in accordance with our laws, the ultimate word in the measurement standards of these United States. While we are here as guests of this widely respected agency of our government, it might be timely to make some introspective explorations of our minds, literally to search our souls, and to ask ourselves, "Why are we here?" and secondly, "Who cares?"

The theme of our Conference is "Making Valuable Measurements." It was not chosen by the Program Committee in a light manner. Rather, it is a reflection of the concern with which we view the whole structure of controlled measurements. It reflects the continuing displays, in a majority of U.S. industries, of the non-serious and non-appreciative attitude displayed by top management toward the impact upon the quality of products and goods of uncontrolled or poorly controlled measurements.

For an example of how simple it is to delude ourselves as to the worthiness and sacredness of our fight for recognition, consider our theme once again. As we say it to ourselves we emphasize each word in a positive, decisive, and self-satisfactory manner:

\section{MAKING VALUABLE MEASUREMENTS}

It is perfectly natural and logical that we hear it that way because that is the inflection we want to hear!

Suppose, however, we repeat those same words and we change the emphasis upon individual words, or change the inflection of our voices. If for instance we emphasize in this manner

\section{Making VALUABLE Measurements!}

we look toward management for a pat on the head and a "Well done," for we have contributed toward profits!

Changing the emphasis once again, let us repeat the phrase in this manner:

\section{Making Valuable MressuREMents!}

Now we look upon ourselves with pride, for we are emphasizing our profession. And of course all measurements we perform are valuable, for it is the nature of our profession to establish and control precision and accuracy, is it not?

But, is there a skeptic within sound of our spoken words? Perhaps he interprets this wonderful phrase in a slightly different manner, thus:

\section{Making valdable (?) Measurements}

or adds insult to injury by raising the inflection of his voice at the end of the phrase and in effect deriding the whole idea, thus:

\section{MAKlNG VALUABLE MEASUREMENTS? ?}

You who are gathered here today are faced with an extraordinary challenge. You know you can make measurements, but how valuable are they- to yourself, to your organization whether it is industrial, educational, or other, and finally to your na. tion? Yes-to your nation! For your nation's economy ultimately rests upon the acceptability of your work. Several times in the next few days you will find this theme repeated, both by our own nationals and by our guests from overseas.

The challenge then is for you to work diligently for a new attitude toward your work and your own participation, in order to earn the respect and cooperation of your management. For, too long a period of time has already ended, during which your role in management has been a passive one. Somewhat like the experience of Prof. Henry Higgins in "My Fair Lady," your management has "grown accustomed to your face" and "like breathing in and out" they regard your presence with a great deal of tolerance. You are after all, in 90 percent of industry, part of overhead and can be tolerated up to a certain point. But-don't forget what happens to a person when he stops "breathing in and out." The same thing can happen to your company or institution, if you and your measurement activities stop "breathing." When you gather together at the several scheduled sessions, think, discuss, and absorb as much as you can from the speakers who have worked so hard to bring to you much of value. Think beyond your daily routines, think beyond the walls of your laboratories, think in terms of top managementTHINK BIG! 


\title{
NCSL 68
}

\section{KEYNOTE ADDRESS}

\author{
Dr. A. V. Astin, Director, \\ National Bureau of Standards \\ Washington, D.C. 20234
}

It is always a pleasure for me to meet with the representatives of the National Conference of Standards Laboratories. We look upon this Conference as an indispensable link between the $\mathrm{Na}$ tional Bureau of Standards and the technological public which we serve, and for that reason your conference, your deliberations, and your membership have high priority in the attention of the $\mathrm{Na}$ tional Bureau of Standards.

I last had the privilege of speaking to you as a Conference when you helped us open up our new laboratories in Gaithersburg a little over two years ago. My purpose here today is to talk on the theme of your Conference, "Making Valuable Measurements."

The primary reasons for making measurements are, first, to increase our knowledge and understanding of the physical world in which we live, and second, to aid us in using that knowledge for a better life. In general, the value of a measurement will increase as its reliability and accuracy increase. The worth of a measurement is essentially the heart of the theme of this Conference.

An appreciation of the value of measurement goes back to the earliest times in recorded history. The science of geometry was invented largely to aid the Egyptians in measurement problems associated with keeping track of land records and with their magnificent structural achievements, many of which survive to this day. The Greeks had great appreciation for measurement. Socrates, as quoted in Book X of Plato's "Republic," made one 'of the best observations of the value of measurements that I recall. He discusses the illusions we are exposed to when we trust to our senses and do not resort to measurement, and is quoted as follows:

\begin{abstract}
Thus, every sort of confusion is revealed within us, and the arts of measuring, numbering, and weighing come to the rescue of the human understanding-there is the beauty of them-the apparent greater or less, or more, or heavier, no longer have mastery over us, but give way before measurement and calculation and weight.
\end{abstract}

Measurement, as you all know, began to assume scientific importance at the time of Gallileo, when he demonstrated that observation and measurement were the only ways to make a careful and meaningful analysis of theory, that they are the only ways in which we can systematically apply our knowledge about the properties of matter and materials. And, following Gallileo, of course, both measurement and science improved at a rapid pace. One hundred years ago, Lord Kelvin made the statement that you are all familiar with: ". . . when you can measure what you are speaking about and can express it with numbers, you know something about it. If you cannot measture it, and if you cannot express it in numbers, your knowledge is of a meager and an unsatisfactory kind." However, it seems to me that this statement resulted in a great deal of attention being given to measurement essentially for measurement's sake, without any real attempt to understand better the process of measurement or the theory of errors both random and systematic. More recently, the whole business of measurement was put into proportion in Charles Singers' "History of Scientific Ideas," when he says: "Science does not seek to solve ultimate problems; rather science seeks to solve its limited problems with a known degree of accuracy and known margin of error." This, in my judgment, emphasizes the aspect of measure.ment which gives it its greatest value.

In considering the subject of making valuable measurements, it should be useful to categorize measurement activity under three headings: First, there are those measurement activities aimed at increasing our understanding of natural phenomena. This essentially represents the work of the scientist, both basic and applied. Second, there are those measurement activities aimed at exploiting scientific and technical information for producing new or better goods or services or producing them more effectively. These measurement activities involve the work of the engineers and technologists. Third, there are those measurement activities aimed at achieving more effective interchangeability, including not only the interchangeability of information, but interchangeability of goods and services. This is the activity that relates directly to the work of this Conference, and is, of course, directly related to the effectiveness of the other two measurement activities.

In most cases, it is extremely difficult if not impossible to make an effective evaluation of a par- 
ticular act of measurement. The value of the act of measurement arises from the value of the objective for which the measurement may be an indispensable ingredient. But it is not fair to use the total value of that objective as the value of the measurement activity itself. Consider the nature of experimental science. Achievement of knowledge involves a complex interaction: scientists, resources of equipment, and experience with the measuring process, each of which is indispensable in terms of the discovery of new knowledge. In this case I think it would be more or less meaningless to attempt to assign a value to measurement activity - certainly we couldn't assign it solely to any of the elements; they are all necessary.

It becomes somewhat more meaningful, however, when we talk about trying to increase accuracy or precision, particularly when we consider the second and third categories of measurement activity that I spoke of. It is on this aspect that I want to put my emphasis, that is, efforts to improve the accuracy and reliability of measurements with which we are concerned. Even for measurements aimed at increasing basic understanding, increases in precision and accuracy have great importance. Of course, measurement activities in basic science seldom have specific objectives, because this would be contrary to the very nature of discovery. But it is important, even in basic science, that we continually be alert to understanding those factors which influence the reliability of a measurement result. Consider the area of atomic weights, which I think is one of the most spectacular in all scientific history. As atomic weights were measured more accurately, inconsistencies were discovered which required new theory to explain. The first go-around led to the discovery of the rare gases. Following this, there were still further refinements in our ability to measure atomic weights, and further inconsistencies arose which required new theory to explain these. The result was the discovery of isotopes. Then, still later, atomic weights were measured with even greater accuracy, and still further inconsistencies arose which required additional explanation. And this development, of course, led to the concept of packing fractions, and the equivalence of mass and energy.

In our efforts to improve accuracy in the other two categories-the exploitation of knowledge and the exchange of information and materialswe are able, I believe, to begin to get to the area where we can assign somewhat meaningful values and make predictions. In designing any technological device it is essential that we have confidence limits assigned to the characteristics which go into the design; otherwise the design is bound to be unreliable. Measurements on the production line are valuable in relation to quality control only insofar as they give us reliability and confidence in the product. I think you are all familiar with many instances of the sort. For example if the design requirements for a particular parameter call for a level of at least 50 units of the parameter and if we can measure this parameter only to plus or minus ten units, then it becomes necessary to over-design by this level of uncertainty, and generally over-design is costly. This is the sort of situation where you can relate value specifically to efforts to improve accuracy.

In the exchange of information or goods, reliability and accuracy of measurements are definitely associated with the reliability of exchange. The whole system of interchangeable manufacture, for example, requires parts which are interchangeable not only from the point of view of dimensional tolerances but for a variety of electrical, optical, and thermal characteristics.

Our program at the National Bureau of Standards on standards reference data is essentially aimed at exploiting published measured values, resolving their inconsistencies, assigning confidence limits to the values, and then making them available to the nation's scientists and engineers for research or design. Here, one can develop many techniques to evaluate improvements in the reliability of the data which increase the efficiency and effectiveness of the scientists and engineers who use them.

The appreciation of the importance of reliability in the exchange of scientific information and the exchange of technological goods and services has led to a number of significant developments which I should like to enumerate briefly. First of all, the NCSL, which is aimed essentially at adding to the reliability and confidence we have in the measured values of goods and services that enter into American industry. Second is the evolution of the national measurement system concept. You have heard from Dr. Huntoon about this concept. The primary focus is to increase our knowledge of the reliability of measurement activities through a better understanding of the inter-relationships of different measurement activities throughout the nation and throughout the world. In this process we have evolved the concept of a number of networks. In looking at the operation within the network, and understanding the interactions there, we are better able to assign values to efforts to improve reliability and confidence in these networks. First of all is the instrument network which involves a calibration process - the one I think most of you are more intimately associated with. Then there is the techniques network, and finally there is the data network. The National Standards Reference Data System which I mentioned a moment ago is, of course, a part of the data network; data being one of the products of the measurement process.

Then, we have a number of international arrangements which seek to increase reliability and effectiveness of the exchange mechanisms for scientific and technical information, and for technological goods and services. Senior place in this 
group of international mechanisms is filled by the International Bureau of Weights and Measures, which seeks to provide reliable and reproducible standards for the units in which all measurements must be expressed. Next is the International Organization for Legal Metrology, which seeks to develop reliable testing techniques and instruments for the measurement of quantity and quality. Next are two related organizations, the International Standards Organization and the International Electrotechnical Commission, which aim at the development of engineering standards, based on, first of all, criteria for the performance of goods and services, and then on measurement techniques to determine performance to such criteria.

Our concern with the value of improved accuracy in measurement has led to significant advances in recent decades in the science of error determination. I'd like to mention a few. First of all are the phenomenal advances that have been made in the statistical sciences, whereby a number of techniques have been evolved which help us to sort out and evaluate random errors in the measurement process. These have been very useful. You've heard reports on a number of NBS contributions to this field at previous meetings of NCSL. Second are the approaches aimed at understanding better the interaction of the measurement process with the object being measured. This is the area which must be explored further if we are to reduce systematic errors in the measurement process. We need to know how the act of measurement itself will influence or alter the measured value. Third are the developments aimed at defining more precisely what it is that we want to measure. This becomes extremely important if we are to make progress in reducing the uncertainty associated with physical measurement. For example, if we push extensively the business of trying to measure the characteristics of a surface, or the level of the surface, or the position of the surface, ultimately we get down to a position where molecular structure and molecular vibration will provide limits beyond which we cannot go.

Coming to the subject of value itself (this is a most difficult task; you're going to hear some discussion about it during your sessions) we of the National Bureau of Standards are very much concerned in trying to evolve techniques for assigning benefit values, hopefully measured in dollars, to a measurement process, or particularly to efforts to achieve increased accuracy or reliability in the measurement processes. We have found that our development of the concept of a measurement system is helpful in this respect, because by understanding better the inter-relatedness of measurement activities to each other and to the achievement of a variety of objectives, we think we are in a better way to make progress in assigning cost values, if not to all, at least to some significant measurement processes. Tomorrow morning we are going to hear about some of our efforts in this direction from Dr. Howard Morgan of our Technical Analysis Division.

In this business of the cost of measurement activities, the cost of making changes, and the improvement of measurement activities, I want to divert for a moment to announce a recent development that all of you may not be familiar with; and that is that the Congress has finally, after many years of discussion and debate, passed a piece of legislation to authorize a study of the problems associated with the increased use of the metric system around the world. The President signed this bill on the 9th of August. There is one hitch in this bill. It directs that during this fiscal year, the study must be undertaken with no additional funds, so our efforts during the fiscal year 1969 will largely be associated with planning. However, we are here definitely confronted with cost/benefit or benefit/cost types of studies. We want to be able to understand the economic impact upon this country of the fact that within a few years all of the technologically sophisticated nations of the world, except the United States and Canada, will be using the metric system unless some change is made. We want to understand the costs associated with whatever changes it seems desirable for us to make. We want to understand what benefits might be derived from such changes. So, we are going to need in this study the best techniques that are available in relating measurement activities to benefit/cost analysis.

Our own effort is being headed by A. G. McNish whom I think many of the members of this Conference know well; he has participated in a number of your activities in the past. We are planning to draw on other resources of the Department of Commerce such as the Office of Business and Defense Services, Census Bureau, Office of Business Economics, as well as the Office of International Trade. Since our fiscal resources are limited, we need help from volunteers, and I earnestly solicit offers of cooperation from you gentlemen. If you would like to contribute to this study, please let us know.

In summary, I would like to say that measurement becomes valuable largely through the confidence and reliability that we can give to a measured value. In addition, measurement is indispensable, as I have pointed out, in achieving many important objectives. But the inherent worth of a particular measurement or a series of measurements is the confidence you have in the results, and the value of measurement activity is usually increased as we improve the reliability and reduce the margin of errors. I'd like to wish you success in your deliberations here over the next few days. It might be that if you can come up with some suggestions for assigning values to various acts of measurement, this may be one of the best measurements we can have. 


\title{
NCSL 68
}

\section{MEASUREMENTS FOR SOCIETY}

\author{
John L. Sloop \\ Assistant Associate Administrator for Advanced Research and Technology, \\ National Aeronautics and Space Administration \\ Washington, D.C. 20546
}

This Conference has been particularly revealing and useful to me. In conducting applied research in propulsion for twenty years, I took measurement standards pretty much for granted. In more recent years of research management, they became even more remote. As Charles White points out, the science of measurement is as old as man's known activities-at least 3,000 years B.C.-and ". . . far more people know more about the principles of good health and medicine than they do of the principles of accurate measurement." He relates poor measurement to scrapped products and waste and, in view of about 20 million measurements made each day, the importance of metrology to science and technology is very great indeed. I salute your work, through this Conference, for improving technical communication and for making the significance of measurements better known.

As I thought about your efforts, a number of recent ideas for new measurements and the need for more accurate measurements came to mind. The use of lasers to measure continental drift, for example, or the need for extremely accurate clocks for use in air traffic control for collision avoidance in the era of supersonic transportation. I am sure, however, that you are well aware of these new measurement challenges. So I have chosen to talk instead, about the need for a different kind of measurement-one focused on the role of science and technology in our society. What yardstick can we apply to measure their importance? How can we assess their impact on social and economic progress? How can we determine how much of our national resources should be devoted to science and technology? For you who deal with exact physical relationships, these intangibles must be the antithesis of your activities. Yet they are equally needed and equally vital to our advancement as are physical measurements. For they are the factors, in one form or another, that are used by decision-makers in government, industry, and universities in balancing science and technology with other social and economic needs.
In the last ten years, the United States has tripled the amount of annual expenditures for research and development-from 5 billion dollars in 1958 to 17 billion dollars this year. What benefits has this brought?

We have only to look about us to see the many changes that have taken place in the last ten years - the improvements and the problems. We enjoy better health and housing, a bountiful production of food and consumer goods, rapid trans. portation and communications, more education for more of us, and more leisure and recreation. But we can also see pollution of our air and our streams, crowding on our highways and in our cities, and mounting problems of disposal of waste from an affluent society.

Europe sees a direct link between our capability in innovation, education, and management and our economic growth. Servan-Schrieber's book "The American Challenge" deals with the American economic invasion of Europe and it has aroused great interest there. In looking at the "American Colossus," Servan-Schrieber points out that "American industry produces twice the goods and services of all European industry combined. . . . It produces a third of the total production of all other countries in the world. The Americans have achieved this with only seven percent of the surface of the globe and six percent of its population. One third of all students in the world pursuing a higher education are American. ... All by themselves, the Americans consume a third of the total world production of energy, and has one third of all the world's highways. Half the passenger miles flown each year are by American airlines. Two trucks of every five on the road are Americanmade and American-based. Americans own three out of every five automobiles in the world." $\mathrm{He}$ adds "Advanced technology and management skills have raised per capita production in the United States to a level 40 percent above that of Sweden (next highest), 60 percent above Germany, 70 percent above France and 80 percent above Britain." 
These statistics and the forces behind them make a very strong case for science and technology. But we live in a period of rapid change and of questioning of all aspects of our social and economic structure. Science and technology are experiencing the full searchlight of this inquiry.

In this process of questioning, critics of technology are speaking out. Lewis Mumford in "The Myth of the Machine" questions the part that technology plays in human development. He believes "megatechnics" will lead to man as ". . . a passive, purposeless, machine-conditioned animal whose proper functions, as technicians now interpret man's role, will either be fed into the machine or strictly limited and controlled for the benefit of de-personalized, collective organization." In short, he argues that we are overcomitted to technics. Wilbur H. Ferry, in the March 3 issue of Saturday Review, echoes the same theme in saying that the infatuation with science and technology is bottomless, and he argues that we must control technology before it controls us. I am sure there are others with similar views.

Critics and proponents alike will agree, I believe, that science and technology can and do bring beneficial results. The issue goes beyond that. It revolves around What science and technologv? How much? and How is it to be used? To answer these questions, we need a good method of measurement or assessment of the impact of science and technology on societ $y$.

In the words of Conoressman Emilio Q. Daddario of Connecticut, "The past few years have brought a change in attitude toward science and technology, both in the public, which is now more technically literate, and in Congress, with its enhanced understanding. Faith in science, and awe of technology, have been supplanted by a recognition of a grave responsibility for decision-that is, what should we do with what we know?" He goes on to say, "Technology assessment is a major key to discharging that responsibility. We are now turning to the natural sciences and asking them to move further in achieving a collective wisdom with politics, law, economics, and social interests for the management of technology."

Aircraft and space technology, carried ont by the NASA, are parts of the nation's total R\&D effort. Aircraft technology is a key element in the rapid growth of air transportation. Aircraft technology comes from the contributions of military needs and from over fifty years of continuous aeronautical research by NASA and its predecessor the NACA-the National Advisory Committee on Aeronautics. Let us take a look at the growth of air transportation. In 1967, United States domestic and international passenger service reached 99 billion passenger miles with 132 million passengers. This is three times the passenger miles of 1958 but only one-third of what the Federal Aviation Administration forecasts for 1977 . In addition, there are over a hundred thousand private aircraft aerospace products in 1967 was 27.2 billion dollars.

We believe that future growth in air transportation requires a continuous support for research and aircraft technology. There is a large future potential in short-haul types of aircraft between and within large urban centers. These V/STOL types, as they are called, have been worked on for a long time but their economical production and operation remain locked in technical problems. The rapid growth of the past has brought problems of noise, pollution, crowded airways, and safety; these must be solved for future growth and social acceptance. There is much to be done.

The benefits of the younger space technology are only beginning to unfold. Briefly, here is where we stand in ten short years:

- The start of a world-wide communication network by satellite organized and operated as a commercial business. Live TV broadcasts of significant events from other continents is getting to be commonplace.

- A world-wide meteorological network created and turned over to the Environmental Sciences and today, and this may double by 1977 . Total sales of Services Administration. Forty countries have automatic picture taking equipment and can get local cloud cover data direct from our Nimbus satellite.

- A greatly increased scientific understanding of our earth and its space environment through measurements by scientific satellites (Explorers, Pioneers, IMP's).

- Beautiful reconnaissance photographs of the moon by five Lunar Orbiter flights and unmanned landing of five Surveyor spacecraft on the moon with close-up photographs of its surface and tests of its soil characteristics.

- Mariner flights to Venus and Mars, measurements made in their vicinity and the pictures of the Martian surface.

- The wonderful, successful Mercury and Gemini flights that laid the base for man's exploration of space, beginning with Apollo flights to the moon.

- The growth in technologies that provides the foundation for future space missions and which stimulates applications on earth.

Yes, we have come a long way in ten years but much more remains to be done. What about the future? Dr. H. A. Hess, Chairman of the Space Science Board of the National Academy of Sciences, points out that the future space program can best be aimed at two goals : the exploitation of space technology for science, and the use of space technology to support applications of benefit to society. The latter goal includes satellites for communication, meteorology, and information handling and, I would add, other technologies serving the basic needs of society. An example of the latter is electronics, an area not exclusively supported by space technology but which is a major element in 
space systems. Let me turn again to ServanSchrieber, who calls electronics the basis for the second industrial revolution-where the labor of the human brain is replaced by computers. He indicates that already American corporations in Europe control 15 percent of the electronic consumer goods, 50 percent of semi-conductors, 80 percent of computers, and 95 percent of integrated circuits. $\mathrm{He}$ attributes American strength in electronics to government help, pointing out that 65 percent of the electronic business is by government contract and 85 percent of the R\&D is government sponsored.

As you know, the Space Program has been receiving its share of criticism and the full brunt of the cut in spending. Such headlines as "U.S. Space Program: Economy Ax Victim?" are not uncommon nor are editorials such as "The Decline of Space." Many of the criticisms focus on the mission-oriented aspect of the program and not the broad benefits and implications of the technology that are evolving. This month the agency announced an interim operating plan of $\$ 3.85$ billion, reflecting a $\$ 362$ million reduction by Congress in appropriation requests, with consideration of further possible reductions under the Capital
Revenue and Capital Expenditure Act of 1968. As Mr. Webb has put it, "The totality of problems our nation faces reaches far beyond NASA. As responsible government officials, we in NASA accept the results of our nation's decision making processes." $\mathrm{He}$ emphasized, however, the need to continue a broad program of advanced research to provide technology for future national needs in aeronautics and space. Deeply conscious of the larger responsibility of the agency, Mr. Webb has continuously stimulated studies to assess the impact of aeronautics and space technology on our society. One such study, conducted by the American Academy of Arts and Sciences, resulted in a book "Social Indicators", a first and important step towards the types of measurements that we need. I will quote from its Foreword by Earl P. Stevenson as my closing thought: "The Space Program is not, of course, the unique or the sole agent of technological change in American society; NASA, however, is a pioneer among government agencies in its sensitivity to the wideranging nature of its effects on society and in its awareness of the need to develop methods for anticipating these effects and-if possible-bringing them under some degree of conscious control." 

NCSL 68

\title{
SESSION 1: DOD ACTIVITIES
}

\author{
Chairman: J. L. Hayes \\ U.S. Navy Metrology Engineering Center, Pomona, California 91766
}

\section{ACTIVITIES OF THE DOD CALIBRATION COORDINATION GROUP}

\author{
Ray Y. Bailey
}

\begin{abstract}
Deputy Chief, Air Force Calibration and Metrology Division, Newark Air Force Station, Ohio 43055
The Department of Defense Calibration Coordination Group (DOD/CCG) is established to provide coordination and cooperation among the three Services in their calibration and metrology programs and in their relations with the National Bureau of Standards (NBS).
\end{abstract}

\section{Introduction}

On December 2, 1966, a task group of Army, Navy, and Air Force personnel was established by the Office of the Deputy Director, Research and Engineering (OOD R\&E) and the Office of the Assistant Secretary of Defense, Installation and Logistics (OASD/I\&L). The initial assignment of this task group was to develop a more effective relationship between the DOD and the NBS. The task group formed the DOD/CCG to carry out their recommendations. Additional responsibilities have been assigned to the DOD/CCG to improve interservice coordination and cooperation on their calibration and metrology programs.

\section{DOD/CCG Membership}

The members of the DOD/CCG selected by each of the Military Departments are: (a) Melvin L. Fruechtenicht, Army; (b) Jerry L. Hayes, Navy; and (c) Ray Y. Bailey, Air Force, the latter serving as chairman for the first two years. The chairmanship will rotate among the members.

\section{Department of Defense/National Bureau of Standards Agreement}

The CCG prepared a proposed Memorandum of Agreement for the DOD and NBS. This agreement was submitted to the NBS in September 1967. The agreement was approved by the NBS in January 1968, and with minor changes subsequently approved by DOD. Basically, this agreement establishes a procedure for: (a) determining DOD requirements for calibration services and calibration engineering; (b) reviewing these requirements with the NBS and determining costs; and (c) funding for the required calibration and related engineering services.

The DOD/CCG will determine requirements for five years in advance. The initial presentation of requirements was made to the NBS for FY 1969. Through this combined effort the NBS can better plan its course of actions to support the DOD requirements. In addition, the DOD will gain more effective utilization of funds programmed for support of calibration services and calibration engineering provided by the NBS.

\section{DOD/CCG Working Groups}

The DOD/CCG has established 14 working groups to carly out interservice coordination. Nine of these groups are engineering working groups in specific measurement categories. These are: Direct Current and Low Frequency; R F Measurements; Field Intensity; Frequency and Time; Infrared and Lasers; Flow; Force and Mass; Pressure, Vacuum, and Leak; Shock and Vibration.

It is planned to establish two additional engineering working groups, one on Time Domain and one on Transducer Dynamics. The functions of the engineering working groups are: (1) Determine measurement requirements of common interest and the method of support; (2) Review of engineering projects being performed in-house; (3) Review of equipment evaluation results; (4) Determine requirements for engineering projects which cannot be performed in-house; (5) Determine requirements for new or improved calibration services from NBS.

Through the efforts of the engineering working groups, the program for future NBS requirements is developed for the CCG. 
Other working groups and their mission and accomplishments are listed below :

Catibration Procedures Working Group: This group is responsible for standardizing the technical procedures so that all three Services can use a procedure written by any one of the Services. They have written a Military Specification MILC-24133 for this purpose. (This Mil Spec is much the same as the recommended form as prepared by the NCSL Procedures Committee.)

Calibnation Intervals Working Group: This group is responsible for reviewing calibration intervals and establishing common policies for changing intervals. This group has not established common policies at this point in time.

Calibration Training Working Group: This group is responsible for coordinating and standardizing calibration training courses for the three
Services. As a result of their efforts, the Air Force and Navy have established joint Calibration training courses at Lowry Air Force Base, Denver, Colorado.

Calibration Workload Interservice Working Group: This group is responsible for analyzing calibration workloads and recommending support agreements between specific organizations. Workload exchange or support from one Service to another is common practice today.

\section{Conclusion}

It can be seen from the activities of the DOD/ CCG and the subgroups that considerable progress has been made in interservice coordination and cooperation. The members of the CCG are quite sure that further advances in such coordination and cooperation will occur in the future. 


\title{
METROLOGY AND CALIBRATION IN DOD QUALITY AND RELIABILITY OPERATIONS
}

\author{
Melvin L. Fruechtenicht \\ Army Metrology and Calibration Center, Army Missile Command, Huntsville, Alabama 35812 \\ A Department of Defense Conference on Quality and Reliability Management was held \\ in August 1966 at Annapolis, Maryland. Panel 8 addressed the subject of the role of \\ metrology (measurement science) and calibration (measurement service) in quality and \\ reliability operations. The report of Panel 8, which is reproduced on the following pages, \\ discussed the following topics : 1 . Identification of new measurement and calibration require- \\ ments; 2. Selection of proper test and inspection equipment and measurement processes; \\ 3. Promulgation of uniform specifications controlling contractors' calibration systems; \\ 4. Provision of metrology support to contract administration personnel ; 5. Establishment \\ of a central point of contact within the Office of the Secretary of Defense responsible for \\ overall policy for metrology and calibration and for coordination with other Government \\ agencies.
}

\section{Identification of New Measurement and Calibration Requirements}

Identification of new systems measurement requirements which are beyond the current state-ofthe-art must be accomplished as early as possible in the materiel life cycle, preferably in the concept stage, to permit maximum lead time for development of supporting standards and instrumentation. Normally the systems development contractor is in the best position to identify and analyze such requirements.

The services and NASA have used several approaches to the problem of early identification of new measurement requirements with varying degrees of success. Documents such as MIL-Q-9858A (DoD), Quality Program Requirements, MILD-9412D (USAF), Data for Aerospace Ground Equipment; and MIL-Q-21549B (IVEP), Product Quality Program Requirements for Fleet Ballistic Missile Weapon System Contractors, contain general requirements. More specific requirements have been outlined in special contract provisions; however, there is no uniform method for submission of such data prescribed by directive or ASPR.

The nature of system development is such that priority of engineering effort is normally directed at development of operational hardware. Consideration for reproducible measurements that will be required to support development and testing is often overlooked until a crisis arises in connection with compatibility of test data.

The forecast of such measurement requirements may require research or development action by the National Bureau of Standards to establish an appropriate national standard. Also, it will afford time to develop test equipment to measure the necessary parameters on a production basis, which is necessary to the successful production of state- of-the-art components. A hasty selection of inappropriate equipment could thereby be avoided.

A complete review of the specifications and contract clauses now included in systems development contracts within DoD is necessary to determine whether new contract language or a revision to existing military specifications is needed. The revision or expansion of MIL-D-9412D (Air Force) to make it applicable to the collection of state-of the-art measurement requirement data as well as systems calibration requirements information is a possible solution.

Experience has shown that, regardless of contract method, the forecast of new measurement requirements is difficult to achieve and often delayed. While the identification of metrology problems to NBS and the service metrology centers has been accomplished by rather informal methods, the concern here is with early, and perhaps more formal identification, so that the lack of ability to measure does not become a deterrent to technological progress or the excuse for lack of ability to determine quality.

\section{Recommendation}

It is recommended that DoD prepare contract language and/or a military specification to require systems development contractors to identify, analyze, and advise the metrology engineering centers, through the contracting officers, of potential new state-of-the-art measurement problems early in the development phase of the materiel.

\section{Selection of Proper Test and Inspection Equipment and Measurement Processes}

Inadequate emphasis is being placed on the proper selection and support of test and measuring 
equipment in research, development, design, production, quality control, and operation and maintenance stages and in monitoring the adequacy of test equipment and its usage in research and development activities.

The literature and technology of instrumentation is widely scattered and difficult to research; hence, the selection of instruments and the techniques for their application are equally difficult. Measurement needs are freqently overwhelmed by "gold plating" or are only partially satisfied. There is a need for the generation and publication of technical guidance to provide assistance for optimizing equipment selection.

Developers, development agencies, and commodity managers, in their zeal to deploy military equipment to meet requirement schedules all too frequently fail to avail themselves of the metrology competence of standards and calibration laboratory personnel and similar specialists in the selection of test and measuring instruments for the field. This has frequently resulted in the fielding of expensive, overly precise, or overly accurate test and measuring instruments.

The losses due to unreliable measuring instruments are inestimable. DoD decision makers must have reliable, accurate data on which to base their conclusions and recommendations. The final data obtained by testing assembled hardware must be sufficiently consistent and repeatable to prove the confidence level of reliability estimates. This can only be achieved through provision of effective equipment, measurement techniques, and data feedback systems.

\section{Recommendations}

That DoD generate and publish a technical guide for use by Government and contractor engineering personnel to aid in selecting test and inspection equipment. The guide should emphasize and/or require the use of metrology and calibration personnel to aid Government and contractor research and design engineering personnel in test equipment selection.

That a requirement be placed in individual service regulations or exisiting regulations to insure that the test and measuring instruments of research and development activities will be subjected to the same quality control measures as are those in other phases of the materiel life cycle.

That DoD revise appropriate military specifications to require controls over the selection, performance, and application of test equipment in DoD contracts.

That DoD develop a training course for engineering and contract administration personnel in the selection and application of test and measuring equipment.

\section{Promulgation of Uniform Specifications Controlling Contractors' Calibration Systems}

Specifications often referenced or required by contracts that delineate calibration requirements are: MIL-Q-9858A, MIL-I-45208A, MIL-C45662A, MIL-C-55163 (Sig. C), MIL-Q-21549B (WEP), NASA NPC-200-1A, NASA NPC-2002, MII-I-45607, MIL-I-8500B and MIL-Handbook 50,51 and 52. These specifications differ as to the extent of the requirements for calibration and measurements.

As examples of confusion created, some specifications require adherence to a strict 10 to $1 \mathrm{accu}-$ racy ratio, while others make no reference to such ratios. Some specifications are not clear as to the requirements for recording results of calibration. Other specifications allude to the requirements for a mandatory recall system whereas still others are specific.

Due to the problems created, Government contract evaluation agencies find it difficult to enforce and administer contractual provisions as envisioned by the procuring agencies.

It is important that NASA and DoD calibration system requirements be consolidated into one specification. Many R\&D contracts, particularly those which are for research studies or do not require fabrication of hardware, do not require control of measuring and test equipment. In many of these contracts, measurement data represent the product, and control of these data is essential.

There are measurements being made of physical or material phenomena by $R \& D$ contractors which must be supported by measuring equipment of known accuracies. In many of these contracts, measurement data represent the product and control of this product's quality is essential. In addition, some small business contracts do not contain requirements for the control of measurement devices. Small business contractors are performing measurements of products with devices which must also be of known accuracy.

\section{Recommendations}

That MIL-C-45662A be revised and adopted as the standard calibration specification to be referenced in all Government contracts including small business and R\&D contractors where measurements are to be performed.

That purchasing officers be required by ASPR or directive to include applicable portions of the revised specification in addition to the special provisions of Standard Form 32.

\section{Provision of Metrology Support to Con- tract Administration Personnel}

There is a lack of understanding of the need for calibration and metrology among Government 
and contractor personnel. To overcome this lack of understanding, it is recommended that an orientation film and lecture material be developed for presentation. The Navy and the Air Force both have films which were developed for the particular requirements of their personnel. These films have proved very successful in motivating and indoctrinating personnel in the specific requirements for calibration and metrology in these military departments. These films could be used as guides in the development of a new film for presentation on a wider scale. (AF Film SFP-1047 "USAF Calibration" and USN Film MN-10105 "Why Calibrate".)

The calibration and measurement specialists in the cognizant contract administration organizations are trained in the overall evaluation of contractor's programs. However, there is a need for specialized support and training in certain measurement areas such as optics, microwaves, pressure, flow and others. Training courses are available in the military services and from commercial sources in most of the specialized areas. A catalog of available courses should be compiled to provide a ready reference for determining where specific training can be provided. The military metrology engineering centers can also provide specialized training and technical assistance to the cognizant contract administration personnel.

\section{Recommendations}

That DoD develop an orientation program for Government and contractor personnel to provide general knowledge of the requirements for a calibration and metrology program in the contractors' plants.

That DoD determine specialized training requirements for Government calibration and meas- urements personnel to improve and augment their capability to evaluate contractors' programs. A catalog of available calibration training courses should be provided. Whenever the specific capability is not available from the cognizant contract administration organization, the technical assistance of the military metrology engineering centers should be requested.

\section{Establishment of a Central Point of Contact}

For the past eight years, the three Departments and AEC have participated in combined meetings to discuss mutual problems concerning metrology engineering and calibration services. These meetings contributed to the important resolution of several problems which interface with NASA, AEC, Department of Commerce, and other Government agencies requiring coordination at the OSD level. However, there is no central point of contact within OSD responsible for overall policy for metrology and calibration, or through which DoD components can present problems involving coordination with other Government agencies. There needs to be a designated office within OSD to provide general policy on metrology and calibration and through which coordination can be attained with Government agencies outside of the DoD. This action will serve the interest of OSD as well as the three Departments and DSA.

\section{Recommendation}

That OSD designate a specific office within OSD (DDR\&E, ASD (I\&L), possibly the DoD Quality and Reliability Council) for policy direction and to serve as a central point of contact for metrology and calibration matters. 


\title{
METROLOGY AND CALIBRATION CONSIDERATIONS IN INTEGRATED LOGISTIC SUPPORT PLANS
}

\author{
Stanley Crandon \\ Deputy Metrology Technical Director, U.S. Bureau of Naval Weapons Metrology Engineering Center, \\ Pomona, California 91766

\begin{abstract}
Integrated Logistic Support is defined by the Department of Defense as a "composite of the elements necessary to assure effective and economical support of a system or equipment at all levels of maintenance for its programmed life cycle." The significant elements of Integrated Logistic Support are planned maintenance, support personnel, technical data, support equipment, spares and repair parts, and facilities. The need for timely and increased emphasis of calibration and metrology considerations in Integrated Logistic Support Plans is examined and discussed.
\end{abstract}

\section{Introduction}

Present Department of Defense policies require the development of integrated logistic support for a new system or equipment concurrently with the performance requirements or at the earliest possible time in the conceptual phase. To meet this requirement, logisticians actively participate in all major phases of development projects--fundamental requirements, feasibility studies, Technical Development Plan (TDP), Project Definition Phase (PDP), bidders' conference, contract negotiation, evaluations of proposals, in-process reviews, engineering change proposals, and service teststo assure ihat logistic support is planned and acquired in an orderly and systematic manner.

Considerable importance is placed by the logisticians on the ability to properly evaluate the readiness of a system to meet its mission requirements, and to perform preventive or corrective maintenance actions when required. Such actions require meaningful measurements; however, as metrologists know, meaningful measurements are a combination of many different factors and are not achieved by mandate or directive.

This paper is directed toward the need for early consideration of metrology and calibration requirements in developing logistic suport for systems and major items of equipment and to the concept of having a professional metrologist and/or calibration engineer as an active member of the Integrated Logistics Support Management Team.

\section{Integrated Logistic Support}

A relatively new concept in Department of Defense procurement of systems and material is Integrated Logistic Support. DOD Directive 4100.35 defines Integrated Logistic Support as "a composite of the elements necessary to assure the ef- fective and economical support of a system or equipment at all levels of maintenance for its programmed life cycle." The significant elements of Integrated Logistic Support are:

(1) planned maintenance-which includes servicing, repair, inspection, corrosion control, calibration, overhaul, modification, handling, and storage;

(2) logistic support personnel-covering skills, performance requirements, training requirements, human factors engineering, special devices, safety, survival, clothing, escape and rescue, and stress;

(3) technical logistic data and informationwhich includes, but is not limited to, production and engineering data, prints and drawings, standards, specifications, technical manuals, inspection and testing procedures, changes and modifications, and performance and failure data;

(4) support equipment--such as special purpose vehicles, power units, maintenance stands, test equipment, special tools, and test benches used to facilitate or support maintenance actions, diagnose malfunctions, or monitor operational status of systems, subsystems or equipments ;

(5) spares and repair parts-used for maintenance replacement purposes in major end-items or for repair of spares of major end-items; and

(6) facilities-including buildings and associated equipment required for, or to contribute to, system or equipment maintenance.

\section{Integrated Logistic Support Plan}

Development of an Integrated Logistic Support (ILS) Plan for a particular end-item, whether this be an aircraft, missile, computer, navigation sub-system, or automatic test equipment complex, is designed to meet the performance and readiness requirements established by the Project Manager for the entire life cycle of the end-item. The ILS Plan is usually developed by the Integrated Log- 
istics Support Management Team comprised of DOD and contractor representatives. Although the ILS Plan goes into considerable detail for each ILS element, consideration of calibration is usually restricted to the planned maintenance ILS element and presented only in terms of defining the calibration interval and procedure for the special support equipment provided with the enditem. Because the interrelationships between calibration and the other ILS elements are not readily seen, the calibration requirements are often developed without sufficient regard to such significant calibration and metrology considerations as measurement state-of-the-art, traceability to national standards, accessibility to calibration and standards laboratories, on-site calibration requirements, and others.

\section{Calibration Support Plan Matrix}

To demonstrate the relationship and importance of metrology and calibration to all ILS elements, let's assume that the special support test equipment required for a particular system is an end-item in itself and develop an ILS plan for it. If we consider each ILS element in terms of calibration, and convert each basic ILS element to a calibration support element, we find that: planned maintenance $=$ calibration concept ; support personnel $=$ calibration technicians; technical data $=$ calibration data; support equipment=calibration standards; spares and repair parts=the same; and facilities = calibration sites .

We can now lay out a matrix of ILS elements/calibration support elements versus major metrology/calibration factors to determine which major metrology factors should be emphasized with respect to individual ILS/calibration elements. Figure 1 is the matrix; it lists measurement state-of-the-art, availability of national standards, calibration methods and procedures, calibration skills and training, timely accessibility to laboratory, built-in standards, portable standards, onsite calibration, calibration environment, calibration data feedback, test equipment and standards loan pool, and calibration intervals, as major

\begin{tabular}{|c|c|c|c|c|c|c|}
\hline \multirow[b]{2}{*}{$\begin{array}{l}\text { MAJOR } \\
\text { METROLOGY CALIBRATION } \\
\text { FACTORS }\end{array}$} & \multicolumn{6}{|c|}{ ILS ELEMENT/CALIBRATION SUPPORT ELEMENT } \\
\hline & $\begin{array}{c}\begin{array}{c}\text { Planned } \\
\text { Ma1ntenance }\end{array} \\
\begin{array}{c}\text { Caldbration } \\
\text { Concept }\end{array}\end{array}$ & \begin{tabular}{|c|}
$\begin{array}{c}\text { Support } \\
\text { Personnel } \\
\text { Cal1bratton } \\
\text { Techntclans }\end{array}$ \\
\end{tabular} & $\frac{\text { Tecbnical }}{\text { Data }}$ & $\begin{array}{c}\text { Support } \\
\text { Bquipment } \\
\begin{array}{c}\text { Calibration } \\
\text { Standards }\end{array}\end{array}$ & $\begin{array}{l}\text { Spares } \\
\text { and } \\
\text { Repair } \\
\text { Parts }\end{array}$ & 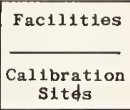 \\
\hline $\begin{array}{l}\text { Measurement } \\
\text { State-of-the-Art }\end{array}$ & $\mathrm{x}$ & $x$ & $x$ & $x$ & & $\mathrm{x}$ \\
\hline $\begin{array}{l}\text { Avallability of } \\
\text { National Standards }\end{array}$ & $\mathrm{x}$ & & $\mathrm{x}$ & $\mathrm{x}$ & & \\
\hline $\begin{array}{l}\text { Calibration Methods } \\
\text { and Procedures }\end{array}$ & $\mathrm{x}$ & $x$ & $\mathrm{x}$ & $\mathrm{x}$ & $\mathrm{x}$ & $\mathrm{x}$ \\
\hline $\begin{array}{l}\text { Calibration Skills } \\
\text { and Training }\end{array}$ & $x$ & $x$ & $\mathrm{x}$ & $x$ & $x$ & $\mathrm{x}$ \\
\hline $\begin{array}{l}\text { T1mely Accessibility } \\
\text { to Laboratory }\end{array}$ & $x$ & $\mathrm{x}$ & & $x$ & $\mathrm{x}$ & $\mathrm{x}$ \\
\hline Built-1n Standards & $\mathrm{x}$ & $\mathrm{x}$ & $\mathrm{x}$ & $\mathrm{x}$ & $\mathrm{x}$ & $\mathrm{x}$ \\
\hline Portable Standards & $\mathrm{x}$ & $\mathrm{x}$ & $\mathrm{x}$ & $\mathrm{x}$ & $x$ & $x$ \\
\hline On-site Calibration & $x$ & $x$ & $\mathrm{x}$ & $\mathrm{x}$ & $x$ & $x$ \\
\hline $\begin{array}{l}\text { Calibration } \\
\text { Bnvironment }\end{array}$ & $x$ & & $x$ & $x$ & & $x$ \\
\hline $\begin{array}{l}\text { Calibration Data } \\
\text { Feed back }\end{array}$ & $x$ & & $\mathrm{x}$ & $\mathrm{x}$ & $\mathrm{x}$ & \\
\hline $\begin{array}{l}\text { Test Equipment and } \\
\text { Standards Loan Pool }\end{array}$ & $\mathrm{x}$ & & $\mathrm{x}$ & $\mathrm{x}$ & $\mathrm{x}$ & $x$ \\
\hline Calibration Intervals & $x$ & & $x$ & $x$ & $x$ & $x$ \\
\hline
\end{tabular}

FIGURE 1.-Calibration support plan matrix. 
metrology and calibration factors. The X's in the matrix identify interrelationships between the major metrology factors and ILS elements. The placement and number of X's in the matrix will vary between end-items, especially with respect to ultimate use of the end-item. For example, a system being placed aboard a guided missile destroyer on an extended deployment schedule may well require emphasis in different ILS elements than another system, similar in complexity, being placed at an ordnance depot in the continental United States.

A third dimension to the matrix which is not shown is cost. The significance of cost will vary for each interrelationship and it is essential to consider cost-effectiveness trade-offs as well as technical problems when developing the calibration portion of the ILS Plan.

\section{The Metrologist and Integrated Logistic Support}

The interrelationships between major calibration considerations and ILS elements in the calibration support plan matrix indicate that as a member of the ILS Management Team, the metrologist has the opportunity to make substantial contributions to the IIS Plan under development. Some of the problems which the metrologist will encounter and resolve are as follows:

(1) Is there commercial test equipment on the market capable of performing the required maintenance functions, or will special test equipment have to be designed and built?

(2) Are the measurements to be made during operational readiness tests and preventive and corrective maintenance within the present stateof-the-art, or will a development program for new measurement capability be required?

(3) Is the designated test equipment sufficiently reliable and stable to remain within required operating tolerances during the projected deployment schedule, or will some means have to be developed to calibrate this equipment during deployment?

(4) Is there already adequate test equipment aboard such that additional equipment is not required, or such that only a minimal amount of additional equipment is required?

(5) Are the calibration laboratories which are intended to service the vessel or station adequately equipped with standards and calibration procedures to calibrate the test equipment? If not, what standards and procedures need to be obtained and when will they be required?

(6) What is the effect of the shipboard or station environment on the test equipment, or on the standards if on-site calibration is required?
(7) Is the test equipment designed to permit "black-box" calibration as well as ready access to adjustment points?

(8) Is the calibration of the test equipment within the skill capabilities of the personnel expected to perform the calibrations, or will additional training be required?

(9) Are there national standards available to which the measurements made by the test equipment may be ultimately referenced, or should the National Bureau of Standards be alerted that reference standards must be developed or improved and made available by a given date?

(10) Should the test equipment be calibrated as a system, as individual components, or as a combination of these extremes?

(11) If the test equipment will require calibration by an off-site laboratory, is the equipment designed to permit ready off-loading or will the size, bulk, and/or interconnections to the prime system require on-site or in-place calibration?

(12) Could the test equipment be designed and packaged so that self-test, fault isolation, or selfcalibration is feasible, thus totally or partially eliminating the need for calibration support except for the few built-in standards?

(13) Will the burden of calibrating the test equipment be such that additional manpower will be needed at the calibrating activity? If so, when will the additional personnel be needed? How many will be needed?

(14) Will additional funding be needed at the calibration laboratories for standards, manpower, and facilities to calibrate the test equipment?

(15) To what extent is a calibration data feedback system needed? To adjust calibration intervals? To identify unreliable test equipment? To effect corrective actions?

(16) Should a loan pool be established for the more critical test equipment and/or standards? Where should the loan pool be located? How will the equipment be transported?

\section{The Metrologist Member of the ILS Management Team}

Because of the intimate knowledge required of a military department's calibration program in terms of laboratory location, standards, personnel, training, workload, etc., the metrologist member of the ILS Management Team should be recruited from the applicable service's metrology engineering center. Since the metrologist member would have the scientific and engineering back-up of the entire staff of his respective center behind him, expertise in specific measurement areas is not required. His most important qualifications are knowledge of the service's calibration program, ability to relate signficant metrology and calibration factors to overall logistic support, and the capability of thinking clearly, and with acumen, 
in order to actively participate in various tradeoff decisions concerning maintenance being made by the ILS Managment Team.

The proposal that the metrologist member of the ILS Management Team be drawn from the service's metrology engineering center is not meant to preclude active participation in Integrated Logistic Support by the contractor's metrologist or calibration expert. Although lacking specific knowledge of the service's calibration program, the contractor metrologist could eliminate many possible future problems associated with the selection of the support test equipment, especially with respect to measurement state-of-the-art, availability of national reference standards, and test and calibration procedures. His technical support of the contractor's ILS Management Team representatives could be most significant if full use is made of his knowledge of measurements, test equipment, and standards.

\section{Conclusions}

This paper has attempted to demonstrate that early, effective, and continuing management of measurements is an extremely necessary part of Integrated Logistics Support, and that the best way to develop and maintain assurance of meaningful measurements throughout the programmed life-cycle of a new system under procurement is to consider metrology and calibration requirements when developing the Integrated Logistic Support Plan and to utilize the services of the professional metrologist with intimate knowledge of the military department's calibration program as a permanent member of the ILS Management Team.

\section{Bibliography}

Department of Defense Directive 4100.35, "Development of Integrated Logistic Support for Systems and Equipments," 19 June 1964. 



\title{
SESSION 2: NCSL LIAISON DELEGATE REPORTS
}

\author{
Chairman: J. L. Hayes \\ U.S. Navy Metrology Engineering Center, Pomona, California 91766

\section{THE INSTRUMENTATION AND MEASUREMENT GROUP OF THE INSTITUTE OF ELECTRICAL AND ELECTRONIC ENGINEERS}

\author{
F. L. Hermach \\ Chief, Electrical Instruments Section, National Bureau of Standards, Washington, D.C 20234

\begin{abstract}
This important organization of the IEEE is active in promoting technical sessions and symposia, in publishing papers describing technical developments, and in preparing standards of practice and performance in its field of interest. This is done through its six very active technical committees, which cover the measurement of frequency and time and of electrical quantities from de through microwave frequencies.
\end{abstract}

We are in the midst of an era of marked advances in instrumentation. Already combinations of electronics and classical measuring techniquessparked among other things by the operational amplifier, the zener diode, and inductive and resistive voltage dividers-have made possible electronic standards of phenomenal accuracy and convenience. With digital voltmeters or dc and ac voltage standards, for example, measurements can now be made on a factory bench by persons without special training and skill, with an accuracy that a decade ago could be obtained only by experienced people in a laboratory environment. There are parallel developments in every area; from taut-band instruments to the "Bolovac" for high frequency and microwave standards. Integrated circuits and the use of special-purpose computers with instruments will surely make even greater advances possible in the near future, to widen the scope and range of measurements tremendously.

These advances-the spectacular showpieces of instrumentation-are based on the science and the art of measurement. Although instruments are used in many fields, and many instruments are developed for specific applications, there is a commonality of principles which forms such a basis. This is the area of G-IM, the IEEE Group on Instrumentation and Measurementthe science and art of measurement, and the instrumentation they bring. G-IM is concerned with the advancement of lnowledge in this area-a part of the charter of IEEE.

It can do this, and serve a really worthwhile function, by providing the mechanism for bringing such advances to the attention of others through the technical sessions and conferences it sponsors and through the journals it publishes. It can do this with high technical competence and authority, and with a standing which few other journals can match. It can also provide a forum for discussion of these advances. As Joseph Henry once said, ${ }^{1}$ "Frequent interchange of ideas and appreciative encouragement are almost essential to the successful prosecution of labors requiring profound thought and continued mental exertion. Hence, it is important that those engaged in similar pursuits should have opportunities for frequent meetings at stated periods. Furthermore, a society of this kind becomes a means of instruction to all its members, the knowledge of each becoming, as it were, the knowledge of the whole. Besides this, man is a sympathetic being, and no incentive to mental exertion is more powerful than that which springs from a desire for the approbation of his fellow men."

The Group can also advance the science and art of its field by writing standards of performance and practice for instrumentation. Here the highest technical competence and the broadest points of view are essential.

G-IM is in an excellent position to meet these needs and goals. Its history goes back many years through its predecessors in the AIEE and the IRE. Thanks to the G-IM Administrative Committees involved, and to their recent chairmen, Charles White and George Schafer, it has come through the period of the merger of the AIEE and IRE very sound financially and greatly strengthened technically. There are now six well organized and

\footnotetext{
${ }^{1}$ From his address to the Philosophical Society of Washington, 1871.
} 
active technical committees in our Group. These and their 1968 chairmen are:
Electromagnetic
Measurements State-
M. Selby
of-the-Art Surveys
Fundamental Electrical
Standards
Low-Frequency
Measurements
High-Frequency
Measurements
Frequency and Time
Materials Measurements
J.Riley
R. Estoppey
R. Soderman
A. Chi
C. Owens

The State-of-the-Art Committee, a continuation of an Ire Standards Committee, is engaged in surveying accuracies and ranges of measurements at the several echelons from NBS standards to shop and field instruments. By publishing these, it will inform designers and users of electrical and electronic equipment what accuracies are feasible today, and, as a corollary, where research is needed if better accuracies are required for a particular measurement at the working level.

The Fundamental Standards Committee is concerned with standards for the basic electrical units, their derivation from mechanical units, and their extension in range. The members are writing performance standards for resistors and capacitors of the highest grades, and have close liaison with the corresponding USASI Committee C100.

The Low and High Frequency Measurements Committees are concerned with advances in the instrumentation and measurement of electrical quantities from de through microwave and laser frequencies-all of the spectrum of coherent electromagnetic radiation. There is intense activity in standards of performance for precision connectors, attenuators, high frequency inmmittance and power measurements, signal generators, and the rapidly growing field of pulse measurements.

The Frequency and Time Committee is a reorganization and an expansion of the former IRE work in crystal frequency standards and is concerned with atomic standards as well. Frequency can be measured more accurately by far than any other quantity, with phenomenal changes recently and further improvements to come.

The Materials Committee has active liaison with other organizations in magnetic and dielectric measurements.

The expansion and reorganization of G-IM is now almost complete. (In question yet is what its role should be in the field of measuring nonelectrical quantities by electrical means.) G-MM now needs to expand its services to meet the needs. This will require changes. For a number of years G-IM has sponsored instrumentation sessions (generally more than one) at the IEEE International Conventions, at which important new developments in its field could be disclosed and disoussed. These sessions have served as a convenient "symposium on new advances in instrumentation," supplementing G-IM's cosponsorship of the highly successful Conference on Precision Electromagnetic Measurements held at Boulder, Colorado, every two years. Now, however, the purpose and focus of the International Convention have changed. Such sessions for specialists cannot be held there. Thus G-IM will sponsor its own instrumentation conferences, probably on the alternate years to the Boulder meetings. But this in turn brings other problems. Conferences don't happen by themselves-considerable planning and doing are required. Financing the publication of the additional papers in the G-IM Transactions (perhaps the most important tangible service) will be difficult too.

The problems which face G-IM are not to be taken lightly. However, they are encouraging ones, for they are signs of growth and of increased service. I am sure that G-IM's technical and other committees will work willingly and competently to meet them-to help advance the science and art of instrumentation and measurements, and to help its members keep up with these advances. 


\title{
JOINT ACTIVITIES OF THE INSTRUMENT SOCIETY OF AMERICA AND NCSL
}

\author{
Orval L. Linebrink \\ Battelle Memorial Institute, Columbus, Ohio 43201
}

It is hoped that a bit of reminiscing about NCSL and ISA-related activities will be condoned and we also hope will prove useful in the future. Many of you may well remember the first Measurement Standards Session at the ISA Conference in Chicago in 1959. It consisted of a panel discussion with W. A. Wildhack as Moderator. The ISA committee involved anticipated an attendance of about 50, but were amazed when 200 attendees showed much enthusiasm for more organized technical activities related to precision measurements and reference standards. The ISA committee planned a more ambitious program for the following year in New York and was given ISA Division Status. The division was called the Mieasurement Standards Instrumentation Division (MESTIND for short), but along with the popular trend for name-changing, it is now called the Metrology Division. Its growth and activities at conference and committee levels are now history.

Most of you are familiar with the growth of the Metrology Division of ISA, and many of you have participated and are now involved in its activities as individual members of a technical society. Simultaneous with the growth of this division, there developed a growing need for an organization which would serve standards laboratories and involve its management. Ad hoc committees nurtured the idea of such an organization suggested by Mr. Harvey Lance of NBS, Boulder, and after many severe labor pains gave birth to the National Conference of Standards Laboratories. Many of these ad hoc committee meetings were held at the time and place of ISA Conferences. Many of the same individuals participated in both.

A significant difference between NCSL and ISA, which is the result of deliberate design by the committees, should be kept in mind at all times. NCSL was planned as an organization of laboratories and is implemented by delegates appointed by the management of the member laboratories. In contrast, IS $\mathrm{A}$ is a technical society consisting of individual members who need not and frequently do not involve their company or organizations in any way with society affairs. 'This simple but basic difference accounts for the fact that many of you find yourselves in dual roles as member delegates to NCSL and as active members of ISA technical program activities. This dual identity makes my position as ISA-NCSL Liaison Delegate both easy and also extremely difficult. Easy because activities of mutual interest to both organizations originate in a common mind and are identical, but difficult because one can identify the NCSL activities separately from those of ISA only with some difficulty. This is a condition which is currently healthy, but conceivably problems may develop unless distinction is made between laboratory matters and the technical development of individuals. My recommendation for the future is for a maximum of cooperation accompanied with a full understanding of the policies and purposes of both organizations.

Several specific current measurement standard activities can be briefly reported at this time.

(1) The C-100 Committee on Specifications of Precision Standard Instruments has Mr. George McGee, as a member, representing the Metrology Division of ISA. Reports of sections of this committee have been released or will be ready soon.

(2) A three-way representation exists in which DeWayne Sharp, NCSL, represents ISA on an IEEE Committee related to Pulse Techniques. I understand that he expects to attend a meeting of the International Electrical Commission in Europe in September 1968.

(3) Of much interest to NCSL is the activity of an ISA committee on Standards Laboratories Environmental Specifications. This work is under the leadership of Mr. Wilbert Snyder and is expected to become an ISA Standard. A technical session related to this subject is being organized for presentation at the New York ISA Conference in October 1968.

(4) The NCSL Committee C-7, with DeWayne Sharp as chairman, is developing some interesting statistical treatment of calibration reports and measurement standards data. He will summarize this in the Committee Report Session of this conference. Several of the full-length technical papers evolved by this NCSL committee will be presented at the New York ISA Conference in October 1968, with Joe Cameron as session developer. Several additional sessions sponsored by NCSL may be organized for presentation at that conference.

This dual existence and mutual individual participation in activities is typical of the relationship of the ISA and NCSL and we hope for a progressive and profitable continuation in the future. 


\title{
THE PRECISION MEASUREMENTS ASSOCIATION
}

\author{
R. B. Ernst \\ North American Rockwell Corporation (Autonetics Division), Anaheim, California 92803 \\ Although the Precision Measurements Association started as a West Coast organization \\ in 1958, it is now international in scope with over 1100 members in 18 Sections. The \\ objectives of PMA are complementary to those of the National Conference of Standards \\ Laboratories (NCSL). This report highlights the aims of the organization, its relationship \\ to the NCSL, and examples of PMA activities.
}

The Precision Measurements Association (PMA) is an international organization with specific interest in metrology activities. Its principal objective is to advance the arts and sciences related to high-accuracy measurement by encouraging the communication of knowledge and the establishment of recommended practices. It seeks to

1. Promote unity and effectiveness of effort among all those who are devoting themselves to high-accuracy measurement.

2. Provide necessary and convenient facilities for the holding of meetings of the Association.

3. Provide for reading, publication, and distribution of papers and publications of the association.

4. Provide for sub-groups of special interest.

5. Encourage the establishment and acceptance of uniform terminology.

\section{Relationship to NCSL}

The objectives and activities of PMA are complementary to - not a substitute for-those of the NCSL. The PMA is an individual membership association, in contrast to NCSL, which is composed of delegates from interested organizations. Many people who actively represent their laboratories in the NCSL are also active PMA members.

The relationship between the two associations may be illustrated by the following example: the company which I represent subscribes to the aim of the NCSL, viz., to promote cooperative action on common problems of management and operation of measurement standards and calibration laboratories. Consequently, the company is a membel' of the NCSL and I have been appointed as the company's delegate. Thus, it becomes my responsibility to reflect the views of company management with respect to problems under consideration by NCSL. In general I expect these problems to be "management-oriented" and rather broad in scope-e.g., involving economic considerations rather than purely technical problems.

On the other hand, there is a need for continuing attention to the more technical side of our laboratory activities. The PMA fills this need by provid- ing meetings, on at least a monthly basis, where methods and techniques of high-accuracy, precision measurements are discussed. In PMA, our laboratory engineers play a prominent role. NCSL, membership is essentially "closed" to these technical personmel who often assume roles of leadership in PMA. Thus, our company division has one delegate to NCSL, but 43 of our personnel have become active participants in PMA.

\section{Example of PMA Activities}

PMA desires to cooperate with the NCSL to make optimum use of available resources. In January of this year PMA and NCSL cooperated in scheduling an NCLS Workshop which immediately followed the First Annual PMA Conference in Anaheim, California. PMA has proposed a similar arrangement for early 1969.

Since 1964, PMA has been a cooperating society with ISA at their annual Conference. PMA promotes and sponsors metrology courses in high schools and colleges. Members of PMA are serving on advisory councils to several West Coast colleges and universities. Scholarships are provided by PMA to deserving metrology students, and metrology books have been contributed to college libraries.

The Measurements and Data magazine serves as PMA Journal and provides a medium for members to exchange ideas on measurement methods and techniques.

Monthly section meetings offer the opportunity to meet socially and to communicate with people with common interests.

\section{Conclusion}

NCSL and PMA objectives are complementary. Cooperation between these organizations is desirable in order to optimize use of a vailable resources. There are tasks that PMA should undertake because they cannot or should not be done by the NCSL. Similarly there are tasks which NCST must perform becanse of its unique role as an association of laboratories and other organizations with related interests. 


\title{
THE AMERICAN ORDNANCE ASSOCIATION
}

\author{
J. A. Mallison \\ McDonnell-Douglas Astronautics Company, Santa Monica, California 95006
}

The American Ordnance Association (AOA) was founded in 1919 and exists solely for the advancement of adequate national defense of the United States. It strives to improve the effectiveness and efficiency of the Government-scienceindustry relationship in the development and production of weapons systems. In fulfilling this objective the AOA acts as a liaison at the management level between industry and Government.

The AOA is a nonprofit and nonpolitical organization of American citizens, and cooperates to every practical extent with other recognized technical and industrial associations in assisting the armed services of the United States. Its mission is to keep the National Defense strong in peace and war. Its functions are important and worthy of support in times of international quiet as in emergency. The AOA presently has more than 3000 individual members and 500 corporate members. About 100 companies have been corporate members for 25 years or more.

The Association endeavors to keep its members and the public informed on problems affecting weapons preparedness. It does this through its publications, through its national and regional meetings, and through the activities of its local Chapters and Branches in all parts of the country. The Division of its Technology and Management Advisory Service provide advice to Government agencies in the areas of weapons technology technical support, and defense management.

The Standards and Metrology Division of the Association has been in existence for more than 23 years. This division exists for the purpose of advancing the effectiveness and efficiency of the Government-science-industry relationship in the development of adequate measurement standards and technology.

The division officers consist of a chairman, deputy chairman, and secretary, with military liaison and National Bureau of Standards representatives. There are three membership sectionsDimensional Standards Section, Electronic and Electrical Standards Section, and General Physical Standards Section-each led by a Steering Committee with a chairman and deputy chairman.

The executive board-made up of the division officers, the section chairmen, and military representatives-meets once each year to set policy and plan activities for the coming year. The primary activity of the division is the annual national meeting of the members of all sections. This is normally a two-day event consisting of approximately six general-interest presentations and a panel discussion on the first day, and section workshop sessions, a forum, and tours on the second day.

The division also provides technical advice and consultation to Government agencies in the area of measurement standards and metrology. 


\title{
REPORT OF THE CALIBRATION AND STANDARDS PROJECT OF THE AEROSPACE INDUSTRIES ASSOCIATION QUALITY ASSURANCE COMMITTEE
}

\author{
Norman D. Smith
}

Manager, Metrology Department, TRW Systems Group, Redondo Beach, California 90277

\begin{abstract}
Reviews of Government requirements for calibration systems used by contractors have covered specifications such as the draft of MIL-C-45662B, MIL-Hdbk-52, NASA NHB 5300.2 and AEC RDT-S-905. One major factor disclosed by these reviews is that some parts of the specifications involve costs which are excessive in relation to the resulting effects on calibration and product quality. Another factor shown by these reviews is that contractors may be handicapped by having to cope with several different specifications from different Government agencies, as well as having to change parts of their calibration systems to conform with specifications telling how something should be done in addition to telling what should be done. Still another area of concern is the continuing and increasing attention to the area of calibration, thus tending to obscure the end result which is required, i.e., accurate measurements and tests in the plant and in the field.

The variety of ways in which tolerances are established seems to be a root cause of many of today's measurement and calibration problems, including the increasingly high costs of obtaining "required" accuracies. In many cases, tolerances seem to be established without proper evaluation of the need versus the cost of maintaining the tolerances in manufacturing and quality control. Better cost visibility, such as might be obtained through design cost guides, seems to be one way of attacking this problem.
\end{abstract}

\section{Review of Government Requirements}

Comments on the MIL-C-45662B draft were discussed at Sperry Gyroscope on April 25, 1968. The AIA recommendations took into account comments received from 46 companies and were submitted to Lt. Col. P. L. Horn, Jr., Director U.S. Army Metrology and Calibration Center, Redstone Arsenal, Alabama, on May 13.

The most compelling factor behind the recommended changes is that of quality versus unnecessary cost. The MIL-C $45662 \mathrm{~B}$ draft would have caused calibration cost increases which would far outweigh the resultant small improvements in calibration and product quality. The recommended changes were intended to provide a quality calibration system at minimum cost. It was also recommended that the title of this specification be changed from Metrology System Requirements to Calibration System Requirements in that this specification should not attempt to cover the entire field of Metrology.

Many of the recommended changes were based on the idea that the specification should provide requirements for "what" must be done, not "how" it should be done. The restrictive nature of "how" something must be done would force many facilities to change operating practices, many of which are currently acceptable and some of which are more sophisticated and efficient than the required changes.

Perhaps the greatest number of comments re- ceived from member companies related to words or phrases difficult to define, or worse, capable of many definitions. For this reason, they were deleted until such time as the new revision of Handbook 52 is available for guidance.

Project team comments on MIL-Hdbk-52 were submitted to the Army Metrology and Calibration Center in January 1967. Since that time a revision of MIL-Hdbk-52 has been in work. The AIA Quality Assurance Committee has requested the draft for review. To date, the AIA has not received the issuance.

The Army, Navy, Air Force working group on calibration procedures agreed with the AIA recommendation for clarifying the intended use of MIL-C-24133 for procurement of calibration procedures as end items, and concurred with the idea of avoiding unnecessary adjustments, but including adjustment information where essential to the calibration. Because of the complexity of the subject the Army, Navy, Air Force working group decided that adjustments should not be included in the specification. That is, there will be no change in regard to adjustments.

Additional work was done during the past five months on AIA comments on the NASA NBH5300.2, Apollo Metrology Requirements Manual. AIA Quality Assurance Committee members are concerned with the need for standardization of government specifications and interpretative documents such as NBH-5300.2. This manual is a move in the opposite direction, forcing contractors 
to establish either an excessively elaborate system or more than one calibration system in order to satisfy the requirements of both DOD and NASA. $\mathrm{NBH}-5300.2$ is an interpretative or handbooktype of document. It is intended to provide the clarification for Apollo system contractors and the requirements contained in NPC-200-2, "Quality Program Provisions for Space System Contractors." NBH-5300.2 applies to all centers, sites, and their prime contractors who are responsible for the selection, evaluation, approval, calibration, maintenance, and control of standards and measuring equipment. The scope of the manual includes development and control of calibration practices for standards and measuring equipment used to determine the conformance of Apollo hardware to design specifications.

Atomic Energy Commission Specification RDT-S-905 "Calibration System Requirement" is a simplified version of DOD-specification, MILC-45662A. It consists primarily of excerpts from MII-C-45662A with minor editorial changes. The major differences between the two documents are as follows: All references to government or government representatives were replaced by the term "purchaser" or "representative of the purchaser"; all references to contractor were deleted and replaced with the term "manufacturer"; the definitions section was placed after Scope rather than at the end of the specification; a definition for accuracy was added but seemed unnecessarily complicated; the definition for measuring and test equipment was amended; and details were deleted regarding the method of changing calibration intervals and the description of records required. The requirement for the contractor to make objective evidence of accuracy conformance readily available to the government representative was deleted, and a reference to foreign contracts as applicable to calibration sources was deleted.

The above changes with respect to MII $-\mathrm{C}-$ $45662 \mathrm{~A}$ are not considered objectionable. The AEC document was probably prepared to fill an AEC need for consistent but less stringent requirements. A contractor who is in compliance with MILC-45662A would certainly be in compliance with the $\mathrm{AEC}$ document. It is not known whether AEC intends to maintain consistency with MII_-C$45662 \mathrm{~A}$ by revising $\mathrm{RDT}-\mathrm{S}-905$ in accordance with changes in MIL-C-45662A. If RDT-S-905 is not revised accordingly, there will be a tendency to move away from the AIA desire to standardize government specifications.

\section{Tolerancing Practices}

A literature survey has been made listing 130 references, 32 of which deal specifically with tolerancing practices. No one comprehensive reference has been found. Instead the references are fragmentary and specialized, usually covering just one aspect of tolerancing, or treating tolerancing briefly as part of some other field.

In general, cost reductions seem likely through the use of improved tolerancing practices. Rule-ofthumb techniques seem to be used most frequently in establishing design tolerances. While this may save time initially, excessive safety factors often result in high manufacturing and test costs. Jobwise, the final setting of tolerances is often considered to be a clerical function or a low-level engineering function. AIA feels that a high degree of engineering skill is required in selecting tolerances so as to minimize costs without degrading product quality and reliability. In addition to the commonly used rule-of-thumb techniques many other types of tolerancing techniques are referenced in the literature. These other techniques include statistical tolerancing, true-position tolerancing, graphical (vector) tolerancing, worst-case tolerancing, and tolerance-chart techniques. During Project AIA team discussions, certain problem areas in applying good tolerancing practices have been defined:

- Cumulative tolerances, for mating parts for systems of varied parts.

- Understanding of measurement concepts such as accuracy versus precision; confidence level of measurements; measurement of uncertainty.

- Limitation imposed by measurements at the state-of-the-art; defining the various states of the art; theoretical limits of measurements.

- Scaling down.

- Significant figures; rounding off of numbers.

- Allowances for instrument uncertainties.

- Design tolerances versus manufacturing tolerances versus test tolerances.

During the past year inquiries were made of several member companies concerning the problem of tolerances and costs. Replies received indicate that there is considerable interest, and a great deal of concern, in the subject of close tolerances and their relationship to costs.

It was stated in one reply that the placing of a tolerance on the design caused a number of related decisions to be made simultaneously :

- The process which shall be used to manufacture the part may be dictated by the tolerance.

- The type and cost of tooling is decided.

- A "make or buy" decision may well hinge on the tolerance involved.

- The kind of quality control and the amount of inspection and test is certainly responsive to the tolerances.

- The "back-up" capability in the calibration laboratory is defined.

There are examples cited where close tolerances are specified because they work on an engineering prototype or the tolerance was chosen from the instrument manufacturer's specifications on the test 
equipment used. Later evaluation often shows that the device or system worked equally well with less stringent tolerances.

Another area which has been discussed is the utilization of metrology or test engineering specialists in the area of technical design reviews.
Some companies have found this approach to $b$ effective in establishing realistic tolerances befor manufacturing problems arise. It seems that would be beneficial if tolerances were reviewed $b$ measurement specialists as early as possible in th development phase of a program. 
NCSL 68

\title{
SESSION 3: NBS ACTIVITIES
}

\author{
Chairman: J. L. Hayes \\ U.S. Navy Metrology Engineering Center, Pomona, California 91766
}

\section{THE ECONOMIC VALUE OF MAKING MEASUREMENTS}

\author{
Howard E. Morgan*
}

Technical Analysis Division, Institute for Applied Technology, National Bureau of Standards, Washington, D.C. 20234

\begin{abstract}
Concepts of economic value are defined and their usefulness in determining the economic value of measurement data are indicated. Resources in the National Measurement System and various classes of users are described to provide a context for examining economic value. The role of measurement data in decision-making is suggested and the economic consequences of decisions are indicated. The effect on economic value of alternative measurement sources and reliability is described. Economic value (benefits) and cost are distinguished. The application of these concepts is illustrated using results of case studies of measurement projects at the National Bureau of Standards.
\end{abstract}

\section{Introduction}

A conference which has as its theme "Making Valuable Measurements" ought to have at least one paper which inquires into the meaning of the word "valuable." It is the intent of this paper to define "valuable" and to indicate how one might measure the value of "valuable measurements."

One of the 1966 Conference Speakers, Mr. W. G. Amey, urged NCSL to form a committee to determine "how to evaluate the value of measurements" [Amey, 1967]. An earlier Conference report announced the formation of an "NCSL Special Committee on Calibration Cost Reduction and Value Analysis" [Panel on Standards Laboratory Information Dissemination]. Apart from these fleeting references to the value of measurements, the Conference reports are barren of substantive discussion of economic value.

Interest in the value of making measurements probably has increased since prior conferences. Many NCSL members appear to be in firms deriving substantial amounts of their revenues from government contract work in space, defense, and atomic energy. Current public debate over the value of science programs and government budget constraints are forcing NCSI members in both government and private laboratories to examine the cost and value of measurements. It seems appropriate, therefore, to ask what we mean by "valuable measurements" and to suggest ways of measuring the value of these measurements.

In a market system where measurement services are provided in a competitive environment in response to prices paid by users, price is an indicator

\footnotetext{
*Mr. Garry Crane provided welcome assistance in the discussion of several concepts appearing in this paper. The author alone, however, is responsible for the contents.
}

of economic value. But measurement services are provided largely in a nonmarket environment by government laboratories or by inhouse laboratories serving business firms of which they are a component. Market price, the traditional indicator of economic value, is absent. It is then necessary to derive substitute indicators of economic value.

The discussion proceeds by asking first what kinds of measurements are made and why they are made. We then define economic value and indicate the economic consequences of making or not making measurements. The argument is largely conceptual in that the emphasis is on how to determine economic value. A few examples, based on recent studies of NBS measurement projects, are provided where appropriate. No attempt is made here to indicate the total economic value of measurement data. This requires a larger study using some of the concepts developed here.

\section{What Measurements are Made?}

\section{The National Measurement System}

The National Measurement System for the measurement of physical quantities was described in some detail at the 1966 conference [Huntoon, 1967]. Essentially, this was postulated as having two interacting systems: (1) an intellectual system having a body of principles arranged in rational coherence, and (2) an operational system having elements to perform functions needed to achieve national goals. The intellectual system consists of a coherent set of measurement units in which the properties of materials and the performance of devices and systems are given quantitative values. From the basic measurement units for length, mass, time, and temperature come a host of derived measures for characterizing a variety of substances 
and systems ranging from simple to complex. The operational system was described as the combination of consistent instrumentation, reference data, and techniques of measurement used by people performing measurements or using measurement data to achieve the purpose of their organizations. The intellectual system provides the rules and conventions which guide the operational system.

Which of these aspects of the National Measurement System is of interest here? While the intellectual and operational systems are interdependent, economic interest here centers in the operational system because it uses resources such as instruments, data, and manpower. A change in the rules of the intellectual system may create changes in the operational system which may then affect the economic value of the measurement system, e.g., a shift from astronomical to atomic time. Essentially, the resources whose value is in question are the instruments, reference data, and skilled manpower in the operational measurement system, of which NCSL members are a part.

\section{Why Make Measurements?}

\section{Measurements and Goal Achievement}

Measurements provide information which assist people in making decisions required to reach a goal or objective. For the average human, his senses provide most of the information needed for the host of decisions he makes each day (e.g., when to go, where to stop, what to eat). For the scientist or engineer, human senses are seldom capable of describing the attributes of a substance, device system, or phenomenon with sufficient exactness. In this situation, his decisions must rest on instruments which transform and magnify these attributes into readings which are quantitative and reliable.

\section{Kinds of Decisions Resulting from Measurements}

Information provided either by instrument readings or by reference data is used to make two kinds of decisions, namely, those which (1) alter the method of attaining a given objective, or (2) undertake the attainment of new objectives.

In making decisions of the first class, the usual aim is to accomplish the given objective at least cost by substitution of a measurement activity for some other resource. Examples are measurements made in navigation, manufacturing processes, or the reading of an auto speedometer. Here, tradeoffs are being made; measurements are being $s u b$ stituted for fuel or manpower in navigation; for raw materials in production; for police action, auto repair, medical facilities or lost income resulting from nonobservance of speed limits. ${ }^{1}$

\footnotetext{
${ }^{1}$ In some cases, measurements will reveal that the objective cannot be achieved without adding another resource (e.g., more fuel to reach a destination as a result
}

The second kind of decision resulting from measurement data may provide new goals, which may include doing something not previously considered possible or which eliminates that which had been considered possible. For example, measurements may provide information about a single attribute or about various functional relationships (basic principles or laws) among attributes of a substance, device, system, or phenomenon which leads to a decision to do further research or to develop the concept into some useful application. The use of measurements in basic research illustrates this kind of decision (e.g., the reduction of uncertainty in time and frequency measurement helped make space navigation possible). Here, measurements are complementary with other resources; i.e., additional resources are needed to achieve the new objective which has emerged. An entirely new set of resources may be called forth to produce a new kind of output.

In summary, the essential economic difference between these two kinds of decisions lies in the nature of the objective. In general, where the objective is given, measurement data permit the the saving of other resources (i.e., productivity is improved). Conversely, where new objectives result from the use of measurement data, additional resources are used (i.e., total output is expanded). While there are qualifying assumptions as indicated in IV below, one may tentatively conclude that measurement activities are resource saving or resource using depending on whether they provide information relevant to existing or new objectives. This has important implications for economic value-a term which will now be defined.

\section{What Is Economic Value?}

Economics is concerned with the production and allocation of resources to satisfy human wants. Value is a measure of worth, utility or importance which users assign, consciously or subconsciously, to resources capable of satisfying their wants or objectives and which partially determines the pattern of resource use. Value normally is measured numerically in money terms (cardinally), but also may be measured ordinally as relative utility when indicated by an opinion survey.

In measuring value it is necessary to distinguish between value to individual users and value to society-the latter may not equal the sum of the former because complex secondary effects in the economic system may exist. In the discussion which follows, the relevance of value to objectives is noted and the distinction between value to individuals and value to society is retained. This

of a navigation measurement). Failure to add that resource may mean failure to reach the objective. Note, however, that a trade-off still exists between the measurement and other resources (e.g., failure to add fuel may cost extra manpower or lost equipment time before the destination is reached). 
dichotomy also is perserved while suggesting ways of measuring the economic value of publiclyfinanced measurement data. The section concludes by observing that economic value and cost are not the same.

\section{Value and Objectives}

It was suggested above that the value of measurement data may depend on whether they provide the user with a better way of reaching a given objective or whether it leads to a decision to undertake a new objective. What are the general objectives of individual users in a capitalist economic system?

It is usually assumed that consumers of final goods seek personal satisfaction of wants through consumption; the objective is to maximize the satisfaction of wants. Producers of goods for sale in the market wish to maximize profits (total revenues less total costs). The value of measurement data to each will depend on the extent to which these data contribute to want-satisfaction or pronit respectively. Methods for determining economic value to individual users in money terms (e.g., dollars) require a consideration of resources saved or used in reaching objectives, as suggested above and described in more detail below.

The aggregate economic value of measurement data is not simply the sum of values to individual users, because of complex interactions in the economic system. ${ }^{2}$ Furthermore, aggregate economic value must be determined with respect to goals of society, some of which may be economic, political, humanitarian or technological. For example, economic goals may include economic growth, price stability, full employment, maximum efficiency in producing a given output, or income redistribution; goals which may require science and technology, as for reaching the moon or reducing environmental pollution. Given one of these goals, the economic value of measurement data will be the cost of resources saved by substitution of these data in reaching the stated goal.

Where multiple social goals are present, someone (Congress representing the people?) must indicate priorities-this is a political or policy choice. Because a shift in the use of other resources occasioned by new measurement data may affect prices for those resources, the economic value of economic value is conceptually easy to define but empirically difficult to determine. From a public policy point of view, particularly when valuing measurement data employed for one goal will affect the empioyment and value of resources used to attain other goals. Consequently, aggregate

${ }^{2}$ These complex interactions generated in the economic system can be simulated using an input-output matrix of the national economy to estimate the probable effect on national income and the demand for the output of other industries. If the final product or service using measurement data is not sold at a market price (e.g., defense capability), the aggregate social value must be approximated by other methods suggested below. publicly-financed measurement data, aggregate value is of greater interest than value to individual users. But the latter is easier to determine than the former.

\section{Value to Individual Users}

It has been noted above that there are two classes of users: (1) producers of goods and services and (2) consumers of final goods and services. Production is for consumption usually after sale to others in a market economy, although it includes the provision of goods and services by government (often at a zero market price). Because the goals of producers and consumers differ, the methods of valuing resources used by each also differ. These methods are now described.

Value to a Producer.-Economic theory tells us that a profit-maximizing business firm will buy more and more units of measurement service until its differential cost equals the associated differential revenue from the sale of its products. ${ }^{3}$ The value of a unit of measurement service under perfect competition equals its contribution to sales revenue, technically known as "value marginal product" (VMP). ${ }^{4}$ The value of an input under perfect competition will equal its cost only at that level of product output which maximizes profits for the firm.

NCSL members within business firms (in-house) may be able to obtain estimates necessary to perform this calculation. ${ }^{5}$ To do so requires knowledge

3 A unit of measurement service may be defined as a single reading on an instrument, a single datum, or any observable measurement.

4 The value of the measurement service is its contribution to value marginal product $(V M P)$. Algebraically: $V M P=M P P \times P$, where $P$ is the price of a unit of output and $M P P$ is defined as the extra physical output resulting from the addition of another unit of input. A related and frequently used concept is "marginal revenue product" $(M R P) . M R P=V M P\left(1+\frac{1}{\epsilon_{x}}\right)$ where $\epsilon_{x}$ is the price elasticity of demand for ouptut $x$ and $\epsilon_{x}$ assumes values of $-a \leq \epsilon_{x} \leq 0$.

${ }^{5}$ For example, assume that output is engineering consulting services and that input is measurement data where:

$Q_{1}=$ number of units of measurement data.

$Q_{2}=$ number of units of consulting service.

$P_{1}=$ price of a unit of measurement data.

$P_{2}=$ price of a unit of consulting service.

$T R=P_{2} \times Q_{2}$

$T C=P_{1} \times Q_{1}$

Engineering Consulting Service Output and Revenue

Q2 $\quad M P P \quad P_{2} \quad T R \quad V M P$

$\begin{array}{rrrrr}0 & - & \$ 3 & \$ 0 & \$- \\ 10 & 10 & 3 & 30 & 30 \\ 19 & 9 & 3 & 57 & 27 \\ 27 & 8 & 3 & 81 & 24 \\ 34 & 7 & 3 & 102 & 21 \\ 40 & 6 & 3 & 120 & 18\end{array}$

\begin{tabular}{cccl}
\multicolumn{2}{c}{ Measurement Data } & \multicolumn{2}{c}{ Profit } \\
\multicolumn{3}{c}{ Input and Cost } & \\
$Q_{1}$ & $P_{1}$ & $T C$ & $(T R-T C)$ \\
0 & $\$ 20$ & $\$ 0$ & $\$ 0$ \\
1 & 20 & 20 & 10 \\
2 & 20 & 40 & 17 \\
3 & 20 & 60 & 21 \\
4 & 20 & 80 & 22 Max. \\
5 & 20 & 100 & 20
\end{tabular}

Note that profit $(T R-T C)$ is at a maximum $(\$ 22)$ when 4 units of measurement service $\left(Q_{1}\right)$ are used to produce 34 units of output. $\left(Q_{2}\right)$. Note also that at this point the price of a unit of input $\left(P_{1}=\$ 20\right)$ approximately equals its value marginal product $(\$ 21)$. The addition

Footnote continued on following page. 
of the technological contribution of the input to output, willingness to pay for various quantities of output, and the unit price of an input. It may be found that the measurement service has a value which differs from its actual cost to the company. Hopefully for NCSL members, value will exceed cost.

Note that VMP theory assumes that: (1) inputs other than the one under consideration are absent or that their prices and quantities are held constant conceptually, and (2) the quantity of output may vary, but not its quality. If these assumptions are relaxed, actions resulting from the kinds of decisions described in Part III may be taken (i.e., resource-saving decisions which effect improvements in the method of reaching given objectives, and resource-using decisions to achieve a new objective).

In the preceding example (footnote 5), a relaxation of the second assumption permits decisions to change the quality of output associated with measurement input (e.g., the use of measurements may influence a decision to add other outputs, such as engineering services, or to claim higher reliability for the services now sold). The value of measurements now is indicated approximately by their contribution to additional sales revenue arising from changes in the quality of output.

By relaxing the first assumptoin, measurement data can influence the use of other inputs which now can vary in price and quantity and be traded for measurement data. Since knowledge of the complex relationship between inputs and output of the firm may be absent, one can conceptually assume output constant. Now the business firm will, if substitution is technologically feasible, be willing to pay for measurement data an amount just short of that saved by not using the cheapest alternate inputs to reach the given output or objective. This is a simple trade-off in which measurements are substituted for other inputs which represent resources saved. The value of other resources saved is the value of the measurement data. In practice, output may be fixed by contract specifications or other market considerations. Hence, the constant output assumption may often reflect reality. Savings which accrue to the firm may result in profits which represent a return on equity capital or higher returns to labor or to other inputs. ${ }^{6}$ Other forms of income redistribution may occur and national income may be higher or lower, depending on the prices of and demands for other inputs.

A relaxation of both assumptions permits all inputs to vary in price and quality and outputs to

of a fifth unit of measurement service would cost $\$ 20$ but return only $\$ 18$ in revenue $(V M P)$. The example can be extended with greater complexity as assumptions are relaxed (e.g., variable input and output prices and quantities of other inputs).

${ }^{\circ}$ Historically, 99 percent of productivity gains have accrued to labor. See: John W. Kendrick, Productivity Trends in the U.S. (Princeton Univ. Press for the National Bureau of Economic Research, 1961), pp. 129-130. vary in quality. While the VMP concept is not now entirely applicable, it offers an approximation sufficiently general for estimating the value of measurement data to a producer of goods or services sold in a market. With both inputs and outputs variable, measurement data may influence decisions which save or use resources. ${ }^{7}$

Whether or not such changes in the use of resources are desirable from the viewpoint of society cannot be determined without having a statement of social goals as criteria. If efficiency (productivity) is a prime goal, those decisions which save resources required to achieve a given objective are socially desirable. On the other hand, if a growth in national product and employment is a goal of society, resource-using decisions are preferable. In reality, of course, we have many social goals, some of which require resource usage and others resource conservation.

Value to Consumers.-In ascertaining the value of measurement data to individual consumers, we must distinguish between: (a) measurement data used directly by consumers and (b) final goods or services used by consumers and which employ measurement data in their production. For example: (a) is illustrated by time or weather reports or by auto diagnostic data for the personal use of consumers, while (b) is illustrated by the purchase and use of an automobile or watch in whose manufacture measurement data were used. Since these are quite different concepts, methods for determining the value of each will differ. However, as noted earlier, value must be defined in terms of an objective; the goal of consumers is to maximize the satisfaction of wants.

The value of measurement data used in the first situation (i.e., directly by consumers) will be the extent to which these data enable consumers to save other resources in attaining a given level of satisfaction, or to use other resources in reaching a higher level of satisfaction. ${ }^{8}$ The value of the measurement data again will be the money value (price $\mathrm{x}$ quality) of resources saved or used in the two cases. As individuals, we theoretically would be willing to pay an amount (price $x$ quantity) for measurement data just short of the cost

\footnotetext{
${ }^{7}$ Technically, measurements will lead to decisions which produce a substitution effcct or an output effect upon other inputs requiled to produce the old and new output level or quality.

${ }^{8}$ If the measurement data were purchased at a price in a market (or if we consider the depreciation and operatting costs of previously purchased instruments), price normally declines with the quantity purchased (see footnote 9). This produces what is technically known as: (1) a substitution effect (more of the data are consumed as price falls), and (2) an income effect (the resulting higher real income permits consumers to buy more of other resources). Depending on assumptions, the substitution and income effects will differ in relative importance. Consumers presumably gain more satisfaction or utility as a result of the two effects. Note that market price paid for measurement data lepresents the costs, but not necessarily the value to the consumer (see discussion of consumer's surplus below).
} 
of alternate goods and services, given some desired level of satisfaction (e.g., auto speed data are worth some amount up to the cost of traffic fines for speeding). Here, a trade-off is made between measurement data and other resources. In contrast, if fuel gauge readings indicate that we have sufficient fuel to take a side trip which consumes more fuel and increases our total satisfaction from the trip, the value of the fuel measurement data is equal to the cost of extra fuel and other resources needed to make the side trip.

The value of measurement data used in the second situation (i.e., the production of final goods or services used by consumers) is more difficult to determine because we are now considering second or higher order economic effects, rather than primary value to individual users who first employ the data directly in production or consumption. If all outputs were final goods or services, we might approximate the value of measurement data used in their production by calculating the VMP of measurement data for the producer: The result would indicate roughly how much consumers value (at cost) the additional output produced with a unit of measurement service. But, this represents costs of the final goods to a consumer at market price and not necessarily its value to him in use. Furthermore, measurement data are used in the production of intermediate goods which then become an input in the production of other goods; the problem of double counting then arises. Consequently, other methods must be used to measure these secondary effects.

\section{Aggregate Economic Value}

The prior warning about the need to value resources in terms of the objectives for which they are used is repeated here. In discussing methods for determining aggregate value, it is assumed that consumer satisfaction is to be maximized and that an increase in goods and services consumed will raise the level of satisfaction. This raises thorny questions about kinds of output and social goals: these problems are handled by the stated assumptions and treated as political or policy issues beyond the scope of economic analysis.
Two methods for approximating the aggregate economic value of measurement data are: (1) the concept of consumer's surplus, and (2) input-output analysis. Both require detailed information about the way measurement data are used and information about the demand for final goods.

Consumer's Surplus.-Economic theory recognizes the concept of consumer's surplus, which indicates the value of goods or services to consumers over and beyond the market price paid for them. Economic value must now be thoughtof as a "block of goods" produced by an industry (a group of firms) and for which a group of consumers pay or are willing to pay various prices for various quantities.

Two associated concepts of value are discernible here: (1) value in exchange (market value), and (2) value in use. The first is the familiar concept where value is measured at market price paid (in money terms) for a given quantity of a product. The second measures the worth or utility of a product to users as reflected by their willingness to pay for each of various quantities. The law of diminishing marginal utility suggests that unit price and quantity are inversely related and, therefore, the price-quantity curve is negative in slope. $^{9}$

Since value in exchange (at market price) normally will be less than value in use (willingness to pay), a difference (known as consumer's surplus) will exist. Technically, consumer's surplus measures value which users obtain and for which they would be willing to pay more than they actually pay, rather than go without the product. In other words, a user in a large market is able to buy at a market price which is lower than the price he would be willing to pay if he were the only pur-

\footnotetext{
${ }^{9}$ The figure indicates these concepts graphically. Points on line $D D$ represent the price which users would be willing to pay for each of the various quantities on the horizontal scale. The rectangle $O Q_{1} S P_{1}$ indicates total value in exchange (market value) on the assumption that $Q_{1}$ was sold at a price $P_{1}$. Value in use (willingness to pay) is indicated by the area that is under that part of the $D D$ line between $O$ and $Q_{1}$ (the sum of the shaded triangle and the rectangle). Here value in use exceeds value in exchange and a consumer's surplus exists in the shaded triangle.
}

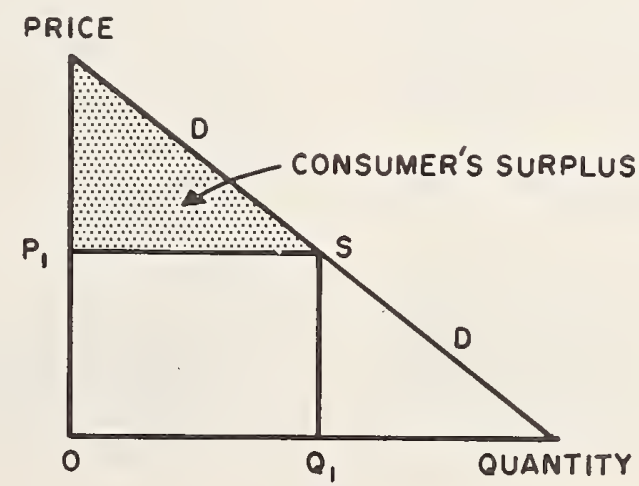


chaser. This is an important feature of a modern exchange economy where we gain by trade.

Note that changes in market value $(\triangle T R)$ will equal the sum of the value marginal product (VMP) of all producers of the final product. Thus, the VMP of an additional unit of measurement data used to produce a final consumer's good equals the additional dollar outlay (cost) which consumers pay at market prices to get the extra output. The value of this additional quantity to consumers is indicated by the increase in willingnessto-pay $(\triangle W T P)$. Although difficult to measure empirically, WTP gives an approximate indicator of the aggregate value of measurement data to consumers of final products in whose manufacture these data are used.10

Input-Output Analysis.-An input-output matrix of the national economy can be used to estimate the probable effects of measurement on other parts of the economy by computer simulation techniques. This requires that industries using measurement data be identified and that we know how decisions resulting from such data effect other inputs. Changes in these input industries can then be simulated to estimate changes in output industries and national income. With adequate case studies of the uses of measurement data and refinement of the input-output matrix, this method offers promise of considerable usefulness in the future.

\section{Value of Publicly Produced or Used Measurement Data}

To what extent do the concepts of value described above apply to measurement data or services provided or used by public agencies? Since both the measurement data and the end product with which it is associated often are provided at a zero price to the public, how is value determined?

$V$ alue to a Using Agency.-Some NCSL members are in government laboratories whose mission requires the use of measurements. Where the mission uses data as an input, its value is determined

${ }^{10}$ Two possible approaches are: $(1)$ conducting opinion surveys which ask users about their willingness to pay under various assumptions, and (2) measuring changes in prices and quantities of goods or services in whose production measurement data are used. Where these final goods have a market price, the change in willingness to pay attributable to new measurement data is approximately equal to the product of the average price and the change in quantity sold. Symbolically :

$$
\Delta W T P=\left(\frac{P_{1}+P_{2}}{2}\right)\left(Q_{2}-Q_{1}\right)
$$

where:

$W T P=$ willingness to pay

$P_{1}=$ price of final product before new measurements

$P_{2}=$ price of final product after new measurements

$Q_{1}=$ quantity of final product sold before new measurements

$Q_{2}=$ quantity of final product sold after new measurements as in the business firm: value equals value marginal product $(V M P)$. But, because the output of the government agency may not be sold at market prices, VMP may not be ascertainable; consequently, it is necessary to assume output constant and inquire about the value of trade-offs among inputs. For example, the value of NBS measurement data furnished other government agencies approximately equals the cost of alternate inputs which would be required to reach the given objective of the using agency. If on the other hand, measurements should lead to a decision to change objectives, their value to the using agency again is indicated by the $V M P$ of the agency output if sold at market prices.

Aggregate Value of Publicly Financed Measurements.-All of the preceding discussion of value also applies to measurement data produced in tax-supported laboratories and used by private firms or consumers. However, since these data are not normally sold at a market price, the concept of VMP is not applicable unless we use the actual cost of producing the data as a proxy for market price. An approximation to aggregate value, frequently used in calculating the value of public water projects, uses a modification of the VMP concept: the value of a public project in national income terms equals the total revenue from products produced with the aid of the public project, less the cost of all resources other than the public project required for their production. ${ }^{11}$

But, this is deceptively simple and may not be determinate because we again need to know the market values of outputs produced with the measurement data and the associated changes in the cost of other inputs. If the simplifying assumption of constant output is used, the value of measurements again becomes the trade-off value of substitutes.

The fact that fees or user charges are paid by users for the publicly furnished measurement data has no bearing on their value. If the fee is less than the price which users are willing to pay, redistribution benefits arise. These are benefits (e.g., profits) which accrue to the user and represent his gain at the expense of others who do not use the public service directly. However, if there are no barriers to the adoption of measurement technology and if markets for final products are competitive, nonusers of the measurement data may derive benefits in the form of better products at lower prices. Redistribution benefits may be justified as a reward to certain users who stimulate technological changes which produce external economies (i.e., price reductions or quality improvements indi-

\footnotetext{
$11 \mathrm{~V}=\mathrm{TR}-\mathrm{C}_{\mathrm{o}}$ Where:

$\mathrm{V}=$ aggregate value of the public project.

$\mathrm{TR}=$ market value of final products produced with the public project.

$\mathrm{C}_{0}=$ market cost of all resources other than the public project.
} 
rectly caused by measurement data and which increase aggregate national income or social value).

Before leaving the topic of publicly produced measurement data, note should be made of the distinction between its value $(V)$ and cost $\left(C_{g}\right)$. The total cost $\left(C_{t}\right)$ of all resources used to produce final products is the sum of the cost of producing measurement data at public expense $\left(C_{g}\right)$ and the cost of all other inputs, public and private $\left(C_{o}\right)$. The net value of the data will be $V-C_{g}$. Since, as indicated above (footnote 11 ),$V=T R-$ $C_{o}$, the net value $\left(V-C_{g}\right)=T R-\left(C_{0}+C_{g}\right)$. Because value and cost frequently are confused, this point is extended below.

\section{Benefits and Costs Distinguished}

Some argue that measurement data are worth at least the price paid by the user. This argument is valid only when data are sold in competitive markets and when value is defined as "value in exchange" (i.e., buyer cost = value in exchange at the market price). However, it has been argued above that "value in use" may be the more useful concept for valuing measurement data (which are seldom sold in competitive markets). "Value in use" provides an indicator of what measurements are worth to users in terms of their capacity to help attain user objectives efficiently. Measurement data constitute only one among many input categories and their cost may differ from their value in use. $^{12}$

Since value in use (benefit) often differs from value in exchange (cost) rational buyers will compare carefully benefits with costs before making a purchase. It probably is naive to assume that consumers of final goods or even producers of complex intermediate products are completely rational in their choice of measurement services. Technological and other noneconomic considerations undoubtedly play an important role in the purchase decision. Yet, economic cost and value also undoubtedly do influence the allocation of resources used to provide measurement data, particularly when funding is scarce.

\footnotetext{
${ }^{12}$ For example, assume the following to achieve a given output :

\begin{tabular}{|c|c|c|c|c|c|}
\hline & $\begin{array}{l}\text { Other } \\
\text { inputs }\end{array}$ & + & $\begin{array}{l}\text { Measure- } \\
\text { ments }\end{array}$ & $=$ & $\begin{array}{c}\text { Total } \\
\text { Cost }\end{array}$ \\
\hline $\begin{array}{l}\text { Before measure- } \\
\text { ment change } \\
\text { After measure- }\end{array}$ & $\$ 50$ & + & $\$ 50$ & $=$ & $\$ 100$ \\
\hline $\begin{array}{c}\text { ment change.-- } \\
\text { Change }\end{array}$ & $\begin{array}{c}20 \\
(-30)\end{array}$ & $\begin{array}{l}+ \\
+\end{array}$ & $\begin{array}{r}75 \\
(+25)\end{array}$ & $\begin{array}{l}= \\
=\end{array}$ & $\begin{array}{c}95 \\
(-5)\end{array}$ \\
\hline
\end{tabular}
}

Measurements now cost $\$ 25$ more and generate a savings of $\$ 30$ in the cost of other inputs, with a net reduction of $\$ 5$ in total cost. Theoretically, the user would substitute measurements for other inputs in any amount up to a cost of $\$ 100$ as long as savings in the cost of other inputs (value of measurement) exceeded the increase in measurement costs.

\section{A Digression on the Sources and Reliability of Measurement Data}

The previous discussion has assumed that all types of measurement activity are similar in their economic effects. A closer examination reveals that there may be significant differences which affect their economic cost and value. One must therefore be concerned with alternatives with in the measurement system. There are at least two questions about measurement data which deserve attention in this respect: (1) What is its source? and (2) How reliable is it?

Sources of Measurement Data. Measurement data may be obtained by making measurements with instruments or by using data compiled by others who previously had made measurements with instruments. If there had been no previous work in a field of interest, the scientist or engineer must purchase or develop the necessary instruments, calibrate them against an acceptable standard and proceed to make the required measurements. Where others had made similar measurements and recorded them in published form, they may be used after critical evaluation by a competent authority. Thus, there is a trade-off between making one's own measurements versus accepting data which already exists. Such critically evaluated data are produced by several government and academic institutions whose work is coordinated by the NBS National Standard Reference Data System. A similar trade-off exists between transportable instruments which are calibrated against an NBS standard and statistical measurement data exchanged among laboratories in a self-calibration program.

To the individual user of data, the cost of making one's own measurements may be large and prohibitive; the cost of published reference data is negligible. For the nation, the total economic cost of reference data may be substantially less than the cost of making new measurements of materials whose attributes are already established. To the extent that the former source of data is less costly than the latter to yield the same technical results, reference data may be substituted for other inputs with a consequent change in the value of the data.

The Value of Measurement Reliability. Similarly, there are trade-offs between the reliability demanded of measurements and the use of other resources. Reliability has two aspects: (1) accuracy (compatibility with a standard) and (2) precision (consistency of successive readings). Unreliability or uncertainty results from systematic or random errors in both accuracy and precision. The uncertainty of a measurement may affect its value since the quantity of other resources used may depend upon measurement uncertainty.

Uncertainty in the measurement process arises from variability which may be inherent in the instrument or data and from the human factor through use of instruments. This variability, along 
with the variability inherent in the characteristics of the product or process being measured, is reflected in the standard deviation $\left(\sigma_{p}\right)$ of a frequency distribution of the mean of successive readings.

To improve the yield of input resources in a production process (i.e., to save resources needed per unit of output), a reduction in measurement uncertainty is required. This might be achieved by reducing the uncertainty of measurement by using instruments or data having greater precision or by reducing human error in measurements. Either of these should reduce the standard deviation of observations and permit closer control of the process. Improved measurement instruments or techniques represent improvements in the "state of the art" which may affect the cost (price) of a "unit of measurement service" and its value as indicated by changes in the use of other resources.

In some situations the precision of measurement may be improved by increasing the number of measurements, rather than by changing measurement techniques. Where a product has given specifications (e.g., $1 \mathrm{~mm}$ with a tolerance of $0.01 \mathrm{~mm}$ ) and where quality is measured by sampling a lot, improved quality assurance may be attained by increasing the number of measurements (i.e., sample size), given a specified standard deviation of process and instruments. ${ }^{13}$ Here, the cost of measurements may increase due to increases in the number of measurements made. Again, as in the preceding case where the quality of measurement was improved, the cost of the reduction in uncertainty must be compared with the value of other inputs saved as a result of the reduction in uncertainty.

Another aspect of precision concerns the range of magnitude and precision required at each order of magnitude. It is generally recognized that measurements of extremely large or extremely small magnitudes involve correspondingly greater uncertainty than magnitudes in the middle range (Huntoon, 1966). As the demand for greater precision increases at the extremes of magnitude, the costs of achieving it rise sharply (Huntoon, 1966). The economic question then becomes one of asking whether the new final product (objective) for which this precision is required is worth the cost of measurement, or whether trade-offs between

${ }^{13}$ The standard error of the process is indicated by:

$$
\sigma_{x}=\frac{\sigma_{p}}{\sqrt{n}}
$$

where:

$\sigma_{x}=$ standard error of the mean of the sampling distribution.

$\sigma_{p}=$ standard deviation of the product or process mean including uncertainty of measurements.

$n=$ sample size (units of measurement service).

The standard error (specification) may be improved (reduced) by decreasing $\sigma_{p}$ (by improving the precision of measurement) or by increasing $n$ (by taking more samples using given measurement techniques). higher precision and other inputs appear to promise savings in achieving a given output.

\section{Empirical Measurement of Economic Value}

To determine the economic value of measurements requires: (1) case studies of specific applications, or (2) statistical data which indicate how measurements may have affected firms or industries. The latter are seldom sufficiently detailed to permit meaningful generalizations. Although census and other published data permit one to describe the boundaries and magnitude of the measurement system, they do not readily permit an analysis of the economic effects of measurements. ${ }^{14}$ Consequently, the case-by-case approach is required to indicate the economic value of measurements. While this does not indicate the aggregate value of the measurement system, it is useful to managers in making choices involving measurement resources such as instruments, data, and people. To illustrate this approach, some results based on studies of seven NBS measurement projects are summarized here. ${ }^{15}$

Since all seven of the projects were publicly financed through NBS appropriations or by funds from other agencies, the appropriate formula for indicating value is: $V=T R-C_{o}$ (see footnote 11). Because each study was made by a physical scientist familiar with one specific project, no uniform method of evaluation was used. Consequently, the projects will be evaluated in the context of this formula.

Four of the seven studies measured value as changes in sales revenue ( $\left.\Delta^{\prime} \mathrm{TR}\right)$ derived as a result of applications of new measurement techniques or data. In these, measurements led to decisions to produce new products (outputs) or to make technological changes in products or processes (i.e., measurements were resource using). Such outputs incorporated measurement developments in which the NBS participated and which were sold in the marketplace by private firms: (1) high accuracy time and frequency receivers and oscillators, (2) precision coaxial connectors, (3) semiconductor materials, and (4) liquid petroleum gas (LPG).

The value formula also requires knowledge of the cost of all inputs other than the measurement resource $\left(\mathrm{C}_{0}\right)$. This was not obtained in these four projects, with the exception of development costs associated with the time and frequency equipment and investments in LPG meter calibration equip-

\footnotetext{
${ }^{14} \mathrm{~A}$ comprehensive analysis of the manpower and instrument industry components of the measurement system was prepared by Wilbur H. Eskite, Jr., in an unpublisher paper entitled Studies of the National Measurement System at the NBS in 1966. This paper provides data indicating the cost but not the value, of the measurement system.

${ }_{15}$ See John T. Yates, Jr., and Howard E. Morgan, "Exploratory Studies of the Benefit-Cost Measurement in Research and Development" (to be published).
} 
ment. Consequently, the value of publicly funded measurement $(\mathrm{V})$ cannot be determined from the formula. The use of market sales data (TR) alone tends to overstate the NBS contribution.

Three of the seven studies provided data which indicate the extent to which measurements were resource saving (i.e., measurements led to decisions to use less of other resources). These projects illustrate improvements in productivitiy of products or processes required to reach a given output or objective. Private firms produced the following products or services sold in the marketplace; (1) thrust measurement transducers, (2) iron and steel, and (3) railroad and trucking services. Since changes in sales were not reported in these cases, TR is assumed constant in the value formula. Changes in the cost of some other inputs $\left(\mathrm{C}_{0}\right)$ associated with measurement changes were reported for these three projects. The value of the NBS contribution (V) could have been determined, if all costs (public and private) other than the NBS project costs had been included. Since they were not, the NBS contribution again cannot be determined by this formula.

In summary, none of the seven studies provided all data needed to estimate the value of the NBS measurement work. However, these studies have been valuable in indicating the kinds of economic effects generated by measurement data and alternate ways of measuring their value. The results represent crude estimates of direct benefits to users who are (with the exception of the LPG project) producers of goods or services. Indirect benefits to society were not measured here; this requires indepth studies to ascertain the effect of changes in outputs on willingness-to-pay or on national income as indicated earlier.

\section{Conclusions}

It is relevant and useful to NCSL members and those who employ their services to determine the economic value of making measurements. Resources used to provide measurements (instruments, data and people) have costs which do not necessarily reflect their economic value. Users of measurement data must consider the value of measurements when providing funds for measurement work.

Measurements are made primarily to provide information which leads to decisions which: (1) alter the method of attaining a given objective or (2) result in new objectives. These two kinds of decisions have implications for the determination of economic value. The alteration generally is resource-saving while new objectives are resourceusing.

Whether or not something has value depends upon its contribution to a goal or objective. Eco- nomic value requires that a resource have utility or a capacity to satisfy user wants or needs. Although utility is not easily measured empirically, the concept of willingness-to-pay permits an indication of economic value on a demand function in which price and quantity are the parameters. If goals are economic and if the contribution of measurement data to changes in willingness-topay for final goods can be ascertained, a crude indication of aggregate economic value can be derived. Where market prices of measurement related goods are known, input-output analysis may permit one to indicate net economic value by tracing through the consequences of interaction in the economic system.

In contrast with the determination of aggregate value, the economic value of measurement data to individual user's who are producer's of goods and services is their marginal revenue product. This is defined as the change, in total revenue from the sale of goods and services by a profit-maximizing producer, induced by an additional unit of measurement service. Private firms having knowledge of how costs and revenues change with output can determine the value of measurements by determining their marginal revenue product.

Where measurement data are supplied at public expense by government laboratories, their value to individual private firms is again their marginal revenue product. Their aggregate economic value can be approximated by a modification of the value marginal product concept: aggregate value equals the extra revenue from the sale of goods produced with the measurement data, less the cost of all inputs other than the measurement data whose value is being determined. The change in sales revenue attributable to the measurement data equals the change in willingness-to-pay, if the product or service is a final good bought by consumers. Both of these methods require that products using measurement data be sold in the market at known prices. In the absence of market prices, product prices must be imputed; or one can assume that price and quantity of the product remains unchanged, then proceed to ask what changes occur in costs of inputs other than measurement data.

The latter implies that measurement data are resource-saving and that their value is the reduction in the cost of other resources used together with measurements to produce the given output (objective). Where prices and quantities (or quality) of output change, the value of measurement data reflects the net effect of other resources used and saved in the production of the output. In short, the economic value of measurement data is determined largely by changes in the cost of other resources with which measurements are used to produce goods and services. 


\section{Bibliography}

Amey, W. G., "Why Don't They Do Something?" Proeecdings of the 1966 Standards Laboratory Conference, Misc. Pub. 291, National Bureau of Standards, pp. 5-7 (Washington: Government Printing Office, 1967).

Huntoon, R. D., "The Measurement System of the United States," Proceedings of the 1966 Standards Laboratory Conferenee, Misic. Pub. 291, National Bureau of Standards, pp. 89-98 (Washington : Government Printing Office, 1967).

Panel on Standards Laboratory Information Dissemination, Proecedings of the 1962 Standards Laboratory Conference, Misc. Pub. 248, National Bureau of Standards, p. 124 (Washington: Government Printing Office, 1963). 


\title{
MAXIMUM USE OF EXISTING ACCURACY IN MEASUREMENTS
}

\author{
Robert S. Powers \\ National Bureau of Standards, Boulder, Colorado 80302
}

\begin{abstract}
As demands for measurement accuracy get more and more severe, it becomes necessary at every echelon in the national measurement system to examine known sources of uncertainty more carefully and make the most efficient possible use of the knowledge so gained. This means not only careful examination and treatment of random variations, but equally careful consideration of whatever may be known about the bias (or systematic) uncertainties. Determining limits to be placed on the magnitudes of bias uncertainties is often one of the most frustrating of the metrologist's tasks, since information on which to base calculations or measurements is often simply not available.

In many of the measurements made by the Boulder Laboratories of NBS, especially the electronic measurements, it is these bias uncertainties which are the major source of uncertainty. Accordingly, we have begun a vigorous program designed to provide users of such measurements with much more detailed information about both random and systematic errors which can affect the results. The eventual goal is for reports of calibration to include not only a brief discussion of each source of error which has been identified, but also an explanation of how the individual uncertainties have been combined to give the estimated overall uncertainty. Standard measures of imprecision, such as the standard error or the standard deviation, will be provided separately.

Such detailed reporting will allow the user to examine for himself the error sources considered by NBS, so that he can use that information to his own best advantage. For example, in case the user is primarily interested in measurement agreement between his laboratory and another, rather than in the absolute value of the measurand with respect to the basic quantities, he may be able to ignore sources of uncertainty which serve only to link the NBS measurement to the basic quantities, but which would remain constant for all similar calibrations done by NBS.
\end{abstract}




\title{
NEW DIRECTIONS FOR NBS OUTPUTS
}

\author{
Eldred C. Wolzien
}

\author{
National Bureau of Standards, Boulder, Colorado 80302
}

\section{Introduction}

"What's new?" is a widely used form of greeting. Since many of you have not visited NBS during the past two years, I shall presume that you are asking that question, and I will try to give you some answers. But you also ask us many times: "Why do you do what you do?" That question is much more difficult to answer and is, in many ways, far more important.

I shall speak to these questions by describing some of the new directions we are facing as a result of forces caused by major current problems. I would also like to sketch quickly what these forces are and what some of their effects are on the National Bureau of Standards (NBS) as well as on other elements of the National Measurement System (NMS).

\section{Major National Problems and Effects on the NMS}

Our major national problems generate forces which mold the shape of the NMS and many of its specific activities. In general terms, these problems may be catalogued as social, technological, and money problems. It is interesting that the acronym of these words is STAMP; we might visualize this "stamp" in many shapes and sizes being applied to form the outline of the National Measurement System.

\section{Social Problems}

Let us look briefly at the effect of social problems on the NMS. In broad terms they are the problems of peace, poverty, pollution, and population. They have had various effects on the activities of technology. A positive effect has been the increasing dependence on technology, for the solution of these problems. However, a negative effect has been the development of a dissatisfaction with technology, resulting from a widespread feeling that technology has failed to meet public needs. And so, forces appear to which we, as part of the general field of technology, must respond. NBS, like all institutions, must reconsider its role in contributing to the solution of these overriding problems. We must ask: "What should our pro- gram be?" And we must expect it to change. For we are learning, as it has been said, "that the very processes and institutions of science and learning, and of technology, will have to change and be modified as the effects of science and technology become socially more important."

\section{Technological Problems}

Technological problems form our second category. In technology itself changes are constantly occurring as a result of rapid advances in establishing scientific and technical areas. These, too, produce problems and forces affecting the National Measurement System. For example, both science and engineering are tending toward the study of more complex systems. Not surprisingly, such systems increasingly involve interdisciplinary interaction between traditional fields such a biology and physics. In electronics this trend toward complexity is illustrated not only by the spreading application of electronics to new fields, but by the increasing emphasis on complex technical problems such as the determination of electromagnetic compatibility, spectrum analysis, and pulse characteristics. These subjects are not replacing the traditional electronic quantities but are supplementing them.

Further program changes are required by the development of new scientific subjects and the fast growth and changing nature of a technical field. For example, we find in an area such as electronics a diversity of applications leading to an increasing number of new measurement problems. be?"

Again, we must ask: "What should our program

\section{Money Problems}

Now, let us go to our third major problem. As a result of our social problems the nation has developed a serious money problem. This, with a change in attitude toward science, has produced a leveling off and changing in emphasis of Federal R\&D spending. No matter how important we may consider our program to be, we cannot gain support for it unless we can show clearly that our efforts contribute directly or indirectly to progress benefiting the whole country. What can we do about all this? We must ask more often and more 
carefully: "What is the right problem and what is the right contribution we should make to the solution of that problem?" Or, "What should our program be?"

These are the major problems generating forces affecting the environment within which we work. Now, specifically, what are some of the changes in the National Measurement System and in NBS, which these forces stimulate?

\section{Effects on the National Measurement System}

In order to answer this question we must first try to examine the potential contributions of the NMS to all problem areas. Such an overall view immediately shows us many areas suffering from the lack of good measurements and suggests remedies for these measurement needs. These involve the following actions :

1. The NMS must be coupled more effectively to fields involved with national goals, such as medicine, transportation, oceanography, education, urban improvement, defense, space, and economic growth.

2. Like all social systems, the NMS is also a people process. Merely providing good instruments, data, and techniques is not enough. People make the system go, and the effectiveness of the system is directly dependent upon the measurement knowledge and skills of these people. Therefore, they need the right kind of information and training:

3. With changing customer needs, methods of disseminating accuracy and measurement knowhow must be constantly evaluated and optimized.

4. Outputs must be tailored to the most urgent needs in order to utilize all available resources most efficiently.

5. The development of new technical areas requires the establishment of new understanding, techniques, and services.

\section{New Responses of NBS to Measurement Needs}

We are now ready to discuss some of the NBS activities which are aimed at satisfying part of these needs. Those which I shall cover are carried on primarily by the Bureau's Radio Standards Engineering Division. More of such activities are described by other NBS speakers.

In general, we are increasingly concerned with the overall needs of the NMS in our subject areas, with what is the right problem, with making our program most relevant to national objectives, and with providing more local services.

\section{Medical Electronics}

An increasing need to which we are giving more attention is that of improving physical measure- ments in medicine and biology. For example, a great amount of attention has been centered recently on radiation hazards caused not only by ionizing electromagnetic radiation but by sound and non-ionizing electromagnetic ladiation such as that from microwave and laser sources. Three bills ${ }^{2}$ aimed at protecting the public health from radiation emissions from electronic products have been presented to the Congress for consideration. Much concern has been expressed about potential dangers from certain types of this radiation. For example, microwave systems are becoming more and more a part of our way of life, not only in communications and industry but in our homes where even microwave ovens are being used. Whether or not serious dangers may be caused by such applications is often difficult to evaluate. And even though microwaves are known to be dangerous under some conditions, much still needs to be learned about their effects. A recent report stated: "Although the biological effects of microwaves have been studied, certain areas, such as the possibility of cumulative effects from subthreshold exposures, functional changes from low intensity irradiation as reported by the Russians and possible nonthermal changes need further clarification. Large gaps also exist in the current knowledge of possible genetic implications and the actual long-term effects, if any, of microwave radiation on humans."

In order to evaluate such hazards and the biological effects of microwaves and other non-ionizing electromagnetic radiation, it is necessary first to measure this energy. This measurement must often be made in near fields at frequencies and levels where not all of the required instrumentation and techniques of sufficient sensitivity and accuracy exist. However, NBS has the capability to develop the needed measurement standards, techniques, and instrumentation for this purpose. It can direct attention to this problem, and so, contribute strongly to the solution of an important health problem.

In other medical areas - such as the monitoring of patients, diagnostics, bio-research, and sophisticated applications for special space and undersea programs-improved electronic measurement know-how appears to be urgently needed. But new hurdles also show up. Getting physicians and electronics people to understand each other is still a problem.

At present we are becoming acquainted with the problems, the organizations, and the people involved in medical electronics so that we may determine the best ways to apply our capabilities.

\section{Dissemination of Measurement Accuracy}

As the state-of-the-art changes in each technical area and as measurement needs appear and disappear, new methods of disseminating measure- 
ment accuracy must be considered. Recently, with support from the Air Force, a new radio standards comparator was developed. The comparator offers a new approach to the problem of transfering accuracy to the ultimate user. This approach utilizes four different but simply related quantities (such as power, voltage, current, and impedance) to provide the redundancy required for monitoring the value of the four quantities. When it is properly applied, it can increase the reliability and accuracy of measurement at any level, and at a substantial reduction in the cost of maintaining the system. The concept is directly applicable to any measurement system which offers a number of quantities which are properly related.

Further studies are also being made of the several approaches available for disseminating standards and for comparing measurement processes. The relative merits and costs of these approaches are being determined on the part of both NBS and the customer. With this information we aim to determine and implement the optimum methods for disseminating measurement standards.

\section{Training}

Another direction which is being emphasized is that of increasing the effectiveness of personnel in the National Measurement System. As we look at the NMS it is clear that it depends upon people-people who possess the right kind of information and skills. Later in this Conference you will hear Mr. Anson describe our new Radio Standards and Measurement Information Center with its emphasis on the selection, evaluation, and production of information.

NBS is also planning an expansion of Handbook 77 to an NBS Special Publication 300 on Precision Measurement and Calibration. This will consist of 12 volumes and an index. You may obtain complete tables of contents by writing to Dr. H. I. Mason, National Bureau of Standards, Gaithersburg, Maryland.

Not only, however, must the right kind of information be developed and disseminated, but attention must be given to the training of practicing metrologists. According to Professor Guilford, ${ }^{4}$ "many educators have assumed, at least implicitly, that if we provide individuals with information they will also be able to use that information productively. Building up the memory store is a necessary condition for productive thinking, but it is not a sufficient condition, for productive abilities are relatively independent of cognitive abilities."

NBS has long promoted and provided limited training experiences for persons interested in precision measurements. Yet, thousands of people who make measurements, at least occasionally, are not able to attend these sessions, or find available adequate substitutes. Most of these people are technicians or non-measurement specialist engineers. Furthermore, measurement activities and needs are growing while the supply of properly trained engineers and technicians is dwindling.

If the Bureau is to fulfill its responsibility in the NMS, it seems that it must give a proper amount of attention to the training and upgrading of the practicing metrologists. Certain aspects of this training can be given only, or at least best, by NBS. For example, many state-of-the-art measurement techniques have not been fully documented and can best be taught or described by the cognizant measurement specialists. Wherever other organizations can provide aspects of this training, NBS must recognize and encourage such activities. An overriding constraint on the Bureau's participation is that it cannot afford to dilute greatly its basic job of generating and maintaining measurement capability and know-how; otherwise it would have no basis for its service. With this limitation in mind, we are looking at major parts of the problem of training practicing metrologists in the radio standards area-namely, the trainee, the curriculum, and the methods-to see how NBS might best help improve the quality of this manpower.

\section{The Trainee}

In considering the trainee, we find that a wide range of potential types and qualifications existsfrom beginning technicians to graduate engineers, all concerned with measurements not only in the physical sciences but also in the life sciences and other fields. Although we are concerned first with the the personnel in the calibration laboratories, we must remember all personnel who contribute to the effectiveness of the NMS-those persons applying measurements in research, development, design, production inspection, operations, maintenance, repair, monitoring and control programs, and teaching. Even the general public can profit from a better understanding and appreciation of measurements.

\section{The Curriculum}

In measurement curricula new subject requirements continuously appear as the technology and applications change. This poses a problem in tailoring training to very specific needs. Nevertheless, there also seems to be a widespread requirement for certain fundamental subject matter to be included in the training of almost all of the students described earlier. Developing this material may be a task best performed by NBS. The content of this subject matter is as follows:

(a) Principles and basic concepts of measurement;

(b) Basic techniques with information to facilitate a selection and instrumentation of the best technique for a given application;

(c) Evaluation of uncertainties, showing types of errors, their effects and treatment, and the interlocking of quantities; 
(d) Sources of relevant information-organizations, persons, and references-where more measurement know-how is available.

\section{The Methods}

A third part of the problem is that of determining where, when, and how the training is to be provided. It is clear that the practicing metrologist will have to grow and absorb new concepts and new tools as they become available. This educational process will have to be a continuing one rather than a cramming effort once every five or ten years. Business recognizes this requirement for its employees and is working hard at the task. It is estimated ${ }^{5}$ that business in the United States is spending 30 billion dollars annually for on-thejob training of workers. In spite of our tremendous investment in training we still do not know how to do the job with predictable results. A recent study ${ }^{6}$ showed that 'our present and most pressing problem is the lack of an empirically validated theory of teaching, and, in fact, instruction that could form the primatives of a theory of teaching. This is not to say that we lack teaching practices that are widely used." It goes on to say that existing data cannot be used to demonstrate the greater effectiveness of one practice over another.

\section{Training Problems and Possible Solutions}

At this point let me summarize the training problems we now see. They may be listed in this way:

\section{Under student-related problems:}

- Many persons with different backgrounds and objectives, applying measurements at different levels of sophistication

- Poor motivation of students.

Under curriculum-related problems:

- Inadequate training materials

- Out-of-date subject matter

- Inadequate identification of subject matter

- Narrowness of materials

- Need for fundamental material.

Under method-related problems:

- Unclear objectives.

- Poor educational techniques.

Under program-related problems:

- Unqualified instructors.

- Insufficient courses in view of levels, subject matter, and numbers of students.

- Unavailability of on-site training.

- Lack of continuous training opportunities.

- Insufficient coordination and coupling between sources of information and distributors of information in government, industry, and schools.

Now, what might NBS do to alleviate these problems and upgrade the training of people in the NMS? As I said earlier, we cannot handle the complete job; there are many possible tasks. Here are some which we are examining with reference to the problems which I have just stated. We might:
- Design and/or conduct packaged courses, seminars, workshops, laboratory experiences, and work-study programs.

- Produce texts, films, slide-tape sets, video tapes, traveling exhibits, programmed instructional materials, home-study courses, and tutorial bulletins.

- Provide tele-talk contact with measurement experts, 'TV instruction, wired blackboard instruction, question and answer service, mobile classroom, rental service of materials, traveling teaching team, and self-help information on references and courses.

- Encourage intern programs in industry and government.

- Encourage better courses in schools and train teachers of such courses.

- Establish cooperative programs with industry, other government agencies, and schools.

We have had some experience with many of these activities and, at present, are carrying on an evaluation of these tasks. We are also planning some experimental seminars to be given in different parts of the country for the purpose of training practicing metrologists who live in those areas.

\section{Conclusion}

In conclusion, I have discussed some of the major problems and forces which affect the National Measurement System. And I have described some of the ways in which NBS is responding. Now, what lies ahead? As I see it, all elements of the NMS must bear responsibilities in tackling these problems. NCSL can share in developing the aims of the NMS and in contributing constructive action toward fulfilling such goals. You can help us in NBS get good solutions to the right problems by providing a feedback of information on needs and the effectiveness of our programs. As we continue, we can expect to develop a better understanding of the NMS, but we can expect it to appear evermore complex. A general criterion has been noted ${ }^{\text {? }}$ that "in order to get more capable systems, be they things or people, the system must become more complex. Usually what we mean by increasing complexity is deeper specialization and better interaction between the specializations and better coupling to the unique purpose."

\section{References}

\footnotetext{
1 Statenient by Dr. Emmanuel G. Mesthene. Technology Assessment Seminar. Proceedings before Subcommittee on Science, Research, and Development of the Committee on Science and Astronautics, U.S. House of Representatives, Ninetieth Congress, 1st Session, Sept. 21-22, 1967, No. 7, U.S. Government Printing Office, p. 20.

2 Three bills: S. 3211, an Administration-sponsored measure introduced March 21, 1968; S. 2067, a measure introduced July 10, 1967; and H. R. 10790, a measure introduced March 21, 1968, and passed by the House.

${ }^{3}$ Biological Aspects of Microwave Radiation-A Review of Hazards by Wellington Moore, Jr., U. S. Dept. of HEW,
} 
Public Health Service, National Center for Radiological Health, TSB 4, July 1968, p. 25.

4 Intelligence Has Three Faces by J. P. Guilford, Science, 10 May 1968 , p. 619.

5 Personnel Policy, Issues and Practices by George S. Odiorne, Charles E. Merrill Books, Inc., 1963, p. 227. Quoted in Business and its Environment, by Keith Davis and Robert L. Blomstrom, McGraw Hill Book Co., 1966, p. 146 .

6 The Myths of Educational Technology by Anthony G. Oettinger, Saturday Review, 18 May 1968, p. 91 .

7 The Evergreen Life, Banquet Address by Jack A. Morton, Proc. 20th National Conference on the Administration of Research, 1966, p. 133. 


\title{
HIGHLIGHTS OF THE NBS BOULDER LABORATORIES
}

\author{
T. M. Flynn
}

\author{
Institute for Basic Standards, National Bureau of Standards, Boulder, Colorado 80302
}

\begin{abstract}
The business of the National Bureau of Standards is standards; i.e., measurement compatibility on a national and international scale in science, commerce, and world trade. The business of the Institute for Basic Standards of the NBS is standards (measurements) in the basic physical qualitues. Here we describe the roles of five Divisions of the IBS that are in Boulder, Colorado: the Radio Standards Physics Division, the Radio Standards Engineering Division, the Time and Frequency Division, the Laboratory Astrophysies Division, and the Cryogenies Division.

Key words: Standards; measurements; time and frequency; plasma physics; astrophysies ; cryogenies.
\end{abstract}

\section{Introduction}

Dr. Astin has essentially four technical resources that he may turn to in fulfilling the mission of the National Bureau of Standards. These are the Center for Radiation Research; the Institute fol Applied Technology; the Institute for Materials Research; and the Institute for Basic. Standards. The last, IBS, has elements both in Washington and Boulder, and employs about 38 percent of the entire permanent staff of the Bureau. The staff at Boulder numbers nearly 600, about 16 percent of the entire Bureau.

The elements of the IBS which are in Washington are the

Office of Measurement Services

Office of Standard Reference Data

Applied Mathematics Division

Electricity Division

Metrology Division

Mechanics Division

Heat Division

A.tomic Physics Division.

Their titles are descriptive of their activities.

And the elements of the IBS which are located here are the

Radio Standards Physics Division

Radio Standards Engineering Division

Time and Frequency Division

Laboratory Astrophysics Division (JILA)

Cryogenics Division.

We also have here the services of the Administrative Services Division

Instrument Shops Division

Plant Division.

The business of all these Divisions of NBS is standards, i.e., measurement to assure compatibility on a national and international scale to assure the progress of science and the flow of com- merce and world trade. They work within and help to lead a "system," the National Measurement System.

It is easy to conceive of the national postal system or the telephone system for, to use either of these, the individual participates in a network which can be readily visualized. There is another system, however, larger than either of these in both dollar value and number of users, which is seldom visualized. It so permeates our society that it is taken for granted. This is our system of measurement. In referring to the National Measurement System, we think of the sum of all those organizations, individuals, and resources that are devoted to providing measurements to the entire Nation. The primary conceptual goal of a national measurement system is compatibility - the actions and decisions of every participant (individual or organization) should be effectively suited to the needs of his environment. It is the business of the National Bureau of Standards, and of these Divisions in Boulder, to assure the efficient and effective operation of the National Measurement System.

As within the nation, so within the world-to avoid chaos there must be a single, complete, and consistent measurement system which meets societal needs. International uniformity of measurement helps U.S. industry expand into foreign markets, helps the armed forces obtain reliable services overseas, and makes possible international exchange of scientific data.

Let me now highlight the role that each of the Boulder Divisions plays in assuring the international compatibility of measurements.

\section{Radio Standards Physics Division}

The first is the Radio Standards Physics Division. It is a resource group concerned pri- 
marily with the interaction of coherent radiation with matter. Its role is to develop and maintain leadership in measurement techniques in this area for NBS, for other Government agencies, and for industry.

\subsection{Quantum Electronics}

One of its major programs is in Quantum Electronics. Here the emphasis is on laser power and energy standards. We have developed an energy standard for pulsed laser systems. Development of power standards for both pulsed and continuous-wave (cw) laser systems is in progress. Industrial and defense laboratories which seek calibration of commercial laser calorimeters need the results of this work. We are currently developing a calibration service for them.

Another major program involves laser techniques applicable to frequency and wavelength standards in the infrared and visible regions. Here a stabilized HCN laser is of considerable interest as the basis of a possible frequency and voltage standard.

The Division also does research in modulation techniques, such as microwave modulation, harmonic mixing, and parametric amplification. These will be useful to both communications and computer technology.

\subsection{Plasma Physics}

In plasma technology, we wish to generate uniform, reproducible plasmas which can be used as standards for making measurements here and elsewhere. In our work on Plasma Diagnostics, we are developing means for measuring plasma parameters.

Given meaningful measurement techniques, one can work in the area of Plasma Mechanisms. By this, we mean interpreting the fundamental atomic and molecular processes in the plasma medium from experimental plasma measurements.

\subsection{Solid-State Electronics}

Our research in solid-state electronics is to a large degree an extension of our work with lasers. For example, one needs to understand detector mechanisms, to get at their frequency response, and to develop fast-response, sensitive detectors in the infrared region.

Similarly, we are concerned with modulation mechanisms. For example, one needs to understand scattering and other loss mechanisms that affect the efficiency of modulator crystals.

\section{Radio Standards Engineering Division}

The Radio Standards Engineering Division provides the central core of the Nation's system of measurements at radio frequencies from $30 \mathrm{kHz}$ to $300 \mathrm{GHz}$. This is one part of the total system of physical measurements upon which the Nation's commerce, science, and industry depend. This Division supplies the measurement foundation for the electronics industry and the many varied uses of its sophisticated products. Every electronic device represents a terminus of the network originating here.

Let us look briefly at some of the areas served directly-

- National Defense: Command, control, guidance, detection, surveillance, destruction, deception

- Space: Voice, telemetry, guidance, control, detection, tracking

- Air Navigation and Safety: Communication, radar, navigation, guidance

- Safety from Electromagnetic Hazards: Personnel, detonation of weapons

- Commerce: Industrial manufacturing, Comsat, telecommunications

- Scientific Research : Measurement technology.

Indirectly, the Division also serves-

- Computers: Manufacturing and process control, product design and scheduling, data processing, management information systems, information retrieval, research

- Consumer electronics: TV, radio, hi-fi and stereo sound equipment, tape recorders, etc.

- Public safety : Aviation, law enforcement, fire, civilian defense

- Health : Electronic medical instruments.

\subsection{Standards}

Most prominent among the roles that the Radio Standards Engineering Division (RSED) plays is that of furnishing standards which provide a common reference point, available to all. The Division does this in three steps: (1) it decides what standards are needed, (2) it establishes and maintains them, and (3) it makes them available to science and industry through its calibration services. The science of metrology has been advanced here to become an almost unique asset in the United States, and a large program for the calibration of transfer standards is carried on.

It is easy to see the chaos that would result in our highly industrialized nation if mechanical parts made in Rhode Island did not fit machines assembled in Wisconsin. Complex mechanisms demand components of the highest accuracy, and mass production completely depends on interchangeability. The problems in electronics, communications, and radio are similar to, but much more complex than, this mechanical example.

\subsection{Measurement Techniques}

A second important role is to develop ways to make exacting electromagnetic measurements. In work of this sort, the value added exceeds the cost only when such an "unprofitable" job is done 
by a central laboratory. The point is that cost is incurred only once by the central laboratory, but value is amplified many times when this laboratory provides technical knowledge and assistance for solving measurement problems.

One example of this is measuring the radiation pattern and gain of large-aperture antennas, such as those used for earth-to-satellite communications. The far-field region, which is the important characteristic, may exist at distances of say 10 to 20 miles. Earth-based measurements of the actual far field are not useful due to terrain effects, and satellite or high-flying aircraft measurements are both expensive and unreliable. Therefore, one wishes to predict the far-field performance from groundbased measurements of the near field up close to the antenna. This Division is developing such a technique, in the hope that a measurement made from an elevated platform at a distance of perhaps hundreds of feet can replace problematic measurements at tens of miles. Potentially this technique can serve Comsat, DoD, NASA, the radio astronomers, and others-none of whom are individually motivated to develop it.

\subsection{The National Measurement System}

A third role that RSED plays in common with the rest of NBS is to assure the effective utilization of the national measurement system as a whole. The effort of the Division here is to help coordinate and guide resources which are external to RSED, but which bear on electromagnetic measurements. This can be accomplished by collecting and making available information on national capabilities, by appropriate referrals, by committee activities, and by recommendations looking to a more useful organization of the national measurement system.

\subsection{International Measurement Agreement}

In the interests of world trade, the national measurement system of the United States must be compatible with the systems of other countries. To this end RSED compares its important standards of power, attenuation, noise, and other quantities - at both radio and microwave frequencieswith all countries ready and willing to do so. It has also made major contributions to other programs, such as the achievement of international agreement on the dimensional and electromagnetic standardization of coaxial connectors.

\subsection{Major Technical Areas of RSED}

The number of standards required for electromagnetic measurements is illustrated by figure 1 , which shows three of the several "dimensions" involved-physical quantity, magnitude, and accuracy. Quantities include power, electric and magnetic field strength, impedance, noise, voltage, attenuation, current, phase, and reflection coefficient. In terms of frequency, RSED is concerned with the spectrum from about $30 \mathrm{kHz}$ to and including millimeter-wave frequencies at about $300 \mathrm{GHz}$. This is a seven-decade range or, in musical terms, 23 octaves! Electrical standards from de to 30 $\mathrm{kHz}$ are supplied by the IBS Electricity Division in Washington, D.C.

The front plane of figure 1 shows the variety of techniques and devices needed to measure just one quantity, power, at various frequencies and in magnitudes ranging from microwatts to megawatts. Each of the other quantities shown requires an entirely new family of standards.

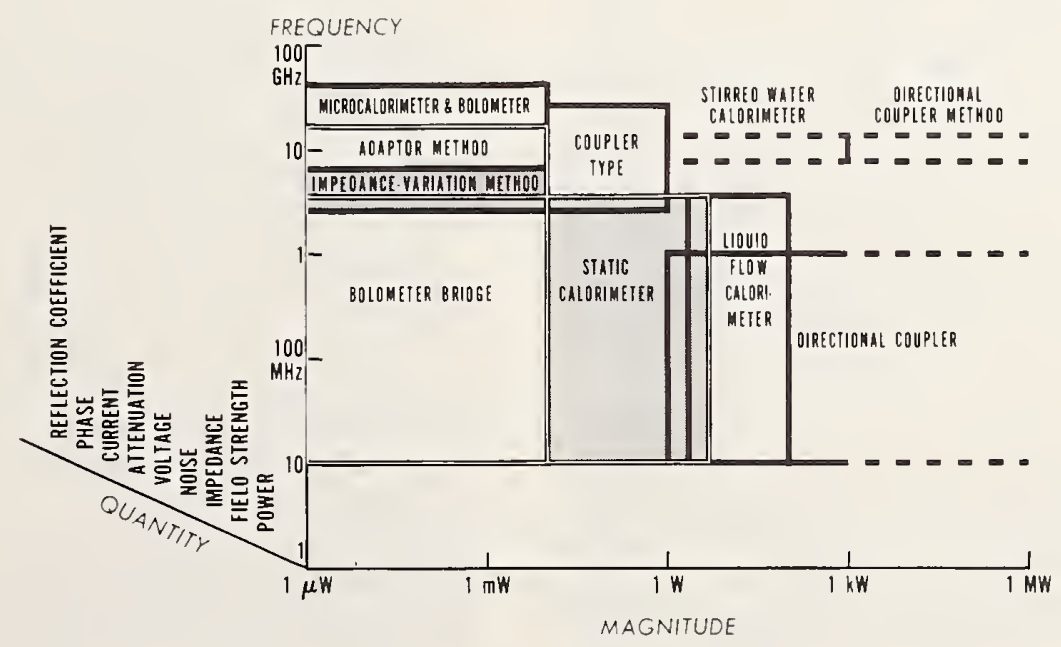

FIGURE 1.-Some standards required for electromagnetic measurements. 


\subsection{Summary}

In summary, RSED must assure that the basis for a system of measurements, fundamental to the determination of the electromagnetic quantities and of certain electromagnetic properties, is provided to the Nation. The Division acts as a central reference point and as a facility which performs tasks most economically carried out by a central laboratory; it also provides leadership in coordinating efforts of other laboratories. These activities extend over many physical quantities and over an extremely wide frequency spectrum.

\section{Time and Frequency Division}

The measurement of time interval is based on the measurement of frequency. Frequency is measured with an instrument that determines the frequency of a particular resonance within the cesium atom, and time is measured by counting the cycles of this resonance as a clock counts the swings of a pendulum.

Time which is accumulated locally on a clock with the aid of a frequency standard is known as "proper time," or "local time." But when broadcast in correct coordination with others, it becomes "coordinate time," useful for synchronization and for epoch, or telling the "time of day."

Thus time becomes a real embodiment of the national measurement system. At a suitable source, proper time is accumulated at the correct coordinate rate and could be sent by wire to nearby terminals. In actuality, numerous stations broadcast signals which are present in accordance with the system at the correct coordinate frequency and epoch. This Division participates by maintaining a frequency standard, accumulating proper time, modifying it suitably in rate and epoch, and distributing it as coordinate time. To effectively eliminate distortion from propagation and gravitation effects, accurate calipers are needed to measure the coordinate time units throughout the network. The calipers in this case are travelling clocks and local atomic standards.

NBS built the world's first atomic frequency standard in 1949. This was followed by the development of two cesium-beam frequency standards which are probably the most accurate and carefully evaluated of any in the world. In 1962 we developed a national standard scale of time, NBSA, based on atomic transitions. These achievements, along with similar developments at other laboratories, led to international agreement in 1964 on the atomic standard to be used for the measurement of time, which was formalized in 1967 by a new definition of the second.

The Time and Frequency Division establishes, maintains, and improves the NBS standards of frequency and time interval. It thus provides the Nation with an accurate realization of the ideal basic standard of time interval - the second-as defined in the International System (SI) of units.
The present standard, NBS-III, is a cesium atomic-beam device employing a magnetic resonance technique. This has a 3-sigma accuracy of $\pm 5 \times 10^{-12}$ (about one second in 6000 years, or 0.4 microseconds per day). Work is in progress to improve its accuracy to $\pm 5 \times 10^{-13}$.

Research also is continuing on the development of two atomic hydrogen masers as possibly improved frequency standards with accuracies approaching $\pm 1 \times 10^{-13}$ (about one second in 300,000 years, or a few billionths of a second per day).

\subsection{Frequency-Time Broadcast Services}

In order to disseminate standard frequency and coordinate time signals to users through the world, NBS operates radio stations WWW (Fort Collins, Colorado) and WWVH (Maui, Hawaii) in the high-frequency bands, IVWVB (Fort Collins, Colorado) in the low-frequency band at $60 \mathrm{kHz}$, and WWVL (Fort Collins, Colorado) in the VLF band. WWVL is an experimental facility, but presently is providing highly stable frequency information with nearly worldwide coverage at 20 $\mathrm{kHz}$. Signals as broadcast from all these stations are referenced to the NBS Frequency Standard. In addition to standard radio frequency and time signals, WWV and WWVH also provide standard audio tones, standard time intervals, binary coded time of day, radio propagation forecasts, and notices of geophysical events.

For years, these broadcasts have met the needs of thousands of users such as radio stations, electrical power companies, standards laboratories, navigators, missile ranges, satellite-tracking stations, navigational-satellite systems, and research laboratorities. A Special Publication, SP 236, describing the signal structure, and a monthly Time and Frequency Services Bulletin giving current data, are available on request.

\subsection{National and International Coordination of Time-Frequency Services}

The CCIR (International Radio Consultative Committee) has organized and established a worldwide system of standard frequency and time broadcasts known as the UTC system. This system is coordinated through the International Bureau of Time (BIH) in Paris. One of the TFD staff is U.S. chairman of the CCIR Study Group VII called "Standard Frequencies and Time Signals." This Study Group is charged with "improvement of measurement accuracy" in this area. On the national scene, we cooperate closely with the U.S. Naval Observatory and are presently engaged with the USNO in the initial formation of a very precise "U.S. coordinate time system." This may act as a pilot model for the evolution of the UTC system into a precise international coordinate time system. We are also concermed with what our role should be in the upcoming Aircraft Collision Avoidance (ACA) System and what its relation 
should be to the UTC system. The ACA System requires a nationwide (and eventually worldwide) network of ground stations, all of which are synchronized to within \pm 0.1 microsecond at all times.

\subsection{Frequency-Time Disemination Research}

The staff is continuing research on better methods of distributing time and frequency-such as using satellites or multiple-frequency VLF broadcasts-and is also doing research on how best to provide time and frequency for deep-space operation.

For example, the short-wave signals from WWV and WWVH are not stable enough over long distances to meet some needs, such as missile range timing or satellite tracking. Therefore, the low-frequency station, WWVL, for example, on $20 \mathrm{kHz}$ has been used for several years to study using multiple-frequency transmissions spaced by, say $100 \mathrm{~Hz}$, to achieve nearly worldwide distribution of coordinate time without the large uncertainties introduced by the ionosphere on HF transmissions. In addition, coordinate-time distribution via satellite has been investigated using the VHF transponder in NASA's ATS-1 satellite to relay time signals from Boulder, Colorado, to Mojave, California; Pitcairn Island in the South Pacific; Maui, Hawaii; and Anchorage, Alaska. Coordinate time has also been transferred by bouncing signals off the moon (using Jet Propulsion Lab's moon-bounce radar system) and by using reflections from meteor trails. Time comparisons between clocks at NBS, Boulder, and our Fort Collins site are being made to 0.1 microsecond using a very simple and inexpensive technique involving the simultaneous monitoring at the two locations of synchronizing pulses broadcast by one of the Denver television stations. Here inexpensive commercial TV sets are used as receivers.

\subsection{Summary}

Time and frequency have many facets, and the NBS Time and Frequency Division is engaged actively in the study of several of these. A prime area of research and development is the establishment, improvement, and maintenance of the NBS basic proper standard of frequency. This realizes the international definition of the local second of time, and is used as a primary reference standard for local use. NBS participates in extended coordinated time systems, both nationally and internationally, through its radio transmissions from Fort Collins, Colorado, and Maui, Hawaii. Research on the organization and standardization of coordinate time systems is carried out through participation in satellite and radio broadcast studies and through active administrative and technical cooperation with other Government and industrial agencies. There is similar intensive coordination with other nations in matters such as the organization of a worldwide coordinate time system, the international comparison of basic standards, and the improvement of measurement accuracy.

\section{Laboratory Astrophysics Division}

Laboratory astrophysics studies atoms in a controlled laboratory environment in an attempt to explain stellar processes. This study of individual atoms and their interactions with each other and with radiation fields may be a new tool for understanding a hot, gaseous environment. Compounded countless times, these individual processes determine the gross features observed not only in a star. but also in a nuclear explosion, in the ionosphere, or in a commercial high-vacuum process.

In order to develop the measurement science required by this field, the National Bureau of Standards joined with the University of Colorado to form the Joint Institute for Laboratory Astrophysics (JILA) in 1962. The Bureau and the University each supplies part of the permanent staff and each contributes to the cost. Approximately ten NBS senior staff members hold faculty appointments (as lecturers or professors adjoint) without pay. With this status, all our JILA staff can participate in the University's academic program, giving lectures and conducting classes, supervising the work of graduate students, and taking part in seminars. Within the NBS this small group, with the addition of some technical and administrative staff, constitutes the NBS Laboratory Astrophysies Division (LAD). This arrangement represents a departure from the conventional form of a university-government agency cooperation, designed to achieve certain specific objectives more effectively than could be done in the central laboratories of the Bureau.

The NBS Laboratory Astrophysics Division pursues the twin objectives of developing methods of measuring the parameters of atomic interactions, and of developing the theory of the macroscopic behavior of hot gases and of the transfer of radiation through such gases in terms of atomic parameters. The NBS group pursues this measurement science surrounded in JILA by academic activity in astrophysics, plasma physics, atmospheric physics, aerodynamics, and other similar fields which overlap with atomic physics. The name Laboratory Astrophysics is intended to describe the whole mutually stimulating research environment.

\subsection{Atomic Physies}

The JILA laboratories include one of the world's foremost centers of research in atomic physics. For example, this laboratory led in the application of laser technology to the study of atomic parameters. A particularly important recent development is the realization of the 
potential of the laser for the study of molecular structure and the determination of molecular constants. A byproduct of this work is a technique for using the laser to provide a greatly improved length standard. Also, the velocity of light may be remeasured with a significant improvement in accuracy.

The main emphasis in the atomic physics effort is, however, the development of methods for measuring or calculating the basic microscopic data needed for predicting propenties of special environments.

\subsection{Astrophysics}

The purpose of the LAD effort in astrophysics is a complete understanding of the production and transfer of radiation in terms of the microscopic processes. The goal is the characterization of the atmospheres of stars, nebulae, and of interstellar media. This requires quantitative information about the collisional and radiative interactions occurring. Realization of this goal would permit definitive interpretation of observed stellar spectra. The astrophysical medium, in a very real sense, provides a laboratory for research in the theory of spectroscopic measurement of the state of an extremely hot gas. The term "spectroscopic diagnostics" has been applied to the relationship between observational spectroscopy and such theoretical studies.

\subsection{Academic Training}

JILA has commitments in two directions: scientific research and academic training in the field of laboratory astrophysics. NBS members of JILA may participate in the academic program in several ways. They may teach undergraduate and graduate courses in physies and astrophysics through appointments as research associates, lecturers, or professors adjoint. In this manner, the University enjoys the full and active participation of the entire NBS group. More than half of the staff are "transients"visiting scientists and post-doctoral and graduate students-who work at JILA for a period of several months or one or two years. The $\mathrm{Na}$ tional Bureau of Standards, through a grant to the University, provides for ten additional outstanding scientists in appropriate fields to come to JILA on one-year appointments as Visiting Fellows. This program is now recognized by scientists all over the world as an outstanding opportunity to contribute effectively in the area of laboratory astrophysics.

\subsection{The JILA Information Analysis Center}

The JILA Information Analysis Center is a part of the National Standard Reference Data System. Its mission is the collection of critically evaluated data on low-energy collisions between electrons, photons, ions, atoms, and molecules of astrophysical interest.

Bibliographies, data compilation, and critical reviews are the major products; these are issued as JILA Information Analysis Center reports, as NBS publications, or as papers in recognized technical journals. These compilations and critical reviews have been one of the more significant contributions which JILA has been able to make in the field of atomic physics. The center now contains some 2,000 papers, adds 40 more per month, and answers approximately 800 queries per year.

\subsection{Summary}

The theories, measurement techniques, and data developed by JILA are used in:

- Federal Programs:

Ballistic Missile Defense Space Exploration

Nuclear Weapons Ef- Ionospheric fects

Controlled Thermonuclear Research Prediction

Basic Standards and Measurements

- Industrial Technology :

Industrial Performance Laser Applications on the above Federal programs

G a s e o u s Electronics, Plasma Devices

Hypersonic Aerodynamics

- Science :

Astronomy and Space Quantum Science Electronics

Atomic and Molecular Chemical Physics Physics

These programs depend for their continued success oll a detailed understanding of the environment: on the availability of basic microscopic data and of reliable methods of measuring or predicting environmental properties.

Thus, the Joint Institute for Laboratory Astrophysics :

Provides a center for advanced research.

Trains graduate and postdoctoral students.

Brings in outstanding scientists from the U.S. and abroad.

Works closely with NBS to advance continuing programs in measurement science.

\section{Cryogenics Division}

The cryogenic laboratory here is the primary agency of the United States Government for providing comprehensive and current information in the field of very low temperatures. The Cryogenics Division provides, in barest terms, data and services. Included in the "data" function are: the properties of matter, a Cryogenic Data Center, 
measurement methodology, and the description of system behavior. Included" in the "services" function are our advisory and consultative activities.

\subsection{Properties of Matter}

This Division conducts extensive experimental research to determine the physical properties of solid materials fluids, and systems. We also conduct theoretical programs to improve the understanding of material behavior at low temperatures.

The properties of solids is a vast field and encompasses a wide variey of parameters, each of which must be evaluated from ambient to very low temperatures. For instance, data on thermal and electrical conductivity; thermal expansion and tensile, yield, and impact strength are needed.

In fluid properties, research is being conducted on cryogenic fluids to determine thermodynamic and transport properties. The basic measurements of the properties of cryopropellants, and other low-temperature fluids used in rocketry, are probably the most valuable and permanent contribution of NBS to the space program. Thus far, the principal effort has been in parahydrogen, the propellant most admired in aerospace applications for its high specific impulse. The data generated are believed to be the most accurate and reliable ever reported and include many properties never before measured over any considerable range of temperature or pressure. A similar program is now being completed on oxygen, and one is in progress for fluorine.

\subsection{Cryogenic Data Center}

The Cryogenic Data Center complements the experimental generation of new data by an evaluation and compilation program which has provided the world's most extensive collection of technical literature on the cryogenic properties of materials. The Center was a charter participant in the $\mathrm{Na}$ tional Standard Reference Data System and now has international stature. Its outputs include charts and tables prepared from experimental and "compiled" data, and the publication of "best values" of thermodynamic and transport data. The Cryogenic Data Center now contains over 52,000 references and adds 7,500 more each year. Nearly 800 paid subscribers receive a weekly currentawareness service covering both new literature and research and engineering activities. Throughout its history, NBS has worked in close collaboration with scientists and engineers in industry, in universities, and in other Government agencies. Our Data Center exemplifies this concept of service and cooperation.

\subsection{Measurement Methodology}

Basic to every technology is the art and science of measurement itself. We conduct both theoretical and experimental cryogenic instrumentation programs to develop new methods of measurement and improved measurement techniques in the areas of pressure, temperature, density, state and flow rate.

For example, we are completing a facility to study cryogenic-fluid measuring practices, to develop recommendations for the custody and transfer of commercially important fluids, and to allow testing of new concepts in measurement. This will also provide regulatory agencies with a facility for type-testing cryogenic-fluid metering devices. Further, it will bring to the cryogenics industry (a $\$ 2$-billion annual market) a better understanding of how to achieve more efficient and economical operation of cryogenic processes.

\subsection{Behavior of Systems}

The research in cryogenic system engineering is aimed at producing fundamental understanding which will lead to large engineering advances. The principal activities are related to investigations of basic problems and phenomena associated with cryogenic technology in order to explain and predict the behavior of cryogenic systems.

Mixtures of solid and liquid hydrogen, because they have a higher heat capacity and a greater density than single-phase material, are of interest in aerospace applications, since the potential exists to reduce vehicle volume, increase storage time, and minimize propellant sloshing. We are measuring the properties of solid and liquid hydrogen and are studying production and flow characteristics of mixtures.

Problems in utilizing cryogenic propellants at high altitudes are being investigated. One such problem is the formation of solids by freezing when the ambient pressure is below the triple-point pressure of the fluid. These solids can obstruct or retard flow and thereby cause a malfunction in the propellant system of a space vehicle.

A recently completed study is making liquid hydrogen more usable as a rocket fuel. A pre-launch problem with vehicles using cryogenic propellants is that environmental heating in the piping system connecting the propellant tank to the delivery pump may cause pump cavitation and faulty combustion. To overcome this situation, we have investigated the cooling of liquid hydrogen by the bubble-through of helium gas. The technique was found to subcool the hydrogen enough through evaporative cooling to provide the pump with properly conditioned fluid immediately prior to rocket engine firing.

All of the Saturn-class rockets fired by the United States are using helium gas injection to provide subcooling to both the hydrogen and oxygen propellants. 


\subsection{Summary}

Cryogenics is sometimes thought of merely as an adjunct to space propulsion, when it is, in fact, a rapidly growing billion-dollar business and a major national resource. We feel that our outputs have had significant impact upon many Government and private areas. For instance, on

- space-particularly propulsion, although cryogenics is also vital to the success of space simulation andl life support;

- health-for blood freezing, cryosurgery, marrow banks, breathing oxygen, and biological archives;

- agriculture-for food preservation, refrigerated transportation, and cryobiology;

- conservation-for power transmission by superconduction and for helium conservation;

- transportation-for magnetically suspended trains, and cryogenically fueled aircraft;

- education-for basic research in high-energy physies and superconductivity.
Cryogenics will be used in the future in every phase of industry: in basic research, materials, process chemistry, production, storage, and transportation. Many capable research men agree that cryogenics will be to the second half of the 20th century what high-temperature processing was to the first half.

\section{Conclusion}

Here, then, are the Boulder Laboratories of the National Bureau of Standards-with work on materials from atomic nuclei to bulk fluids, on electrical quantities at frequencies from kilohertz to gigahertz, on temperatures from near absolute zero to those of stellar atmospheres. Despite this diversity, they achieve their strength through a common bond : the business of advancing measurement science and making measurements in the extreme frontiers of the physical world. 
NCSL 68

\title{
SESSION 4: INTERNATIONAL MEASUREMENTS
}

\author{
Chairman: H. W. Lance \\ National Bureau of Standards, Boulder, Colorado 80302 \\ MEASUREMENT CONTROL AS A VALUABLE NATIONAL ASSET
}

\author{
C. E. White
}

Avco Missile Systems Division, Wilmington, Massachussets 01887

\section{Introduction}

Five hundred thousand years ago history recorded the first stirrings of technology. However, before man generally learned to use iron and steel, before there was any conception that this was an inhabited world, and before the discovery of natural fuels other than wood and charcoal, the Egyptians had skillfully produced flaked knife blades of flint, constructed exquisite and precise memorials such as the inner coffin of Tutankhamen, and evolved methods for quarrying, dressing, and erecting intricate stone shapes to form the temple columns, pyramids, and obelisks which mark Egyptian architceture. It is needless to point out the requirement of precise measurement standards which had to exist in order to perform such tasks.

\section{The Growing Awareness}

In order to promote commercial transactions, the techniques and practices first employed in weighing gold-dust were transferred to commerce, about 2500 B.C., by merchants of northern India and some cities of Mesopotamia. Previously, most transactions had been made through the medium of barter. Introduction of this system served to encourage a large expansion of trading among nations all over the Middle East region and with it the influence of Indian and Mesopotamian culture. Even after the decline of the great ancient empires of the Middle East, the standards of weights and measures which had become an integral part of trade, were maintained by the Greeks and Romans and formed the basis of new systems evolved by these nations. In fact, the Greek and Roman systems controlled most international trade from the seventh century B.C. to the seventh century A.D.
We observe that in the year 789 A.D., the ambassador of the Abbasid Caliph Harun al-Rashid (of The Thousand and One Nights stories), presented to the emperor Charlemagne, as a token of esteem, a standard of linear measure (the Hashimi cubit of 25.56 inches) and a set of weights controlling Arabic gold coinage.

The rise of the Islamic empire and the advent of the Crusades and their failures did much to destroy the continuity of western measurement systems. In passing it should be noted that prior to the introduction of the metric system into Europe, not only did every nation have its own system of weights and measures, but large cities in each nation usually had separate and distinct standards of their own. This confusion and profusion of systems encouraged tariffs on imported articles, illegal profiteering on international and intercity exchanges of goods, shoddy merchandising, and low rewards to the artisans.

Many years later, speaking before the 1966 Technology and World Trade Symposium at Gaithersburg, Maryland, the following statements were made by $\mathrm{Mr}$. F. Hadass, representative from Israel :

An important tool of technological advancement is standardization. It is of utmost importance particularly to developing countries as suppliers, as well as purchasers in the world market :

- It helps them to establish, right from the beginning, an adequate quality of production

- It helps them to become discriminating buyers, thus intelligent spenders.

- It offers them a kind of clearing house in the complex of world trade

- It also offers to beginners the benefits of knowledge and experience accumulated in the existing standards.

Developing countries are particularly interested in international standards. 


\section{The Barriers of Self Interest}

Consider for a moment, if you will, the United States to be made up of fifty states, each with its own currency and language. Would we be the strong industrial nation we are? Undoubtedly not! And the picture would be even blacker were there fifty measurement systems. Perhaps, then, we should count our blessings, and consider instead the problems faced in other continents.

In Europe, for example, a situation existed which approached the suppositious case mentioned previously. Note that in the period 1780 to 1966, twenty-nine sovereign countries overcame the handicap of separate currency and language barriers to agree upon a common measurement system. During those years, the flow of trade between the distinctive nations brought with it a commonality which has done much to bring together into a loosely-knit family the many people who make up this conglomerate. As an example, there is the Treaty of Rome which established the Common Market, which in turn has helped to reduce or eliminate tariffs between the six member nations, and to establish mutually acceptable standards of technical performance to assure compatibility of articles and reasonable levels of quality and reliability.

It is interesting to note however, that national standardization brings with it all the problems associated with provincialism. There was a great deal of debate, before a standard was accepted, on the number of television scanning lines to be employed in European television receivers. Still unresolved is the prevailing number of national standards for automobiles in Europe today. Manufacturers find it necessary to produce at least nine versions of an automobile in order to fulfill the various national requirements for design.

The developing nation of Israel, in attempting to attain a degree of economic stability, has turned to the export of plywood. Their national standard of sizes provides for 47 varieties, but because of the lack of uniformity of standards in the importing nations, Israel is required to deliver several hundred different sizes of boards.

Let's consider our own country. The United States has been reluctant or inhibited in its attempts to participate in the workings of the International Electrotechnical Commission. This has helped precipitate an incompatibility in environmental testing standards which eventually will rule out international acceptance of U.S. products manufactured and tested to our national provincial quality standards. The loss, in part or in total, of our industrial export market ultimately will seriously affect our economy. This is true simply because the U.S. market would be flooded by the products of industrial giants formed from the conglomeration of the many metric-system- oriented nations. These nations are capable of interchanging among themselves all the components which form the ultimate product finding its way to our shores. Remember that the U.S. consumer has no blind loyalty to purely U.S. productshe is perfectly happy, under most circumstances, to purchase any product in his local market, as long as it is compatible with his immediate needs.

\section{National System Concepts}

It is apparent, then, that a nation must have a form of "measurement control" or put in another way, a nation must have a "National Measurement System." This is so, simply because without such a system there can be no way to:

- Provide a sound and equitable basis for trade in goods and commodities.

- Provide a commonly accepted measurement basis in order that interchangeable parts, components, and subsystems may be produced at separate but compatible facilities.

- Provide a measurement basis which will permit and encourage the interchange of meaningful scientific and technical information.

But after measurement control is in being, one major problem area must be examined-is the control of such a nature as to permit coordinated interchange of industrial products with other nations? If not, it is incumbent upon that nation to become self-sufficient for all of its industrial needs, or find itself forced to convert its imports to such a form as to permit interchange or interface with home-produced components.

There are areas of measurement control other than that of industrial production. Areas such as health, safety, recreation, and communication are commonly overlooked when considering the desirability or value of such controls. Particularly is this true in the areas of closely associated, comparatively small (geographically) nations such as exist in Europe, the Middle East, many parts of Africa, and parts of South and Central America.

It is well to have a National Measurement System through which a nation can establish standards for air and water pollution; noise control; air, sea, and land traffic. But how does one nation's controls coincide with its neighbor's? Without a great deal of thought, compromise, and some sacrifice of national pride, it is almost impossible to create an internationally unified system of controls which are for the good of the greatest number. Lest we become too complacent in regarding the troubles which beset our European friends, remember that our own nation is beset by many problems which normally arise from the peculiar form of secularism which is known as "state's rights." 


\section{Some Social Aspects}

In concluding these remarks, it might be pointed out that not much has been said of the impact upon the social behavior of nations which are subject to commonality of measurements. But in reality, is there much that is needed to be said?

Take a few practical examples and consider the disruption to international social intercourse which results without standardization and measurement control.

- How many remember the impact upon American golf, of the acceptance of the smaller, livelier English golf ball in the 1930's?

- How many non-musicians know why many European recordings of brass instruments sound sharp as compared to recordings of the same composition made in the United States? The answer is simple-the European concert standard of pitch for $\alpha^{\prime}$ is 450 cycles as compared with the accepted American or philharmonic standard of 440 cycles. The European "high" pitch has been giving way to the standard or "philharmonie" pitch of 440 cycles, but European trumpeters still maintain their individuality.

- Baseball is played all over the world with a single-sized ball, as also are hockey and basketball.

- American housewives still complain about the cakes they make when using measuring cups manufactured in Japan-they are slightly larger in volume since they are based upon the Imperial Gallon.

In a more serious vein it is interesting to note the reactions of three noted Americans who are aspiring to the role of President of the United States, to the subject of Technology and Society. Queried on this subject, Vice-President Hubert $H$. Humphrey wrote this for the Engineers Joint Council publication "Engineer" in the July-August 1968 issue :

Engineering has nearly always been a social activity. This role is not new. Throughout history, advances in culture and civilization have been accompanied or preceded by bold engineering.
Governor Nelson A. Rockefeller, in the same issue, made these points :

\begin{abstract}
Within their profession, - engineers have the opportunity to greatly enlarge their own roles. But they will not achieve this as technologists alone. If engineers are to have a major voice on projects, fund allocations, and policies, they will attain it first as citizens and only secondly as technologists. Therefore I would say that the engineer of the future is the man whose knowledge of society, and his role in society is at least the equal of his technical proficiency.
\end{abstract}

Finally, Senator Eugene J. McCarthy voiced opinions as follows:

\begin{abstract}
Engineers and politicians and others who are involved in this practical world must test their applications not only against truths and standards of science, philosophy, and theology. They are also called upon to be concerned with the findings and standards of the social sciences and art.
\end{abstract}

Although these men are speaking of the profession of engineering in a general sense, note the reference to standards, made by Senator McCarthy. I suggest that metrologists take a deep breath and dive into the pool of relationship between measurement standards and social behavior.

\section{Conclusion}

One of the most difficult tasks set before any group of metrologists is to establish dollar values upon the employment of standard units for international trade and balance of payments. This has become a subject of more than normal interest to the United States with the resurgence of interest in establishing the metric system as the one legal system in the United States. In particular, the Director of the National Bureau of Standards has established a Task Force under A. G. McNish, to study the problem and to draw upon the technical, financial, institutional, and govermmental resources of the United States in an attempt to discover the cost and the value of metric standardization. The work of this group, together with studies being made by many U.S. industries, can certainly point to at least one conclusion-controlled measurements must exist, regardless of the measurement system in volved. 



\title{
LEGAL METROLOGY AND ESTABLISHMENT OF METROLOGY CENTRES IN INDIA
}

\author{
V. B. Mainkar \\ Director, Weights and Measures, Indian Ministry of Commerce, New Delhi, India
}

\section{Introduction}

The National Conference of Standards Laboratories has chosen as its theme for the 1968 Standards Laboratory Conference a simple statement"Measurements Are Valuable" —and I would like to direct some thoughts to that theme.

It is very possible that many of the attendees at this Conference are not aware of the extensive efforts being made by the less developed nations toward adoption of a unified measurement system. Perhaps also, they are not aware of the support and sponsorship of these efforts by an activity known as the International Organisation of Legal Metrology (OIML) with headquarters in Paris.

I propose today to demonstrate for you some steps being taken by OIML in its efforts to encourage and support formation of Departments of Legal Metrology in all nations, developing or developed. The first part of this paper is devoted to a short discussion of the philosophy of the OIML and some practical problems it proposes to face. The second part comments on a series of questions directed to countries participating in OIML, the answers to which will serve as guides for future cooperative action between the OIML and the individual nations. The third and final part of this discussion presents some thoughts concerning the impact of legal metrology upon the economic and social life of a nation, in particular drawing upon the experiences encountered in India as it has moved from a nation with over 130 measurement systems to a nation which has adopted, and is slowly but certainly applying, a single measurement system to the conduct of the business of its many millions of citizens.

\section{Introducing Legal Metrology to the State}

The control of weights and measures through legal means to ensure honest transactions and accurate measurements has been considered as an important duty of the State from ancient times all over the world. The result is that every coun- try, whether developed or developing, has certain laws or customs relating to the various aspects of the control of weights and measures. With the development of modern science and technology, the functions of the State in this field have been extended to the control of accuracy of measurement in industry and to those cases in which the safety of human beings depends on these measurements.

As a result of the rapid progress of science and technology and the consequent extension of the field of control, the gap between the coverage of the weights and measures laws in the developed and developing countries has widened. Today the weights and measures laws in developing countries differ widely in their application and coverage from those in industrial countries.

The International Organisation of Legal Metrology (OIML), which was set up in 1955, is now considering how the developing countries and the industrialized countries could benefit mutually from each others' experiences in the field of legal metrology. The Organisation has undertaken the preparation of a Model Law on Weights and Measures. It is to give advice on the constitution and equipment of a Department of control of weights and measures, also on specifications for various types of weights, measures, and weighing and measuring instruments and methods of verification which are essential for the legal state control of weights and measures.

The Organisation is trying to prepare prescriptions which would be equally valid for both the developed and the developing countries. The OIML is now anxious both to receive general "advice" on its work and also to assess the "needs" of the developing countries with regard to the basic law on control of weights and measures and to expedite the work which is likely to be of immediate use in developing countries. At the meeting of the Presidential Council held in October 1967, it was therefore proposed that a questionnaire* should be issued to all countries to obtain their views on these

* EDITOR's NoTe : Copies may be obtained from the NCSL Secre tariat, $\%$ National Bureau of Standards, Washington, D.C. 20234. 
matters. Questions have been included on the following five main points :

\section{The Weights and Measures Law}

The law which enables the State to control the accuracy and use of weights and measures in trade, industry and other sectors of the national economy is of prime importance.

The state of development of the Weights and Measures Organisation which could implement such a law differs from country to country as do also the type of instruments used in trade, industry or other fields to which it is anticipated that the law shall apply.

The international Model Law has to be framed in such a manner that it will be equally useful in industrialized and developing countries.

To ensure this general usefulness, should it contain provisions for its implementation in well-defined phases? For example, in the first phase, only commercial weights, capacity and length measures and related instruments could be subject to verification and inspection. In the second phase, simple instruments like taximeters, water meters and electricity meters etc. could be taken up. In the third phase, more complicated instruments like automatic weighing machines, totalisers, electronic instruments, work-shop equipment, equipment for measurement of sounds and noise etc. could be subjected to control.

Or should the scope of the Model Law be such as would cover the entire work now on the programme of the OIML or which may be undertaken in the future, and it be left to the Departments to decide on its progressiveness? Such a Model Law applied in stages would facilitate the setting up and planned expansions of the Organisation of Weights and Measures and progressive training of the officials.

\section{Organisation of the Weights and Measures Department}

To ensure the progressive application of the Law, it is necesary to create from the beginning an adequate Weights and Measures Department which can be expanded progressively. The officials of the Department should possess excellent technical qualifications and their remuneration should be adequate with good prospects of advancement.

In setting up such a Service it may be desirable to seek the help of experts from other developing countries who have greater experience of enforcement of legal metrology laws. Such an association would be fruitful because problems of developing countries have considerable similarity and solutions devised in one of them could prove useful, with certain modifications, where necessary, for the others. Experts from developed countries could be associated with the subsequent development of the Service when sufficient progress had been made.

\section{Training}

In order that the Weights and Measures Services shall be effective it is necessary to give the officials a sound training in the methods of verification, calibration, inspection and other technical, legal and administrative duties imposed on them by the Weights and Measures Laws. Setting up of training Institutes is an arduous and expensive but an important task. It may, however, not be possible for every country to set up such schools. The existing facilities in developing countries might, therefore, be utilised to the maximum extent possible, as is being done, for example, at the All India Training Institute of Weights and Measures (AITIWM) at Patna in India, which is also training officials from other countries such as Nepal. The training of some of the senior officers could also be arranged in a developing country like India where the National Physical Laboratory imparts more advanced training after the instruction given by the All India Training Institute of Weights and Measures, Patna.

Imparting of training in developed countries in the initial stages might not be as useful as it might not have immediate practical application for a developing country, so far as everyday instruments are concerned; so far as complicated instruments are concerned, it would always be possible to use the Services of developed countries. The training in developed countries, therefore, should be envisaged only when sufficient progress had been made by the Weights and Measures Services of the developing countries concerned.

\section{Standard Equipment for the Organisation}

The Weights and Measures Organisations will have to be adequately equipped at the national, regional and inspectorial levels to enable them to carry out verification and inspection of weights and measures, and the standard equipment to be used at these three levels as well as accessory devices would have to be purchased and set up. Such equipment of adequate accuracy could be obtained from other developing countries which have been able to set up the necessary manufacturing facilities, this resulting in a saving of time, effort and money.

\section{Measuring Equipment for Use in Public Transactions}

In developing countries, too many kinds of weights and measures are used for different public purposes. For state control of weights and measures to be effective, the law must require, as a fundamental principle, that the weights and measures used throughout the country conform to internationally accepted specifications. OIML should prepare specifications for cast iron weights, brass weights, capacity measures for milk and kerosene, length measures for textiles, surveying chains, and 
other length measures for survey purposes, equalarmed beam scales, counter scales etc. on a priority basis. As the Weights and Measures Law would be implemented in stages, it is necessary that priorities should be laid down for standardising those weights, measures and instruments which are required immediately by the developing countries.

\section{Financial Assistance}

Most of the countries in the world charge small fees for their verification services, and even developing countries are normally not able to provide such services free of charge. In spite of these receipts, however, some technical and also financial assistance, preferably from international sources, may be necessary, particularly in the initial stages, for setting up and equipping the new Department of Weights and Measures in a developing country, as well as for ensuring the training of its officials.

The purchase of national, regional, and inspectorial standard equipment might have to be fully or partially financed through the varied generous assistance of governments or international bodies. It might also be possible to arrange bilteral or group schemes for mutual technical assistance between two or more countries, efforts being made to utilise these sources for the purposes of the development of the Weights and Measures Organisations. The International Bureau of Legal Metrology is in touch with inter-governmental Organisations and could assess the assistance which may be available to the Weights and Measures Organisations in developing countries for this purpose.

\section{Metrology Centres and Scientific Instru- ments in Developing Countries}

Metrology, the science and technique of measurement, is of fundamental importance in the economy of every country. Without it science, technology, trade, commerce, education, in fact, any work done by man would be possible. In the light of the tremendous progress made by metrology during the last 50 years, it can now be said to be the most important branch of human knowledge. Just as steel production used to be an indication of the state of development, of a country, today, in the age of sputniks and moon-shots, the state of metrology in a country is a more accurate index of its progress. In developing countries, metrology, as could be expected, is of a rudimentary character. The purpose of this paper is to consider the state of metrology and its proper growth in what are called developing countries.

Metrology may be considered under two broad aspects. The first is fundamental metrology, which is concerned with the definitions of units of weights and measures, their practical realization at the highest national and international levels and researches for improving their accuracies and ex- tending their applicability. The second aspect is applied metrology, which is concerned with the application of the various units of weights and measures through instruments and other means to the innumerable tasks of measurement carried out every day. A developing country will have to take care of both these fields with meticulous care, if it desires to develop its trade and industry on sound lines.

\section{Fundamental Metrology}

We may now consider the impact of fundamental metrology on the developing countries. At the international level, the Conference Générale des Poids et Mesures (CGPM) has prescribed six fundamental units of weights and measures, namely, length (metre), mass (kilogram), time (second), intensity of electric current (ampere), thermodynamic temperature (degree kelvin), and luminous intensity (candela) as the fundamental units of a universal system called the Système International d'Unités (SI). A number of secondary, supplementary and derived units have also been prescribed by this body under the SI. All the important countries in the world have accepted these fundamental units and the other specified units as the basic units to be used for all purposes of measurement. The developing countries, if they wish to benefit from the labours of this international body, should also adopt these units.

Such adoption immediately imposes on the country the duty to abtain the various standards, that is, the national prototypes by which these units can be translated into practice for application in various fields. Thus, the national prototypes of the metre and the kilogram are maintained by a number of countries, including India. For the remaining four units, considerable exchange of technical and scientific information is arranged between countries. On a comparison of the data, methods to realize these in practice have been evolved for international use. In India, the National Physical Laboratory (NPI) is responsible for the custody and maintenance of the national prototypes of the metre and the kilogram, as also for the realization of the remaining four fundamental units.

The maintenance and realization of these fundamental units is an expensive task. It is not possible for every developing country to obtain the national prototypes and their equivalents, and to maintain them systematically on a continuing basis. In such cases, it would be desirable to seek assistance from other developing countries, such as India, rather than spend large amounts of money for obtaining the prototypes and their equivalents. Thus copies of the standards of length and weight required by a smaller developing country could be certified by the NPL, India. The NPL could also supply to developing countries copies of the standards by which to realize the remaining four 
units. As and when these countries find it possible, they could obtain their own national prototypes and other standards.

If a developing country wishes to establish a progressive fundamental metrology, it is necessary that it should have suitable equipment for obtaining the highest possible accuracy in the national standards of weights and measures. This is essential because an important problem for a developing country is that while it has to improve old metrological traditions so as not to disrupt the economic life of the country, it has also to prepare itself to receive and benefit from the most advanced technology to improve its economy. It has, in short, to cater to the two extremes of metrology. The usual tendency is to develop metrology in line with the progress of traditional measurements, and neglect the requirements of modern technology, with the result that a co-ordinated metrological service does not take shape. The nation remains tied down completely to its traditions and cannot emerge easily into modern metrology. Although it may be a little costlier to maintain or arrange for the best type of fundamental metrology right from the beginning, there is no doubt that in the long run this would be beneficial.

It can, therefore, be concluded that in view of the need to protect and improve old traditions as also to modernize the economy quickly, a developing country should, if it is practical for it, maintain the national prototypes of the metre and the kilogram as also other standards where possible. If this is not possible, it should make arrangements with other developing countries to obtain certified copies of standards for its national use until such time as it can afford them. It would also be desirable for some of the developing countries to participate in the international work being carried out by the CGPM so as to gain experience in establishing and maintaining standards of various types of weights and measures.

\section{Applied Metrology}

While establishing its fundamental metrology on a sound footing, a developing country should translate the accuracy obtained through its fundamental metrology, into a series of practical steps and make it available to meet the various needs of its trade and industry. This is the domain of applied metrology which transforms the results of the work of CGPM and the National Laboratory into a practical pattern of use. The range of applied metrology is extremely wide because it can extend from highly sophisticated industrial and technological measures down to the weights and measures used in the day-to-day market transactions in the village shop. A distinct characteristic of a developing country is the wide variety of weights and measures in use for different facets of its economy. The first requirement, therefore, would be to standardize the system of weights and measures. There is no doubt that the metric sys- tem of weights and rneasures is the best suited for a developing country besause of its universal acceptance. Having done that it would be possible to extend it to every activity in the economy. Because of the variety of weighing and measuring practices in a developing country, a large number of operations under applied metrology would have to be carried out in a co-ordinated and uniform manner. Such co-ordination and uniformity is possible only through legal means.

\section{Legal Metrology}

The basic principle of the metrological law is that all measurements made in any industry or trade should be derived in a well-established manner from the national standards and should be within prescribed limits of errors. In developed countries this guarantee is ensured by the periodical calibration, under law, of the various types of weights and measures and weighing and measuring instruments used in trade, industry and for other purposes.

When applied metrology is practised under a law, it becomes legal metrology. Potentially, the entire field of applied metrology is open to the application of legal metrology. But in practice it is restricted mainly to all commercial and industrial measurements and to instruments used for public safety and protection. Another international body called the Organisation Internationale de Métrologie Légale (OIML) deals with this vast field of legal metrology just as the CGPM is the international authority for the work on fundamental units of metrology. The OIML takes up the thread of metrology where the CGPM leaves it.

Just as the work of the CGPM is accepted by all the countries as the basis for their fundamental metrology, similarly the work of the OIML has to be adopted by all the countries for the purposes of their legal metrology.

In the light of these international considerations, we may now consider the needs of applied metrology so far as developing countries are concerned. The requirements could be considered nnder the following broad heads:

1. The organisation necessary for translating and practising the metrological accuracies derived from the national prototypes,

2 . The need for a scheme to produce instruments only after they have been approved in the model stage,

3. The specifications for accuracies required for various purposes in the field of applied metrology, and

4. The training of the various categories of personnel associated with metrology.

\section{Organisational Problems}

While there should be a central laboratory like the NPL in India which has the custody of the 
national prototypes and other standards and maintains them at approved accuracies, it will be unreasonable to expect the laboratory to look after the entire work of metrology, fundamental as well as applied. It would be necessary to set up other organisations to deal with the various aspects of applied metrology.

Legal metrology has a signficant role to play in the field of applied metrology in developing countries. It is necessary to establish a sound and efficient organisation of legal metrology-an organisation of weights and measures which can serve as the medium through which the calibration services in terms of fundamental metrology could be made available to the various aspects of trade and industry in the country.

The Organisation should ensure through legal means that all weights, measures, and weighing and measuring instruments used in trade as well as in industry should be submitted for periodical calibration to it. In order to cope with the countrywide work, a number of small offices would have to be set up at various centres which could cater to the requirements of a well-defined and reasonable area. This organisation would work through a series of standards, each of graded accuracy, and would calibrate various types of weights and measures with the appropriate standards. The principal difficulty in setting up such an organisation is the production of the standard equipment, and its supply to officials. Such equipment is costly because of the great care which has to be exercised in its production to obtain the required precision. In India such equipment has been produced at the State Mint, also at other sources as well.

It may not be possible for smaller developing countries to incur the large expense of producing this costly but essential equipment. India is already supplying it to a number of countries in Asia and Africa at a cost which is within their reach, and could extend this facility to other countries, if they so desire. Among the equipments supplied are reference standards of weights and measures which are required at the State level, secondary standards of weights and measures which are essential at the regional level, and the working standards of weights and measures which are required at the level of local offices. Besides these, India has also supplied to other countries ordinary weights and measures as also various types of weighing and measuring instruments which are used for measurement by the public in trade and industry. India has made services of its experts available to developing countries in setting up such organisations of legal metrology as well as preparing the legal documents required for the purpose.

At the moment, the field of legal metrology in India is confined mainly to the periodical calibration of weights, measures and various types of weighing and measuring instruments used in trade and industry. It is being extended now to the calibration of engineering measures like end measures, gauges, calipers, rules and the like, as also to the instruments used for ensuring safety, protection and health of public such as instruments for measurement of noise, blood-pressure instruments, medical thermometers and the like. The intention is to apply the weights and measures law to all the fields which are covered by the work of the OIML. The extension of these activities would take place as financial resources become available in larger measure. The principal difficulty envisaged is that of procuring eqnipments like interferometers and other highprecision instruments for undertaking the higher calibrations. The help of the UNESCO would go a long way in setting up the required facilities early.

\section{Model Approval Schemes}

A second activity under legal metrology which is likely to be taken up in the near future relates to the scheme for model approval. It is intended that every weight, measure, or weighing or measuring instrument should be assessed thoroughly and rigorously for its performance and life in the model stage before regular production is undertaken. Only after it has been found that the model meets with the requirements of law would the manufacturer be given permission to produce the instrument on regular industrial basis. Such a step would ensure that reliable instruments would be made available to users. Here also no major difficulties are anticipated in the execution of the scheme.

In a developing country such a scheme of model approval would be beneficial if it is extended to cover all types of instruments, whether they are used in trade or industry or in education or for any other purpose. Every measurement made by an instrument must have the accuracy expected of it. Where it may not be possible to cover all meas. uring instruments under the weights and measures law, it should be made a general practice tl:at such instruments which are not covered by the weights and measures law should be submitted for model approval under some other law.

\section{Specifications for Instruments and Accuracies}

For practising applied metrology, legally or otherwise, a system of well defined specifications for instruments and tolerances on measurements made with them has to be prescribed. The preparation of standard specifications for a variety of products is the task of a separate national standards organization in a country. At the international level, the tasks of co-ordination of various national standard specifications is carried out by the International Organisation for Standardiza- 
tion (ISO) and the International Electrotechnical Commission (IEC).

In India, the Indian Standards Institution (ISI) prepares standard specifications for various types of weights and measures and weighing and measuring instruments, as also for a variety of other products. It has produced over 4,000 standard specifications, codes of practice, methods of test, glossaries, etc., in the course of the 20 years of its existence, covering not only the requirements of applied metrology but also other industrial activities. It may be said that ISI has laid the foundation on which the edifice of applied metrology can be built. The standard specifications, codes of practice, etc. are revised from time to time to bring them up-to-date, and, unless otherwise necessary, in line with the international practices as also with those obtaining in developed countries.

It is possible that many developing countries may not be able to set up a separate national Organisation for preparing standard specifications, codes of practice, etc. at the present juncture. It may be desirable for them to adopt the Indian specifications, codes of practice, etc. because they cater to the skills and requirements of developing countries.

\section{Training}

The edifice of fundamental as well as applied metrology depends for its sustenance on the continuous manning of the organisations concerned with competent personnel. In developing countries such personnel is not readily available. It is essential that adequate training facilities should be established for the various categories of officials.

In India, the NPL has been training officials of the weights and measures organisations in ad- vanced techniques of fundamental and applied measurements. Preliminary training in legal metrology is imparted at the All India Institute of Weights and Measures Training at Patna, sponsored by the Government of India. Officials of the Weights and Measures Organisation at the Centre and in the States are trained in this Institute as also at the NPL. The training facilities available at both the NPL as well as the Institute have been made available also to candidates from other countries in Asia and Africa. There would be no difficulty in accommodating trainees from developing countries for these training courses.

A specialized training course in the technique of preparing specifications is also conducted by the ISI. This training course is also open to candidates from other countries and is being utilized by them.

The training facilities available in India at the moment would satisfy the requirements of the development of trade and industry today. The facilities are, however, being extended to cover newer and newer activities. It is intended to extend these training facilities to cover the work now being done under the aegis of the CGPM, the OIML, the ISO and IEC.

\section{Conclusion}

While developing countries have to face a number of problems in the establishment of centres of metrology, they have been tackling them in a progressive manner. The principal difficulty faced is in extending the activities to keep abreast of the progress of industry and technology. Every effort is made by countries like India to extend the facilities they possess in the field of metrology, both fundamental and applied, to other countries which may need them. 


\title{
PROGRESS OF THE BRITISH CALIBRATION SERVICE
}

\author{
H. E. Barnett \\ Director, British Calibration Service, Ministry of Technology, Millbank Tower, London S.W. 1.
}

\section{Introduction}

Just over two years ago I was delighted to be invited to your 1966 Conference and to be able to tell you something of the factors which had led to the proposal to establish in Britain a national calibration service. As I told you then a statement had just been made in Parliament (April 1966) announcing the inauguration of the British Calibration Service which at that time had a staff of one, and no other resources. What I propose to do in this paper is to give a brief report on our progress during the period since then. The fact that I am unable to do this in person is a disappointment to me and is solely due to the current financial policy which has resulted in refusal of funds for the purpose.

\section{The First Two Years}

The first steps taken were to recruit some headquarters staff and to establish an advisory body called the Advisory Council on Calibration and Measurement (A.C.C.M.) which is intended to advise the Minister of Technology on the country's needs in this field, taking the widest possible range of viewpoints. This Council is about twenty strong and the members come from all spheres of activity, being chosen for their knowledge of, or involvement in, measurements in some way or other.

The present headquarter staff includes a Director, two Deputy Directors, one covering electrical measurements and one covering non-electrical, and six Principal Officers each covering one field, these being respectively L.F. and D.C. electrical measurements, H.F. electrical measurements, mechanical measurements, measurements on fluids, thermal measurements and optical measurements.

The Advisory Council first met in November 1966 and agreed upon the need to establish technical panels, one to deal with each of the fields of measurement already mentioned. Six panels have now been established, four initially and the last two recently; each is about ten strong and consists of members chosen for personal expertise, from industry, government departments, research organizations and academic organizations (e.g. universities).
These panels first devoted their activities to assessing needs in each field and priorities for tackling different types of measurement within that field. They then set out to determine and specify the criteria which should be applied in assessing the suitability of a calibration laboratory for operation under the scheme.

A principle which has been adopted is that the participation of a laboratory shall be entirely voluntary. No attempt is being made by B.C.S. to press anyone to join nor is there any intention of attempting to set up any new laboratory, at least until it has been established that voluntary participation will not produce sufficient resources to meet the known or foreseen demand.

The Treasury, in agreeing to the establishment of the scheme, required that the headquarters unit be made as far as possible financially self-supporting, while recognizing that this would, of necessity, take some time to achieve. Each laboratory therefore has to pay a single fee for initial inspection and an annual fee for subsequent supervision plus a small percentage of the fees charged for calibration work done under the scheme. It is hoped that the participating laboratories will be able to recover the charges by attracting more calibration work from their customers.

The first few months following the inauguration of the Service were spent in recruitment, and in setting up the Advisory Council and the first four Technical Panels. These panels were in operation by the beginning of 1967, and while they were establishing the criteria for laboratory approval the $H / Q$ staff wrote the rules which govern the operation of the Service. By the summer of 1967 the organization was able to invite applications from laboratories for approval.

The first applications were processed, the first inspections arranged, and the first approvals were announced in January 1968. To date (May 1968) six laboratories have been approved, three in the field of Panel 1 (D.C. and L.F. electrical) and three in the field of Panel 3 (mechanical). Two more in the mechanical field will be announced shortly. Progress in the field of Panel 2 (H.F. electrical) has been delayed mainly by the lack of U.K. national standards in this field. It is hoped that new arrangements for the programs in the 
national laboratories will go some way towards removing this difficulty and that some approvals in this field may be possible by the end of 1968. The first assessment in the field of Panel 4 (fluids) is now in hand. Panels 5 (optical) and 6 (thermal) have just been established and are working on the criteria appropriate to their fields.

Progress with the first approvals has been rather slower than was hoped. This has been partly because many interested laboratories, having digested the published criteria, have deferred application while making improvements in their facilities, and partly because in building up a technique for laboratory assessment all concerned have been feeling their way. It has been found that considerably more effort than originally estimated is necessary, not so much on the assessment itself but in preliminary discussions and in arranging evaluation and checking of laboratories' working standards.

Initial inspection is normally by a team of two, one being the Principal Officer concerned with the field of measurement covered by the laboratory, the other being a member of the appropriate technical panel. Supervision for the future will be by a combination of visits (analogous to initial assessment visits) and a fairly comprehensive scheme of audit measurements.

B.C.S. has recently been granted Royal approval for a badge for use by headquarters on correspondence and by participating laboratories on certificates of calibration. The NCSL Secretariat has been sent a complete set of B.C.S. Publications to date, and a set of schedules showing the measurements for which the first six laboratories have been approved.

In presenting this short summary of progress to date I send best wishes for the success of your Conference and look forward hopefully to the possibility of reporting a lot more progress by the time of your next gathering.

\section{Appendix 1. General Conditions Applicable to Approved Laboratories}

\section{After Grant of Approval}

1. Continuing approval of a laboratory demands continuous compliance with the general and special conditions and with the restrictions as laid down on the Approval Certificate and schedules.

2. Re-calibration of laboratory standards and equipment at stated intervals, and maintenance of adequate records of such re-calibration, as set out in the relevant Publications covering the various fields of measurement, are of vital importance.

3. To give further assurance to the accuracy of measurements, a laboratory will be required to undertake from time to time (at its own expense) an occasional set of check measurements (audit measurement survey) as specified by B.C.S. H.Q.

4. A supervisory visit may be made at any time to an approved laboratory by the Director, B.C.S., or by his authorised representatives. Access shall be granted for such visits at all reasonable times and facilities for proper inspection shall be made freely available.

\section{Retention and Renewal of Approval}

5. Approval is retained by the laboratory for the period stated on the Approval Certificate, provided that it is not suspended or withdrawn as set out below.

6. Renewal of approval will normally be made by the issue of a fresh Approval Certificate. Where circumstances warrant, a new application form may be required, but no application fee will be payable unless an extension of the scope of approval is requested.

\section{Suspension or Withdrawal of Approval}

7. Approval may be suspended by the Director, B.C.S., if, temporarily, the laboratory fails to comply with the conditions of approval.

8. Approval may be withdrawn for a breach of the conditions if, in the opinion of the Director, B.C.S., satisfactory conditions cannot be restored within a specified time. Re-instatement of approval may involve re-assessment of the laboratory in a manner similar to that for a new application, and payment of an appropriate charge.

9. No rebate of the fixed annual fee will normally be given in respect of any suspension or withdrawal of approval.

\section{Fees for Assessment and Supervision of Laboratories}

10. Continuance of approval depends on prompt payment of fees as laid in Publication 0031.

\section{Changes Affecting Approval}

11. Any significant change in the approved conditious must be notified in writing in advance (or, if this is nor possible, then as soon as possible) to B.C.S. H.Q. Such a change may involve one or more of the following considerations :

\section{a. Head of Laboratory}

The approval of a laboratory refers specifically to the head of the laboratory. If he leaves, then (unless a deputy has been approved by Director, B.C.S.) the approval must be reconsidered. One of the most important features of approval is the standing of the head of laboratory. His qualifications, experience, independence, and authority, and his relation to the directors of the enterprise, have to be considered in relation to the size of the laboratory and the nature of the work. If a change of head is proposed, details of the proposed new head of laboratory, together with a covering letter explaining the situation, should be sent to B.C.S. H.Q.

\section{b. Approved Signatory}

Similarly a proposal for a new approved signatory shouin be sent to B.C.S. H.Q.

\section{c. Organisation}

Any changes in the relationship between the head or tus laboratory and the management of the operating orgausation must be reported.

\section{Variation of the Scope of Approval}

12. Any variation of the schedules must be agreeu is writing by B.C.S. H.Q. The scope of the laboratory may be reduced, in accordance with the facilities and tne wishes of the laboratory, or may be extended subject to re-assessment of the additional facilities or re-assessment of the laboratory as a whole. Any such exutu sion will be treated as an application for approval in ic spect of the additional facilities offered.

\section{Publicity}

13. The Approval Certificate and schedules are to be open to inspection on demand by anyone who uses the British Calibration Service or may wish to do so ; duplicates will similarly be available at B.C.S. H.Q. 
14. It is incumbent on an approved laboratory to ensure that no claim is made on its behalf that B.C.S. approval relates to any products, or to any services other than those set out in the Approval Certifica te.

15. Any use for publicity or commercial purposes of the grant of approval to a laboratory shall be either in accordance with the following conditions or as otherwise specifically agreed by B.C.S. H.Q.

a. No claim to be a 'B.C.S. Approved Laboratory' shall be made, either explicitly or by implication, unless accompanied by a statement of the full details of approval as set out in the Approval Certificate and its schedules, or as provided in $b$.

b. An approved laboratory mas use, with variation, the phrase:

\section{'Listed in the British Calibration Service directory of approved laboratories}

If it is desired to accompany this by a statement of the calibration facilities offered, these shall be specified only by reproduction in full of the relevant part of the first schedule to the Approval Certificate together with any relevant special conditions imposed.

c. The B.C.S. badge may be reproduced only by written authority from B.C.S. H.Q. An approved laboratory may be authorised to reproduce the B.C.S. badge on Certificates of Calibration, on stationery relevant to the laboratory's activities in the field of calibration, on wall plaques within the laboratory, and on house flags.

A laboratory wishing to reproduce the B.C.S. badge should, in each instance, submit proposals to B.C.S. H.Q. for approval. When authority is granted for reproduction of the badge on letter-headings and in advertisements, it will normally be for the badge accompanied by the single word LISTED.

Masters suitable for photographic reproduction processes may be obtained on request to B.C.S. H.Q.

\section{Calibration Certificates}

16. Certificates issued under B.C.S. aegis must comply with the requirements set out in Publication 0103.

\section{Records}

17. The detailed records of all measurements must be kept in the manner and for the period described by the Director, B.C.S.

\section{Arrangements Between Head of Laboratory and B.C.S.}

18. As defined in Publication 0101, the Head of Laboratory is the responsible person who maintains the link with B.C.S. H.Q. He must ensure that all relevant B.C.S. rules, instructions, and procedures are observed, and that such B.C.S. publications are available for reference at the laboratory. He must encure that the Calibration Certificate is a true record of the results of the calibration, and that it is free from ambiguity. He must report any difficulty to B.C.S. H.Q.

\section{Arrangements Between Laboratories and Customers}

19. The arrangements between a laboratory and its customer are ordinary commercial transactions. The charges made by the laboratory, whilst open to inspection by Director, B.C.S., or his authorised representatives, are not controlled by Director, B.C.S. Neither the Ministry of Technology nor the Director, B.C.S. is responsible for any loss or damage alleged to result from any such transaction.

\section{Appendix 2. Certificates of Calibration}

\section{Introduction}

1. The varied requirements for calibration are best met by the preparation and issue of certificates by in- dividual laboratories. Ease of recognition as certificates issued under B.C.S. approval and avoidance of ambiguity in content require some, uniformity in appearance and adherence to certain rules. Attention has to be paid to the suitability of certificates for subsequent analysis by a utomatic data processing.

2. The format and other matters set out below are mandatory for all Certificates of Calibration issued by an Approved Laboratory under B.C.S. aegis.

3. Additional requirements for certificates of calibration may arise in relation to certain measurements. Reference should be made to the B.C.S. Publication(s) on the criteria for the approval of laboratories in the particular field of measurement.

4. It is an over-riding requirement that no B.C.S. certificate shall be issued in circumstances likely to reduce public confidence in the integrity of the Service or the correctness of the results reported.

\section{Format and Materials}

5. The preferred sizes of paper are $\mathbf{A 4}$ and $\mathbf{A 5}$ to B.S. 3176 ; it shall be white, and its durability and weight adequate for the purpose. If fold-out sheets are included, for example for extensive tables, they shall have a width which is an integral multiple of the basic sheet width less an allowance for a filing margin (normally $1^{\prime \prime}$ to $1 \frac{1}{2}$ ' per fold).

6. Printing or other marking shall be in black and may be on one or both sides. Data entered may be in typescript or in manuscript, provided it is legible and durable. Washable ink shall not be used.

7. Durability must be such that the certificate will remain fully legible under reasonable storage conditions, including limited exposure to sunlight, for at lea st 5 years.

\section{First Page Content}

8. The upper part of the first page shall be a heading including the B.C.S. badge (details available separately) together with the content given below (see specimen on page 5) :

a. the words "CERTIFICATE OF' CALIBRATION"

b. the name and address of the issuing laboratory, as stated on the Approval Certificate

c. the 4-digit approval number of the laboratory

d. the 5-digit serial number of the certificate. Serial numbers shall be allocated by each approved laboratory in a single series commencing at 00001 and used in chronological order.

e. the date of issue of the certificate, with the month given as a word not figures, in the order: day, month, year

f. the number of pages to the certificate, including the first page, and counting each side of the paper on which any information is entered as one page.

9. The first page shall include the following statement

"This certificate is issued in accordance with the conditions of the approval granted by the British Calibration Service. The measurements reported were correct on the date of calibration. Copyright of this certificate is owned jointly by the Crown and by the issuing laboratory. The certificate may not be reproduced other than in full, except with the prior written approval of the Director, B.C.S., and of the issuing labora tory.'

10. The first page (or optionally, every page) shall bear the signature of a person approved by B.C.S. H.Q. ("approved signatory"). This signature accepts personal responsibility for the correctness of all information presented. The signature shall follow the statement in the preceding paragraph, except where the signature is given on every page. In the latter case, it shall be associated with the word 'Certified' at the foot of each page, and the statement on the first page shall precede any measurements reported. (see also paragraph 25 ).

11. The equipment, instrument or device in respect of which the certificate is issued shall be clearly identified by 
make, type number, serial number and list of units or accessories where these are significant to the calibration.

12. When it is known that a calibration certificate has previously been issued in respect of the same item, the relevant details of the preceding certificate (laboratory approval number, certificate serial number, date) shall be quoted.

13. The date of calibration shall be given where different from the date of issue of the certificate (see 8e.)

\section{Page Headings and Additional Signatures}

14. The top of each subsequent page shall bear:

a. the approval number of the laboratory

b. the serial number of the certificate

c. the page number.

15. At the option of the head of the laboratory, the signature of the person carrying out the calibration ntay appear at the foot of every page.

\section{Technical Content}

16. When measured quantities are reported, all relevant conditions of test shall be given :

a. in full

or b. by reference to a British Standard by number, year and clause

or c. by similar reference to other published standard

or d. by similar reference to manufacturer's handbook accompanying the item tested.

17. When measured quantities are reported, each result shall be associated with an uncertainty of measurement estimated in accordance with relevant B.C.S. recommendations.

18. When compliance with a specification, but not a record of actual measurements, is reported, relevant clauses of the specification must be unambiguously identified. For compliance, the measurement results (indicated values) shall lie within the specification limits narrowed by the estimated uncertainty of measurement.

19. Any special conditioning, precautions taken, or adjustments made, must be reported in the certificate.

20. Any relevant environmental conditions (e.g. temperature) must be reported with the estimated variations during the calibration period.

21. If any significant instability or other adverse factor manifests itself before, during or after calibration, and is likely to affect the validity of the calibration, it must be reported in the certificate. In serious cases, it is expected that the laboratory would decline to issue a certificate.

\section{Distribution}

22. The certificate shall be supplied to the customer for the particular calibration.

23. A copy of each certificate shall be retained in the issuing laboratory's records.

24. Unless otherwise agreed, a copy of each certificate of adequate contrast and legibility for microfilming shall be dispatched promptly to B.C.S. H.Q. A carbon, photographic, Xerox, or similar copy will normally be acceptable.

25. The certifying signature must be legible on all copies (see paragraph 10).

\section{Amendments}

26. No supplementary measurement results shall be reported by other means, e.g. by letter, if the validity of a certificate issued is affected.

27. Any correction or addition to a certificate shall be made only by the issue of a further certificate marked 'supplementary to certificate serial No. ..........' and complying with the requirements of the foregoing paragraphs of this publication. The B.C.S. H.Q. copy of such supplementary certificate shall be accompanied by a letter explaining the attendant circumstances. 


\title{
SOME REFLECTIONS UPON COMMON MEASUREMENT SYSTEMS
}

\author{
H. F. Monaghan
}

\author{
Registrar, National Association of Testing Authorities, Chatswood, N.S.W., Australia
}

\section{Introduction}

Your session Chairman has asked me to comment briefly upon several points which relate measurements and measurement systems to national progress and economic well-being. In particular, he was interested in the viewpoint of an Australian toward international standards, dual measurement systems, and the political and economic benefits of adhering to an internationally accepted measurement system. The following remarks are purely of a personal nature and are not to be considered as representing the viewpoint of the Australian Government.

\section{Weights and Measures}

The dependence of Australia upon internationally accepted measurements standards is illustrated by the fact that we have traditionally been an exporter of primary products. Our Government has, in the past twenty years, been endeavoring to foster development of exports of industrial products, as part of a plan to lift the gross national income. In these circumstances Australia must adopt internationally accepted measurements, standards, and definitions.

I cannot speak of the significance and advantages of a nation's adherence to a single system of measurements, in anything like general terms. I can only say that Australia has used the English system of weights and measures since 1788 , but is realising that a better system will have to be adopted soon.

The English system is illogical, inconsistent and inconvenient. But we learned it in our earlier years and have used it with the ease that familiarity brings. It is accepted and used for practically all. purposes within the Australian community. It is only when we come into contact with other communities using or contemplating other systems that we are forced to appraise the adequacy of our own.

Two years ago Australia adopted a system of decimal currency. The success, and ease, of that change made Australians amenable to proposals that the weights and measures system be rationalised, also. At the same time, interest by the English and American communities in metrication, and commercial pressures from other communities, such as Japan, make it essential that Australia look very carefully at the possibility of change.

During 1967 a Senate Committee took evidence across Australia on the adequacy of the English system, the need for change, and the problems involved in retaining the old system or introducing the new. It has reported a wide acceptance of the desirability of a change. It has expressed the opinnion that the problems involved in changing will be solved more easily if they are tackled soon. It has recommended introduction of the Système International d'Unités.

The Government is not committed to acceptance of the Senate Committee report. But it is widely believed that action will be initiated soon, and that the change will be effected in the next decade.

The change will not be an easy one. It will be complicated by the desire of many industries to introduce other rationalisations at the same time. But some industries are already changing. Pharmaceuticals are already made, sold and prescribed in metric units. Foods are commonly labelled in English units with metric equivalents.

Will this bring "a favourable environment for" industrial production of precision instrumentation"? I do not think that it will, in itself. An environment of this kind is developed in a stable industrial community which enjoys steady access to good markets. The American and Swiss communities enjoy these environments developed by quite different circumstances.

Introduction of metric units to the Australian community may well provide an occasion for clearing out old ideas and methods, tightening systems and improving contact with foreign markets which will bring about improved production of precision instrumentation.

We hope it will.

We have noted the controversy presently being generated within the United States concerning adoption of the metric system as the sole legal system, and recognise many of the arguments presented pro and con. If your Government were to take this step in the future, I do not believe that such a move would affect the industries of Australia to any significant degree. We would hope to have completed our own change, and to have de- 
veloped metric export markets to such an extent as to be relatively secure from the possibility of the new competition which would arise from a converted American industry.

\section{Product Quality Control-Industry or Government?}

Australians are fundamentally opposed to government control.

At the same time, they are sensible people. They would not contemplate or tolerate anarchy in government, industry, or commerce. They realise that consumers look for quality, normally pay more for it, and repeat orders when they get it. They know that a good reputation cannot be beaten in the public relations field, but can be destroyed very easily by carelessness, or by foolish lack of appreciation of market requirements.

The Australian community needs trade. The Government is doing all it can to encourage export of industrial products. Government and industry are making vigorous efforts to show overseas consumers of Australian products that we can offer high quality on a continuing basis.

We cannot contemplate control, by either gov- ernment alone or industry alone of the quality and reliability of export precision instrumentation. We must have a form of control which is exercised by the intelligent and willing cooperation of the two.

The Australian Government reflects the views and attitudes of the Australian people. It is therefore working vigorously to improve the Austrnlian industrial image in foreign markets. To do this, it must insist that only those products which match clearly defined standards are released for export.

Australian industrial managment reflects the views of company shareholders. It must work vigorously to improve the Australian image at home and abroad. Export markets offer entrancing avenues for expansion. Australian industrialists have been more and more interested in these avenues. Here, rigid quality control pays dividends. Industry is, broadly, interested in exporting goods at a quality level which will build confidence and bring about a continuing demand.

The Australian attitude is thus, not that government or industry control is needed, but that control exercised by each will bring maximum benefit to the community, to the individual manufacturer and then to the consumer. 


\title{
PROGRESS IN ADOPTING THE METRIC SYSTEM IN THE UNITED KINGDOM
}

\author{
A. H. A. Wynn \\ Chairman, Standing Joint Committee on Metrication \\ Ministry of Technology, Abell House, London S.W. 1
}

\section{Introduction}

For many years the adoption of the metric system throughout the United Kingdom has been widely regarded as inevitable. A Government Committee, called the Hodgson Committee, following an investigation concluded in 1950, "that a change from imperial to metric for all trade purposes is sooner or later inevitable."

It was not, however, until 1964 that a repeated canvas of all British Trade Associations by the then Federation of British Industry showed an overwhelming majority of industry, both in numbers and size, and including the engineering industry, in favour of the adoption of the metric system by British industry. There were at that time some exceptions: particularly the brewing, motor vehicle and oil industries. Representations were made to the British Government by the Federation and the Government undertook in May, 1965, to support the plans of industry for the adoption of metric units "sector by sector, until that system can become in time the primary system of weights and measures for the country as a whole." A target date of 1975 was laid down by which it was hoped that "the greater part of industry would have changed."

The adoption of the metric system by industry since 1965 is not only inevitable but is now committed: and the "exception" industries are also making their plans. Discussion within each sector of industry is now concerned not with whether to change but when to change. Timetables have become the essence of policy for each sector, large and small. They are also the essence of planning for the extension of metrication to the non-industrial parts of the economy (i.e. total metrication) which is now (May, 1968) going forward for decision.

\section{Motivation}

The dominant motive of industry in advocating change to the metric system has been the needs of export trade. The change has been seen as an essential part of the larger task of internationalisation of engineering and other standards and practices involving measurement.
This motive is probably stronger in the United Kingdom, exporting 14 per cent of Gross National Product (1964) than in the USA, exporting only 4 per cent. The United Kingdom is vitally dependent upon overseas trade and must be concerned about any factor, such as the continued use of obsolescent units, that may impede exports or contribute to isolation.

In all countries the use of metric units has steadily advanced in science and engineering for many years. It became apparent that the Système International d'Unités would gradually become the only world unit language in science and engineering. The change has therefore had the overwhelming support of scientists and engineers, who saw the need for accelerating an inevitable historical development.

\section{Education}

Since 1965 there has been a nation-wide discussion within the educational system aimed at programming the change in education. It is not the British tradition for the Government to concern itself with educational curricula. It is left to the educational authorities themselves to adapt their teaching to the needs of the community. The Royal Society and Council of Engineering Institutions and many other organisations have called meetings and conferences to discuss plans. The emphasis is now likely to change to the teaching of SI units in primary schools in 1969. School examinations are likely to be set in SI units not later than 1972. Students entering courses of higher education in science, technology, or engineering during 1969 and thereafter will be taught in SI units. Engineering examinations will be set in SI units not later than 1972.

The great response by the educational system has been dictated by the wish to eliminate redundant learning. In an increasingly technological and complicated world the task of simplifying teaching to make room for more essential, modern knowledge and attitudes is seen to be a task of great importance. The teaching of obsolescent units is time-wasting and it has been estimated that $£ 100$ million worth of teaching resources is expended in the UK purely because of the extra efforts made to 


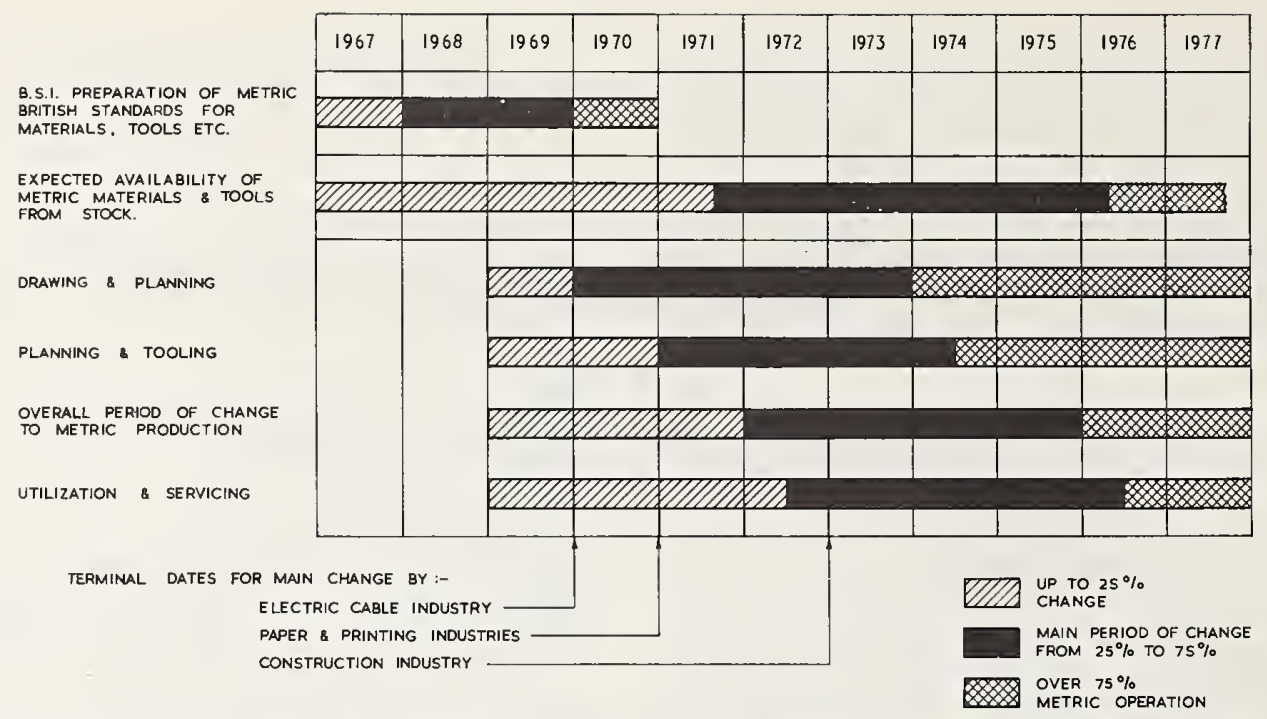

FIGURE 1.-The timing of change in the engineering industry-national averages for the industry.

teach in units which are not coherent like those of the SI and are in effect obsolescent. The learning of obsolescent units is also regarded as discouraging and tedious to pupils, and an impediment to mathematical education. The teaching of SI units, exclusively in due course, will provide a unique opportunity for revising and modemising textbooks and curricula.

\section{Industrial Programmes}

The plans for the adoption of the metric system by industry are conceived by elaborate consultation. The British Standards Institution is the central coordinating body. Figures 1 and 2 illustrate two provisional plans for the engineering industry. These are both part of consultative documents and may be revised before final adoption. These charts summarize the answers to questionnaires widely distributed to engineering industry. The British Government has not supported these detailed plans at this point of time (May 1968). The Government is so far only committed to support the plans for the building and construction industry, which is, however, the largest industry. Only final plans are submitted to the Government for support, including procurement support, when consultation on draft plans is completed and the procedure has been completed only for the building and construction industry and for a few minor sectors of industry. It is hoped that the final programme for engineering will receive Government support during 1968, including the shipbuilding and electrical engineering detailed programmes coordinated with the broad engineering programme.

Figures 1 and 2 imply that about three-quarters of the engineering industry will be working in SI units by 1976 . The building and construction industry programme has a terminal date of January, 1973 for the completion of general conversion, though maintenance will continue in imperial measurements for some time after that. The electric cable industry has a date for final change of 1970 . Indeed different sectors of industry have different, but compatible, time-tables. The sector-by-sector approach to programming has proved essential. Thus the adoption of internationally standard electric motors is already well advanced, but the change in the foundry industry is still some years away.

\section{Non-Industrial Programming}

During the last twelve months industry has expressed increasing concern at the absence of planning in the non-industrial sectors of the economy including retail and transport. The Confederation of British Industry has asked the Government to establish a Metrication Board to coordinate plans for the change by the country as a whole and to lay down a target date of the end of 1975 for the programmes for all sectors of the economy. These sector plans (e.g. for the retail trade, for agriculture, transport and so on) will be framed by those who will have to operate them and the planning groups will represent all interests concerned, including Government. It is a vital feature of all this programme making that the result is the outcome of a consensus of all interested organizations.

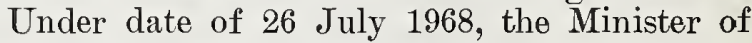
Technology made the following announcement* in Parliament concerning a Report from the Standing Joint Committee on Metrication,

*Hansard, vol. 769, no. 164, col. 1167-8. 


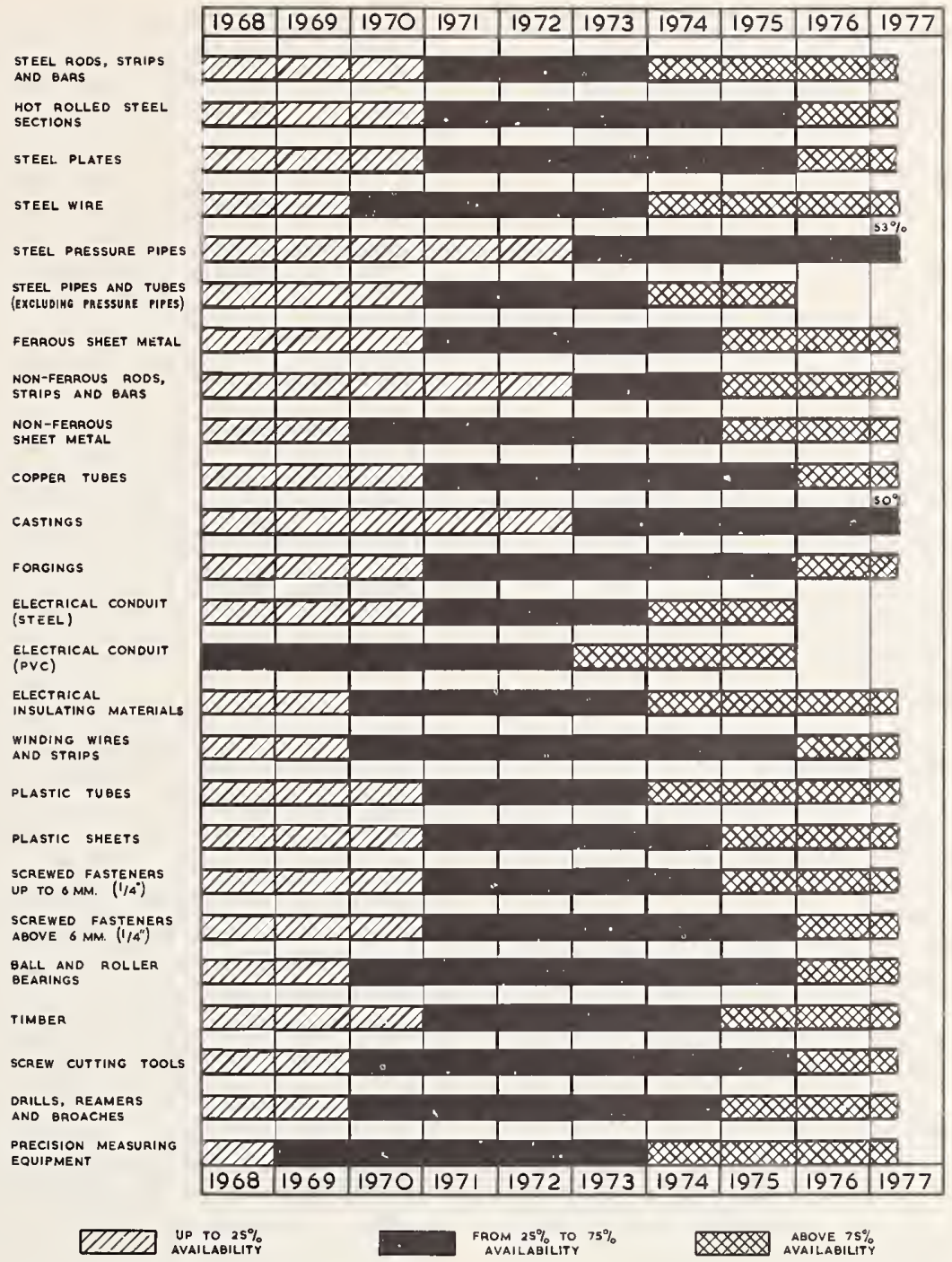

FTGURE 2.-Expected availability of metric materials.

"Change to the Metric System in the United Kingdom":

The Report makes three main recommendations. First, that manufacturing industry can make the change efficiently and economically only if the economy as a whole moves in the same direction on a broadly similar time-scale, and in an orderly way. Second, that a Metrication Board should be established to guide, stimulate and coordinate the planning for the transition for the various sectors of the economy. Third, that any legal barriers to the use of the metric system for all purposes within the United Kingdom should be removed.

The Government accept the recommendation that a Metrication Board should be set up as soon as possible. Every sector of the economy need not move at the same pace. But there will be unnecessary confusion and expense, and great difficulties for industry, unless there is central machinery for co-ordinating the programmes of change for the various sectors.
The Board will be advisory. The adoption of the metric system must be gradual, through democratic procedures based on the widest consultation. Membership of the Board will, therefore, reflect the interests of industry, the distributive trades, education-for which there are important implications-and, particularly, the general public and consumers. The Board will need to ensure that the distributive trades and consumers are consulted and have ample notice of proposed changes.

No compulsory powers will be sought. There can be no question of compensation; the costs of adopting metric weights and measures must lie where they fall.

The Government agree that programmes for the different sectors of the economy can be properly co-ordinated only if there is some general guidance on the timing. They therefore accept the end of 1975 as the target date for all provisional programmes, with the qualification that if this date proves to be unreasonable for any particular sector, the programme may aim at an earlier or later date. An initial task of the Metrication 
Board will be to submit to the Government an appreciation for each sector, including, so far as practicable, the costs and other considerations involved. In the light of this, programmes can be drawn for individual sectors. The Government will not be committed to endorse the programme for any sector of the economy before final proposals for that sector are submitted.

The Government accept that legislation will be needed to remove obstacles to the adoption of metric units and to define the units to be used. Further consultation is, however, needed before the timing of the legislation can be decided. Arrangements will be made to coordinate the interests of Government Departments so that they play their full part.

The educational system will need to keep pace with, and to some extent anticipate, changes. The conversion will stimulate industrial and commercial modernisation and the rationalisation of production by variety reduction. We must also use it to help our export trade by harmonising our standards with those of our customers overseas.

The adoption of the metric system in the United Kingdom will represent a major change affecting many aspects of the national life, and I hope that publication of this Report will lead to a wide public discussion of the issues involved.

\section{Economics}

There has been much discussion of the costs and benefits of metrication. The preparation of any global balance sheet has proved impossible. Some of the motives for change that are essentially imponderable have been discussed above. It has become apparent during the last three years that the most important economic incentive is to be found in variety reduction, notably of building construction and engineering components. Metrication has become almost an overt excuse for far-reaching exercises in rationalization. Thus in the construction industry a modular coordination, based on a $100 \mathrm{~mm}$. module, has become the main objective, and it is almost incidental that the basic modules are expressed in millimetres. The varieties of raw materials such as rod, bar, sheet, or components such as fasteners or cables, are being greatly reduced as part of the exercise. In appropriate cases important machines are being redesigned in metric terms with reductions in the number of components and resulting economies of 20 and more per cent in overall manufacturing costs. How much of the reduction is attributable to metrication cannot be estimated. The real dividends come not from metrication in the abstract but from redesign and from consequential reductions in stock holding and concentration of production on a much reduced range. In particular the opportunity is being taken to eliminate components such as Whitworth fasteners, British Standard pipe-flanges, electric motors with non-international dimensions or other features that are not acceptable in export markets. The economic dividend cannot be estimated. There are, however, many manufacturers who make one product for the home market and a different product for export, and there are many manufacturers using both imperial and metric units in their drawing offices and workshops, whose production costs will benefit from the adoption of a single, simplified system of units for all purposes.

\section{Conclusion}

The British metrication programme must be seen as part of a worldwide historical change that must continue its inevitable progress. The developing programmes in the United Kingdom are no more than an endeavour to accelerate and coordinate a change that was proceeding in any event. Experience since 1965 has emphasized that the change must still be gradual and must be programmed sector-by-sector and that there is probably an optimum rate of change for each sector. In the end there may have to be a sweeping-up operation involving compulsion but this is not yet being contemplated, much less planned. Legislation of an enabling character is under discussion but this will be primarily directed to enabling amendments to existing legislation to be undertaken piecemeal by statutory instruments aimed at removing obstacles to the change. The optimum timing must take fully into account the rationalization, variety reduction and international standardization which take time but produce the main dividends. Metrication will indeed only pay off if the dominant thought is how to make profits out of the change. 


\title{
IRELAND AND THE METRIC SYSTEM
}

\author{
M. E. O'Hagan
}

\author{
Industrial Research Center, Dublin
}

The following news release was made by the Irish Government on January 12, 1968:

The Government have had under consideration the question of the more general use in the economy of the metric system of weights and measures. They note that in Great Britain, the only other European country not using the system, there is a policy of conversion which it is expected will be largely implemented by 1967. The Government welcome indications that some sectors of Irish industry are anxious to prepare for the general introduction of the metric system and urge on all sectors that they should plan for orderly conversion. The Government would expect that the greater part of Irish industry will have converted to the metric system by 1975.

The Government propose, as the move towards the use of the metric system develops, to promote the move by seeking tenders in metric terms and encouraging other public authorities to do likewise. Regulations involving reference to weight or measure (for instance in regard to retail trade or transport regulations) will in due course be expressed in metric terms. The giving of greater emphasis to the use of the metric system in education will be encouraged. Standards declared by the Institute for Industrial Research and Standards will be progressively recast in metric terms. Legislation will be examined and where necessary amended. It will be the aim of the Government so to time their moves as to encourage conversion whilst at the same time avoiding unnecessary difficulties for industry, the distributive sector or the public generally.

It is envisaged that the speed of change will vary from one sector to another, depending in some cases on the physical replacement of equipment. The task of converting industry to the metric system is clearly one calling for consultation and cooperation between different sectors of industry and between industry and distribution. While the primary responsibility must rest on industry itself, the Government will be prepared to assist where called upon by promoting intersectoral discussions and the Minister for Industry and Commerce will keep developments under review in relation to metrication generally, while the Minister for Local Government in consultation with him will be responsible for supervision of the work in regard to the building and construction industry. . . .

\section{The Need for Change}

Ireland, a small island adjacent to Great Britain, is divided into 32 counties of which 6 in the northeastern section of the country are still under British rule. The other 26 counties constitute the Republic of Ireland with a population of just under 3 million people. Ireland is predominantly an agricultural country, but in accordance with modern trends the industrial sector of the community is growing rapidly and assuming increased importance. Historical circumstances saddled Ireland with the imperial system of weights and measures and it is this system which prevails today.

The question of whether Ireland should change to the metric system was first raised in 1953. On February 9 th of that year the Minister for Industry and Commerce appointed a committee to consider and report to him on the desirability of establishing a metric system of weights and measures and a decimal system of coinage. Reporting on November 25, 1959 the Committee advocated the adoption of the metric system, stating
.. . we came to the conclusion that the metric system of weights and measures is instrinsically superior to the imperial system and that its superiority for all purposes is sufficient to justify the inconveniences and expense incidental to its adoption. We recommend therefore, that the metric system be adopted at the earliest practicable date as the sole statutory system of weights and measures for use in the country.

The Committee felt that the inherent advantages of the metric system, in facilitating arithmetic and reducing learning time in school, outweighed the disadvantages created for our foreign trade, most of which is conducted with the U.K. which, at that time, gave no indication of going metric. Some members of the Committee however did not share this point of view and in a Reservation stated that

In view of the extent of our external transactions and their diversity we are of the opinion that a change by this State alone would give rise to difficulties in relation to foreign trade in all its aspects which, on balance, would outweigh any benefits to be derived in matters of a purely internal nature. We are also influenced by the con- 
sideration that the adoption of systems of weights and measures, or coinage, different from those in general use in Britain and the Six Counties would seem to run counter to the prevailing international trends towards integration and rationalisation in economic affairs between countries with important trade connections.

The statement went on to conclude that "we do not favour a change in either system except in conjunction with Britain and the Six Counties.

The soundness of this reservation cannot be denied. The bulk of Ireland's foreign trade is with the U.K. For example, in 1967, 50 percent of our imports came from the U.K. while 73 percent of our exports went there. Imports from metric countries accounted for 36 percent of our 1967 total and exports to metric countries amounted to 14 percent.

By virtue of its small population and limited resources, foreign trade is particularly important to Ireland. A comparison of OECD countries, based on 1964 trade statistics published in the OECD Observer No. 20, February, 1966, shows total imports to Ireland as 42.6 percent of its G.N.P., the highest percentage among the 21 member countries. The figures for some of the other countries were as follows: United Kingdom, 16.8 percent; France, 11.4 percent ; Germany, 14.0 percent; Japan, 11.5 percent; Denmark, 29.1 per cent; and United States, 2.9 percent. Total exports as a percentage of G.N.P. for Ireland were 27.8 percent as compared with 13.4 percent for U.K., 10.2 percent for France, 15.6 percent for Germany, 9.7 percent for Japan, 23.3 percent for Denmark, and 4.1 percent for U.S. In 1967 the G.N.P. was $£ 1146$ million and imports amounted to £391 million, of which 51 percent were classified as manufactured goods or machinery. In the same year manufactured goods accounted for 32 percent of the total exports of $£ 276$ million.

\section{Problems of Changing}

Trade of any nature requires a consistent system of measurement as a frame of reference. The actual system used within a particular country or economic unit is of only secondary importance. People get used to a system and it becomes second nature to them. The technician in the workshop has a "feel" for $1 / 32$ " or 0.001 " and finds no trouble in operating in these units. When you talk to him of millimetres he has 110 conception of the size you are referring to. The housewife knows what to expect when she asks for a pound of sugar or a pint of milk. They are convenient measures with which she is familiar. There is no advantage to her in buying 500 grams of sugar or a litre of milk.

Just as it is essential to have a consistent system of measurement for internal trade, it is also essential to have a uniform system of measurement for international trade. The world is unfortunate in being saddled with two major systems of measurement, the imperial and the metric. Of the two, the metric undoubtedly has the greater appeal. It is a logical decimal system which facilitates arithmetic and is more pleasing aesthetically. While it is questionable as to whether the inherent advantages of the metric system of themselves justify a country's change from imperial to metric, there is no doubt that a single system of weights and measures is more economic and desirable than a dual system. The disadvantages of a dual system extend to all phases of production and trade including purchase of raw materials, manufacture, inspection, packaging, pricing, distribution, and sales.

On May 24, 1965, after representations from industry, the British Government announced its support for a change to the metric system of weights and measures in the United Kingdom. The target date by which it is hoped that the greater part of British industry will have made the change to metric in 1975 . This means that by 1975 , assuming our trade with the U.K. remains essentially as it is now, over 90 percent of our foreign trade will be with metric countries. Following the British Government's decision, the choice facing Irish industry and the Irish Government was to stick with the imperial system and put up with the disadvantages in foreign trade, or to go metric with its long-term advantages. Maintaining the status quo would have put Irish industry at the disadvantage of having to operate a dual measuring system and would have left Ireland as the only country in Europe not on the metric system. The change to metric in Ireland thus became inevitable, and consequently in January of this year the Irish Government released the statement at the beginning of this paper giving support to the change.

However, the statement is cautious: the Government is not willing to commit itself wholeheartedly to spearhead the change. Responsibility for this is left to industry who must take the initiative. The reason for this is simply that the Government does not want to be left with the bill. If the Government makes a positive statement requiring industry to change to metric within a specified time period then it immediately lays itself open to claims for grants to help industry to make the change. The Government rightly or wrongly does not want to commit a large section of public funds to such an expense. As time goes on, however, the Government will be obliged to play a more positive role to ensure proper coordination and timing of the change.

As demand for products in metric sizes and to metric specifications increases, so will the pressure on individual companies to change over to metric.

The change will be forced on the manufacturer and will have a sound economic basis. The demand for metric products will come from metric countries to which our exports go. Some Irish companies are already working exclusively in metric units. 
Retail trade on the home market will have no such lever providing the incentive to go metric. In the sphere of retail trade, particularly for the consumer market, the need for positive Government action is critical. If the country is to go metric there is need for a coordinated and planned campaign. Legislation has to be changed, education and text books revised. A practical way of introducing the change has to be devised so as to cause as little confusion as possible for the man in the street, and proper control of the change is required to protect the consumer from exploitation.

\section{Meeting of the Challenge}

As in Great Britain, it has been the building industry which has taken the initiative and is paving the way to metric in Ireland. In recent months at the direction of the Minister for Local Government, An Foras Forbortha Teoranta (The National Institute for Physical Planning and Construction Research) has set up a committee to coordinate the change to metric for the building industry. At its first meeting on May 27, 1968, the committee unanimously proposed that Ireland adopt the International System of units. At a later meeting it was agreed that the Irish building industry should in essence follow the British program for the change to metric, aiming to complete the change by the same date.

A second committee within the Department of Education is currently considering the steps to be taken to implement the change to metric in education, while the National University has established a metric committee to consider appropriate changes in University curriculae.

It is expected that the Government will shortly appoint further committees to deal with other aspects of the change to the metric system of weights and measures. The Institute for Industrial Research and Standards in Dublin will probably be appointed as the central coordinating body for the change to metric in Irish industry, and play a role corresponding to that of BSI in Britain. The Institute is a State sponsored body established as a service to Irish industry. It carries out research and development work for industry, provides a wide range of test facilities, draws up Irish Standard Specifications and offers technical information and advice on an extensive range of topics. Recently the Institute established a Metrology Section responsible for maintaining the physical standards of measurement for the country, and for disseminating the units of measurement through the provision of an adequate calibration service. The primary electrical standards for the country are maintained in an Electrical Standards Laboratory at the Institute and an extensive service is provided for the calibration of electrical instruments. The primary standards for dimensional metrology are maintained in a second laboratory where there are facilities for the calibration of most dimensional gauges. In addition to providing calibration services, the Metrology Section at the Institute offers advice and assistance on questions of measurement and calibration.

Trade Measurements in Ireland are regulated by the Office of Weights and Measures. Imperial standards of mass, length and volume are maintained in the office and used for calibrating local standard weights and measures. The measuring instruments employed and the accuracy of measurement are consistent with trade requirements but are not adequate for the demands of industrial and scientific measurements. There is need for rationalisation between the Office of Weights and Measures and the Metrology Section of the IIRS. The proposed change to metric in Ireland has afforded a perfect chance for a review of the entire system of weights and measures in the country, and the author is currently drafting proposals for the new system.

Linked with the change to metric is the change to decimal currency in Ireland. Following recommendations by the Committee appointed in 1953 the Government, in February 1962, decided in principle to adopt a decimal system of currency, and appointed a further committee to advise on the timing of the change and the steps necessary to effect the change in the most economical way. In addition to other recommendations, this committee in its report of 1964 supported the earlier committee in advocating the $10 /$ - cent system. Despite the recommendations of the two committees for the adoption of the $10 /$ - cent system the Government, on the 23rd of April, 1968, finally announced its decision to introduce the $£ 1$ - cent system, thereby maintaining parity with the British system. This decision was reached in view of the extremely high volume of trade between Ireland and the U.K., and for the convenience of people travelling from Britain and the Six Counties to Ireland, over 8 million in 1967. The specific program for the change to decimal currency has not been finalized, but decimal day is the 15 th of February, 1971 and the change is expected to be completed within two years of that date.

\section{Conclusion}

'To summarize then, one can say that the move to the metric system in Ireland is under way. While a great deal has not yet been done in concrete terms, the decision has been made and the change is inevitable. Trade and industry in Ireland are relatively small and unsophisticated, so that in comparison with other countries the change to metric should be effected quite easily without undue expense or inconvenience. The change from the imperial to the metric system of weights and measures is basically a simple task in any country. While one cannot doubt or belittle the short term inconveniences and expenses, the 
change creates no major difficulty given a proper frame of mind and sound planning. Many people seem to have a mental block about such a change and cower back in fright of what appears to be a mammoth and nigh impossible task. The first and perhaps the most difficult step is dispelling this misapprehension. The metric system is logical and simple. The change to metric is simple when conducted in a logical manner. The advantages of a single universally accepted system of measurement are undeniable. It is to be hoped that this ideal will one day be fully realized.

The author is indebted to Mr. Jim Daly, chairman of the advisory committee on the introduction of the metric system in the building industry, for his kind assistance. 


\title{
THE VALUE OF INTERNATIONAL MEASUREMENTS
}

\author{
R. H. C. Foxwell
}

\author{
Chairman, The Wayne Kerr Company Ltd., New Malden, Surrey, England
}

\section{Introduction}

May I first thank you, and particularly your Chairman, for inviting me to this Conference. I have been here before and I hope, in spite of what now follows, that I may be allowed to come again.

Your National Conference of Standards Laboratories is an enterprise which commands great respect in my country and we follow your activities with admiration and not a little envy. If I may say so, the N.B.S. also sets quite a standard and there are many of us who regard this place, Boulder, as a typical example of the American ability to look forward into the more speculative areas of measurement technology and then do something about it.

When your Chairman wrote to me last December inviting me to take part in the Conference he suggested nine topics for consideration and I was foolish enough, in replying, to agree to offer comment on four of them. Briefly these were:

(1) the dependence of our nation upon, and the value of, internationally accepted measurement standards and definitions in promoting exports of scientific instruments

(2) the political significance of a common measurement system in promoting closer economic and social ties with other nations

(3) the advantage or disadvantage of Government control of the quality and reliability of exported precision instrumentation

(4) the advantage or disadvantage of industrial control of the quality and reliability of exported precision instrumentation.

These are loaded questions and the more I think about them the more tempting it becomes to try and find means of evading the issues.

However, I am here and clearly I must say something. Fortunately the Moderator has limited me to ten minutes and it ought to be possible to keep out of trouble for ten minutes.

\section{Export Significance}

First then-the dependence of our nation upon, and the value of, internationally accepted measurement standards in promoting exports of scien- tific instruments; and, of course, the importance of internationally accepted definitions.

I can perhaps best sum up the British view of the importance of this matter by reminding you that when our new Ministry of Technology was established in 1964 one of its first basic departments was the Standards Division set up under the leadership of Mr. Arthur Wynn. This Division immediately became extremely active in promoting international discussion of standards in all the contexts of the word. The appointment of Arthur Wynn himself is not without significance. He had had considerable industrial experience and was able to develop in a very short space of time a high degree of mutual confidence between his Department and the various sector's of Industry with which they came into contact. His Organisation often leads but it makes no attempt to compel. Consultation and co-operation with Industry are quite fundamental to their work philosophy and, amongst many other things, this rapidly led to the establishment of the British Calibration Service, with the Scientific Instrument Manufacturers' Association aiding and abetting by submitting draft proposals in the first place. The raison d'etre for the British Calibration Service, and incidentally the argument which prised the necessary financial support out of Her Majesty's Government, was the development of our export potential.

One could quote example after example of the accuracy of an instrument being disputed by a foreign customer for no other reason than that there was no common definition of the measured parameter or no common definition of the conditions of measurement. Most measurements made in Industry are, after all, relative. The absolute measurement is normally reserved for more esoteric establishments and so, inevitably, common standards, in the sense of an agreed point of reference and an agreed measurement procedure, are essential to secure confidence in the validity of the result achieved. Only by obtaining this com. monality of approach can a proper trade in instruments be secured and, if and when this happens, all countries can take full advantage of the innovative skill of their trading partners. 
Establishing traceability of industrial measurements to internationally compared standards through specified procedures and disciplines, is the primary task of the British Calibration Service. There can be no doubt but that both Government and Industry in the United Kingdom are equally committed to achieving success for this venture.

From the industrial or commercial point of view this is a subject which is not easily quantified in terms of business gained or lost. I can only say that in the United Kingdom we are becoming increasingly convinced that we must know what we mean by, say $10 \Omega @ 1 \mathrm{MHz}$, whether we describe it in German, French, Russian, Japanese, or English.

\section{Political Implications}

Now, political significance-and we are still trying to concentrate on this concept of a common measurement system. I think we in the U.K. incline to the view that the political significance of a common measurement system in promoting economic and social ties abroad is negligible unless it has achieved a substantial increase in the volume of trade. I would suggest to you that respect for another country's trading ability, and the intimate personal contacts which are established through it, will contribute far more to the development of a social compatibility than the interchange of holidaying visitors on any foreseeable scale, jumbo jets notwithstanding. Also I suspect that the existence of a healthy mutual trade must constitute a restraint upon quarrelling and ambitious politicians. It is possible, for example, that tensions in the Middle East would be greatly reduced if there were a strong circulating trade between the countries concerned.

It must surely now be considered an established fact that the rate of growth of mutual trade between advanced industrial nations will be very largely dependent upon the success of the various national bodies concerned with the effort to achieve commonality of standards and internationally accepted reference standards of measurement.

If my premise is right, the growth of mutual trade which must follow international standardisation will indeed have a profound effect upon the political scene.

If, then, in this vital cause we achieve commonality of standards, commonality of measurement procedures, commonality of language or definitions, it follows logically, I think, that customers at home or abroad will often wish to receive an assurance that the products they are buying truly conform to the rules, and, because quite a lot has already been done to meet these objectives, there is a growing interest in quality assurance procedures impartially carried out.

\section{The Role of Government in Quality Assurance}

I am now going to try and deal with questions 3 and 4 together, because really I take them to mean "What about the Government? Should they or should they not control this part of the exercise?" To me, quite definitely, they should not. But I am none the less convinced that Government patronage will usually be necessary to establish confidence in the foreign buyer that an assessment has been carried out with proper freedom from bias.

On the other hand, competent assessment of quality and reliability implies a high degree of expertise in the assessor and where will the expertise be found? Except perhaps in defence equipment and-I hasten to add this, because I remember where I am-in the development of national standards - except in these special areas the best expertise must normally exist in Industry, though often, no doubt, within the Universities. Therefore any authority providing quality assurance must, if it is to achieve the necessary status, include representatives from all three sections of the community. This is certainly the pattern developing in Europe. The British Standards Institution is a fair example of what I mean and, incidentally, it undertakes a substantial amount of quality assessment work, using its Kite mark. It derives its subscription income from Government and Industry in equal proportion but there are only three Government representatives on the governing Board of 28. The rest are drawn from Industry, the Universities, and senior permanent officials of the Institution. This is enough to ensure the Institution's image abroad as an independent national body, whilst leaving Industry ample opportunity to give effective voice to its commercial needs. (I must add, of course, that it also leaves Her Majesty's Government free to disown the Organisation if that should ever prove expedient.)

Most of you will be aware that the British and Soviet Governments have recently signed an Agreement to collaborate in certain industrial areas and this has led to the formation of a number of Anglo-Soviet Working Groups set up to study ways and means. It is a particularly interesting exercise because both sides are seeking to develop trade between two very different industrial systems within the framework of existing political restrictions. One of the Groups, need I say, is concerned with standards in all aspects, including hardware, another with instrumentation per se. These Groups will normally comprise six to eight members from either side. In the first case, Standards, the United Kingdom representation is shared between Her Majesty's Govermment with its responsibility for the National Physical Laboratory, the National Engineering Laboratory, The British Calibration Service etc., then the British Standards Institution and Industry, with eight 
members in all. In the second case, Instrumentation, there are five industrial members and the Head of the Instruments Branch of the Ministry of Technology whose presence, I must say, is of the utmost value in providing not only a direct communications link with Government, but also the implied assurance of official support and national backing, which is welcome to the party of the other part, if you follow me. This co-operation with Government may or may not be developing as smoothly in other industries in Britain-we can assume it is but I just do not know-nevertheless in our Industry, Scientific Instruments, there can be no doubt that a very solid basis of partnership is being forged and the question of Govermment control really does not arise.

\section{Problems of Education}

May I just touch on the question of education. I am a member of the Advisory Council on Calibration and Measurement, to which Mr. Barnett of the British Calibration Service referred in his paper. This, of course, is a body set up to advise our Minister on the steps Government can take to assist in the development of a national measurement system. Apart from our obvious duties in establishing criteria for approval of Calibration Laboratories operating within this system, we are very much concerned with promoting education in the general field of measurement. I think I recall Dr. Grisamore in 1966 referring to a shortage of recruits to this subject at his university in Washington, D.C. We have precisely the same problem-measurement is not fashionable-but we believe that it is important to encourage teaching of this subject in the universities, not only at the graduate level where some linderstanding of basic measurement philosophy is essential in all science subjects, but also by specialist training at the postgraduate level. It is tre intention of the Council to do everything in its power to stimulate interest in the subject amongst our student population.

\section{Conclusion}

At the risk of being trite-and this really has connection with my previous observation-may I say that most of us when we are assembled find that we are preaching to the converted. I am sure all you gentlemen would not be here if you were not interested in the benefits to be derived from the logical but never fanatical development of international standards. The trouble is, there are not enough of us and we really must give attention to the attraction of converts. It seems to me that this is one of the most important tasks facing us at this present time. 


\title{
LARGE PROBLEMS OF SMALL COUNTRIES
}

\author{
Lars Frank
}

\author{
Research Institute of National Defence, Stockholm, Sweden
}

First of all I should like you to consider that the situation for a "super power" such as the United States is rather unique. While America is self-supporting in almost every respect and could in principle go on quite well if it were isolated from the rest of the world, this is certainly not the case for the majority of the smaller countries. Thus it is not astonishing that the per capita import and export are considerably lower in the United States than in the smaller industrialized countries, being, for example, approximately one fifth of Sweden's.

Now, do not get alarmed. Your inferiority in this field is just an example of the fact that you can satisfy most of your needs yourselves. If you look upon the whole world as an entity, you cannot say that it is doing badly just because its per capita export equals zero. If, on the other hand, you choose to look separately upon each state within the United States and include the interstate trade, you will presumably get substantially higher figures than apply to most European countries at present. Nevertheless, I think that the interstate trade would be the closest analogy you can get.

Of course there are a number of differences which olle must not overlook. The States in America have a common language, a common currency, and no customs or other formalities for the interstate trade, while the opposite is true for the European countries. True, the creation of the European Common Market and the European Free Trade Association is bound to reduce the latter barriers. Furthermore, while it may be natural for Americans to confine most of their trade to the United States, it is an old tradition for many European countries to do business all over the world.

Now, you know much better than I what tremendous importance the NBS and the American National Measurement System have had upon the economy and development of your Nation. It would not be the same if every State had had its own units, even if the conversion factors were known.

For the very same reason, most of the countries in the world have adopted the metric system. The sole exceptions in all Europe have been
Great Britain and Ireland but since the British Commonwealth is no longer the world of its own that it used to be, Britain is turning more and more to continental Europe and consequently is planning to adopt the metric system. After that, America will probably have to do the same, sooner or later, or else it might have to content itself with a decreasing share of the international commerce.

On the other hand, the American market is very attractive and some companies may be willing to sacrifice rationality for a chance to enter it and stay there. What other explanation can there be for the fact that Volvo switched from metric threads some ten years ago? An analogous situation applies to the wall-board made in Sweden. To suit the export to Great Britain, the standard width is four feet, in spite of the fact that all dimensions are given in centimeters on the drawings used for housebuilding in Sweden. Thus it seems that an eventual abolishment of the inch would have direct consequences also in some "metric" countries.

Thus far I have mentioned only the wellknown problem of the world being divided into one metric bloc and one inch bloc. Now, turning to the field of precise electrical measurements, I should like to draw your attention to the fact that there seems to be a slight risk of a similar development into blocs in that field as well, although the differences are much smaller and concern fewer people. This is because the accuracy of the absolute determination of fundamental electrical quantities is inferior to the precision of relative measurements. Thus, while in principle all countries use the same definitions for their volts, ohms, amperes, etc., in practice there do exist discrepancies of some 10 parts per million.

As yet, most people do not bother about 10 ppm, but in a number of fields, higher precision is actually needed, and these fields seem to be growing. Generally the constancy of the units is more important than their conformity with the definition or with the units used in other coulltries. For instance, measurements and calibrations made in the United States refer to the National Standards as maintained by the NBS and not to the international units of the BIPM. The 
argument goes something like this : "We could not possibly keep changing our calibrated values every time they manage to make a better absolute determination in England, Canada, Australia, France, Russia, Germany, or Japan, or-for the sake of the argument-in Monaco, Mesopotamia, or what have you."

This perhaps may be true, but-honestly spoken-is it not also a question of national pride and prejudice (not only in America but as much in the other countries with resources for absolute determinations)? If one country's determinations were really much more reliable than those made in other countries, due consideration could be given to that fact by forming an appro. priately weighted international mean, in much the same way as the BIH is now giving the U.S. Frequency Standard a weight of five in the international atomic time system.

The present system, where the most developed nations keep adhering to their own national standards and use the BIPM only for intercomparisons (the results of which are never really used), is bound to cause trouble in a shrinking world. In Sweden, for instance, certified standards are sometimes bought from Germany, sometimes from England, sometimes from the United States, and sometimes from other countries. This, as you can understand, often makes communications difficult and forces people to apply different corrections on different occasions.

We once asked Dr. James L. Thomas, formerly of the NBS, what he thought should be done about it. He told us to develop our own national standards and make people stick to them. But in rebuttal, let me go back to the analogy of the individual States in America. Suppose that the U.S. measurement system was recognized on paper only but not used by all the States. Suppose that a few States, e.g., New York and California, maintained their own units according to their own absolute determinations. If then Nebraska complained about the inequality, would it really help if it too adopted standards of its own, thus adding one more new set of units? I think not, and so did the founding fathers who gave all the States a common measurement system.
If you measure distance not in miles or kilometers but in the time it takes to travel between the places in question, then you will find that the whole earth is much smaller now than the United States was some 70 years ago, when Treasury Secretary Lyman J. Gage advocated the need for a federal standards laboratory. Furthermore, the international trade is now much larger than the interstate trade of Gage's time, so it seems that his arguments should be even more relevant today, applied on a worldwide basis.

Hence, I think that the time has now come when all countries should make their units equal and give ample support to the BIPM, so that it can be to all the countries of the world what the NBS has proved to be to America.

Finally, my national pride forces me to tell you about a recent change of a different kind of standard in Sweden. Last year-after much too long a hesitation-we changed our road traffic system from left to right. The desirability of such a change had been made quite clear for a long time, because all the countries in continental Europe keep to the right. But every time a changeover was discussed the costs were found to be prohibitive and the matter was postponed. Finally however, the increased international traffic made a change unavoidable and we simply had to pay, no matter how high the costs were. Of course our wallets were hurt badly, but we are convinced that in the long run the investment will prove to be a very profitable one indeed. The funny thing is that the costs that looked absolutely prohibitive 20 years ago were just a very small fraction of what we were forced to pay now.

One more thing-a large fraction of the costs was caused by the necessity of replacing all the buses. It might appear that this could have been avoided if we had maintained a dual system for a couple of years, allowing the old buses to drive on the left side until they were worn out, while the new ones kept to the right! However, for some reason we decided against it, and if you people think that I am still hinting something about inches and national units-well, so be it! 


\section{DEVELOPMENTS IN THE CANADIAN MEASUREMENT SYSTEM}

\section{J. G. Cameron}

\section{Quality Assurance Laboratories, Department of National Defence, Ottawa, Ontario, Canada}

A report on the Federal-Provincial Conference held in Ottawa in February 1968 concerning the proposed "Standards Council of Canada," some Canadian attitudes toward standardization activities and consideration of the adoption of the International (Metric) System in Canada.

\section{The Standards Council of Canada}

In February 1968 a Federal-Provincial Conference was held in Ottawa concerning the establishment of the proposed "Standards Council of Canada."

The function of the new standards body will be to create a co-ordinated and dynamic national standards programme, adequately organized and financed, and representative of all levels of Government, Industry and the consumer.

The major objectives would be:

$i$. to foster the formulation of truly national standards and to promote their general adoption in both the public and private sectors;

ii. to provide for the effective coordination of the activities of all existing Canadian standardssetting bodies;

iii. to provide for the establishment of standards where a need arises which is not met by the existing standards institutions;

iv. to harmonize standards practices in different industrial sectors and to ensure adherence to the consensus principle in standards formulation with particular respect to the interests of the consumer and the public at large;

v. to provide for effective representation of all Clanadian interests in international standardization activities, which have a direct bearing on the access of Canadian products to export markets. ${ }^{1}$

In taking the initiative in proposing the formation of a Standards Council of Canada, the Federal Government has acted in response to the broad national interest and intends to consult fully with interested governments, primary and secondary industries, industrial and trade associations, and consumer representatives before its implementation.

The consensus principle, which the council plans to apply throughout its operations, shone through in the communique issued after the meeting, "-It was the consensus of the meeting that a council should be established to promote and coordinate

\footnotetext{
${ }^{1}$ Briefing papers on a National Standards System for Canada. 1968. Canada. Department of Industry.
}

standardization activities in Canada and Canadian participation in International Standards Organizations." Consultation with the trade, industry, consumer and other groups is now under way to gain their appreciation of the situation, in depth.

\section{An Effective Environment for Standardization}

By creating an effective environment in which standardization activity can flourish, many other benefits may come along as well-simplified product designs, reduced engineering effort and production costs, adequate levels of quality, reliability and performance as well as lessened inventory costs, to mention a few. Unless the standards that are produced can provide solutions to practical problems, as well as listing the best theoretical approach, we could find volume after volume stored carefully on book shelves, dusted in accordance with the periodicity specified for good libraries but not filling the total need to the proper extent.

The Council would promote the formation of a Standards Information Centre with a comprehensive index of all domestic, foreign and international standards. Such a centre would disseminate information throughout Canada and encourage the introduction of standardization systems and techniques. To a representative preparing to attend an international meeting, it would be an extremely valuable source of information. A basic facility of this nature is already in operation.

It is quite possible that translation of foreign language standards, and perhaps English-French translation services may be required.

The formation of an integrated national standards organization in our country is a necessary first step in the establishment of a responsible body which could act as a kindly father, if you will, who keeps pointing the direction and patting the backs of all members of the standards family so that they stay on the same roadway, taking curves together and lending each other a helping hand on the steeper hills. 
It is my understanding that the Standards Council will concern itself with fostering standardization activities in Canada and strengthening our International voice and efforts. Activities arising from and operated in support of International Treaties would not come within the Council's purview; however, active liaison and close cooperation would take place in the overall interests of the nation.

Since the primary purpose of this paper is to inform you concerning what lies ahead for Canada, little will be said of the scope of past and present activities, although many are significant and far reaching in their impact.

\section{Metrication for Canada?}

There is a growing recognition in Canada of the advantages in terms of trade in manufactured goods, which would accrue from wider use of the International System of Units. The metric system of measurement is already legal in Canada and has been since 1873 when the Weights and Measuures Act was passed. Although commonly used in particular fields of science and industry, its adoption is inhibited by the widespread usage of the foot/pound system in the North American market and of course the many factors and costs involved in conversion.

Those Canadians who are considering the matter of "Metrication" for Canada recognize our trade relationships with many nations throughout the world and in particular our close association with the United States of America. I think it would be reasonable to assume that your country's attitude toward metrication and the recent steps taken in that direction have great significance for us and developments here will be under close observation from above the 45 th parallel.

The general attitude of leaders in our scientific fields toward metrication is not a question of yes or no but when. I think it would be fair to say that the engineering and technical community has a similar attitude, however, it is too early to state any breadth of opinion in this area. The Government of Canada has not established a firm policy in this manner, but for a period of two years consultations amongst senior members of govermment departments and agencies concerned, such as Trade and Commerce, Industry, and the National Research Council of Canada have been underway and when specific legislation is brought before our parliament, it is anticipated that some statement of policy on conversion to the SI units would be included. It is anticipated that this activity will be one of the prime and initial responsibilities of the Standards Council. If conversion to SI is initiated, dual measurement systems would be required where necessary for interim periods of time, however, the short and long term benefits should be similar to those you have heard expressed here today.

\section{Special Considerations in Standardiza- tion Activities}

Where do standards come from and how far do they go? Many answers can be given to this question. Let us consider one or two approaches.

The International Standards Organization Recommendations are to be considered as the bases for the national standards. Discrete sections can be adopted without change, other sections adapted to suit local conditions. However, if we look at industrial standards developed in other countries and made available for adoption for domestic use in Canada, certain factors must be considered. In many cases, we should be doing more adapting when we adopt. Our level of industrial development and scale of production may be quite different from that of the country originating the standard.

If the product is intended solely for use in Canada, we must give consideration to the anticipated environmental conditions in which it must perform satisfactorily. If however we except to market the product in South America, Japan or Australia, we should consider their environmental conditions and other local factors as well. If it takes three weeks to deliver a product by surface shipment to a foreign port, and customs clearance action takes two or three more, the product formulation may have to be changed to extend the normal shelf life to suit this situation. ${ }^{2}$

Just to bring the situation into focus, in respect to production and utilization of precision devices, oul exports of measuring, controlling, laboratory, medical and optical equipment amount to about 0.15 percent of our Gross National Product. Imports of approximately the same types of devices make up 0.4 percent of the Gross National Product. It is interesting to note that Canadian use of domestically produced material of the same class runs in the order of 0.6 percent of our Gross National Product. ${ }^{3}$

Except for the opinions already expressed, it is too early, at this particular time, to report the general attitude of Federal and Provincial governments, primary and secondary industries, industry and trade and consumer associations, universities and labor unions toward "Metrication." However, it is expected that we will be hearing more and more on this subject in the reasonably near future.

Those of you who know the Standards community in Canada will recognize that certain realignments and changes are on the horizon and there are many interested "Standards Organization" watchers who are training and focusing their telescopes at this time. Some of you have participated with Canadians in the American Society for Testing and Materials, The International Standards Organization, The International Electro-

\footnotetext{
a Cameron, J. G., A Proposed Programme of Quality Control for Canadian-Made Products, 1965

3 Dominion Bureau of Statistics.
} 
technical Commission, the ABC Committee on Unification of Engineering Standards, and in a host of other committee operations.

I trust that benefit derived from these activities has been substantial, and would expect that the standards agencies in Canada and the United States would look at the problem of "Metrication" together since it has such significance for our continent.
I would like to acknowledge the assistance and information provided by officials of the Department of Industry, the National Research Council and the Department of National Defense in the preparation of this paper. Perhaps at a later date, I will have the opportunity of reporting future developments to you on the impact of the Standards Council of Canada and the part Canada is playing in world-wide standardizing endeavours. 


\title{
THE ADVANTAGES AND DISADVANTAGES OF INDUSTRALIZED NATIONS DEVELOPING AND SUPPORTING A DUAL SYSTEM OF WEIGHTS AND MEASURES
}

\begin{abstract}
J. S. Weber
Director, Engineering Methods, Hughes Aircraft Company, Culver City, California 90230

The United States, while producing one-third of the world's goods with only 6 percent of the world's population, is nevertheless losing ground rapidly in foreign marketplaces, with a resulting unfavorable balance of payments. As one of the key countries responsible for stabilization of world monetary affairs, the U.S.A. must promote acceptance at home and abroad of the importance of achieving balanced trade relations among all nations.

The achievement of this balance can be materially enhanced by the acceptance by all nations of existing international standards of measurement which are now used by 90 percent of the industrialized nations of the world.

The accomplishment of this objective does not imply a "switch to metric system" for U.S.A., nor a "switch to inch system" by metric countries, nor does it involve large expenditures for capital investment or re-tooling. The secret lies in developing flexibility in thinking and attitudes among workers and management alike, in producing and selling things that the people want to buy in a "language" they understand. That "language" must include written and spoken words, as well as standards for definition, terminology, performance, and weights and measures.

A dual system of measurement and measurement equipment is not only a possibility, but could be a profltable reality if preceded by careful planning and proper education.
\end{abstract}

\section{Introduction}

The United States, while producing one-third of the world's goods with only 6 percent of the world's population, nevertheless is losing ground rapidly in foreign marketplaces, with an unfavorable balance of payments the result.

Looking for a moment at published statistics, we find that during the last six years the U.S. share of world export of goods to major countries of the world has dropped 8 percent. Moreover, in a category where U.S. technological capability excelsthe field of machinery and transport equipment, including aircraft-the U.S. share of export has dropped 12.5 percent in the same period. This does not mean that total U.S. export is declining; it means that other nations, including the many which have recently industralized, are more aggressive in expanding and developing foreign markets for their goods.

As one of the key countries responsible for stabilization of world monetary affairs, the U.S.A. must promote acceptance, at home and abroad, of the importance of achieving balanced trade relations among all nations. This cannot be done by complacently accepting the known fact that at present U.S. exports represent only 5 percent of its GNP. It can be done only by maintaining a share of world trade in balance with the fast expanding universal consumption of goods. It can be done by recognizing now that world trade depends on communications (understanding). It can be done by developing a language now-a language that is understood universally in situations where the type, size, and performance of products must be understood before they will be bought.

\section{Past and Future}

Figure 1 indicates where we are today in relation to the big picture, and brackets the period of time which we will be discussing. If we look in detail at this figure, we will see the three segments of time which are important to this discussion-the first being the period just six to eight years prior to today, the second being the period six to eight years after today, and the third being the period at the end of the century.

The period prior to today is one we must look at in order to analyze which decisions must be made now to prepare us for the second time period. Then our next time period (next six to eight years) is the span where "pick and shovel" work must be done to assure our complete success in the last third of the century.

Looking back at the last seven to eight years, let us examine the trend. Let's look at the data and statistics available to show the impact of the then existing languages on current world-wide conditions. Obviously, the percentage of change in the 


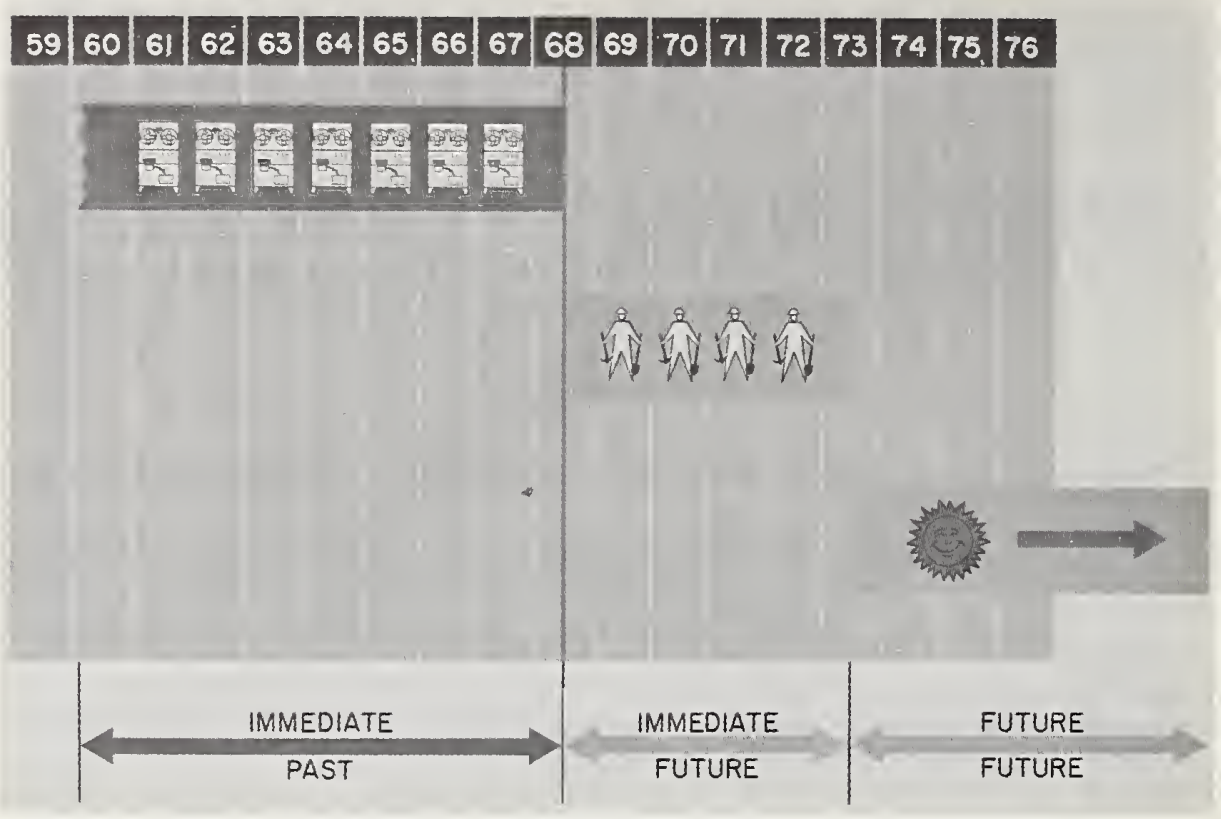

share of world markets for goods fluctuates up and down depending on many factors. Let's look at several figures of the U.S. share of various categories of goods to indicate this point. (We picked the United States since statistics of this country are readily available.) Examining our share of imports of goods by all countries of the world during the period 1960 to 1966 , we find that in 1960 the United States supplied 20.5 percent, and in 1966 , only 19.0 percent. In manufactured goods during the period 1950 to 1967 , we dropped from 27.3 per- cent to 20.1 percent. In transport equipment, we dropped from 35.5 percent to 31.1 percent, and in machinery, from 20.5 percent to 19 percent.

Let's look at how measuring systems (or language) play a role in the export situation. Figure 2 indicates that in U.S. exports of machinery and transportation equipment to countries which are on the inch system of measurement, our share of world imports has risen from 54 to 58 percent; in our exports to countries that use the metric system, our share has dropped from 27 to 20 percent.

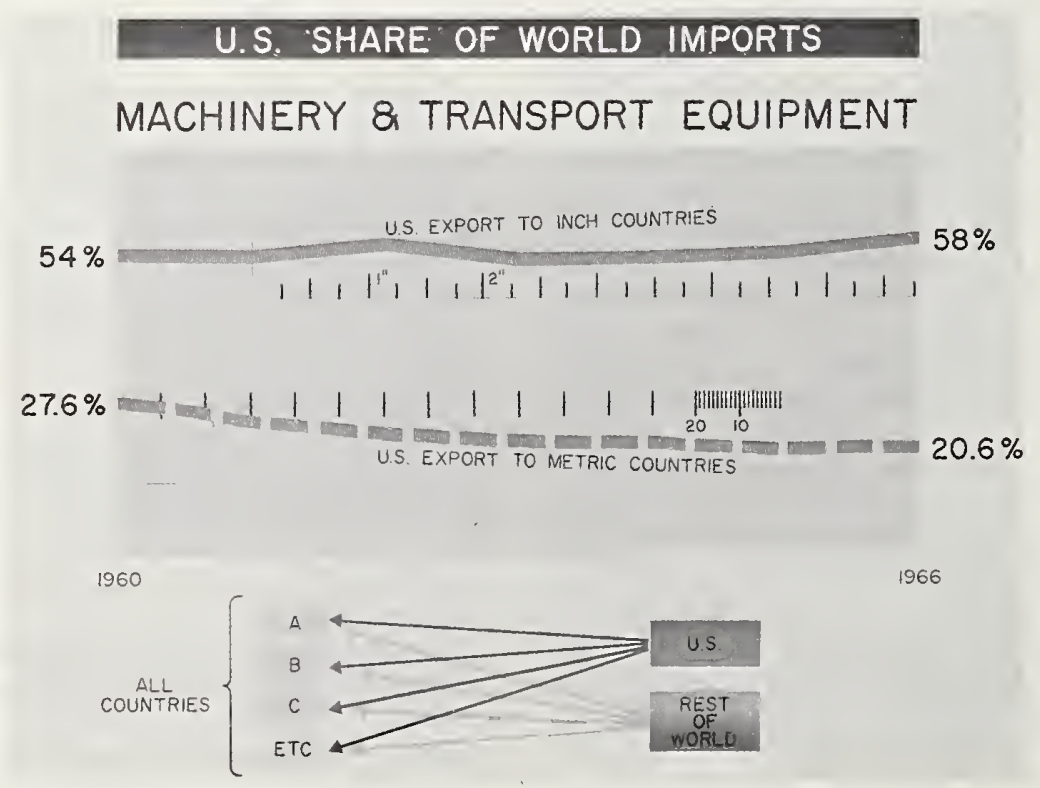


It is apparent that the lack of flexibility of this Nation is not paying off and, as a matter of fact, appears to be growing worse. Obviously, we cannot be indifferent about the rest of the world, since trade must be kept in balance for all countries.

Let's look in detail at the "pick and shovel" work required now :

1. Adequate planning,

2. Education and training,

3. Public relations,

4. Increased development of national and international standards,

5. Increased support of national and international standards organizations (both time and dollars),

6. Increased distribution of ISO and USA standards-worldwide, including multi-lingual versions,

7. Development of dual systems, as appropriate, and

8. Encouragement of technical exchanges of data.

Let's examine how the communications industries are doing. They have progressed with their "pick and shovel" work much further than have the other industries we have been discussing.

When the International Telecommunications Satellite Consortium (INTELSAT) was established in 1964, there were only eleven participants, all of them developed nations. Of the 61 present IN'TELSAT members listed in table 1, approximately 40 can be called developing nations.

In other massive international joint ventures, such as the UK/French/Concorde Project, a common language has been developed, is working, and is making money for those who have done their "pick and shovel" work early in relation to today. Advances in high-speed modern communication

TABLE 1. Participants in the International Telecommunication Satellite Consortium

$\begin{array}{lll}\text { Algeria } & \text { Japan } & \text { Portugal } \\ \text { Argentina } & \text { Jordan } & \text { Saudi Arabia } \\ \text { Australia } & \text { Kenya } & \text { Singapore } \\ \text { Austria } & \text { Korea } & \text { South Africa } \\ \text { Belgium } & \text { Kuwait } & \text { Spain } \\ \text { Brazil } & \text { Lebanon } & \text { Sudan } \\ \text { Canada } & \text { Libya } & \text { Sweden } \\ \text { Ceylon } & \text { Liechtenstein } & \text { Switzerland } \\ \text { Chile } & \text { Malaysia } & \text { Syria } \\ \text { Colombia } & \text { Mexico } & \text { Taiwan } \\ \text { Denmark } & \text { Monaco } & \text { Tanzania } \\ \text { Ethiopia } & \text { Morocco } & \text { Thailand } \\ \text { France } & \text { Netherlands } & \text { Tunisia } \\ \text { Germany } & \text { New Zealand } & \text { United Arab } \\ \text { Greece } & \text { Nigeria } & \text { Republic } \\ \text { India } & \text { Norway } & \text { United Kingdom } \\ \text { Indonesia } & \text { Pakistan } & \text { United States } \\ \text { Iraq } & \text { Panama } & \text { Vatican City } \\ \text { Ireland } & \text { Peru } & \text { Venezuela } \\ \text { Israel } & \text { Philippines } & \text { Yemen } \\ \text { Italy } & & \end{array}$

systems, such as the one we are discussing, make it necessary that the U.S.A. also speed up the progress of developing compatible languages.

\section{Conclusion}

In summary, let me highlight a few of the key conclusions, which by now might be obvious from the foregoing statistics:

1. The balance of trade for all nations must be kept within balance itself. The events of the past several months make it clear that every nation must move at a relatively even pace. No one nation can progress too fast, nor can the rest progress too slow, since the balance of trade among all nations is the base for a sound worldwide monetary system.

2. In order to achieve this balance of trade among all nations, we must learn to communicate in the marketplace.

3. This communication, whether it be spoken words, measurements, quality of products, etc., has to become more standardized throughout the world, if trade is going to become more and more standardized throughout the world.

Since many of you are here as a result of financial support from your organizations, you may wish to leave with a couple of thoughts on how to accomplish these three objectives:

1. Obviously your support and your understanding of national standards bodies is requiredthese bodies being those recognized by organizations such as ISO, IEC, and others.

2. You must be capable of supporting the needs of, and working closely with, those industries who wish to start or wish to increase their dual capability. 'This must be a two-way street. You people may have the capability and they may have the need, but if you don't get together, these resources are wasted.

Please don't consider that developing a common language, and supporting national standards bodies, and working with dual-capability industries will themselves solve all the problems. A major problem in many countries, regardless of everything else, is the continuing spiral of increased costs and inflation which tends to price a country or a company out of the world market. You all must recognize and discuss this subject.

As a final comment (referring back to the business of communication), let us realize that not only is the problem of the balance of world trade helped through standard communication, but that a major fallout of this is an increase in understanding among those people involved in trade at the working level. Because you people know more than most people, your understanding at this level may be more of a factor in solving some of the problems of the world than is assumed through normal diplomatic relations. 
For your information, I have with me copies of several dual dimensioning systems* being consid-

* Hughes Alrcraft Company Engineering Standardization Notice No. 681. Inch-Metric Practlce, June, 1968; Radio Corporation of America Drafting Practice 8-42-2, Metric Conversion Tables, March 1, 1967 : International Harvester Englneering Standard (proposed) on Dunl Dimensioning Practice, June 1967. Copies a re obtainable unon request to the NCSL Secretarlat $\%$ Nationa

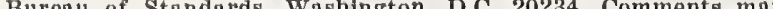
be directed to the author, \% USA Standards Institute, 10 Fast 40 th Street, New York, New York 10016. ered at the moment by the USASI National Committee on Dual Dimensioning Practices. You are invited and encouraged to submit comments on these, or to submit other plans, which will be considered prior to adoption of a national recommendation on this subjeot. 


\title{
NCSL 68 \\ SESSION 5: NCSL COMMITTEE REPORTS
}

\author{
Chairman: W. L. Vandal
}

McDonnell-Douglas Corporation, St. Louis, Missouri 63166

INFORMATION COMMITTEE A-6

NCSL Vice-Chairman 0. L. Linebrink

P. H. Hunter

Western Electric Company, Winston Salem, North Carolina 27102

and

\section{J. H. Blount}

LTV Aerospace Corporation, Dallas, Texas 75222

\section{COMMITTEe Membership}

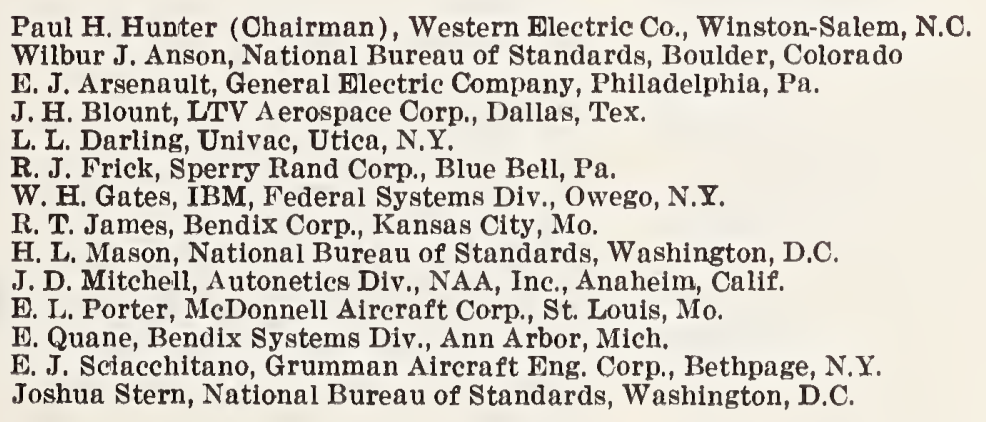

\section{Introduction}

Second only to the challenge implicit in the chairmanship of a standing committee is the challenge of defining what the committee is supposed to be doing. Fortunately, the founding fathers of the National Conference of Standards Laboratories carefully defined the function of our Standing Committee on Information as follows:

"To identify sources of bibliographical information covering both instrumentation and management and to promote dissemination of this material."

This is our political platform and, like all good platforms, it has seven degrees of freedom. We could go forward, up or down, left or right, or we could stand still. I ain happy to announce that we have not stood still, although we have undoubt- edly utilized several degrees of freedom at the same time in order to enlist the special interests and talents of as many committee members as possible. I am proud to say that exactly fifty percent of the people on our present roster of membership have made significant contributions to the four main projects undertaken during 1967 and 1968. In my experience with committees, ten percent participation has been more typical of committee work, so we should be gratified, but not complacent.

\section{Projects}

As you know, the membership of the NCSL and its committees is drawn largely from professional engineers and scientists in various fields relating to measurement. However, the members of a committee may be, and frequently are, amateurs in the particular field of their committee's activity. For 
example, we of the Information Committee do not necessarily have much, if any, background in the science of information retrieval, even though this is a most essential part of our basic function. To be truly functional in such an area for which we do not have professional training, we have no choice but to lean heavily on our sponsoring organization, the National Bureau of Standards, and other sources of professional expertise.

Our Information Committee activity during my eighteen months' tenure as chairman has embraced the following four projects:

Project No. 1: Analysis and presentation of the results of the Information Committee Questionnaire that was distributed to all NCSL members delegates in 1966 to determine their information needs.

Project No. 2: Development and presentation of a panel discussion at the Fourth Annual Measurement Standards Instrumentation Division Symposium in Chicago last September, as guests of the Instrument Society of America.

Project No. 3: Preparation and publication of the first Information Committee bibliography for general distribution to NCSL members. The topic, chosen for its generality as well as its pertinence as a source of background material for the Chicago panel discussion, was "Measurement Statistics." David Mitchell of Autonetics Division was in charge of final editing, and you will find this bibliography in your NCSL Newsletter 68-2 of June, 1968.

Project No. 4: Presentation of several papers at this Conference, discussing various aspects of the information retrieval problem as applied to the management and technical administration of standards laboratories. Participating in this effort are Wilbur Anson, Larry Darling, and Frank Sciacchitano.

In addition to these four planned projects we have had a few spontaneous contacts with people and organizations who asked special information on standards laboratories, or called our attention to existing sources of such information. For example, the Aerospace Research Applications Center at Indiana University requested information, on behalf of one of their clients, on how to establish an industrial standards laboratory. A list of references and specifications on standards laboratories was furnished, including references to papers on this subject presented at previous NCSL conferences. A graduate student requested material on the management of standards laboratories for use in his master's thesis. 'The North Carolina Science and Technology Research Center donated a number of pertinent references on NASA technology relating to aerospace measurement work and the general field of technical information retrieval. Their offer to make an extensive search on Measurement Standards Technology, at a nominal fee, has been referred to the NCSL Board of Directors.

\section{MESTIND Session}

As a report on the first of the four projects planned and executed by the Information Committee since February of last year, Jim Blount will present an analysis of the 1966 Information Committee Questionnaire. This analysis was partially completed by my predecessor, Orval Linebrink of the Battelle Memorial Institute, when I took office. It will be clear, from Mr. Blount's presentation, why we selected the subject of Measurement Statisties for Project No. 2, the panel discussion session at the ISA MESTIND session. The panelists were

Morris J. Brooks, Chief, Microwave Standards Section, U.S. Army Metrology Section, Redstone Arsenal, Alabama

Joseph M. Cameron, Chief, Statistical Engineering Laboratory, National Bureau of Standards, Washington, D.C.

Lawrence L. Darling, Manager, Measurement Standards Laboratory, UNIVAC Division, Sperry Rand Corp., Utica, N.Y.

John F. Hersh, Develop Engineer, General Radio Co., West Concord, Mass.

Robert S. Powers, Jr., Systems Analyst, Radio Standards Laboratory, National Bureau of Standards, Boulder, Colo.

Wesley II. Shirk, Jr., Project Engineer, Laboratory Analytical Section, Leeds \& Northrup Co., North Wales, Pa.

George D. Vincent, Director, Metrology and Quality Control, Electro Scientific Industries, Inc., Portland, Ore.

Harvey Weiss, Corporate Instrumentation and Data Services Division, Grumman Aircraft Corp., Bethpage, N.Y.

and the moderator was Dr. H. L. Mason, Office of Measurement Services, Institute of Basic Standards, National Bureau of Standards. The panel of eight experts was rather carefully selected to include three from the precision instrument development field, two managers of industrial standards laboratories, two representatives of Government standards laboratories, and, last but not least, one authority on measurement statistics from the National Bureau of Standards. Dr. Harry H. Ku of the NBS Statistical Engineering Laboratory presented a most appropriate keynote paper at this session entitled " $\Lambda$ Guide to Commonly Used Terms and Expressions of Imprecision, Systematic Error, and Uncertainty Associated with a Reported Value." This was published (Aug. 1968) in the Journal of the Precision Measurement Association.

The discussion question was: What does this accuracy statement mean?

A measuring device has an advertised accuracy of $\pm 0.01 \%$. This means that:

(1) Any measurement performed with this device, in accordance with the manufacturer's instructions will fall within $\pm 0.01 \%$ of the true 
value of the measured parameter

(2) $99.73 \%$ (three standard deviations) of all measurements will be within $\pm 0.01 \%$ of the true value

(3) The average (arithmetic mean) of $n$ measurements will have a $99 \%$ probability of falling within st/ $\sqrt{n}$, in which $s$ is the standard deviation of $n$ measurements, $t$ is the Student's coefficient for $n-1$ degrees of freedom at a $99 \%$ confidence level, and $3 s=0.01 \%$

(4) Any measurement will have a $99 \%$ probability of falling within st as defined in (3) above

(5) The sum of all measurement uncertainties due to systematic causes (as, for example, the uncertainty of definition of the National Unit) and random causes (as defined in 3 or 4 above) will not exceed $\pm 0.01 \%$

(6) If none of the above, what is your interpretation of the accuracy statement

It cannot be claimed that the problems of accuracy statement formulation and interpretation were settled at this 90 -minute session. There was, in fact, no general agreement that accuracy statements necessarily are or should be quantitatively or statistically standardized!

Project No. 3 for the Information Committee was one of those open-ended undertakings, the preparation of a bibliography on a specific area of measurement science. The Information Committee is committed to such bibliographical undertakings, either by specific request of member organizations or committees or, as in this case, when a survey of NCSL members had indicated a substantial need for such a special compilation not available elsewhere. On pages $28-32$ of the June 15 issue of the NCSL Newsletter you will find a rather extensive list of selected references on Measurement Statistics. The initial impetus for this bibliography came, of course, from the 1966 Information Committee Questionnaire. In par- ticular, Mr. Don Hervig of the U.S. Army Missile Command Metrology Laboratory attached a list of references on measurement statistics obtained from the Missile Command Library. This got us off to a good start. I undertook to add comments to these references and others that I came across, because I feel that the mere listing of titles and sources of technical papel's is often quite inadequate to describe their content. I wish also to acknowledge gratefully the major contributions of Information Committee members L. Darling of the Univac Division, J. D. Mitchell of Autonetics, and W. J. Anson of the NBS here at Boulder. For lack of time, a more recent contribution by Frank Sciacchitano of Grumman Aircraft may have missed the deadline for this bibliography.

It is a truism that no bibliography is ever complete, but in the case of our Information Committee Bibliography on measurement statistics, several rich sources of information were deliberately omitted. For example, the exclusion of all textbook material on the subject not only eliminated the innumerable texts that contain some reference to measurement statistics, but also restricted our bibliography to papers which could be separately reproduced and distributed at a nominal cost and without extensive copyright negotiations. Only a few of the many contributions to measurement statisties originating at the NBS are included, since the NBS has the enviable ability to keep us up to date on the published work of its staff. We refer you to Volume 1 of SP300, Statistical Concepts and Procedures in Precision Measurements and Calibration; MP265, a 300-page bibliography on dimensional metrology; MP240, listing all publications through June 1966; SP305, with listings through December 1967; and current listings in the NBS Technical News Bulletin.

I thought you might be interested in the approximate size of standards labolatories that make up the NCSL (fig. 1). This histogram is derived

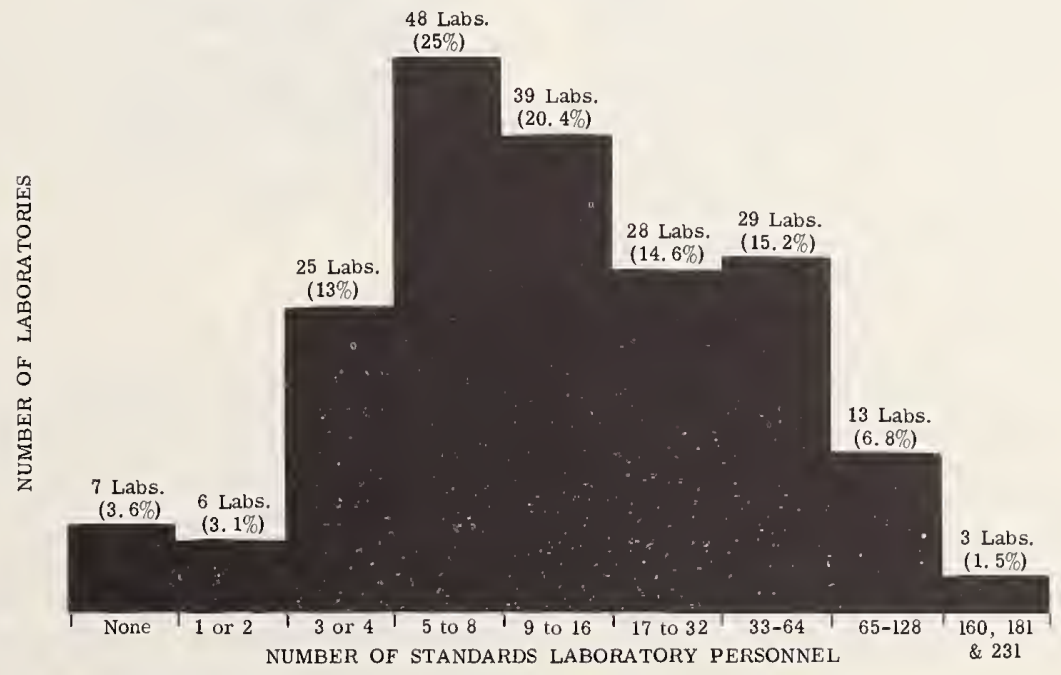

FigURE 1 
from data prepared by Bill Bostwick and Paul Long of the Directory Committee $(\mathrm{A}-7)$, which are published in the latest edition of the NCSL Directory of Standards Laboratories. I have classified standards laboratories into groups according to the number of professional and technical personnel they reported as being primarily engaged in standards laboratory work.

The average size staff of the 192 laboratories listed in our 1967 Directory is $271 / 4$ persons per laboratory, and the median size is 53 persons.

It is not so strange, perhaps, that seven companies reported having no full-time standards laboratory staff. What is strange is that two of these companies are leading manufacturers of electrical standards. At the other extreme, one company reported 231 people in their standards laboratory organization. They must be using automation! Nevertheless, this is the best source of information we have on the size distribution of standards laboratories in the United States.

Unfortunately, there is no industry standard for assigning a fixed fraction of total company employees to measurement standards work. In fact, the problem of justifying the mere existence of standards laboratories is still with us. I would like to close with the suggestion that we do some coordinated chewing on this problem.

\section{RESULTS OF QUESTIONNAIRE}

\section{(J. H. Blount)}

During 1966 a four-page questionnaire was prepared by the Information Committee under the direction of Orval Linebrink, who was Information Committee Chairman at that time. The purpose was "to identify the most pertinent and useful information needs, in both technical and administrative areas, of the NCSL membership." By February of 1967 a total of 68 replies had been received, representing about half of our NCSI paid membership at that time. In order to interpret fairly the results of this questionnaire, it is necessary to point out that the 68 replies were not necessarily a representative cross-section of our membership at that time. In fact, the roster of companies and organizations that undertook to answer the ten rather difficult questions * would make an excellent catalog of major aerospace and governmental laboratories in the United States and Canada. There were few replies from instrument manufacturers, including the principal vendors of electrical and physical standards. Please bear in mind, therefore, that the data I will present are heavily weighted toward the large aerospace users of standards and associated instrumentation.

In response to question number one, the supervisors replying indicated that, of the information needs of their laboratories during the past 12

\footnotetext{
* Coples avallable on request from NCSL Secretariat.
}

months, approximately $76.5 \%$ were technical and $23.5 \%$ were administrative.

The result from question two was quite astonishing. Fifty-one laboratories reported a total of 96,741 hours of searching for information during the previous 12 months. This is an average search time of 1,897 hours per laboratory, or about 95 man-hours per week per laboratory. This no doubt reflects the predominance of replies from the larger and presumably more highly organized laboratories; probably those in the upper portion of the distribution of standards laboratory population noted by Mr. Hunter. It is partly to reduce this sort of disorganized activity that several members of our Information Committee have been working on the information retrieval problem. Many engineers and scientists tend to look upon information retrieval as one of those activities that are just part of the nature of things, like breathing. However, if you find yourself sinking in the sea of technical information, perhaps you need to learn a new breathing technique. Wilbur Anson, here at the Boulder Laboratories, and other members of the Information Committee will present some suggestions tomorrow on how to hold your head above this flood of technical and administrative information.

Question number three asked NCSL members to rank six common technical needs in order of urgency to them; the result appears in figure 2. The numbers at the right are the summations of 7 minus $R$, where $R$ was the rank order from 1 through 6 given to each question by each respondent.

\section{TECHNICAL NEEDS}

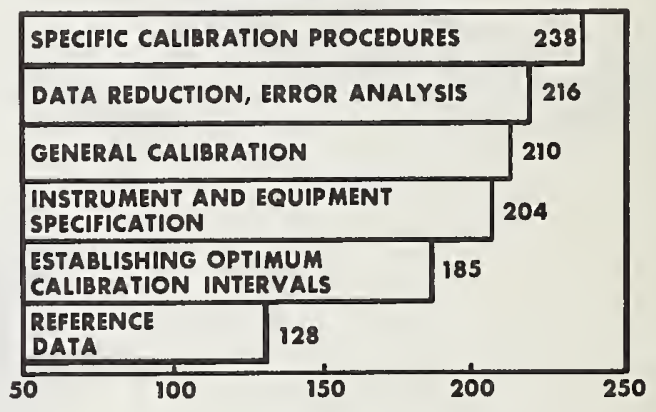

Figure 2

Obviously the development and availability of specific calibration procedures leads all other problem areas in weighted response points. Fortunately the NCSL Calibration Procedures Committee (C-6) under the chairmanship of Don DeLauer was well along with the establishment of the NCSL Calibration Procedures Library at Vandenburgh Air Force Base at the time this questionnaire went the rounds. The Calibration Procedures Committee will be reporting to us today on the 
extent to which this first-ranking problem has been resolved.

The second-ranking problem area, data reduction and error analysis, became the basis of the two projects mentioned previously by our chairman. Project number 2, the panel discussion on error analysis, was an effort to get a reaction from some of the leaders in the data analysis field on this subject. Project number three, our Information Committee bibliography on measurement statistics, was developed in an effort to provide basic information which appears to be lacking, or at least not yet assimilated by the standards laboratory fraternity.

Of course, the six problems listed were those that the Information Committee considered important at the time. In order to be democratic about this whole thing, Section 4 of the questionnaire invited respondents to list additional technical needs. Only 15 did so, and 8 of the 15 gave Personnel Training as the further technical need. One or two votes each were given to semiconductor information, bibliography of calibration articles, recommended standards by name and model number, and information on available storage and information systems.

The six-part question on administrative problems was analyzed in the same maner as the one on technical problems. As you will note from figure 3, Record Keeping and Property Control was only a slightly more urgent area than Laboratory Organization and Policy Practices. Of course, all six of these problem areas have technical aspects, but they happen to be the sort of thing that laboratory administrators have to deal with, especially when setting up new laboratory facilities. Notice that information on National Bureau of Standards Capabilities and Services is well down the list of needs. I am sure that this reflects the excellent information services of the NBS, such as MP 262 and the new editions of SP 250 and SP 260, as well as the many notices in periodicals and elsewhere that provide up-to-date information. At this time the Information Committee cannot claim to have contributed anything of value to the solution of these administrative problems.

As before, the list of six common administrative problems was supplemented by a free-for-all invi-

\section{ADMINISTRATIVE PROBLEMS}

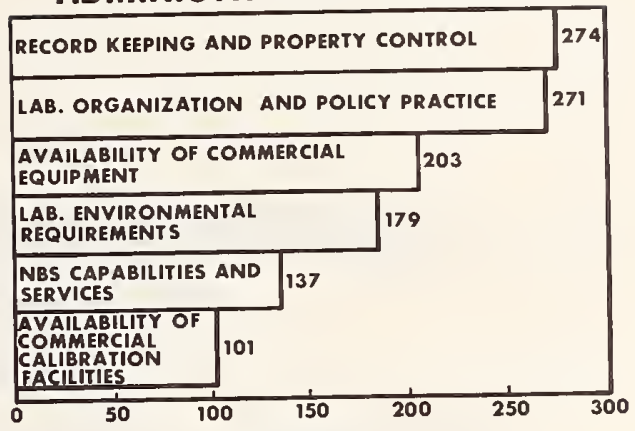

Figure 3

tation to list additional administrative needs. Eight out of 15 respondents listed Education of Corporate Management. This, of course, is basic to the very existence of standards laboratories. Other problems mentioned were budget systems, history systems, labor unions, selection and training, justification, and workload control.

I believe that the best approach, by far, to most of these problem areas would be to encourage more interchange of experience between NCSL member laboratories. I recommend this approach to the 1969 Information Committee and to such other existing committees as Recommended Practices (A-9), Work Load Control (B-1), and National Requirements $(\mathrm{A}-8)$.

In closing, I wish to say that the statistical data and comments generated by this questionnaire have given our Information Committee a sense of direction in planning our future activities. Member Delegates who invested time and thought in their answers to the questionnaire have served the National Conference well and in doing so have, of course, served themselves and their companies. We wish to thank each and every one of them, and to urge the other 150 members to make their information needs known to the Information Committee. One way to do this is to get a copy of the questionnaire from the NCSL secretariat and fill it out! 


\title{
RECOMMENDED PRACTICES COMMITTEE A-9
}

\author{
NCSL Vice-Chairman 0. L. Linebrink
}

\section{W. R. Holmes}

Quality Assurance Dept., Ingalls Shipbuilding Company, Pascagoula, Mississippi 39567

The first tentative RP "A Format for the Preparation of Recommended Practices" is nearly ready for distribution. Several others are in various stages of review, including one on "Preparation of Calibration Procedures."

\section{STATISTICAL PROCEDURES COMMITTEE C-7 \\ NCSL Vice-Chairman 0. L. Linebrink \\ DeWayne B. Sharp \\ IBM Corporation, San Jose, California 95100}

This Committee has developed sessions at both the 1967 and 1968 Conferences of the Instrument Society of America. A Glossary of Definitions has been prepared and some special statistical procedures have been prepared for intercomparing standard cells. Active participants on the Committee are Joseph Cameron, Woodward Eicke, and Paul Pontius of NBS. Others involved are Norman Belecki of the Air Force, Heath Air Force Base, Ohio, and A. E. Warwich of IBM, San Jose, California. This Committee has as a goal the production of a standard procedure for handling calibration data.

\section{CALIBRATION PROCEDURES COMMITTEE C-6 \\ NCSL Vice-Chairman J. L. Hayes}

\section{A. R. Baughman}

U.S. Air Force Metrology \& Calibration Center Detachment, Vandenberg AFB, California 93437

Chairman C. D. Koop has announced that three proposals have been received for operation of the Library, but none of these is satisfactory. The Library is being closed to permit purging the procedures for technical content, and will thereafter he closed for six months, or until new arrangements for its transfer are completed. 


\title{
MEASUREMENT AGREEMENT COMPARISON COMMITTEE C-5
}

\author{
NCSL Vice-Chairman H. W. Lance \\ H. S. Ingraham, Jr.
}

RCA, Camden, New Jersey 08102

\section{COMMITTEE MEMBERSHIP}

H. S. Ingraham, Jr. (Chairman), RCA, Camden, N.J.

H. D. Barnhart, General Electric Co., Syracuse, N.Y.

J. S. Beers, Metrology Division, NBS, Washington, D.C.

J. M. Cameron, Statistical Engineering, NBS, Washington, D.C.

F. K. Harris, Institute of Basic Standards, NBS, Washington, D.C.

R. P. Hecklemann, Sperry Gyroscope Co., Great Neck, N.Y. W. B. McCallum, General Electric Co., Daytona Beach, Florida

S. C. Richardson, General Electric Co., Schenectady, N.Y. W. F. Snyder, Electronic Calibration Center, NBS, Boulder, Colorado

\section{Workshops}

Two workshop sessions were conducted during the period 1967 to 1968 . The first of these was held at the NEREM Conference in Boston on November 3, 1967 and conducted by Shel Richardson assisted by H. S. Ingraham. The second was held at the NCSL Workshop Conference in Anaheim, California on January 26, 1968 and conducted by H. S. Ingraham.

It was the primary objective of both of these workshops to derive guidance from the membership of NCSL (and other interested attendees) with regard to direction for the future program of the MAC Committee. The need for MAC programs, the values derived and the problems with past comparisons were discussed and a firm consensus received on continuation of the round-robin comparison program.

\section{Questionnaires}

Following the NEREM Workshop, a questionnaire was sent to all participants in the $1965-66$ MAC round robin, to derive much the same information that was discussed in the workshop sessions. Of 40 questionnaires set out, there were 20 returns, which confirmed the answers we obtained at the workshop session. The direction for the committee was definitive on the question of the MAC round-robin programs, and provided many improvements considered important by the membership.

\section{Workshop and Questionnaire Results}

Topics discussed in the workshop and the responses to the questionnaire provided the answers to several generalized questions. The values of the comparison and the reasons for participation were generally the same. Some of these factors were (1) evaluation of measurement capability; (2) comparison with other laboratories at the same level; (3) increased confidence in measurement capabilities and techniques; and (4) the location of problem areas which would otherwise have been unknown.

The last of these values, location of problem areas, seems to be the most important value of all, based on the emphasis which the majority placed on this factor. It was very apparent that the comparisons revealed deficiencies of measurement which were not previously recognized, and allowed for corrective action to be taken before real problems were generated.

The gripes about the program and the recommended improvements and changes were also very similar. These included such items as (1) faster data turnaround and feedback; $(2)$ better scheduling of route; (3) shorter routes; and (4) smaller packages.

There is no question that the timely feedback of data and the final comparative results is vital to the overall value of the program. Data which is 18 months to two years old is of little value in timely improvement of problem areas and even a year may be too long. Attempts will be made to accommodate the needed improvements and to obviate the gripes.

The question of major importance, regarding the continuation of the round-robin program, received an overwhelming vote to continue with the comparisons.

\section{Committee Meetings}

Armed with the results of the two workshops and the returns from the questionnaire, a meeting of the MAC Committee was conducted at NBS, Gaithersburg, Maryland on March 12, 1968, to 
formalize plans for the committee and the goals for 1968. The goals established for the committee were only three:

1. Reactivate the MAC round-robin program.

2. Prepare for the 1968 Standards Laboratory Conference.

3. Revise the operating practices for MAC programs for submission to the Recommended Practice Committee.

\section{Round-Robin Comparisons}

The results of the committee meeting with regard to the round-robin comparisons were as follows:

1. The number of participants in each route would be limited to ten $(10)$, with enough routes established to include all who desire to participate.

2. Route supervision will remain within the MAC Committee and members of the NCSL.

3. Participant coding, liaison, and data reduction and analysis will be coordinated by the NBS, including what is hoped to be an improved data feedback to participants.

A questionnaire has been sent to the full membership of the NCSL to obtain an indication of their interest in participating in the program, and to allow them to specify the area of participation. In addition, the questionnaire includes a list of special categories from which, if sufficient interest is shown, additional comparison packages may be generated. A minimum of ten members must show interest in the same special category for a package to be assembled and circulated.

\section{Other Activities}

The MAC Committee has under consideration two other techniques of Measurement Agreement Comparison, other than the current round-robin technique. When these have been more fully explored, either or both may be implemented on an exploratory evaluation basis to a limited number of volunteer laboratories.

In addition to these techniques, we are also preparing two revised Operating Practices for Measurement Agreement comparisons, one to fully document the current National Round-Robin Comparison and the other to provide a Recommended Practice for inter-company comparison programs. Upon completion these will be submitted to the Recommended Practices Committee for publication.

\section{A Look Ahead}

The primary emphasis of the Committee over the next few months will be on the round-robin program. It is hoped that this can be completed within six months time, and that by the 1970 Standards Laboratory Conference, we may have completed three round robins and have activated one or more improved techniques of comparison as well. 


\title{
PROCUREMENT REGULATIONS COMMITTEE B-7
}

\author{
NCSL Vice-Chairman H. W. Lance
}

\author{
F. J. Dyce
}

Martin-Marietta Corporation, Orlando, Florida 23800

COMMITTEe MeMbershIP

\begin{abstract}
Frank J. Dyce (Chairman), Martin-Marietta Corp., Orlando, Fla. 23800
Forrest C. Russell, NAA/Space \& Information Systems Division, Downey, Calif.

William B. McCollum, General Electric Company, Apollo Support, Daytona Beach, Fla. 32015
\end{abstract}

\section{Introduction}

This Committee was an outgrowth of the 1966 NCSL Conference, and its aim was to review and attempt revisions of the Government specifications which affect calibration and standards laboratories. The Committee was initially chaired by Bill Vandal of McDonnell Aircraft Corporation, St. Louis. He was followed by Forrest Russell of North American Aviation, Downey, California, from whom I received the chair in February 1968. I adopted the goal of striving toward one general specification covering standards laboratory requirements to meet Government regulations.

Committee presentations have been made at NCSL Workshops at the ISA Conference in New York, at the ISA Conference in Chicago, and at the NCSL Workshop in Anaheim, California (Reference: NCSL B-7 Committee Reports-Russell, $1966,1967,1968)$.

At the 1967 Workshop, Forrest Russell reported on the Committee's progress (Russell, 1967). Donald Ransom reviewed the NASA Apollo Metrology Requirements (Ransom, 1967), and I presented a paper on Subcontract or Calibration Program Requirements (Dyce, 1967). All of these papers were concerned with the basic drive of this Committee, which is to remove vagueness and duplication from the present specifications which control Government procurement.

\section{Current Effort}

The following progress report is a first step towards achieving our goal. It is a small step in that it covers only ten of the specifications which affect standards laboratories. It is only a committee compilation and therefore does not represent any government action or acceptance.

During the past year the Committee has assembled ten specifications which reference calibration operations. It was felt that if this compilation could be presented in a tabular format and made available to NCSI members it might prove useful. At the conclusion of this session we would be interested in hearing your comments on this document. However, regardless of value to you personally, it does represent a necessary step towards our final goal. In order to generate a document which contains all specification requirements, one must first know what the specification requirements are.

The document here described sets forth the specification requirements in the following 18 major categories of calibration work: 1.0, applicable specifications; 2.0 , Government audit; 3.0 , subcontractor calibration system; 4.0, system description; 5.0 calibration records; 6.0 , recall system; 7.0, labelling; 8.0 calibration procedures; 9.0 , reliability test equipment; 10.0 , traceability; 11.0 , standard certificates; 12.0 , environmental controls; 13.0 , state of the art ; 14.0 , calibration intervals; 15.0 , maintenance; 16.0 , storage ; 17.0 , personnel; and 18.0, evaluation. We considered specifications MIL-Q-9858A, MIL-C-45662, MIL_HBK 52, MIL-I-450607A, MIL-STD 120, MIL-I-45208A, MIL-STD 790C, NPC 200-2, NPC 200-3, and NHB 5300.2. If anyone in the audience has any other pertinent Government specifications which we did not consider, we would be grateful if you would bring them to our attention. In addition, if anyone has any binding industry contract specifications, we would appreciate obtaining copies of these also. As this Committee continues its work, it will survey industry for its non-government-enforced requirements, which to our understanding are based on the prime contractors' interpretations of the Government specifications.

The 18 categories selected by the Committee are intended to best group the parallel but conflicting specification requirements. Each major cate- 
gory is divided into subcategories; e.g., 14.0, Calibration Intervals Purpose, lists 14.1 Interval Basis; to 14.55 , Lengthening Intervals.

I show two pages from this document-those concerned with Calibration Interval Purpose. MIL-Q-9858A, MIL-I-45208, NPC 200-2, and NPC 200-3 state that "measuring and test devices shall be calibrated at established periods to assure continued accuracy." MIL-C-45662 and MIL Handbook 52 do not indicate a specific purpose for calibration intervals. MIL-I-45607A requires "periodic inspection for continued accuracy" and adds a requirement for "inspection prior to unserviceability." MIL-STD 120 states that "gages must be rechecked to assure they do not accept defective or reject acceptable material," and NASA Handbook 5300.2 adds the requirement that "calibration intervals provide the required confidence level of the equipment."

This is an example of a category which is covered by most of the specifications. We shall see categories that appear in only one specification and note that there is no one specification that has all the requirements, and this points out the ridiculous state of affairs in which our calibration is controlled by ten different documents. What is even more of a problem is as shown in Category 3.0, Subcontraictor Calibration System. As subcontractors we are liable for audit of all the requirements of each specification that applies to us. It is conceivable that we could pass an audit to one specification one day, and fail an audit to another specification another day. One often wonders in this business why we are so often audited. It is no wonder when one considers the number of documents involved, as well as the different prime contractors' interpretations of these documents.

As I have indicated, this document is a worksheet to be used to generate a composite specification including all these requirements. We feel it is a useful document, as it permits checking your standards laboratory organization against all existing specifications.

How often have you been asked: What is the specification requirement for accuracy ratio? In what specification is it located? Is that a binding specification on your contract? When I was asked that question, I had to pull out my ten specifications and start leafing through them to find the right paragraph in each one. Now, with this document I can look under the category for accuracy ratio and locate the specifications which have accuracy ratio requirements. So, even though this is not a binding document, it does serve as an index. If you are required to reference the official text, the applicable paragraph numbers are given for each specification.

\section{Conclusion}

Our Committee's accomplishments for the past year have been (1) to make our goals known to interested parties at various workshops throughout the country and (2) to generate a Government calibration specification sequential tabulation. This tabulation will be available pending any editing that results from this meeting, possibly through NCSL as an official document if approved; if not, limited copies may be obtained from my office. Our work for the next year will be to generate a composite specification from the above tabulation and to circulate it to NCSL members for comments.

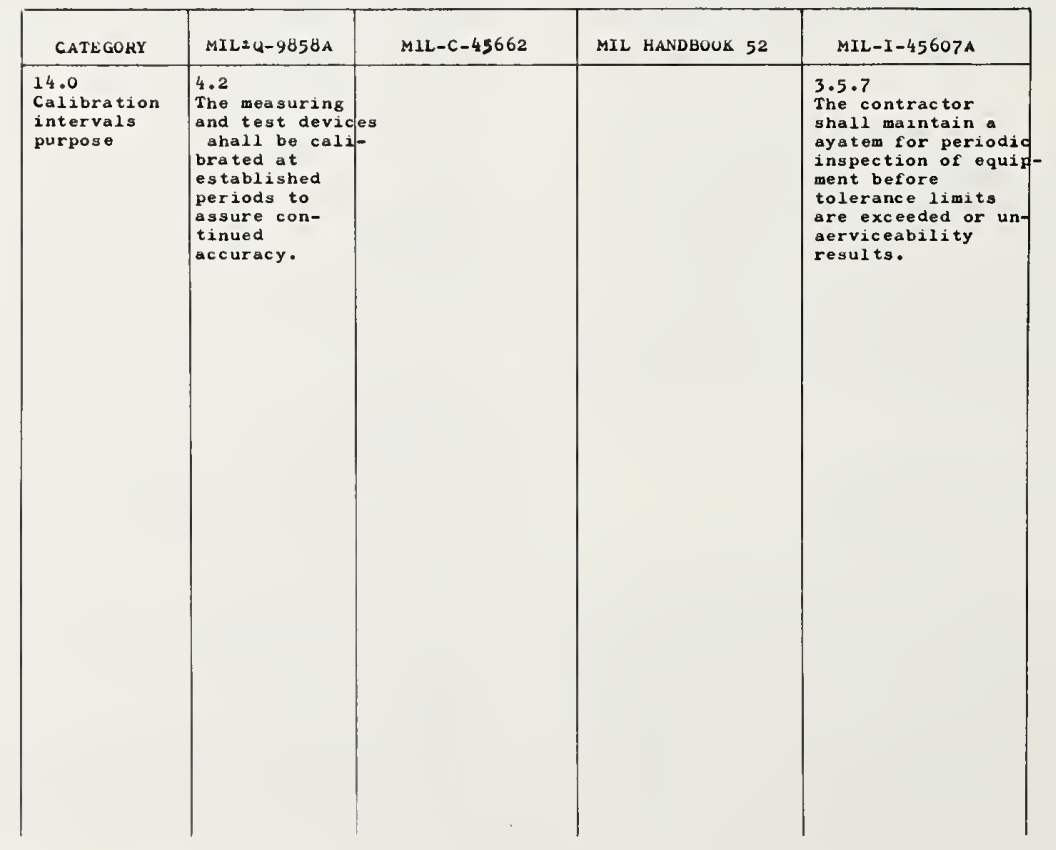




\begin{tabular}{|c|c|c|c|c|c|c|}
\hline CATEGORY & MIL-STD. 120 & $M I L-I-45200$ & MIL-STD.790C & NPC $200-2$ & NPC $200-3$ & NHB 5300.2 \\
\hline $\begin{array}{l}14.0 \\
\text { Celibration } \\
\text { intervala } \\
\text { purpoae }\end{array}$ & $\begin{array}{l}6.2 .5 \\
\text { nages in uaa } \\
\text { must be } \\
\text { chacked } \\
\text { periodically } \\
\text { 2nsure that } \\
\text { thay heve not } \\
\text { worn to the } \\
\text { extent that } \\
\text { thay accept } \\
\text { dafectiva } \\
\text { meterial or } \\
\text { reject accept- } \\
\text { abla meterial. } \\
6.2 .5 \\
\text { Periodic in- } \\
\text { epection of } \\
\text { gages should } \\
\text { be cerried on } \\
\text { in ell manu- } \\
\text { facturing } \\
\text { plents } \\
\text { aupplying } \\
\text { material to } \\
\text { the gervicas. }\end{array}$ & $\begin{array}{l}3.3 \\
\text { In order to } \\
\text { asaure con- } \\
\text { tinued } \\
\text { occurecy, } \\
\text { measuring } \\
\text { and testing } \\
\text { davicea end } \\
\text { toola ueed } \\
\text { for inspect } \\
\text { ion ahall } \\
\text { be cali- } \\
\text { breted at } \\
\text { establiehed } \\
\text { intervals. }\end{array}$ & & $\begin{array}{l}9.2 \\
\text { All inepection, } \\
\text { meesuring and test } \\
\text { ayuipment shell be } \\
\text { calibrated at } \\
\text { echeduled intervel } \\
9.2 .1 \\
\text { Toola which } \\
\text { meaaured dimansions } \\
\text { contoure or } \\
\text { locatione effecting } \\
\text { quelity cherecter- } \\
\text { igtieg ahell be } \\
\text { checked end ra- } \\
\text { callbrated period- } \\
\text { 2cally at pre- } \\
\text { determinad interval } \\
\text { to ensure continued } \\
\text { accurecy. } \\
\text { 9.5 } \\
\text { The contractor } \\
\text { ahall periodically } \\
\text { inapect, mantain } \\
\text { ond recalibrata all } \\
\text { inapection, } \\
\text { measuring and test } \\
\text { equipment. }\end{array}$ & $\begin{array}{l}3.9 \\
\text { At intarval } \\
\text { astablished } \\
\text { to ineure } \\
\text { continued } \\
\text { accuracy, } \\
\text { eech unit } \\
\text { of inapect- } \\
\text { ion, } \\
\text { meeauring } \\
\text { and test } \\
\text { equipment } \\
\text { ehall ba } \\
\text { calibrated. } \\
\text { 3.9.l } \\
\text { Toole which } \\
\text { maaaure } \\
\text { dimenaione, } \\
\text { contoure on } \\
\text { locatione } \\
\text { affecting } \\
\text { quelity } \\
\text { character- } \\
\text { istica, } \\
\text { ohll ba } \\
\text { initially } \\
\text { checked for } \\
\text { accuracy } \\
\text { prior to } \\
\text { use and ra- } \\
\text { calibrated } \\
\text { periodically } \\
\text { at pra- } \\
\text { determined } \\
\text { intervala } \\
\text { to ensure } \\
\text { continued } \\
\text { accuracy. }\end{array}$ & 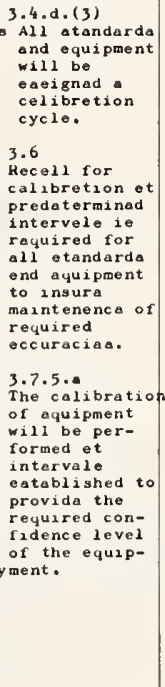 \\
\hline
\end{tabular}

After the incorporation of comments, we will solicit Government action.

\section{Bibliography}

Dyce, F. J., Subcontractor Calibration Specification Problems, presented at the ISA Annual Conference, Chicago, Illinois, September 1967.
Ransom, D. R., Apollo Metrology Requirements, presented at the ISA Annual Conference, Chicago, Illinois, September 1967.

Russell, F. C., The Accuracy Ratio Problem, presented at NCSL Conference, Gaithersburg, Maryland, May 1966. Russell, F. C., NCSL B-7 Committee Report, presented at NCSL Conference, Chicago, Illinois, September 1967.

Russell, F. C., NCSL B-7 Committee Report, presented at NCSL Workshop, Anaheim, California, January 1968. 


\title{
WORKLOAD CONTROL COMMITTEE B-1
}

\author{
NCSL Vice-Chairman H. W. Lance \\ D. J. Greb \\ Lockheed Missiles and Space Company, Sunnyvale, California 94086 \\ COMMITTEE MEMBERSHIP (1967-1968)

\begin{abstract}
D. I. Hervig (Chairman), TREC Industries, Orlando, Florida
E. J. Arsenault, General Electric Re-Entry Systems, Philadelphia, Pa.

J. R. Myers, National Astro Laboratories, Pasadena, Calif.

C. L. Rudd, Lockheed Missiles and Space Co., Sunnyvale, Calif.

W. F. Snyder, NBS, Boulder, Colorado

J. E. Vondracek, General Dynamics/Convair, San Diego, Calif.

W. L. Bates, Navy Metrology Engineering Center, Pomona, Calif.

Hugh Durkin, General Electric, Philadelphia, Pa.
\end{abstract}

CommitTee MembershiP (1968-1969)

D. J. Greb (Chairman), Lockheed Missiles and Space Co., Sunnyvale, Calif.

K. W. Hedlund, Naval Air Station, San Diego, Calif.

H. C. Keith, Philco-Ford Aeronutronics, Newport Beach, Calif.

T. J. Rollins, North American Rockwell Autonetics, Anaheim, Calif.

This report is essentially that of the 1967-1968 Committee, since the 1968-1969 Committee was not fully constituted until June 1968.

In 1967, the Committee identified three major areas of responsibility as follows:

1. Calibration data collection and utilization.

2. Development of techniques to measure efficiency, effectiveness, and productivity of calibration laboratories and agencies.

3. Reduction of calibration laboratory costs.

Subcommittees were established for each of these responsibilities with the intent that, through specialization, the Committee could make more significant contributions. During the past year, subcommittee activities have been directed toward gathering data, information, and techniques employed throughout the country in each of the identified areas of responsibility.
In 1967, the Committee established two objectives for the ensuing year. First, they were to prepare a report for presentation at the Fourth NCSL Conference in Boulder in 1968. Second, they were to review all the information that had been accumulated with the intention of identifying laboratory practices which have been employed and have achieved a substantial amount of success. These practices in return would be submitted to the NCSL Conference to be considered for inclusion in the Recommended Practices for Standards Laboratories Manual. To obtain as much information as possible in a short period of time, a series of workshops were held in September 1967 in Chicago and in January 1968 in Anaheim, California. The results of these sessions are included as part of this report. Mr. Vondracek reported in January that the Recall System and Recall Periods were ready for Recommended Practices. 


\title{
ADJUSTING CALIBRATION INTERVALS
}

\author{
R. H. Johnson
}

\author{
Calibration Branch Head, Repair Division, Marine Corps Supply Center, Albany, Georgia 31704
}

To achieve satisfactory instrument reliability, either a fixed calibration interval must be established which is sufficiently short to insure recalibration of at least 85 percent or more of the population of a given test instrument prior to an out-of-tolerance condition, or a means must be developed to realistically adjust the calibration interval for each individual instrument. This paper describes a program for adjusting calibration intervals for individual test and measuring instruments which has been in use by the Marine Corps Supply Center, Albany, Georgia, for approximately three years. The program described has increased instrument reliability significantly and has proven to be especially helpful in the identification and evaluation of unstable and unreliable test and measuring instruments.

\section{Introduction}

The practice of utilizing fixed calibration intervals was considered quite effective for many years. Adjustment of calibration intervals was handled generally on an exception basis for a given family, group, or model of equipment and was effected only after the lengthy evaluation of various data, with the eventual establishment of a new calibration cycle for universal application within a given organization. This approach reportedly worked well for the "average" instrument-something we have found rather difficult to identify.

In recent years, however, considerable effort and discussion have been devoted to the subject of adjusting calibration intervals for individual instruments. Several organizations have developed and implemented programs for calibration recall adjustment for individual test and measuring instruments-an effort found necessary to substantially increase instrument reliability and simultaneously improve the effectiveness of their calibration programs. I would like to describe the system used at the Marine Corps Supply Center in Albany, Georgia, which is known as the Sliding Recall Program.

\section{Background}

First, it would seem appropriate to describe the circumstances which led us to recognize the need for adjusting calibration intervals. After approximately two years of operation, using a fixed calibration interval concept, we conducted a review of the condition upon receipt of test and measuring instruments scheduled for calibration. The results of this review indicated that generally about $50 \%$ of the instruments received each month for scheduled recalibration were found out of tolerance.

An evaluation of our overall program revealed that several improvements were necessary; however, the wide variance in the age of the instruments supported, the percent of utilization, and the environmental conditions to which instruments were subjected presented the biggest problem. It was felt that the fixed interval established for each instrument type-in some cases only by association with a similar instrument in a common family - was not effectively satisfying our requirements. We then proceeded to develop the Sliding Recall Program with the basic objective of recalibrating each individual instrument when such action was necessary to maintain in-tolerance operation. Guidelines were established to define the scope of the program.

First: Recall periods would range between 1 and 12 months and would be adjusted in one-month increments.

Second: The initial calibration interval would be the then current fixed interval. This would also be the starting point for new instruments introduced into the inventory.

Third: The detailed criteria to be developed for recall adjustments must consider previous calibration history and the timely receipt of instruments scheduled.

\section{Recall Adjustment Criteria}

The criteria for adjusting calibration recall periods are based on the three functional stages listed below. Application of these criteria is primarily determined by the date an instrument is received in relation to its calibration-due date: 16 days ahead, within \pm 15 days, or 16 days past.

\section{Inspection Requirements}

Each instrument is thoroughly tested and inspected to determine its operating status. Adjustment of power supply voltages, power levels, frequency response, etc., and/or other adjustments 
normally not made by the user are not made during this inspection to functionally operative instruments, because such adjustments could ultimately affect the validity of the evaluation of calibration results in stage 2 . Functionally inoperative instruments are further inspected prior to effecting repair, to determine if the trouble results from operator abuse, in which case the recall period is unchanged. If failure has resulted from normal operation, the recall period is unchanged.

\section{Evaluation of Calibration Results}

The proportion of out-of-tolerance measurements recorded during a calibration which is to be considered sufficient cause for adjustment of the recall period was arbitrarily established at 20 percent. Plans are being established to determine if a more realistic value can be identified. No change is made in the recall period if more than 20 percent out-of-tolerance measurements or a critical parameter or function is out at less than 16 days ahead or less than 16 days past. The period is decreased by one month if all critical parameters and functions and less than 20 percent of measurements are unsatisfactory.

\section{Evaluation of Calibration History}

An evaluation of the instrument's calibration history is a fairly straightforward review of available facts which have been recorded in a Kardex file.

In summary, recall periods are adjusted basically as follows: if:

1. The recall period is decreased by one month

a. The instrument is received because of operation failure within \pm 15 days of its calibrationdue date, or is found functionally inoperative upon receipt for scheduled calibration, and the failure is not considered a direct result of incorrect application, operator abuse, or tampering; or if

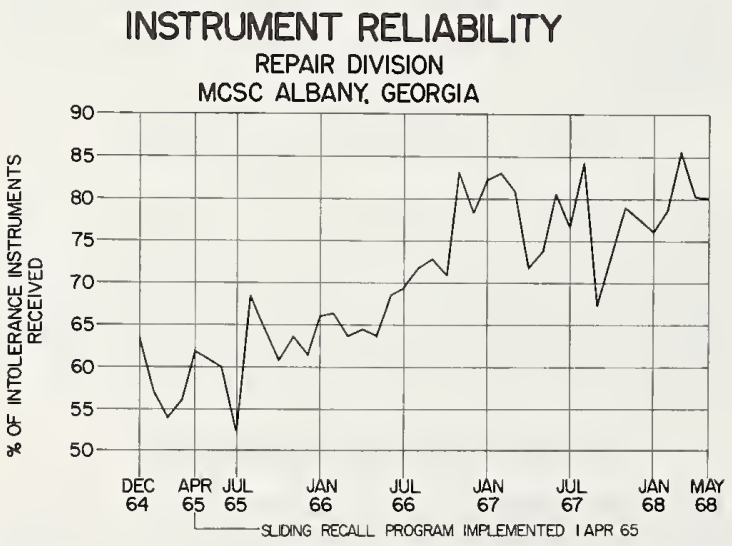

FIgURE 1. The three-year improvement in instrument reliability using the Sliding Recall Program. b. A critical parameter (one which would alter the accuracy of a primary function of the instrument) is out of tolerance, and the instrument was received no later than 15 days past the calibration due date; or if

c. 20 percent or more of the measurements made during a routine calibration are out of tolerance, and the instrument was received within plus or minus 15 days of its due date.

2. The recall period is extended one month if all of the measurements made during the calibration are found within tolerance and the instrument was received no earlier than 15 days prior to its calibration-due date and it was found in tolerance when last calibrated.

3. The recall period is not adjusted upon the first in-tolerance condition upon receipt for scheduled calibration, or if less than 20 percent of the measurements made during the calibration are found out of tolerance and no critical parameters are involved.

I have described this program on several occasions to groups of technical people. Generally, their first question is, "How do you handle the tremendous increase in workload created by shortening all the calibration intervals?" We don't actually shorten that many. Less than 18 percent of the instruments calibrated this fiscal year had calibration intervals decreased.

The second most frequently asked question is "How do you handle the scheduling problem? Odd calibration intervals must certainly make workload planning and scheduling problems." We use a Kardex file system with a flag to indicate the month calibration is due for each instrument and prepare our calibration schedule from this record. The workload planning problem is with us no matter what we do. Instrument failures, 1 through 12-month calibration intervals, and other variables have created an unpredictable workload in the past; therefore, calibration interval adjustments really present no new problems in that area.

\section{Progress}

Figure 1 illustrates the percent of in-tolerance instruments received each month for scheduled recalibration. As you can see, we have progressed somewhat since 1 April 1965 when the program was implemented, achieving a high of $85.6 \%$ in March 1968. Some time ago we identified nearly 80 unstable and unreliable instruments in the inventory that, regardless of the extent of the corrective action taken, would return for recalibration at 1 - or 2-month calibration interval in an out-oftolerance condition. These items represented a sizable workload and have hindered the indicated progress of the program in terms of overall reliability. Twenty-four of these items were recently replaced; replacements for an additional 33 are being procured, and several others are being phased out. In total, these actions will result in an esti- 


\section{SLIDING RECALL PROGRAM}

\section{REPAIR DIVISION \\ MCSC ALBANY. GEORGIA}

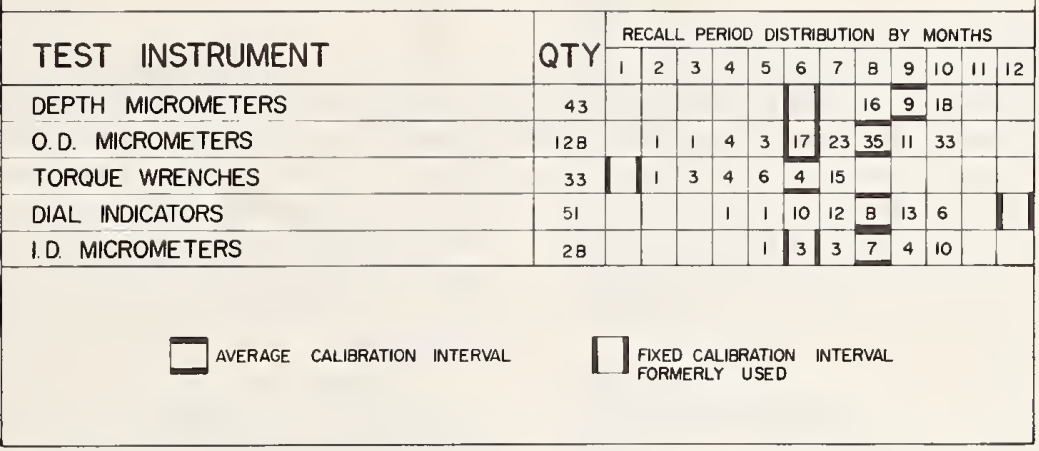

FIGURE 2. Recall period distribution for selected mechanical instruments.

mated annual saving of over 4,000 calibration manhours.

The identification of unstable and unreliable instruments, we feel, has been one of the most significant contributions of our program. It has focused our attention on calibration procedure problems, technical deficiencies in equipment, unrealistic calibration tolerances, detrimental environmental conditions, and many other problem areas which perhaps would have gone unnoticed.

\section{Effect on Workload}

Recall adjustments can have a significant effect on the overall calibration workload. In Fiscal 1967 , for example, 38.6 percent of the instruments processed required no adjustment to the calibra- tion interval while 17.4 percent required a reduction. During that year, 44 percent of the instruments serviced by our calibration laboratory under the Sliding Recall Program had their calibration periods extended. This is particularly significant since recall periods are increased only upon the second in-tolerance-upon-receipt condition. This reduction in workload was accomplished while there was an 11.8 percent increase in instrument reliability for that period.

Figures 2 and 3 illustrate the current distribution of recall periods for several of our highdensity instruments. The fixed recall period formerly used for each instrument is included to illustrate our deviation from that value. The distribution of recall period in several of the cases illustrated has had a sizable effect on overall work-

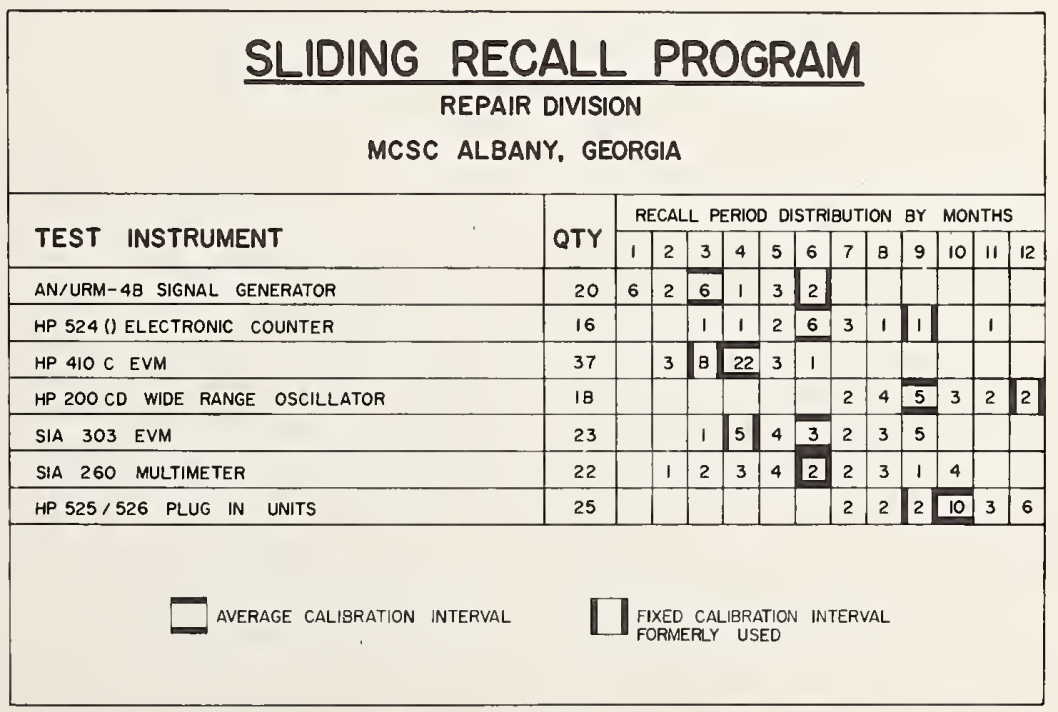

FIGURE 3. Recall period distribution for selected electronic instruments. 
load. Thirty-three torque wrenches, for example, if calibrated at the former fixed interval, represent 792 calibrations in 24 months. Current workload, with the distribution of recall periods as illustrated, represents 145 calibrations for the same period.

The overall 24-month workload for the mechanical instruments listed in Figure 2, if processed at the former fixed interval, represents 1,690 calibrations. Using the individual intervals indicated in Figure 2, the 283 instruments represent a 24 -month workload of 861 calibrations-a net savings of 825 calibrations. Along with this substantial decrease in workload, mechanical instrument reliability has steadily increased and has averaged 88.7 percent for the last 12 months, 6.1 percent above the prior 12 -month period.

The overall workload for electronic instruments listed in Figure 3 is now slightly higher, using the adjusted intervals in comparison to the former fixed ones. For selected items, however, there are substantial increases and decreases as illustrated below :
Calibrations Required in 24 months

AN/URM-48

HP 524D

HP $410 \mathrm{C}$

SIA 303
Increase or Decrease

\begin{tabular}{rrr} 
Fixed & Adjusted & \multicolumn{1}{c}{ Decrease } \\
Interval & Interval & \\
180 & 246 & +66 \\
32 & 60 & +28 \\
296 & 248 & -48 \\
138 & 91 & -47
\end{tabular}

Electronic instrument reliability for the past 12 months has averaged 69.14 percent-up 6 percent from the previous 12 -month period. The overall effect of individually adjusting calibration intervals in terms of total workload for the $4,000+$ calibrations performed this year under the Sliding Recall Program has not been determined; however, in selected areas the reduction has been measured.

In summary: A program for the realistic adjustment of calibration intervals such as I have described will increase instrument reliability. It will identify unstable and unreliable test and measuring instruments. In all probability, it will reduce your workload; it has for the Marine Corps. 
NCSL 68

\title{
SESSION 6: THE VALUE OF MEASUREMENT AGREEMENT COMPARISON
}

\author{
Chairman : H. S. Ingraham, Jr.
}

Radio Corporation of America, Camden, New Jersey 08102

\section{AN INTERNATIONAL COMPARISON OF POWER STANDARDS AT 3 GHz}

\author{
Paul A. Hudson and Glenn F. Engen
}

National Bureau of Standards, Boulder, Colo. 80302

Preliminary reseults are presented for an international comparison of power standards at $3 \mathrm{GHz}$ for which NBS was the pilot laboratory. Other participants included Japan, U.S.S.R., and Canada, each of which (and NBS) furnished transfer standards for use in the intercomparison. A fifth laboratory, German Office for Metrology and Product Testing (DAMW-East Berlin) also participated to the extent of making measurements on transfer standards submitted by others.

Measurement results obtained at each laboratory were sent to the International Bureau of Weights and Measures (Sévres, France) which sponsored the intercomparison and will issue the final report summarizing the results. 


\title{
SOME U.S./U.K. CALIBRATION LABORATORY MEASUREMENT COMPARISONS
}

\author{
F. E. Parr, B.Se (Eng.), M.I.E.E., M.I.Mech.E., F.I.E.R.E.
}

\begin{abstract}
Head of Naval Calibration Service, Portsmouth, Hampshire, U.K.
The paper lists the steps taken to ensure compatibility of measurement between the Polaris calibration facilities of the United States and the United Kingdom, and discusses the results of measurement audit exercises carried out between them.
\end{abstract}

\section{Introduction}

Following the 1963 Polaris Sales Agreement between the United Kingdom and the United States, three now Calibration Centres were set up by the Royal Navy. One Centre was at the shipyard where the first U.K. Polaris submarine was to be built, another at the base from which the submarines were to operate, and the third at the depot where the missiles were to be stored and tested. Each Centre was housed in a new building, constructed specially for the purpose, with temperature, humidity and dust control, and provided with new equipment of up-to-date design. Their calibration capabilities varied slightly, but in general extended over a wide range of electrical, electronic, mechanical, optical and physical quantities.

\section{Measurement Compatibility}

Particular emphasis was laid upon the need to establish measurement compatibility between the U.K. and the U.S. Calibration Centres. In planning to meet this requirement, it was agreed that the two countries would:

(a) Use the same calibration equipment (or its equivalent in specification and characteristics).

(b) Use the same calibration procedures.

(c) Record calibration data at identical checkpoints on each item of test equipment.

(d): Calibrate instruments at the same intervals of time.

(e) Carry out calibration within the same environments (or apply environmental corrections).

(f) Employ equally well-trained personnel operating under equally stringent management and technical directives.

(g) Use standards 4 to 10 times more accurate than the equipment being calibrated.

Another technical requirement was that the measurement capabilities of the new U.K. Centres should be derived from, and traceable back to, the national standards. Since these are held by the National Physical Laboratory whereas the U.S.
Centres derive their capabilities from the National Bureau of Standards, the ultimate references were different.

\section{Technical Audits}

It was deemed prudent, therefore, to verify that measurement compatibility had been achieved by conducting periodic technical audits of the U.K. Centres. Each audit consisted of making several measurements on a number of selected test items and comparing the results with measurements made on the same items in the U.S.

Now although intercomparisons of national standards have been carried out and relationships established at this top level, little has been done to determine by how much and within what limits measurements made at working level in different countries differ from one another. Certainly very little of such information has been published. This paper details some of the results of the audits, therefore, in the belief that they will be of interest, and discusses their significance.

\section{Audit Arrangements}

Responsibility for the technical oversight of the audits was delegated to the U.S. Navy Metrology Engineering Centre (M.E.C.), Pomona, California and to the U.K.'s Naval Calibration Service (N.C.S.), Portsmouth, Hampshire. These two authorities collaborated in planning and overseeing the exercises and in analysing and assessing the results.

On the basis that each audit was required to assess the whole range of any Centre's capability, the following measurement areas were selected for investigation-conductance, voltage (d.c. and a.c.), phase angle (electrical), attenuation, length, flatness, angular displacement, temperature, pressure and torque.

The choice of test items presented problems. Ideally they should all have been highly stable 
and very robust so that they could stand up to the rigours of being transported between the U.S. and the U.K. without any detectable change of values. In practice, it was necessary to compromise to some extent. The items ultimately used, though not always to the highest quality possible of attainment, were nevertheless selected as being significantly better than the "tolerance" of the measurements to be made on them. Factors which had to be taken into account were size and weight, as well as such down-to-earth matters as cost and availability for the period of the audit. In other words, the policy was to use the best items readily available, always provided that they were good enough for the job, rather than to develop or to purchase ideal ones.

M.E.C. provided the test items so that they could be measured first in the U.S., prior to dispatch to the U.K. Remeasurements were carried out in the U.S. after the audit so that any changes could be detected. In general, both these measurements were carried out to a higher order of accuracy than in the U.K. so that it would be fair to use them as a datum against which the U.K. results could be critically examined.

Instructions were provided describing the measurements to be made on each test item. These were not step-by-step instructions and no formal standardisation of procedures or techniques was attempted, each Calibration Centre being left to use its own normal methods. What the instructions did clearly state were the nature of each measurement to be made, the number of times a measurement was to be taken, the number of significant figures to which instruments were to be read, etc. An abstract from the general instructions for the audits reads as follows:

"Each standard is to be measured as per the specific instructions given at the end of this discussion. Each series of measurements is to be conducted three times unless otherwise stated. The mean value for the U.K. measurements should be the mean of nine values. (Three each day for three days). As many technicians as possible should be involved in the making of these measurements. Each technician should make independent measurements from the other technicians in his area of performance. If, for example, three technicians are available to perform the voltage measurements, each one should make one set of measurements on each of the three testing days without knowledge of the results of the other two technicians' work."

The specific instructions for one of the test items, a voltage standard, were as follows:

"Voltage measurements for this test should be made utilizing a typical calibration laboratory level voltage measurement system. The $\mathrm{K}-3$ potentiometric system should be used during this audit. Upon completion of the audit measurements, a more sophisticated voltage measurement system may be employed for verification of results, if desired. The K-3 data are not to be altered by other tests, unless jointly agreed upon by the M.E.C. and N.C.S. representatives.

"Turn the instrument on and allow it to warm up until the output stabilizes (rate of change less than 20 microvolts per hour at 1000 volt level). Measure the output at settings of 1,5 , and 10 volts. Leave instrument on and repeat readings on the hour until 3 complete tests have been run and then turn the instrument off. Record measurements to the nearest 10 ppm."

It will be noted that measurements were to be made on three or more consecutive days and that a number of technicians were required to take part in measuring each test item. The aim was to make the results approximate, as far as possible, to the work-load output of the Centre, by including the variability due to different day-to-day conditions and different operators (and incidentally minimising the risk of one technician invalidating all the results in a particular measurement area by making a gross error).

\section{Data Analysis Plan}

The analysis was designed to provide answers with the minimum of data processing. Each U.K. set of measurement was plotted against the initial U.S. values using the "Youden plot" method. This method requires the values of two nominally equal test items for each plot point, consequently two nominally equal test items were used throughout the audit. The plot-point is the intersection of the values of the difference between the U.S. value and the U.K. value for each item with the intersection of the U.S. values for the two test items forming the centre point $(\mathrm{O}, \mathrm{O})$ or origin of the graph. The units of the graph were chosen to conform with the units of measurement established for control, i.e. volt, lb-in., degree, arc second, etc.

Using this method, systematic errors between U.S. and U.K. measurements appear as displacements along a $45^{\circ}$ line through the centre of the graph, extending into the first or third quadrants. First quadrant points indicate that U.K. readings are higher than U.S. readings whereas third quadrant points indicate U.K. readings which are lower than U.S. readings. Displacement away from the $45^{\circ}$ line indicates some lack of precision.

Control limits are represented by a hexagon. The primary points of the hexagon lie along the $45^{\circ}$ line from the centre of the graph at the intersection of the allowable systematic error for each test item of the pair. Two lines parallel to the $45^{\circ}$ line are then drawn so that they intersect the axis at a distance from the centre equal to the assessed permissible variability. The intersection of these lines with the control limits for systematic error for each test piece generate the other four points of the hexagon. While an ellipse with its major axis along the $45^{\circ}$ line through the centre would be mathematically more correct, the hexagon shape 
TABLE 1.-Test items and measurement plan

\begin{tabular}{|c|c|c|c|c|c|}
\hline \multirow{2}{*}{$\begin{array}{l}\text { Measure- } \\
\text { ment }\end{array}$} & \multirow{2}{*}{ Test Item } & \multirow{2}{*}{ Description } & \multirow{2}{*}{ Nominal Measurement } & \multicolumn{2}{|c|}{ Control Limits } \\
\hline & & & & Systematic & Variability \\
\hline Conductance. & Conductance Box. & $\begin{array}{l}\text { Fixed wire resistors with } \\
\text { high quality switch. }\end{array}$ & $\begin{array}{l}10 \text { mhos } \\
10^{-4} \text { mhos } \\
10^{-8} \text { mhos }\end{array}$ & $\begin{array}{l}5 \times 10^{-4} \text { ohms } \\
0.7 \text { ohms } \\
2 \times 10^{8} \mathrm{ohms}\end{array}$ & $\begin{array}{l}2.5 \times 10^{-4} \mathrm{ohms} \\
0.35 \mathrm{ohms} \\
1 \times 10^{6} \mathrm{ohms}\end{array}$ \\
\hline d.c. Voltage. & Voltage Standard. & $\begin{array}{l}\text { Solid state voltage refer- } \\
\text { ence (low current). }\end{array}$ & $\begin{array}{l}1 \text { volt } \\
5 \text { volt } \\
10 \text { volt }\end{array}$ & $\begin{array}{l}50 \mu \mathrm{V} \\
500 \mu \mathrm{V} \\
1 \mathrm{mV}\end{array}$ & $\begin{array}{l}25 \mu \mathrm{V} \\
250 \mu \mathrm{V} \\
500 \mu \mathrm{V}\end{array}$ \\
\hline d.c. Voltage. & Millivoltmeter. & $\begin{array}{l}\text { Permanent magnet } \\
\text { moving coil, taut band } \\
\text { type. }\end{array}$ & $\begin{array}{l}25 \mathrm{mV} \\
30 \mathrm{mV} \\
50 \mathrm{mV} \\
60 \mathrm{mV} \\
100 \mathrm{mV}\end{array}$ & $\begin{array}{l}250 \mu \mathrm{V} \\
250 \mu \mathrm{V} \\
250 \mu \mathrm{V} \\
500 \mu \mathrm{V} \\
500 \mu \mathrm{V}\end{array}$ & $\begin{array}{l}125 \mu \mathrm{V} \\
125 \mu \mathrm{V} \\
125 \mu \mathrm{V} \\
250 \mu \mathrm{V} \\
250 \mu \mathrm{V}\end{array}$ \\
\hline a.c. Voltage. & $\begin{array}{l}\text { a.c./d.c. Con- } \\
\text { verter. }\end{array}$ & $\begin{array}{l}\text { Precision a.c. voltage } \\
\text { divider, fixed stable } \\
\text { amplifier and rectifier. }\end{array}$ & $\begin{array}{l}1 \text { volt, } 1 \mathrm{kHz} \\
10 \text { volt, } 1 \mathrm{kHz} \\
100 \text { volt, } 1 \mathrm{kHz} \\
10 \text { volt, } 50 \mathrm{~Hz} \\
10 \text { volt, } 10 \mathrm{kHz} \\
10 \text { volt, } 20 \mathrm{kHz}\end{array}$ & $\begin{array}{l}100 \mu \mathrm{V} \\
100 \mu \mathrm{V} \\
100 \mu \mathrm{V} \\
200 \mu \mathrm{V} \\
200 \mu \mathrm{V} \\
200 \mu \mathrm{V}\end{array}$ & $\begin{array}{l}50 \mu \mathrm{V} \\
50 \mu \mathrm{V} \\
50 \mu \mathrm{V} \\
100 \mu \mathrm{V} \\
100 \mu \mathrm{V} \\
100 \mu \mathrm{V}\end{array}$ \\
\hline a.c. Voltage. & $\begin{array}{l}\text { Electronic Volt- } \\
\text { meter. }\end{array}$ & $\begin{array}{l}\text { Transistorised voltmeter. } \\
\text { a.c. responding, r.m.s. } \\
\text { indicating, taut band } \\
\text { type. }\end{array}$ & $\begin{array}{l}0.94 \text { volt, } 1 \mathrm{kHz} \\
0.94 \text { volt, } 1 \mathrm{MHz} \\
0.94 \text { volt, } 2 \mathrm{MHz}\end{array}$ & $\begin{array}{l}10 \mathrm{mV} \\
10 \mathrm{mV} \\
10 \mathrm{mV}\end{array}$ & $\begin{array}{l}5 \mathrm{mV} \\
5 \mathrm{mV} \\
5 \mathrm{mV}\end{array}$ \\
\hline a.c. Voltage. & Amplifier. & $\begin{array}{l}\text { Dual channel plug-in } \\
\text { pre-amplifier for } \\
\text { oscilloscopes. }\end{array}$ & $\begin{array}{l}400: 1 \text { (ratio), } 1 \mathrm{kHz} \\
10: 1 \text { (ratio), } 1 \mathrm{kHz} \\
2: 1 \text { (ratio), } 1 \mathrm{kHz}\end{array}$ & $\begin{array}{l}4 \\
0.1 \\
0.02\end{array}$ & $\begin{array}{l}2 \\
0.05 \\
0.01\end{array}$ \\
\hline Phase Angle. & Phase Shifter. & $\begin{array}{l}\text { Resolver with precise } \\
\text { dial and associated } \\
\text { circuitry. }\end{array}$ & $\begin{array}{l}10^{\circ}, 500 \mathrm{~Hz} \\
30^{\circ}, 500 \mathrm{~Hz} \\
180^{\circ}, 500 \mathrm{~Hz}\end{array}$ & $\begin{array}{l}0.6^{\circ} \\
0.6^{\circ} \\
0.6^{\circ}\end{array}$ & $\begin{array}{l}0.3^{\circ} \\
0.3^{\circ} \\
0.3^{\circ}\end{array}$ \\
\hline Attenuation. & Attenuator. & $\begin{array}{l}\text { Fixed co-axial resistive } \\
\text { film. }\end{array}$ & $\begin{array}{l}30 \mathrm{~dB}, 400 \mathrm{MHz} \\
30 \mathrm{~dB}, 800 \mathrm{MHz} \\
30 \mathrm{~dB}, 1000 \mathrm{MHz}\end{array}$ & $\begin{array}{l}0.3 \mathrm{~dB} \\
0.3 \mathrm{~dB} \\
0.3 \mathrm{~dB}\end{array}$ & $\begin{array}{l}0.05 \mathrm{~dB} \\
0.05 \mathrm{~dB} \\
0.05 \mathrm{~dB}\end{array}$ \\
\hline Length. & End Standard. & $\begin{array}{l}1 \text { inch rod with hemi- } \\
\text { spherical ends. }\end{array}$ & 8 in. & $150 \mu$ in. & $100 \mu \mathrm{in}$. \\
\hline Length. & $\begin{array}{l}\text { Verneir Height } \\
\text { Gauge. }\end{array}$ & $\begin{array}{l}\text { Steel rule on mounting } \\
\text { base. }\end{array}$ & $\begin{array}{l}1 \text { in. } \\
1.5 \mathrm{in} . \\
1.75 \mathrm{in} . \\
2 \mathrm{in.} \\
8 \mathrm{in.} \\
12 \mathrm{in} .\end{array}$ & $\begin{array}{l}0.003 \text { in. } \\
0.003 \text { in. } \\
0.003 \text { in. } \\
0.003 \text { in. } \\
0.003 \text { in. } \\
0.003 \text { in. }\end{array}$ & $\begin{array}{l}0.001 \text { in. } \\
0.001 \text { in. } \\
0.001 \text { in. } \\
0.001 \text { in. } \\
0.001 \text { in. } \\
0.001 \text { in. }\end{array}$ \\
\hline Flatness. & $\begin{array}{l}\text { Adjustable Ref- } \\
\text { erence Mirror. }\end{array}$ & $\begin{array}{l}3.5 \text { in. pyrex mirror with } \\
1 / 4 \text { fringe flatness. }\end{array}$ & $<10 \mu$ in. & $6 \mu$ in. & $4 \mu \mathrm{in}$. \\
\hline $\begin{array}{l}\text { Angular Dis- } \\
\text { placement. }\end{array}$ & $\begin{array}{l}\text { Three-angle } \\
\text { Mirror. }\end{array}$ & $\begin{array}{l}3 \text { wrung mirrors, each } \\
\text { with } 2.5 \text { in. } x 0.5 \text { in. } \\
\text { faces, fused quartz. }\end{array}$ & 100 arc sec. & 1 arc sec. & 0.5 arc sec. \\
\hline $\begin{array}{l}\text { Angular } \\
\text { Displace- } \\
\text { ment. }\end{array}$ & Pentaprism. & $\begin{array}{l}\text { Crown glass ( } 4 \text { in. } \times 4 \\
\text { in. } x 2.5 \text { in.) with } \\
1.75 \text { in. } \times 1.875 \text { in. } \\
\text { aperture. }\end{array}$ & $90^{\circ}$ & 1.5 arc sec. & 0.5 arc sec. \\
\hline Temperature. & Thermometer. & $\begin{array}{l}\text { Total immersion liquid- } \\
\text { in-glass mercury } \\
\text { ASTM type. }\end{array}$ & $\begin{array}{l}120^{\circ} \mathrm{F} \\
135^{\circ} \mathrm{F} \\
150^{\circ} \mathrm{F} \\
165^{\circ} \mathrm{F}\end{array}$ & $\begin{array}{l}0.1^{\circ} \mathrm{F} \\
0.1^{\circ} \mathrm{F} \\
0.1^{\circ} \mathrm{F} \\
0.1^{\circ} \mathrm{F}\end{array}$ & 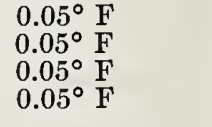 \\
\hline Temperature. & Thermometer. & As above. & $\begin{array}{l}400^{\circ} \mathrm{F} \\
425^{\circ} \mathrm{F} \\
460^{\circ} \mathrm{F} \\
500^{\circ} \mathrm{F}\end{array}$ & $\begin{array}{l}0.5^{\circ} \mathrm{F} \\
0.5^{\circ} \mathrm{F} \\
0.5^{\circ} \mathrm{F} \\
0.5^{\circ} \mathrm{F}\end{array}$ & $\begin{array}{ll}0.25^{\circ} & \mathrm{F} \\
0.25^{\circ} & \mathrm{F} \\
0.25^{\circ} & \mathrm{F} \\
0.25^{\circ} & \mathrm{F}\end{array}$ \\
\hline Temperature. & Thermocouple. & Copper Constantan. & $\begin{array}{l}100^{\circ} \mathrm{F} \\
200^{\circ} \mathrm{F} \\
300^{\circ} \mathrm{F} \\
400^{\circ} \mathrm{F} \\
500^{\circ} \mathrm{F}\end{array}$ & $\begin{array}{l}0.75^{\circ} \mathrm{F} \\
0.75^{\circ} \mathrm{F} \\
1.0^{\circ} \mathrm{F} \\
1.0^{\circ} \mathrm{F} \\
1.0^{\circ} \mathrm{F}\end{array}$ & $\begin{array}{l}0.38^{\circ} \mathrm{F} \\
0.38^{\circ} \mathrm{F} \\
0.5^{\circ} \mathrm{F} \\
0.5^{\circ} \mathrm{F} \\
0.5^{\circ} \mathrm{F}\end{array}$ \\
\hline
\end{tabular}


TABLE 1.-Test items and measurement plan

Measurement
Test Item
Description
Nominal Measurement
Control Limits

Systematic

Variability

\begin{tabular}{|c|c|c|c|c|c|}
\hline Pressure. & Pressure Actuator. & Indicating Switch. & $\begin{array}{l}8 \mathrm{psi} \\
16 \mathrm{psi} \\
24 \mathrm{psi}\end{array}$ & $\begin{array}{l}0.9 \mathrm{psi} \\
0.45 \mathrm{psi} \\
0.45 \mathrm{psi}\end{array}$ & $\begin{array}{l}0.9 \mathrm{psi} \\
0.45 \mathrm{psi} \\
0.45 \mathrm{psi}\end{array}$ \\
\hline Pressure. & Pressure Gauge. & $\begin{array}{l}\text { Bourdon tube, com- } \\
\text { pensated type. }\end{array}$ & $\begin{array}{l}2000 \mathrm{psi} \\
4000 \mathrm{psi} \\
6000 \mathrm{psi} \\
8000 \mathrm{psi}\end{array}$ & $\begin{array}{l}10 \mathrm{psi} \text { (up) } \\
10 \mathrm{psi} \text { (up) } \\
10 \mathrm{psi} \text { (up) } \\
10 \mathrm{psi} \text { (up) }\end{array}$ & $\begin{array}{l}10 \text { psi (up) } \\
10 \text { psi (up) } \\
10 \text { psi (up) } \\
10 \text { psi (up) }\end{array}$ \\
\hline Torque. & Torque Wrench. & Flexible beam indicator. & $900 \mathrm{lb}$-in. & 20 lb-in. & $10 \mathrm{lb}$-in. \\
\hline
\end{tabular}

was accepted because of its simplicity of construction.

The U.S. remeasurements have, in general, been plotted on the same graphs and in a similar manner to the U.K. measurements. In a few instances, however, the graph origins have been adjusted to a "best" value somewhere between the original and the remeasured value. The graphs clearly indicate where such an adjustment has been made.

\section{Control Limits}

The setting of the control limits involved a detailed appraisal of the equipment to be used and the conditions under which measurements were to be made. Each set of measurements on each pair of test items was given separate consideration.

The systematic error control limit took account of such things as possible calibration errors in the equipment utilised in the measurement systems. Where several instruments were used, the r.m.s. value of the several estimated maximum errors was computed and adopted as the limit.

The variability control limits took account of the short-term stability of both the test items and the equipment used in the measurement systems, possible reading errors, etc., and again the limit was computed as the r.m.s. value of the individual maximum errors of this type which might affect a particular set of measurements.

In general, the control limits were a practical compromise between, on the one hand, the desire to determine just how close an agreement could be obtained on measurements and, on the other hand, the recognition that agreement within certain limits was all that was needful for the U.K. Calibration Centres to perform their allotted roles.

Table 1 lists and describes a typical set of audit test items (as used for the very first audit exercise), indicates the specific values at which measurements were to be taken, and states the applicable control limits.

\section{First Audit}

The first technical audit was conducted at the Shipyard Calibration Centre in September 1965 and Youden plots of some of the results are shown in figures 1-8 (space considerations preclude reproduction of more than a small amount of the total data). Each figure is identified as to the test items concerned, control limits, significance of plot points, etc.

In most measurement areas-Conductance (see fig. 1); Voltage a.c. and d.c. (see fig. 2); Phase angle, electrical; Flatness; Temperature; and Pressure (see fig. 7)-compatibility was satisfactorily demonstrated to the required accuracy. Results generally showed little scatter as, for example in figures 1, 2, and 7, or acceptable scatter, with only one or two points falling outside the control limit envelope. One exception was the Thermocouples (see fig. 6) used in the temperature assessment, which showed high day-to-day variations but with very little daily scatter. This suggested that systematic erlors were introduced

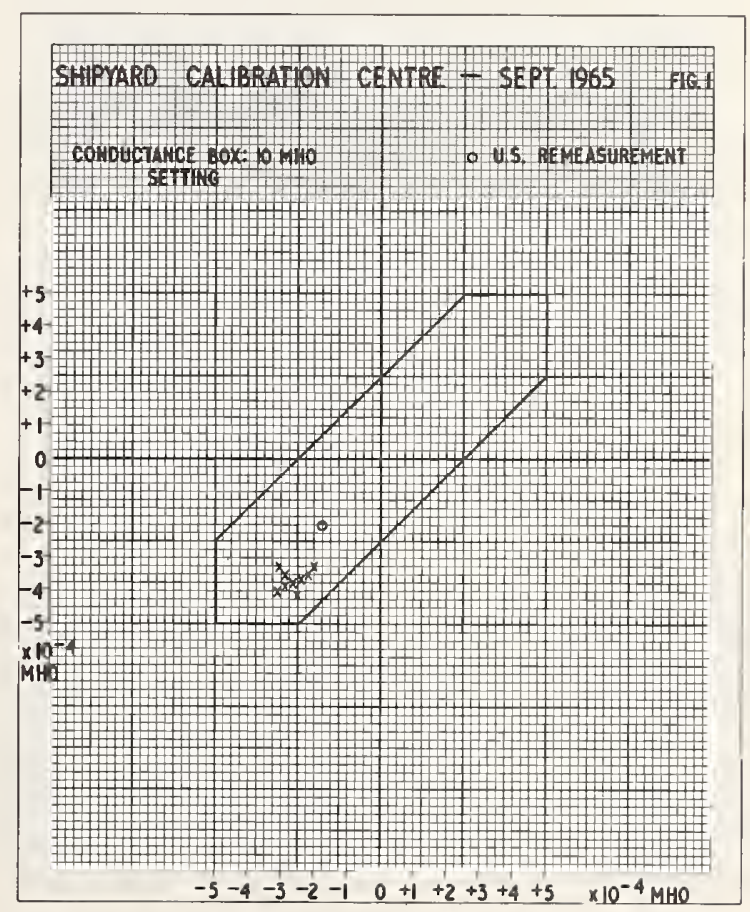



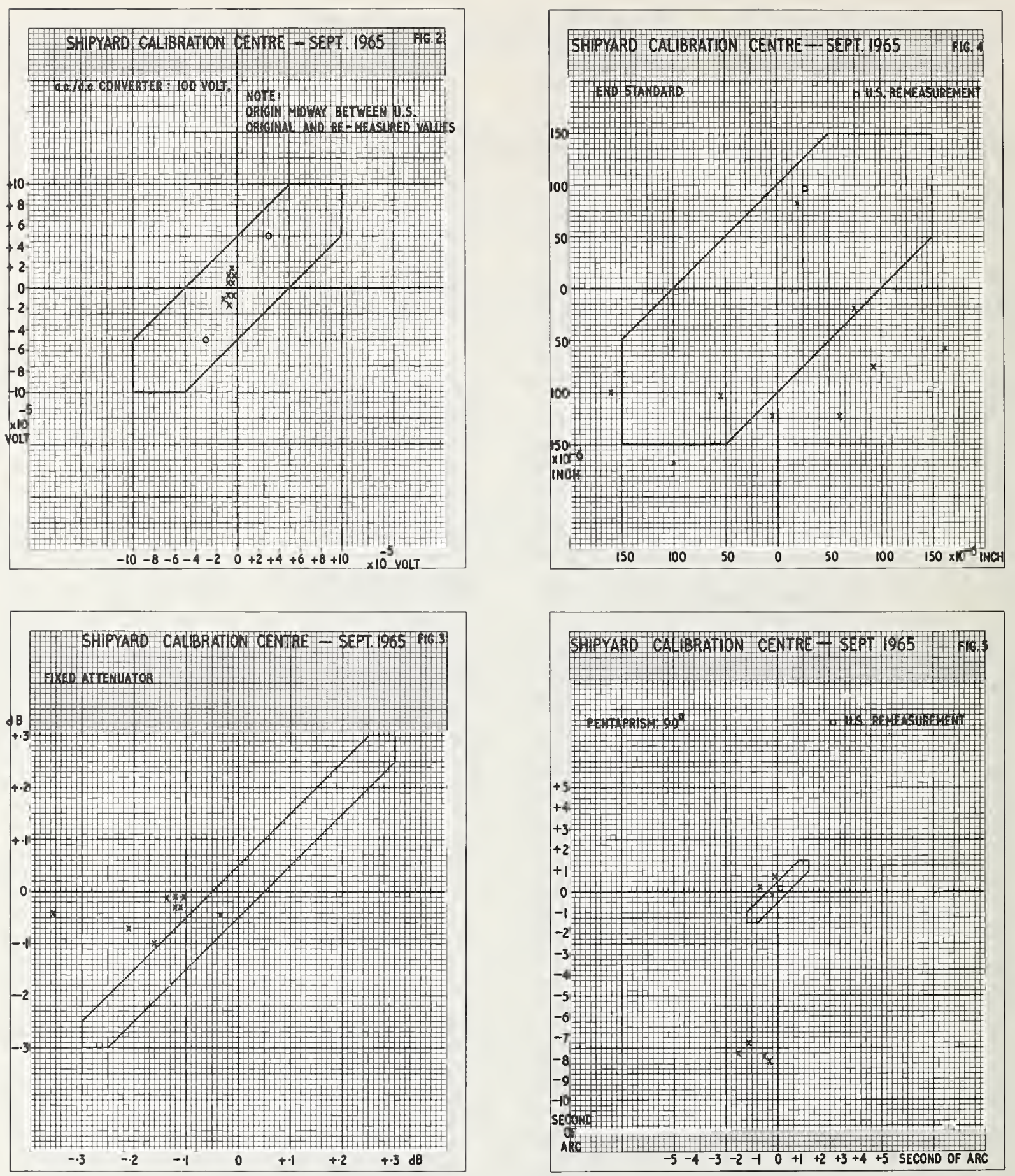

during the setting up of the equipment (standard temperature versus test couple temperature) or during the processing of the data.

Where the U.K. measurements were consistent but offset from the initial U.S. values, remeasurements in the U.S. almost always showed a similar trend, as in figure 1, and indeed the U.K. values fell neatly between the two U.S. values on occasion, as in figure 2.

This first audit was adjudged to have failed to demonstrate measurement compatibility on Attenuation, Length, Angular Displacement, and Torque.

As regards Attenuation, the scatter of results was excessive (see fig. 3). This was due to the inexperience of the technicians with the calibration equipment concerned, which was received only just in time for the audit and which was 

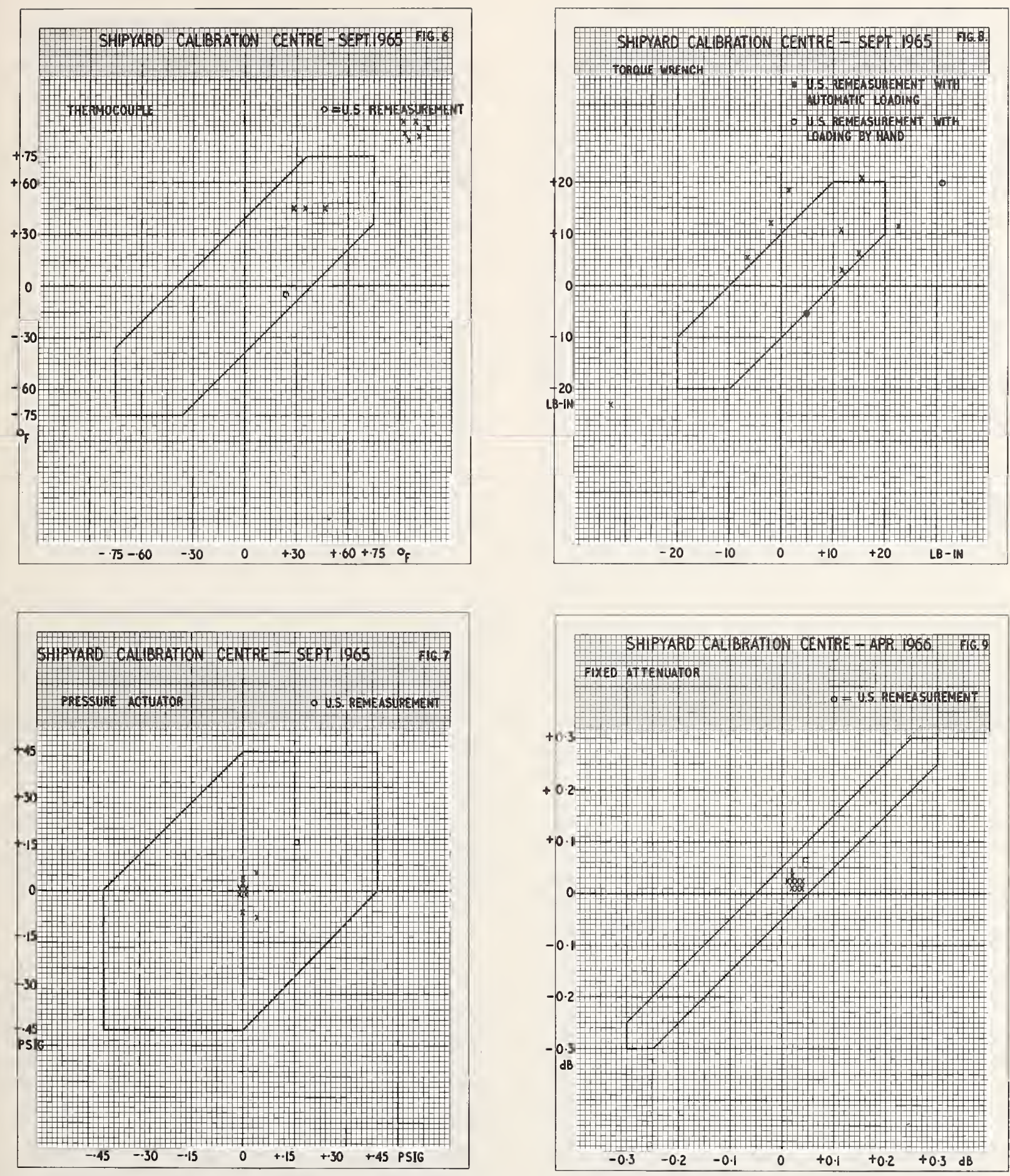

obviously unfamiliar to them. In fact, the results obtained on the third day of the audit were much better than on the first day and the plots clearly showed on-the-job learning.

The poor results on Length comparisons were attributable to the test items. The end standards had hemispherical ends, as had the U.K. measuring equipment, and accurate measurements under such conditions were virtually impossible. The plot (fig. 4) had a lot of scatter with very few points within the control limits. A pair of vernier height gauges which were also used as test items were found to be unstable.

Angular displacement results were varied, being good on three-angle mirrors but unacceptable on pentaprisms (see fig. 5). Observing how closely 
the distant pentaprism points were grouped together, it would appear that they were misplaced because of an error in procedure or calculation.

Considering Torque, the test items were very susceptible to the method of loading employed. The U.K. equipment did not provide a means of loading the wrenches mechanically and the excessive scatter of the results (see fig. 8) was largely due to this lack.

\section{Partial Re-Audit}

Because the results of the first audit exercise were inconclusive with respect to Attenuation, Length and Torque and unsatisfactory on the pentaprism (Angular Displacement), a second audit exercise was carried out at the Shipyard Calibration Centre some six months later, in these measurement areas only.

The results on the Attenuation test items (fig. 9) were excellent with very little scatter and a clear indication that the systematic error, if any, was very small indeed. The interesting point was that these good results were obtained using exactly the same test items as for the original audit. Clearly, in the intervening period the technicians had familiarised themselves with the particular measuring equipment involved.

The Length measurement comparison was also excellent and variability control was so good that the points had to be plotted on an expanded scale graph on which the control limits could not be seen (fig. 10).

On the Angle gauge block, compatibility of measurement was good (fig. 11) and, although

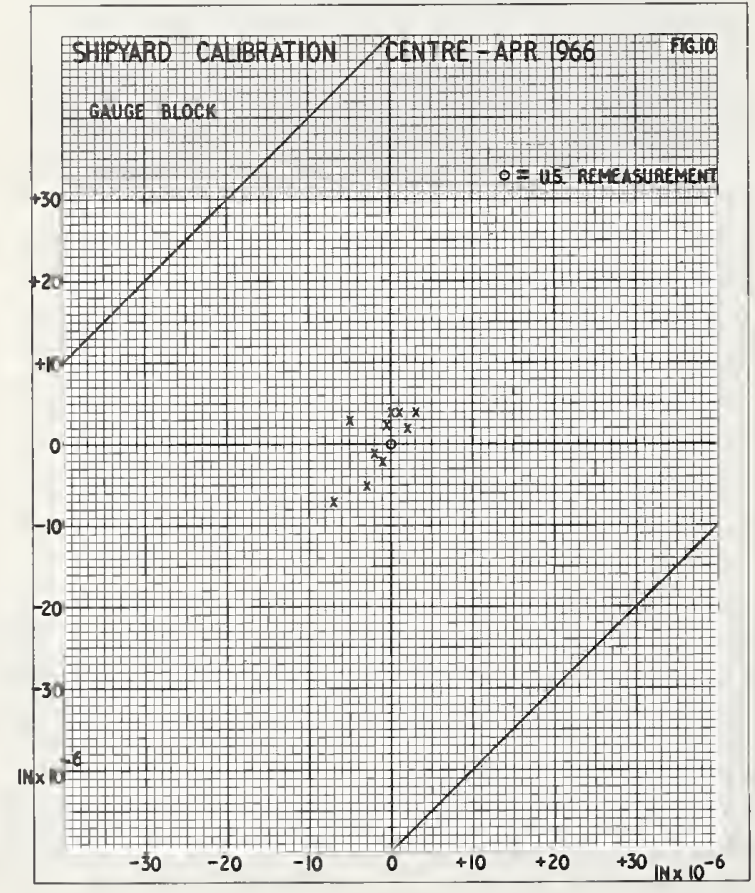

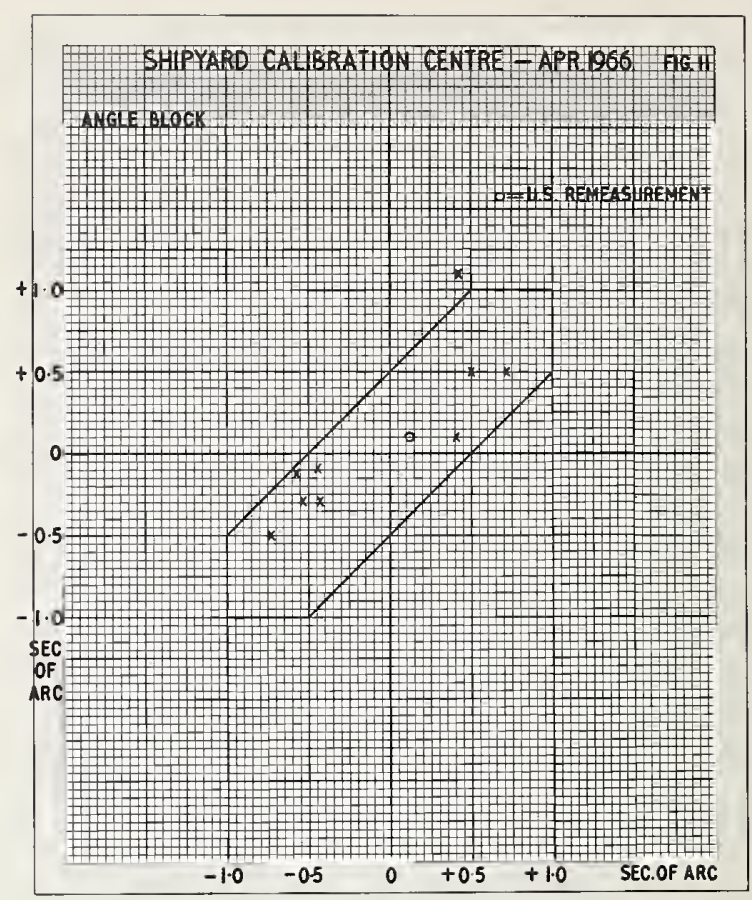

there was appreciable scatter, only one point fell outside the control limits set. It is of interest that the U.S. used an automatic measuring system with a known error of less than 0.3 arc second and repeatability of the order of 0.1 arc second.

The results obtained with the Torque test items were very good (fig. 12). There was very little scatter and the U.S. remeasurements indicated that the results were all that could be expected.

The outcome, therefore, was the establishment of compatibility between the U.S. and the U.K. Shipyard Calibration Centre over the whole range of measurements which the Centre was equipped to perform.

\section{Second Audit}

A year later the Missile Depot Calibration Centre was completed and it was, therefore, subjected to an audit exercise in March, 1967. This Centre's measurement capability was less than that of the Shipyard Centre but nevertheless ranged over Conductance, Current, Voltage, a.c. and d.c., Phase Angle (electrical), Attenuation, Frequency, Torque, Temperature and Pressure.

Measurement compatibility was successfully demonstrated in most of these areas. The results of one set of measurements on a pair of electronic voltmeters are shown in figure 13 . Note that both the points which fall outside the control limits are the work of one particular technician. The Youden plot is first-class for showing up the inexperience of any operator in this way.

Measurement compatibility was not proved as regards Torque, Temperature and Pressure. The 

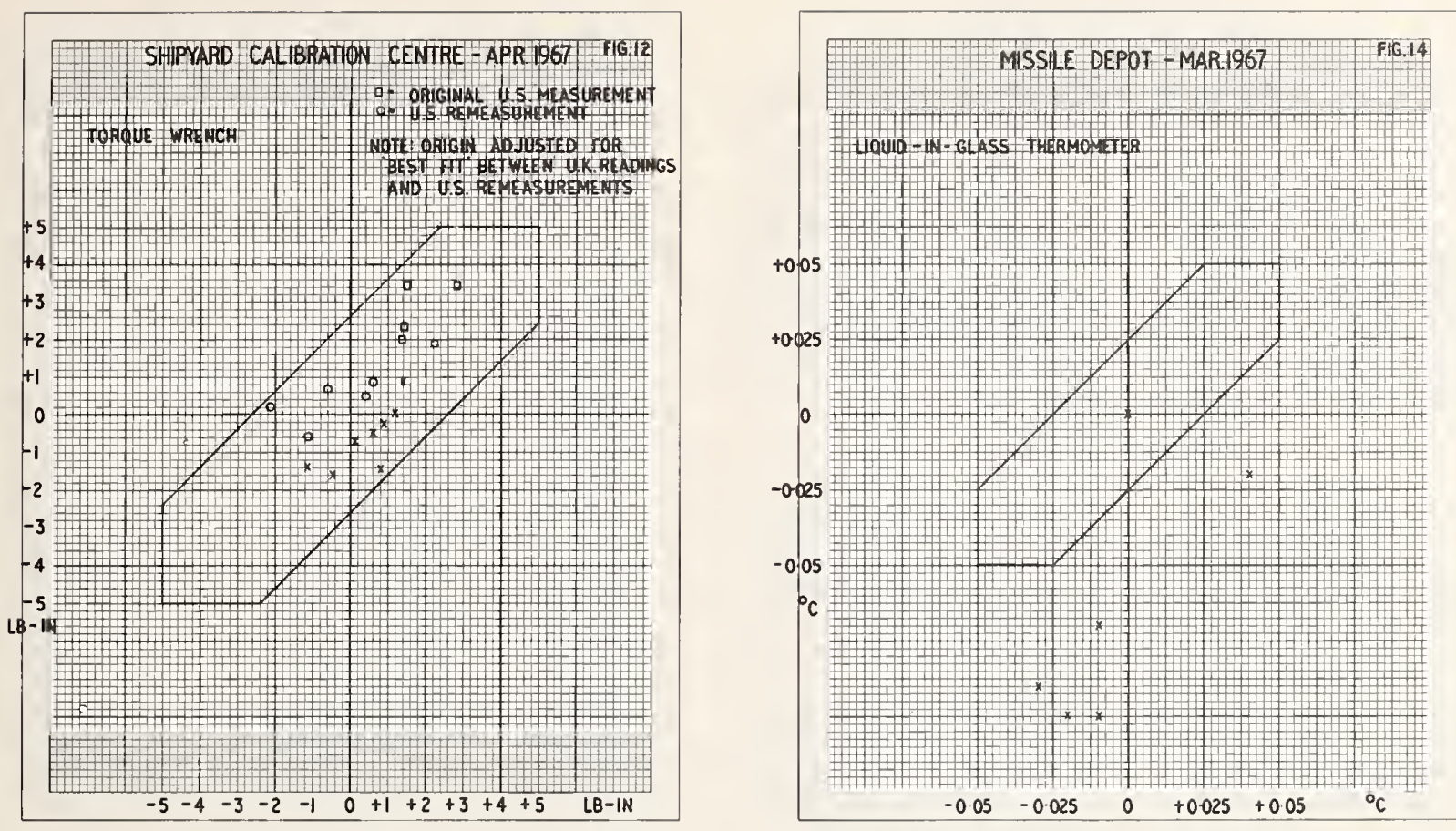

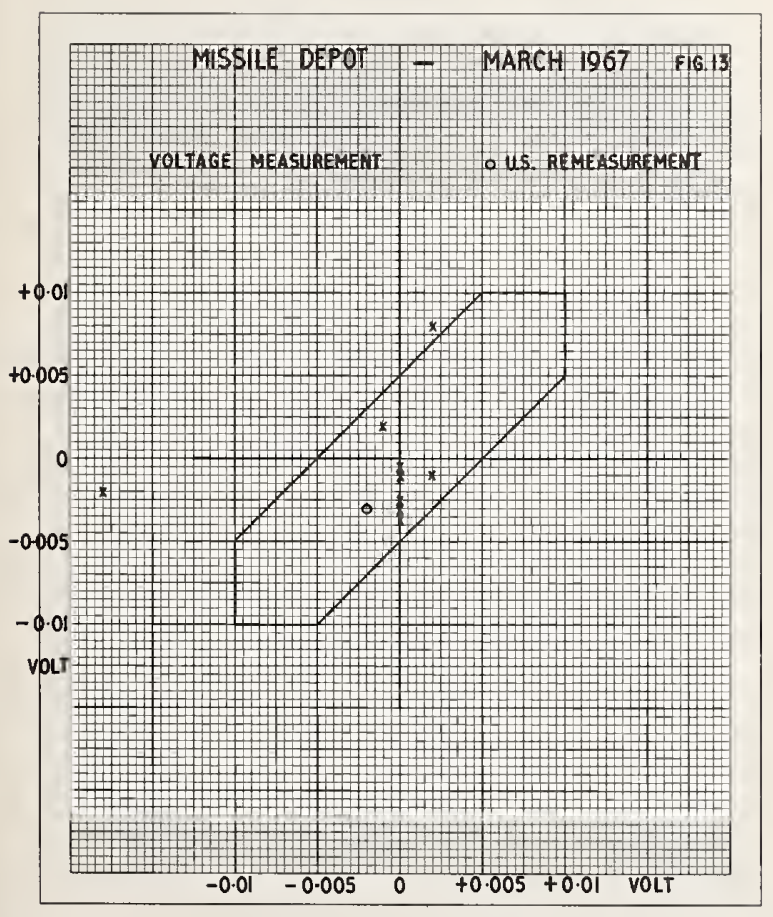

Depot had no proper Torque calibration equipment, only comparators which themselves required fairly frequent attention, and it was obviously necessary to remedy this deficiency. The scatter of the results on Temperature was very poor (see fig. 14), due to the bath having been received only

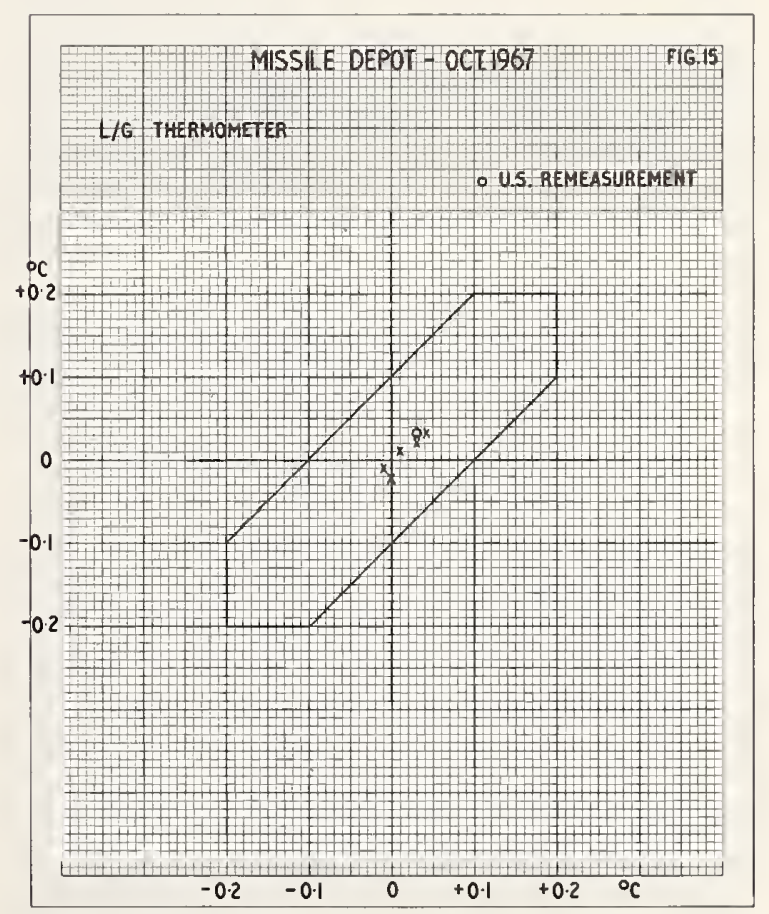

just prior to the audit so that the technicians had not had sufficient experience at operating it. The Pressure audit items (load cells) required absolute pressure measurements to be made and as the Centre was not equipped to do this, no audit was possible in the Pressure area. 


\section{Partial Re-Audit}

Here again, then, it was necessary to conduct a partial re-audit of the Missile Depot Calibration Centre some six months later in respect of Torque, Temperature and Pressure. This time, compatibility of measurement was successfully demonstrated in all three areas. Figure 15, for example, shows the excellent results achieved on a pair of liquid-in-glass thermometers. It is interesting to compare these results with those obtained at the same temperature and on similar test items during the initial audit of the Centre (see fig. 14).

\section{Third Audit}

When the Submarine Base Calibration Centre was completed and ready to become operational, yet another audit exercise was mounted, in October 1967. The test items used for this audit were also routed via the Shipyard Calibration Centre, just to check that all was well.

At the same time, some additional more accurate measurements were attempted by the Shipyard Calibration Centre in order that it could prove its capability to undertake certain higher grade work. The results were quite satisfactory. Figure 16 is the plot of measurements taken on a pair of current shunts; these. were obtained using equipment and techniques unfamiliar in practice to the technicians concerned. At first sight the Centre's results on a pair of Voltage Standards (see fig. 18) were suspect because of an apparent systematic error of some 10 microvolts but virtually the same error was indicated by the Submarine Base Calibration Centre (fig. 20) and substantiated by the Ministry

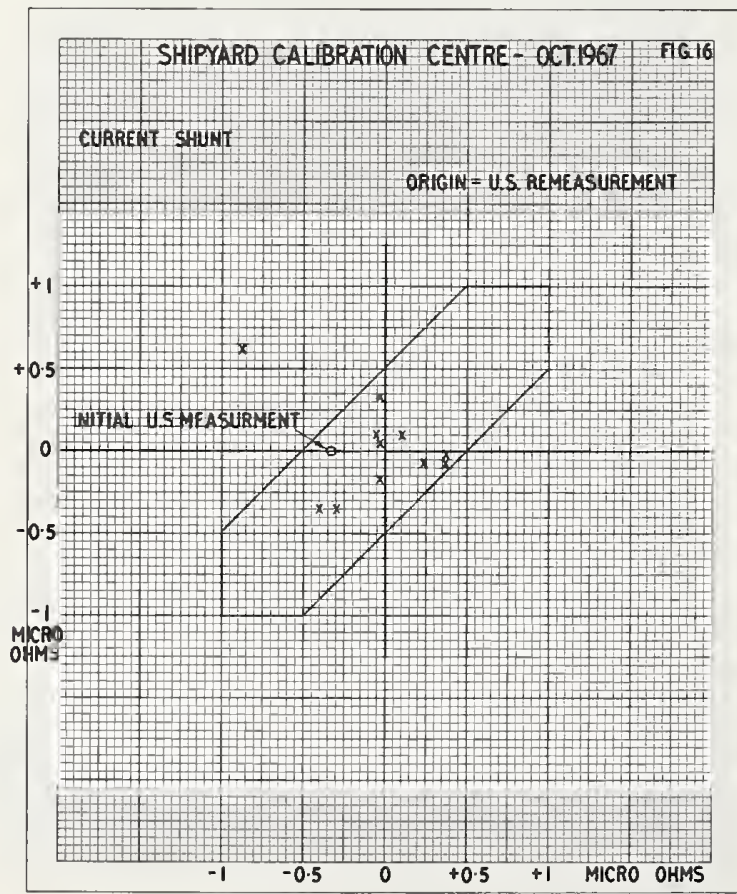

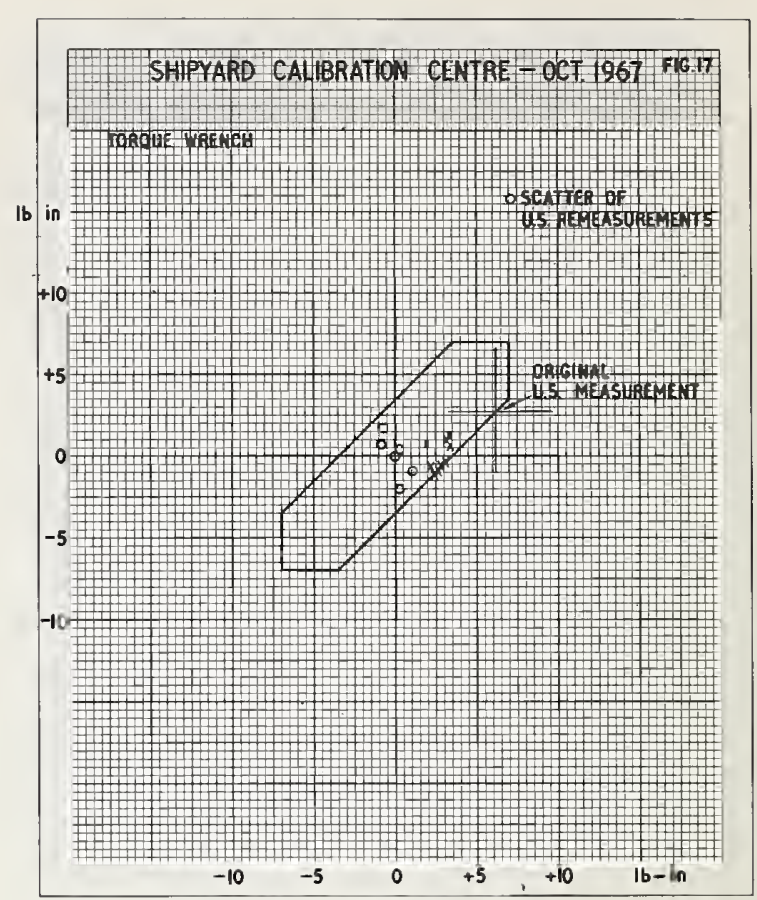

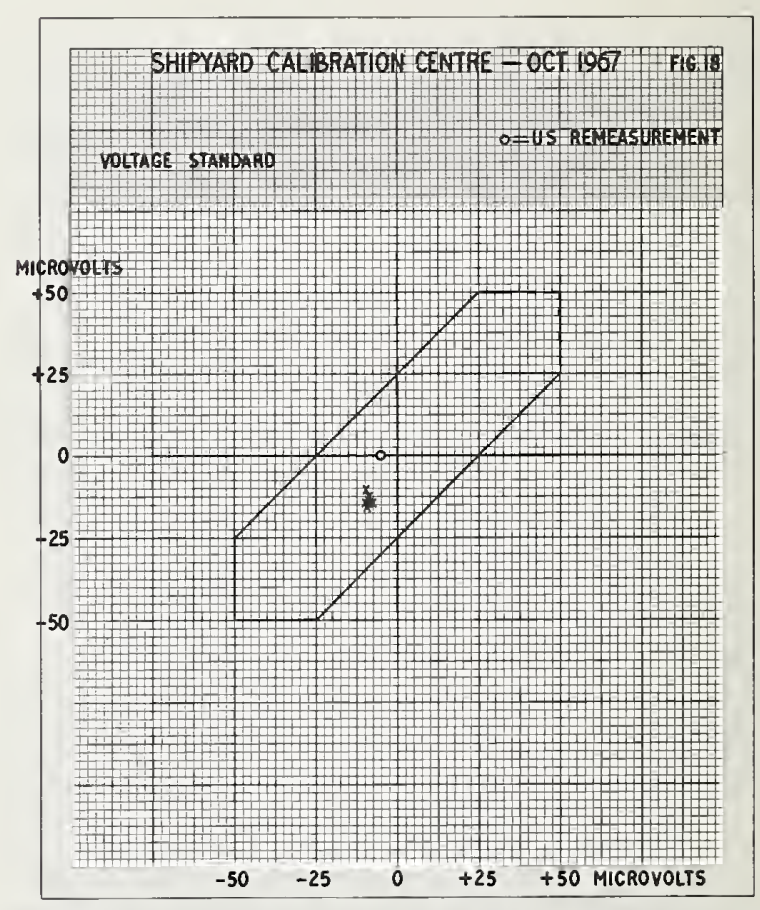

of Defence's prime standards laboratory, the Services Electrical Standards Centre at Bromley, Kent (fig. 19). In fact this apparent systematic error arises mainly from the difference between the banks of standard reference cells maintained by the N.P.L. in the U.K. and N.B.S. in the U.S., a difference which is well established.

The Submarine Base Calibration Centre demonstrated measurement compatibility over the full 


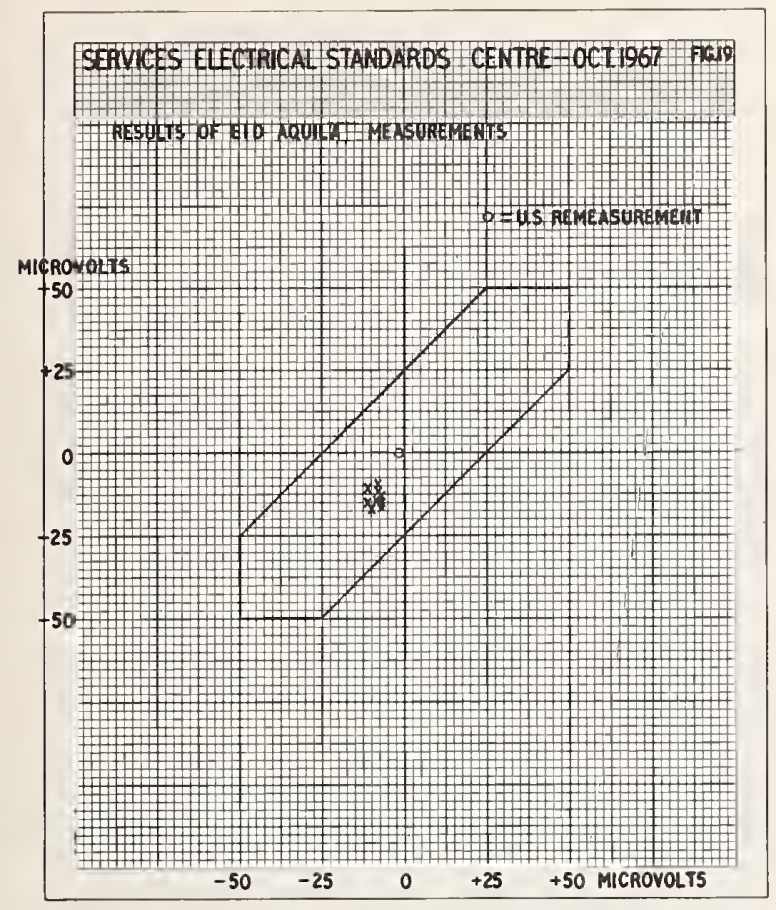

range of measurement areas. This achievement undoubtedly reflected the experience gained in organising and carrying out audits. The Shipyard Calibration Centre also successfully demonstrated measurement compatibility again, and the Youden plot (see fig. 17) for Torque, an area in which it is difficult to find stable, robust test items, underlines the improvement resulting from two years of operation.

\section{Comment}

The U.S./U.K. audit exercises were highly successful since measurement compatibility between the Naval Calibration facilities of two countries was established at the required accuracy level in all the measurement area selected for intercomparison. No significant systematic errors were detected apart from the known voltage difference. If any systematic errors exist, they are too small to need taking into account at the working level concerned.

The Youden plots were a relatively simple and yet a very sensitive means of displaying results and ruthlessly exposing any inexperience on the part of the technicians making the measurements, as well as any instability in the test items. The control limits must be set with great care, however, if full value is to be obtained from this method of presentation. Nevertheless, the method is a first-class means of appraising the results of measurement

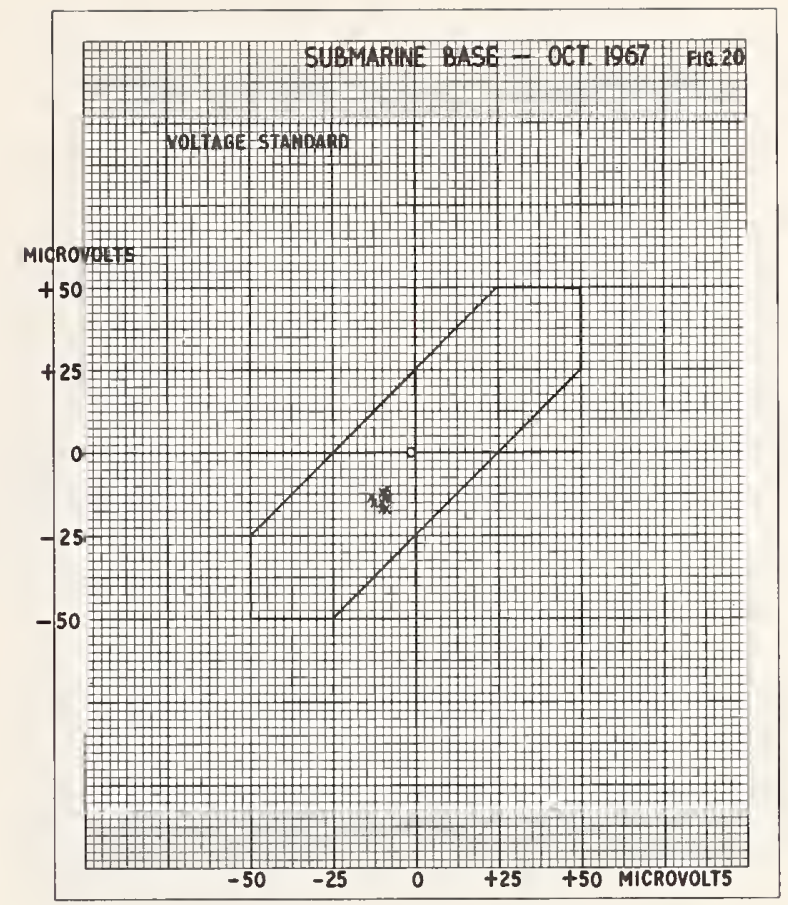

audits of the type described, and the workers in this field are much indebted to Dr. W. J. Youden, late of N.B.S., for it.

That the U.K. benefited the most from this programme is without question. But even the U.S. gained considerable experience which was of value - not least through the problems that made re-audits necessary on two occasions. Thus, for example, U.S. Navy methods of torque-tool loading were changed, improved test items for length and torque measurement were selected, and control limits were more validly established. The benefit of this knowledge is now being reflected in the U.S. Navy's internal audits.

\section{Acknowledgments}

The author thanks the Chief Polaris Executive, Ministry of Defence (Navy Department) for permission to publish this paper. Also the many technical personnel in both countries who made the measurements, processed the data and analyzed the results; in particular Mr. J. L. Hayes of the U.S. Navy's Metrology Engineering Center under whose direction the intercomparison programme was developed and whose personal comment has been much appreciated in the preparation of this paper. 


\title{
THE NCSL INTERLABORATORY COMPARISON OF 1965
}

\author{
H. L. Mason
}

Office of Measurement Services, Institute for Basic Standards, National Bureau of Standards, Washington, D.C. 20234

\begin{abstract}
From the data reported in the NCSL round-robin of 1965-66, Youden diagrams have been plotted for 20 types of standards which were circulated among 5 to 19 participating laboratories. The patterns generally show strong evidence of systematic errors in the measurements reported. Suggestions are offered for interpretation of the diagrams and improvement of future round-robins.
\end{abstract}

A measurement agreement comparison among 62 laboratories was planned in 1965 by a committee of NCSL headed by S. C. Richardson. The participants included 46 industrial and commercial laboratories, 3 military laboratories, and 11 NBS laboratories at Washington or Boulder. According to the 1967 edition of the NCSL Directory, most of them offer to service primary standards for one or more physical quantities. In number of personnel they ranged from 2 engineers and 5 technicians to 20 engineers and 140 technicians. The physical quantities measured included length, diameter, angle, mass, temperature, resistance, voltage, capacitance, attenuation, $\mathrm{Q}$, microwave frequency, and microwave power. Several pairs of nearly identical instruments for the measurements of these quantities were grouped in packages designated as Physical, LF Electrical, and HF Electrical. Each pair of instruments was calibrated at specified test points by NBS, sent out on a circuit (some through 5 laboratories and some through as many as 22) and then returned to NBS for another reference calibration, either once or twice during the circuit. No calibration procedures were specified, since the Committee believed it desirable to sample the usual practice of each laboratory.

A report of the result of each such measurement was forwarded to a single individual at NBS, who kept a confidential record of the code numbers identifying the individual participants. The accumulated results with the coded designations were then sent to one of four NCSL members acting as route supervisors, who analyzed the data and prepared the published tables and graphs [Proceedings, 1966].

The present paper reviews briefly the method of constructing a Youden diagram [Youden, 1959] and explains how the resulting plot can under certain circumstances provide a reasonable indication as to whether the extreme values shown result from random error or from systematic error. This leads to some suggestions as to how the next NCSL measurement agreement comparison, now in the planning stages, can be made to yield more meaningful results.

Let us examine, as a typical useful example, the Youden diagram shown as figure 1, for a pair of nearly identical coaxial attenuators of reference standard quality, rated at $50 \mathrm{~dB}$. Here and in the other examples shown, the data come from the 1965-66 measurement agreement comparison. However, the diagrams published in the NCSL 1966 Proceedings used the NBS average value as the zero datum from which measurement deviations of other laboratories were plotted, but the diagrams here use medians of all values as the zero datum, and attach no special distinction to the NBS points. The 18 sets of measurements reported for these $50 \mathrm{~dB}$ attenuators are tabulated in Appendix B. The median value is $49.83 \mathrm{~dB}$ for unit I and $50.12 \mathrm{~dB}$ for unit II. Horizontal and vertical axes have been drawn at these values, as shown by the respective scales, which have uniform and equal intervals. Experience with many such diagrams leads us to expect that points representing measurements by a number of laboratories on that same pair of standard instruments will fall into an oval cluster stretched out along a $45^{\circ}$ line drawn through the first and third quadrants. This pattern helps us to understand the nature of deviations from the median of the group. If every primary standards laboratory had identically-valued reference standards, used exactly the same measurement procedure, and had equally expert personnel exercising equal care, then every point for the group might be expected to fall closely around the median. However, these conditions are never fulfilled in practice, and errors of both random and systematic types may be expected to show up in the results. The Youden diagram enables us to see at a glance which type of error is the dominant one for this single pair of measurements, and which laboratories differ from the consensus of the group.

If errors were purely systematic, each of the two measurements of a pair made by any one 
laboratory would be biased in the same way. Thus all deviations from the median point would be either positive by about the same amount, or negative by about the same amount, so that points would lie closely along the $45^{\circ}$ line. If errors were the result of imprecision, the measurements of such a sample of two would show up as points falling away from this line, since the randomness is not likely to affect units I and II in the same amount.

Statistical theory (see Appendix B) provides a method for determining a circular region in which practically all the points may be expected to fall, if the measurements reported were influenced by random errors only, and not at all by systematic errors. For the $50-\mathrm{dB}$ pair of figure 1 , this "circle of reasonable randomness" includes only 7 laboratories; that is, only 7 of these laboratories can be regarded as being reasonably free from systematic errors. They do show some random errors (see fig. 1 and Appendix B) on the order of $\pm 0.05 \mathrm{~dB}$. For the entire 18, however, the systematic error indicated is ten times that, since the highest and lowest values shown are half a decibel apart, or about 1 percent of the nominal value. Perhaps this is adequate uniformity for the national measurement system of USA, but there is no doubt that it could be improved. Of course, the diagram tells us nothing whatever about accuracy. It only shows a lack of consensus among certain NCSL laboratories.

On the other hand, figure 1 is strong evidence that the lack of consensus is the result of systematic error on the part of some of the laboratories reporting. The 11 laboratories outside the randomness circle should examine their operation for systematic errors which might be affecting both measurements of the pair. One suspects an inadequate calibration procedure, a missing correction for temperature or humidity, an inexperienced technician, or a reference standard which is overdue for recalibration. To see whether these 11 show unreasonably large random errors, lines may be drawn tangent to the randomness circle and parallel to the $45^{\circ}$ line. Within this band, precision may be considered adequate for the twovalue sample. In figure 1 , the one laboratory outside this band should examine its operation for random errors affecting only one of the two measurements of the pair-say a slammed door, an overnight cooling off, a power failure, a telegram with bad news, or what not.

Figure 1 is a useful example, in that most of the plotted points cluster around the $45^{\circ}$ line as predicted. Let us now look at another example, the plot for the 1-gram standard pair, shown in figure 2. Here the 15 points do not form a cluster, nor do they follow the $45^{\circ}$ line through the median. Instead, they appear to scatter vertically! How shall we interpret this?

One possible explanation is that the basic assumption for Youden's two-sample test has been violated in this case. Note this quotation [Youden $1960]$ :

"Once it is accepted that differences in precision between laboratories can be forgotten ... the way is open for a revealing examination of the data."

In the data which yielded figure 2, can we forget differences in precision between laboratories? An examination of table 2 [Proceedings, 1966, p. $57]$ of the "estimated accuracies" reported by the participants shows that we cannot. Of the 15 laboratories, NBS estimated an uncertainty of 0.004 milligrams, 6 others estimated their uncertainty to be about 0.01 to $0.03 \mathrm{mg}, 3$ others estimated it to be between 0.1 to $0.2 \mathrm{mg}$, and 3 others estimated it as $10 \mathrm{mg}$ or larger. The total range is more than $3000: 1$, so the assumption of small differences of precision is hardly justified. For this reason figure 2 defies any meaningful interpretation.

For the $50 \mathrm{~dB}$ coax attenuators of figure 1 , the estimated uncertainty ranges only between 0.1 and $0.3 \mathrm{~dB}$, and the resulting plot apparently makes sense. In fact, it is this assumption regarding small differences of precision among laboratories that allows us to combine the readings and compute a standard deviation as in Appendix B.

As an example of a nearly circular Youden diagram, consider figure 3 for the $10-\mathrm{dB}$ coax attenuators. Here the randomness circle is extremely large, and we may deduce that for this case the random errors are larger than the systematic errors. Improvement may be effected, perhaps, through more precise specification of the calibration method or apparatus, which should reduce the magnitude of random errors. The resulting plot might then turn out to be clustered in a narrower band along the $45^{\circ}$ line. Some points might still lie at its upper and lower ends, indicating the necessity of examining ways to reduce the systematic errors. In practice, the need for prcision and accuracy in the calibration service will dictate at what stage we may be satisfied with this cycling process.

Figures 4 through 24 are additional Youden diagrams similarly computed from the NCSL data of 1965-66. Several are plotted for deviations from the median rather than for absolute values, but the interpretation remains the same. There are interesting differences between results for devices which are much alike; the cause is not evident. However, any laboratory which sent a report to the NCSL route supervisors can identify itself by noting the $(x, y)$ reading of its reported point as read from the scales marked on these plots, and can determine its position relative to the other participants.

In anticipating the next measurement agreement comparison planned by NCSL, I offer these recommendations:

(1) Any laboratory lying outside a circle of reasonable randomness in 1965 should make a serious examination of its reference standards, its cali- 
brating equipment, and its calibration techniques, before participating.

(2) A thoroughly documented calibration procedure, generally approved by the participants, should be adopted and followed carefully.

(3) The reported results should be analyzed as separate groups, each including only those laboratories which claim a similar level of estimated uncertainty.

Finally, let me point out that such a snapshot view of performance, even that shown by the 7 laboratories within the randomness circle of figure 1 , is no guarantee of continuing excellence. This snapshot is based on a single set of conditions, with unknown parameters affecting personnel, equipment, and environment. It involves a single pair of standard devices of only one type, a single pair of measurements, and a norm based on a limited number of laboratories. The standards laboratory which hopes to do good work must make frequent repetitive measurements on its secondary standards, to compare them with the primary standards which determine their accuracy. Continuous records of readings on devices received for calibration will help to establish that the measurement process is in statistical control [Pontius and Cameron, 1967]. The Bureau stands ready to help with reference standards [Mason, 1968a], with computer programs [Hilsenrath et al, 1968], and with effective calibration procedures [Mason, 1968b].

Acknowledgments are due J. M. Cameron and his statistical engineering staff for helpful discússions and technical assistance.

\section{Appendix A}

To supplement the results of the 1965-66 Measurement Agreement Comparison, the committee reports the following end-of-route data, for measurements delayed by the NBS move to Gaithersburg. They are the NBS recorded values and estimated accuracies for items in the Physical Package, and may be entered at the bottom of the McCallum tables, Proceedings 1966, pages 57, 58, and 59.

Table 1:

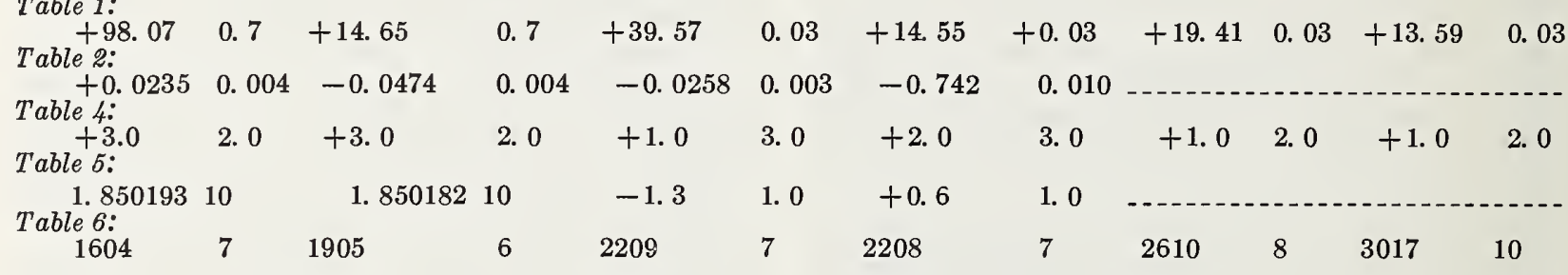

\section{Appendix B}

Columns 2 and 3 of table 1 show the measurement values reported by the participating laboratories on the pair of $50 \mathrm{~dB}$ coaxial attenuators. These were plotted by an OMNITAB computer routine, from which figure 1 was traced. In Column 4, $\mathrm{d}$ is the unit II reading minus the unit I reading. The difference from laboratory $16 \mathrm{E}$ was not included, being apparently out of line with the rest. The standard deviation of the group of 18 differences was found to be $s_{d}=0.02348$. The estimated standard deviation of any individual measurement among the 36 in columns 2 and 3 is then $\hat{\sigma}=s_{d} / \sqrt{2}=0.0166$. Assuming a circular Gaussian distribution with 99 percent coverage, the circle of reasonable randomness has a radius of 3.035 $\hat{\sigma}$ or $0.0504 \mathrm{~dB}$, centered on the median intersection $(50.12$, 49.83). If points fall outside this circle, it is strong evidence that those points reflect systematic errors.

$\begin{array}{cccc}\text { Laboratory } & \text { Unit I } & \text { Unit II } & \text { DIF F. } d \\ \text { NBS Dec. 1 } & 49.87 & 50.15 & .28 \\ \text { NBS Apr. 2 } & 49.86 & 50.15 & .29 \\ \text { NBS June 3 } & 49.87 & 50.15 & .28 \\ 17 \mathrm{E} & 49.83 & 50.10 & .27 \\ 18 \mathrm{~F} & 49.82 & 50.12 & .30 \\ 20 \mathrm{E} & 49.80 & 50.06 & .26 \\ 22 \mathrm{~F} & 50.07 & 50.37 & .30 \\ 32 \mathrm{~F} & 50.04 & 50.32 & .28 \\ 34 \mathrm{~F} & 49.58 & 49.86 & .28 \\ 37 \mathrm{~F} & 49.90 & 50.23 & .33 \\ 43 \mathrm{G} & 49.94 & 50.23 & .29 \\ 45 \mathrm{~A} & 49.80 & 50.09 & .29 \\ 48 \mathrm{G} & 49.73 & 50.02 & .29 \\ 51 \mathrm{E} & 49.59 & 49.95 & .36 \\ 56 \mathrm{~F} & 49.81 & 50.12 & .31 \\ 57 \mathrm{G} & 49.76 & 50.07 & .31 \\ 58 \mathrm{E} & 49.91 & 50.20 & .29 \\ 16 \mathrm{E} & 49.75 & 49.91 & .16\end{array}$




\section{Bibliography}

Hilsenrath, J., G. G. Ziegler, C. G. Messina, P. J. Walsh, and R. J. Herbold, OMNITAB, A computer program for statistical and numerical analysis, NBS Handbook 101, ed. 2, 1968.

Mason, H. L., editor, Calibration and Test Services of the National Bureau of Standards, NBS Spec. Pub. 250, May 1968; see Measurement Users Bulletins for changes.

Mason, H. L., editor, Precision Measurement and Calibration-A compilation of previously published papers by the staff of the National Bureau of Standards, 12 volumes in press 1968-1969, NBS Spec. Publ. 300.

Pontius, P. E., and J. M. Cameron, Realistic uncertainties and the mass measurement process-an illustrated review, NBS Monograph 103, Aug. 15, 1968.

Proceedings of the 1966 Standards Laboratory Conference, NBS Misc. Pub. 291, July 13, 1967.

Youden, W. J., Graphical diagnosis of interlaboratory test results, Indus. Qual. Control, Vol. XV, No. 11, pp. 1-5, May 1959.

Youden, W. J., The sample, the procedure, and the laboratory, Analytical Chemistry, Vol. 32, No. 13, December, 1960 .

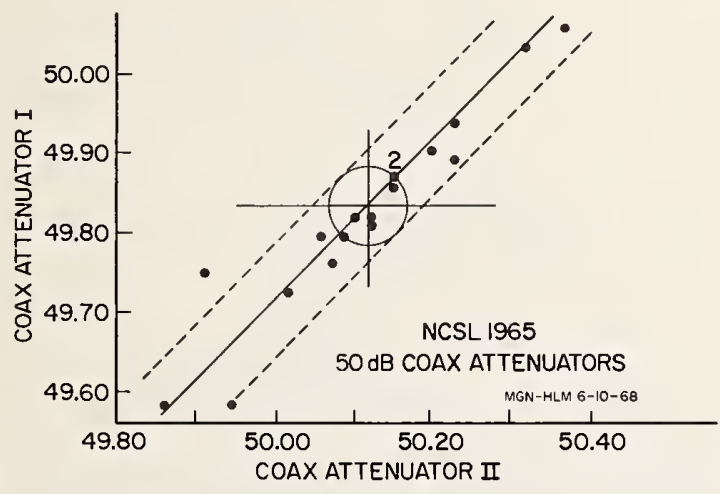

Figure 1. A useful Youden diagram: 50dB coaxial attenuators.

Points outside the circle are strong evidence of systematic errors.

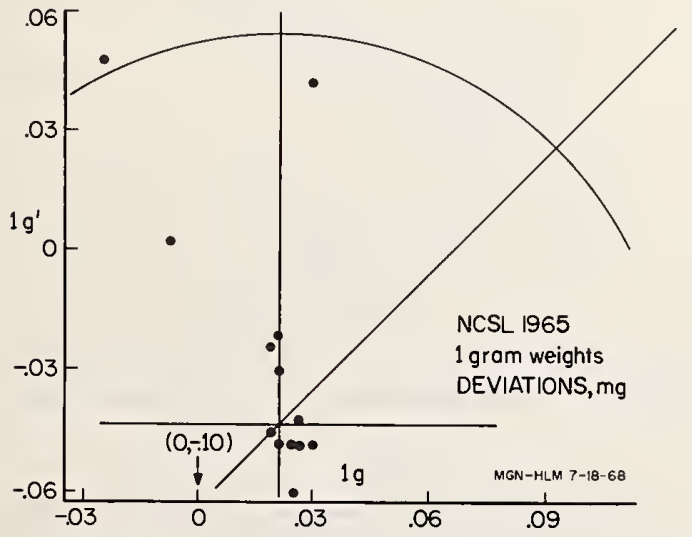

Figure 2. A diagram indicating violation of Youden's basic assumption: 1-gram weights. Points scatter vertically.

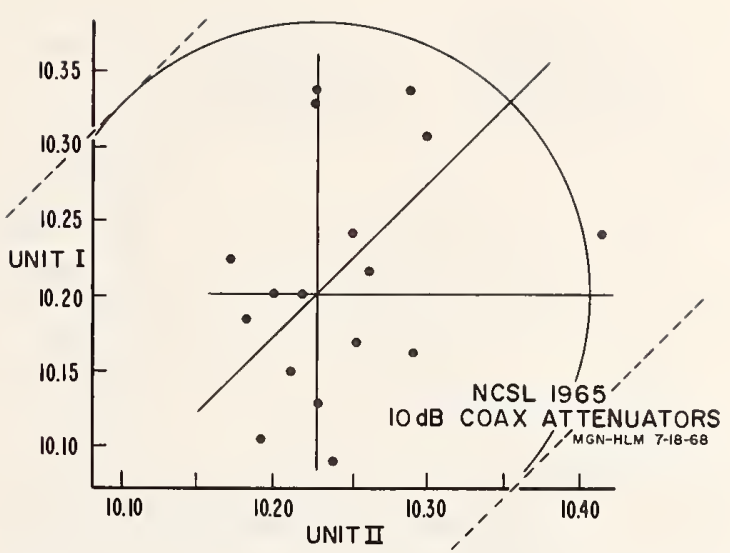

Figure 3. A Youden diagram indicating large random errors: $10 d B$ coaxial attenuators.

The plot is nearly circular.

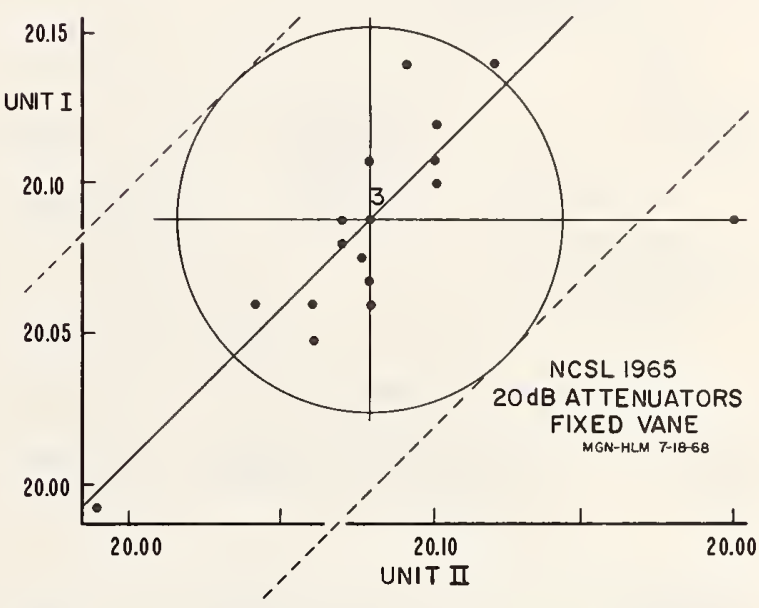

Figure 4. Youden diagram for $20 d B$ fixed wave attenuators; there are 3 points at the intersection of medians.

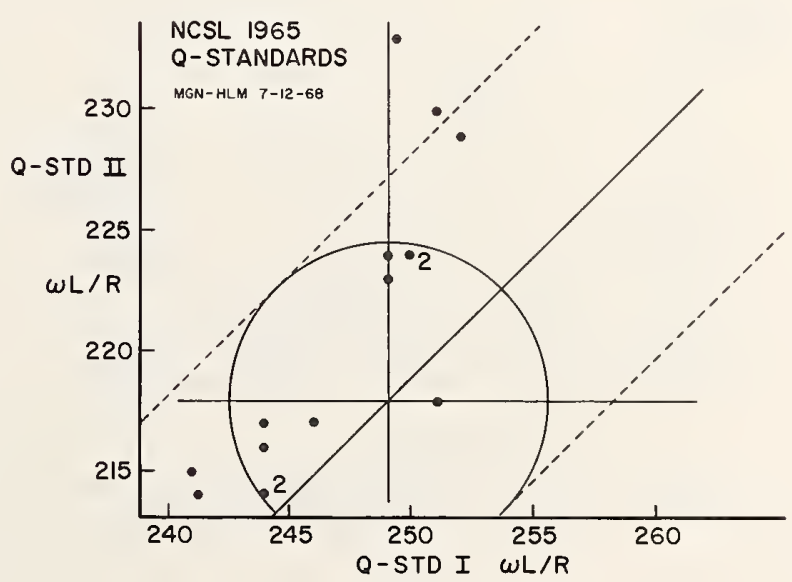

FIgure 5. Youden diagram for Q-standards. 


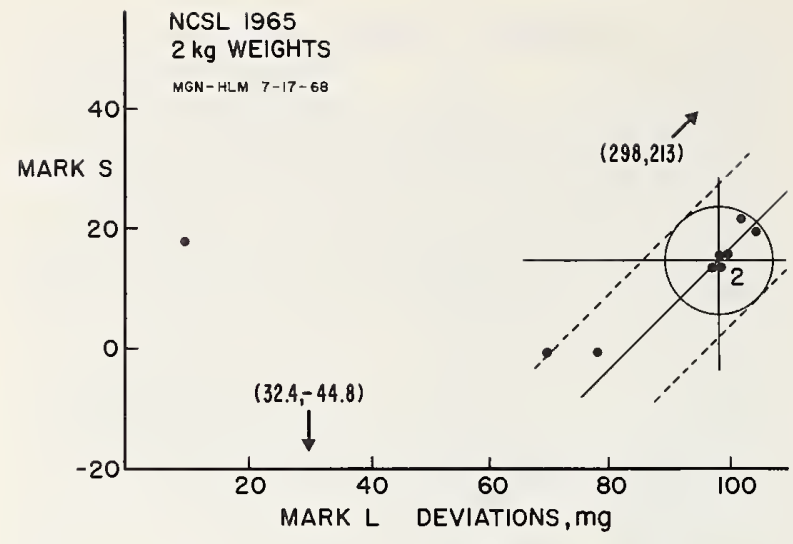

FIGURE 6. A Youden diagram suggesting human error: 2-kg weights.

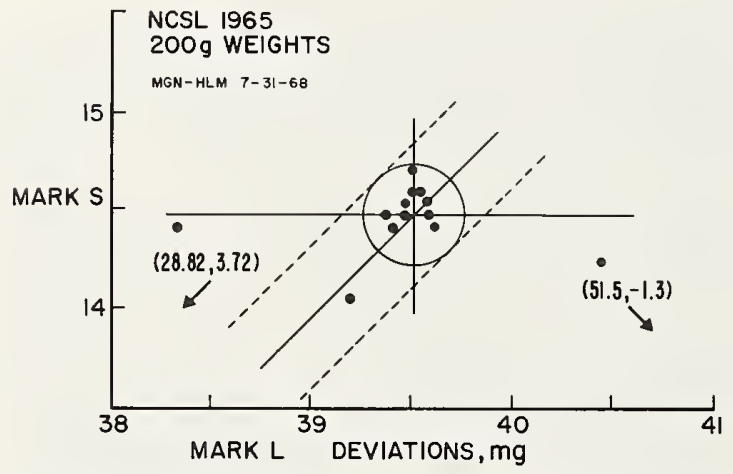

Figure 7. A Youden diagram suggesting human error: 200-g weights.

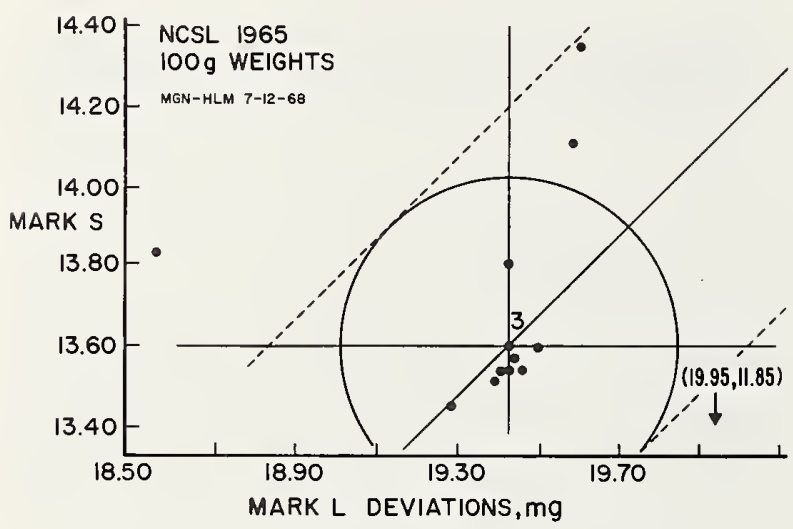

F'TGURE 8. Fouden diagram for 100-g weights.

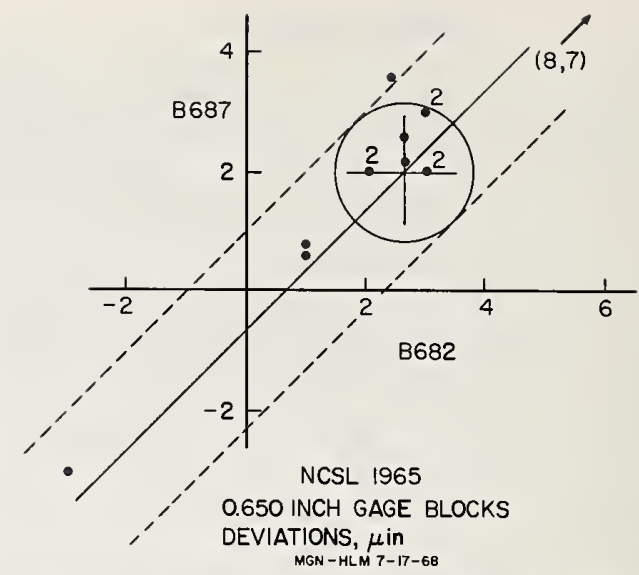

FIgURE 9. A Youden diagram indicating 6 points within the randomness circle: 0.650-inch gage blocks.

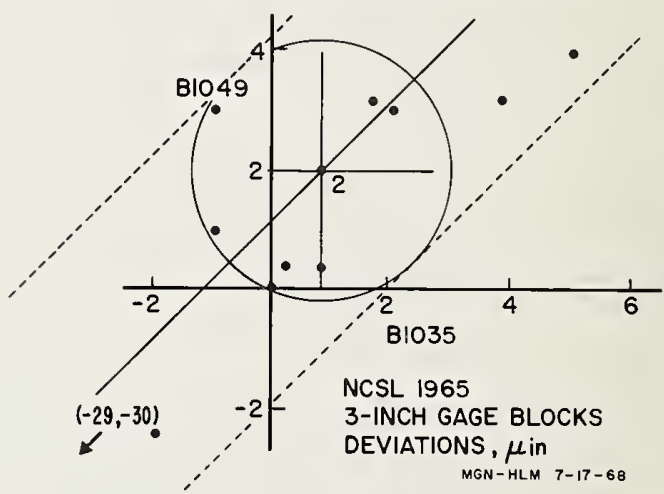

Figure 10. A Youden diagram indicating 9 points within the randomness circle: 3-inch gage blocks.

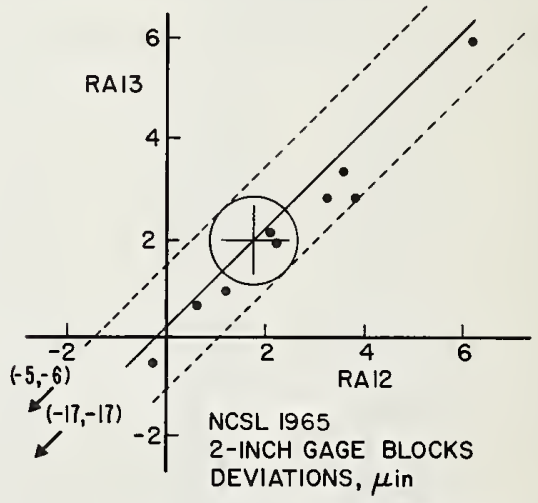

MGN - HLM $7-31-68$

Figure 11. Youden diagram for 2-inch gage blocks. 


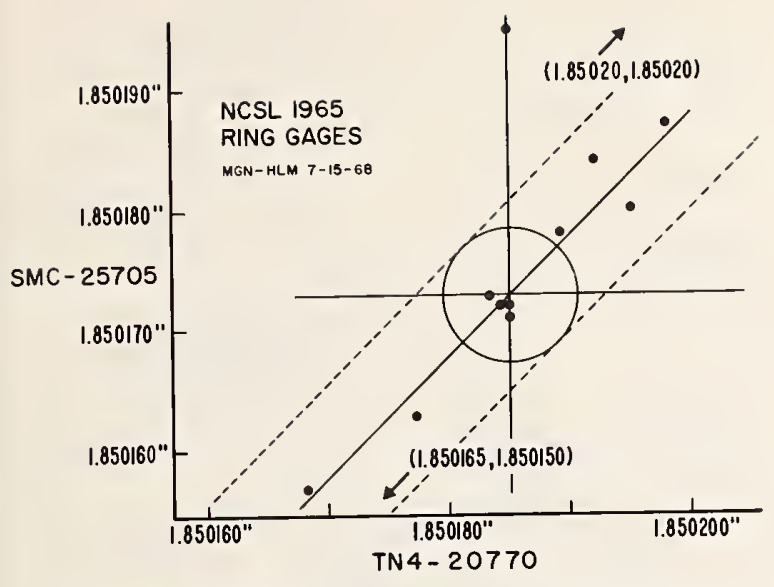

Figure 12. Youden diagram for ring gages.

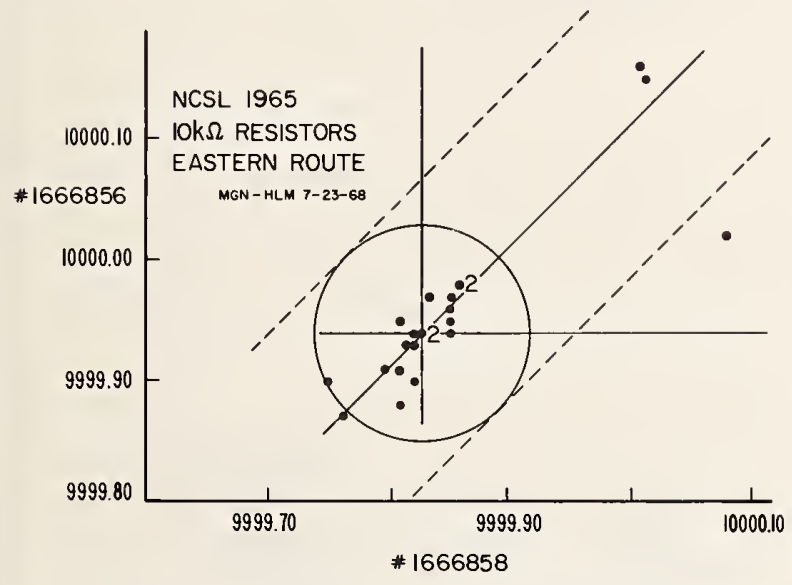

FIgURE 13. Youden diagram for $10 \mathrm{kilo-ohm}$ resistors, Eastern route.

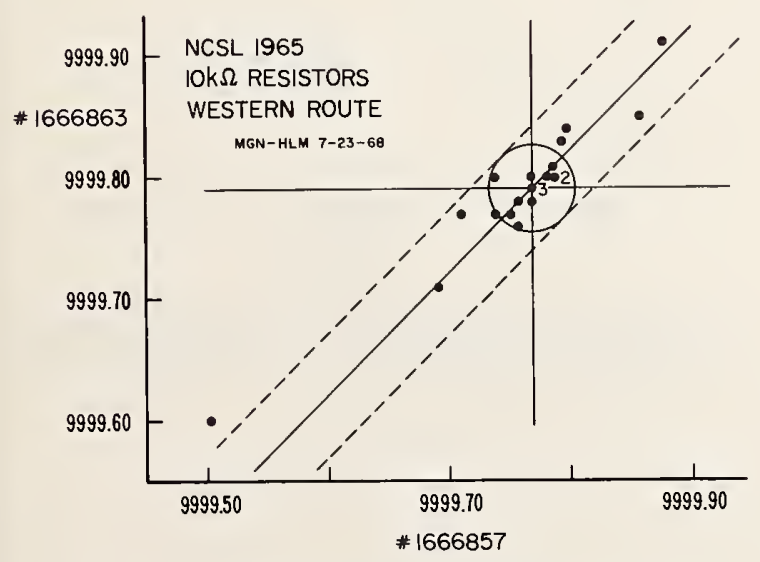

FTGURe 14. Fouden diagram for 10 kilo-ohm resistors, Western route.

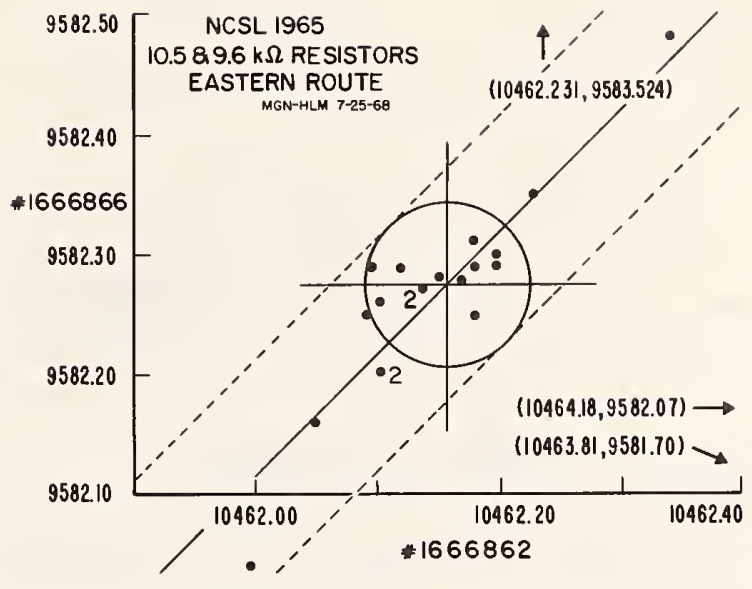

FIgURE 15. Youden diagram for 10.5 and 9.6 kiloohm resistors, Eastern route.

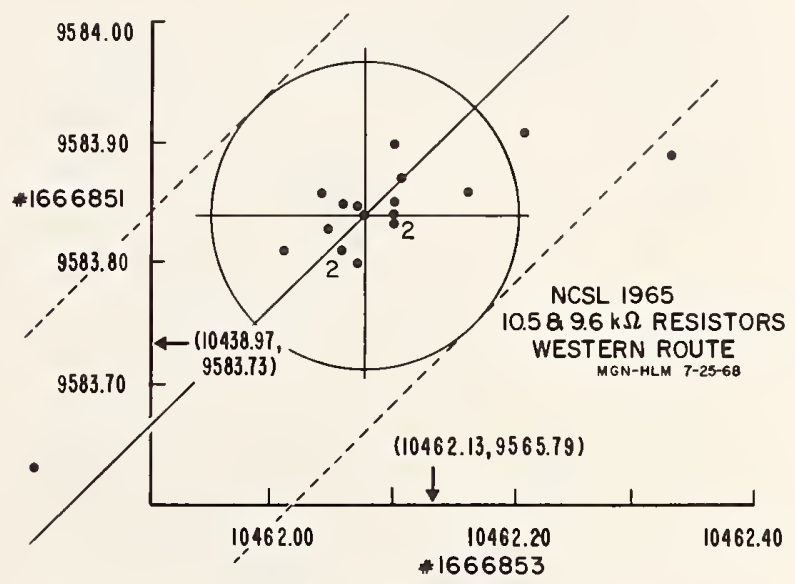

FIG. 16. A Youden diagram suggesting human error: 10.5 and $9.6 \mathrm{kilo-ohm}$ resistors, Western route.

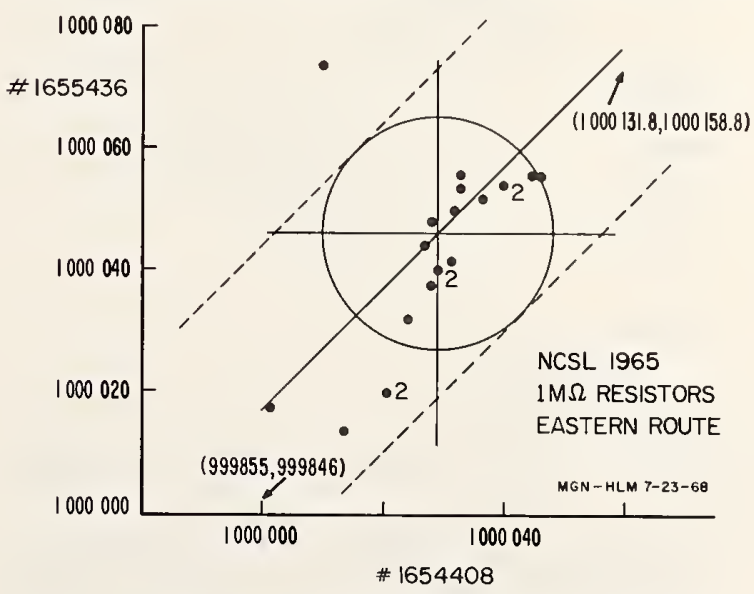

FIG. 17. Youden diagram for 1 megohm resistors, Eastern route. 


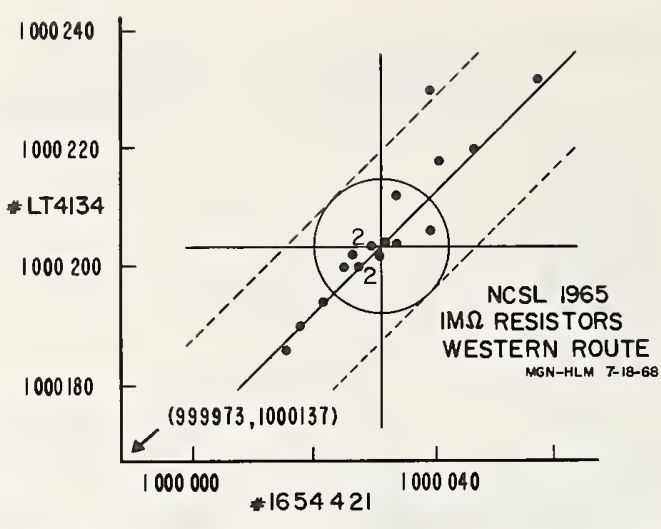

FIG. 18. Youden diagram for 1 megohm resistors, Western route.

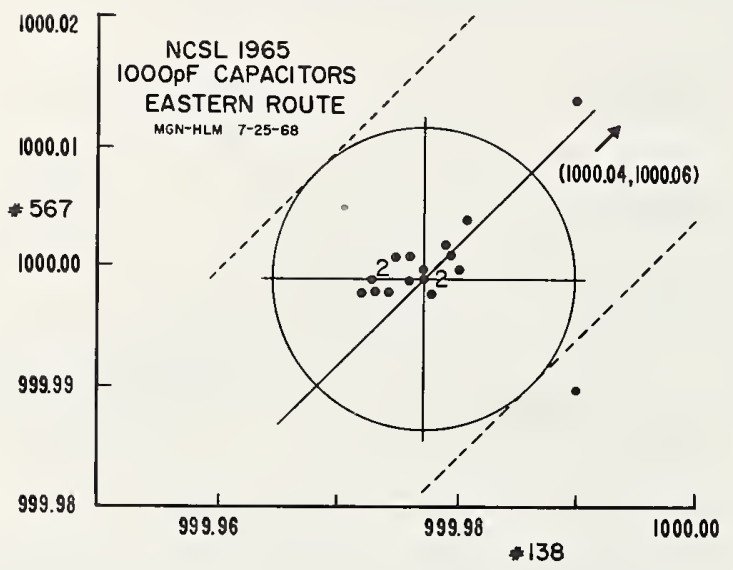

FIG. 19. Youden diagram for 1000-picofarad capacitors, Eastern route.

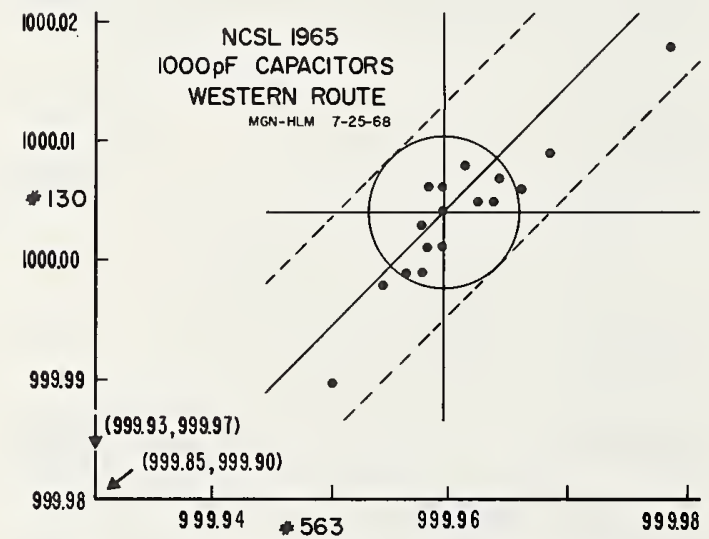

FIg. 20. A Youden diagram with 2 points indicating unusually large systematic error: 1000-picofarad capacitors, Western route.

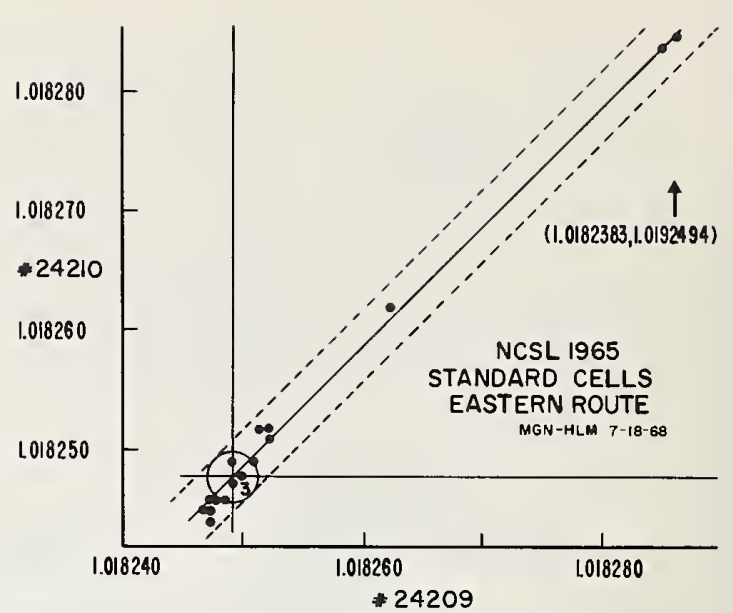

FIG. 21. A Youden diagram with 4 points indicating unusually large systematic errors; standard cells, Eastern route.

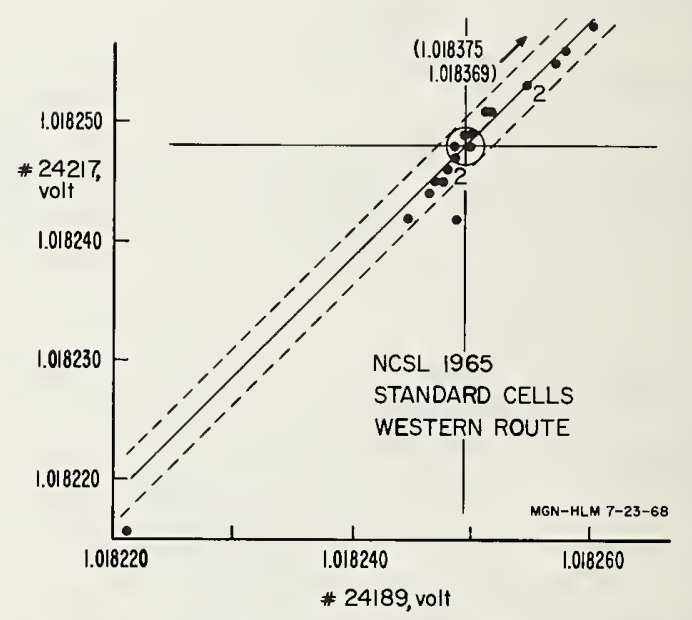

FIG. 22. A Youden diagram indicating small random error but relatively large systematic error: standard cells, Western route. 


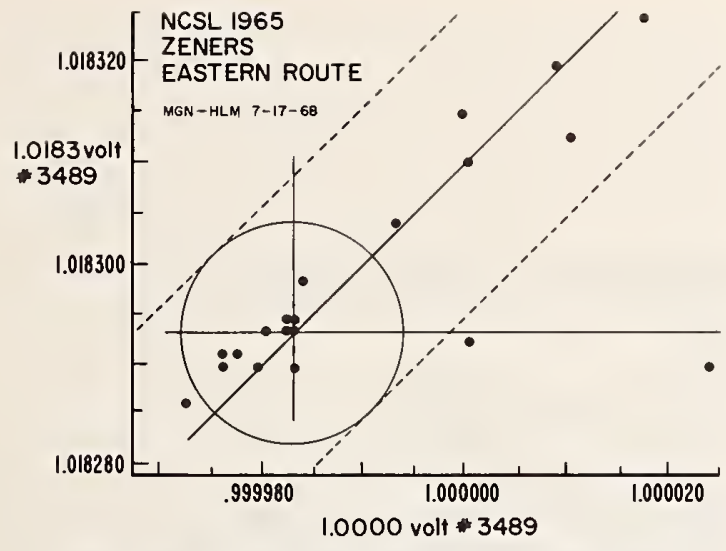

Fig. 23. Youden diagram for zener diodes, Eastern route.

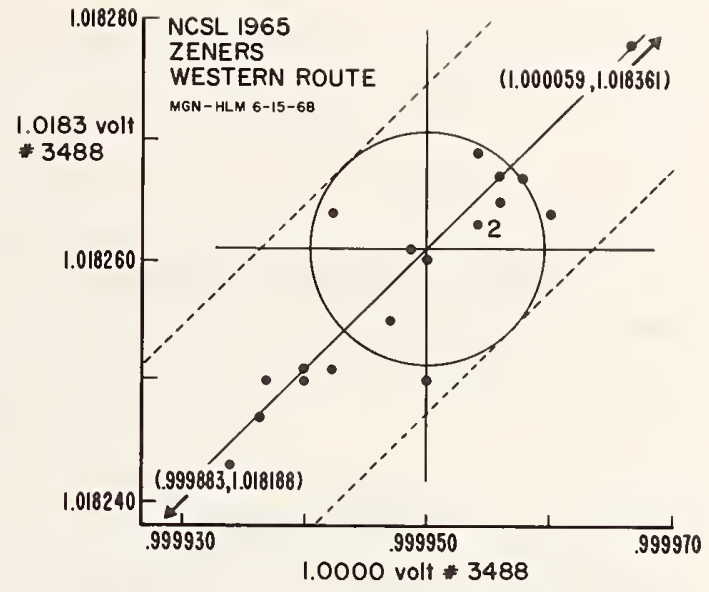

FIG. 24. Youden diagram for zener diodes, Western route. 


\title{
THE INTERSERVICE MEASUREMENT AUDIT PROGRAM
}

\author{
G. G. May \\ Naval Air Rework Facility, San Diego, California 92135
}

\section{Introduction}

The primary purpose of the Interservice Measurement Audit Program, which was inaugurated in 1959 , is to confirm or reaffirm measurement capability by measurement comparison among leading Government standards laboratories, together with the National Bureau of Standards. A secondary purpose is to provide mutual assistance among laboratories in analyzing and determining the causes of any measurement differences or errors noted during the audit. The third purpose is to provide an opportunity for the technical personnel to discuss audit results, measurement techniques and equipment, and to make plans for the next audit. This is done at a symposium which is hosted by one of the laboratories.

The laboratories which participate in the Interservice Measurement Audit are as follows:

1. National Bureau of Standards

Gaithersburg, Maryland, or Boulder, Colorado

depending on the measurement area

2. Navy Eastern Standards Laboratory

Washington, D.C.

3. Navy Western Standards Laboratory

North Island, San Diego, California

4. Army Primary Standards Laboratory

Redstone Arsenal, Huntsville, Alabama

5. Air Force Primary Standards Laboratory Newark, Ohio

6. ALO Primary Standards Laboratory

(Sandia Corporation)

Albuquerque, New Mexico

\section{Organization}

The responsibility for each audit is assigned on a rotating basis to each of the participating Primary Standards Laboratories. The responsible laboratory arranges for the audit items; plans the shipping schedule; opens and closes the audit; receives, tabulates and analyzes the measurement data; and plans and hosts the audit symposium.

Areas in which comparison measurements have been made are shown in table 1 . These measurement areas are chosen by mutual agreement at the symposium held at the close of the preceding audit.
Measurement areas are selected from those that have been previously audited as well as new areas. Special consideration is given to measurement areas which are not tightly coupled to the National Bureau of Standards.

Audit items are selected within the chosen measurement areas. General test procedures, test con ditions and specific measuring points, packing and shipping instructions are provided with each audit package.

An audit symposium, which is a high point of the Interservice Measurement Audit, is held after completion of the laboratory measurements. The host laboratory collects, tabulates and analyzes the data, and plans the symposium. A typical program would be similar to that presented at the Fifth Interservice Audit. The program for this audit symposium program included the following:

1. NBS investigations of errors in measurements-J. M. Cameron, NBS Washington

2. Measurements which cannot be tightly coupled to an NBS reference-Dave Russell, NBS Boulder

3. Air Force Technical Audit Program

4. Navy Calibration Audits-S. Crandon, Navy Pomona

5. Pitfalls in computer computations-L. F. Shampine, Sandia

6. Discussion of data from 5th InterserviceAEC Audit from a Statistician's Viewpoint-J. M. Cameron, NBS and D. A. Edelman, Sandia

7. Presentation of audit data relative to each audit item. This includes discussion of measurement techniques, comparison of measurement systems, and causes for errors noted during the audit

8. A tour of the host laboratory

9. A session for planning the next audit

A major advantage of the Interservice Audit program is the open discussion and the mutual assistance provided among these laboratories in determining the causes of errors and measurement disagreements. Problems which would be difficult for a single laboratory to resolve are simplified when the knowledge and information available at all laboratories are employed. 
The values which can be realized from the Interservice Audit program are as numerous as the ways in which errors creep into the final value applied to the customer standards. These errors can develop even with the best standards, best instrumentation, best measurement personnel, and the best data processing systems. These values can best be described by analyzing the causes of some of the measurement errors which have occurred during various audits.

The dimensional audit problem in 1960 consisted of measuring seven selected Hoke-style gage blocks of $0.100,0.200,0.300,0.400,1.00,3.00$, and 4.00 inch nominal size, Grade A quality. Three laboratories calibrated the gage blocks by mechanical comparison, one by interferometry, and one by both methods. Sixty-two of the seventy measurements involved were within \pm 1 microinch.

The measurement made by one laboratory on the 0.100 -inch block differed from the other laboratories by eight microinches. The reason for this discrepancy was traced to the master gage block which was found to be 7 microinches smaller than the stated value. Whether the gage block had shrunk subsequent to calibration, or whether incorrect calibration data had been supplied, was not resolved. In any case, this master was not suitable for use and was discarded.

Measurements made on the 3.00 inch and 4.00 inch blocks by one laboratory differed from the other laboratories by 6 to 10 microinches respectively. During review of the measurement techniques it was noted that conversion of a 3.00 -inch measurement from the old U.S. inch ( 1 inch= $2.54000508 \mathrm{~cm})$ to the international inch $(1 \mathrm{inch}=$ $2.54 \mathrm{~cm}$ ) required the addition of six microinches. This was equal to the error in the reported value for the 3.00-inch gage block. Also, 8 microinches must likewise be added to a 4.00 -inch measurement, which would have reduced the reported error to 2 microniches.

The agreement of the Directors of the National Standards Laboratories of Australia, Canada, New Zealand, South Africa, the United Kingdom, and the United States to report gage block lengths in international inches was inaugurated July 1, 1959. The Interservice Audit measurements were performed about one year later. There were, however, gage blocks still in use with calibration reports in U.S. inches.

This particular audit assisted in locating a bad master gage block, and brought to light errors which were introduced during computation and reporting.

In 1968 the flowmeter audit problem consisted of finding the $K$ factor (cycles per gallon) vs. frequency characteristics of two Cox AN-8-4 and two $16 \mathrm{H}$ turbine meters. A ten-point calibration on each meter in an ascending order on one day and a ten-point calibration in descending order the following day. The average of the two measurement made at each point was recorded. The test fluid used was MIL-F-7024A, Type II, at a temperature near $80^{\circ} \mathrm{F}$. The goal was to obtain correlation within $\pm 0.15 \%$ among measurements made by all laboratories.

A Cox 311 dynamic-weight flowmeter calibrator was used by all participating laboratories. The test stand calibration consists of calibrating the individual test-stand parameters. These parameters and estimated uncertainties are listed as follows:

Temperature $\pm 0.1^{\circ} \mathrm{F}$ (Maintained within $\pm 0.5^{\circ} \mathrm{F}$ during flowmeter calibration)

TABLE 1. Interservice audit items, 1960-1968.

\begin{tabular}{|c|c|c|c|c|c|c|c|c|c|c|c|c|c|c|c|c|c|c|}
\hline $\begin{array}{r}\text { AUDIT } \\
\text { ITEM } \\
\text { YEAR }\end{array}$ & 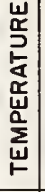 & 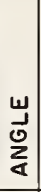 & 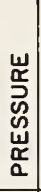 & $\begin{array}{l}3 \\
0 \\
11 \\
\end{array}$ & 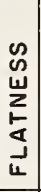 & $\begin{array}{l}\infty \\
\infty \\
\Sigma \\
\Sigma\end{array}$ & $\begin{array}{l}1 \\
\\
0 \\
2 \\
4\end{array}$ & 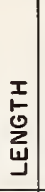 & 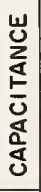 & 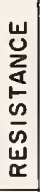 & 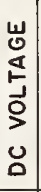 & 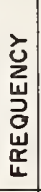 & 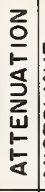 & 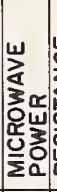 & 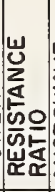 & 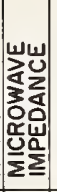 & $\begin{array}{l}5 \\
\frac{5}{u d} \\
\frac{\pi}{\pi} \\
\frac{\pi}{J} \\
0 \\
0 \\
0\end{array}$ & 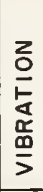 \\
\hline $\begin{array}{l}1960 \\
\text { FIRST } \\
\text { AUDIT }\end{array}$ & $x$ & & $x$ & & & & & & & $x$ & $x$ & & & & & & & \\
\hline $\begin{array}{l}1961 \\
\text { SECOND } \\
\text { AUDIT }\end{array}$ & & & $x$ & & & $x$ & & $x$ & & & $x$ & & $x$ & $\begin{array}{l}\text { SE } x \\
\text { BAND }\end{array}$ & & & $x$ & \\
\hline $\begin{array}{l}1962 \\
\text { THIRD } \\
\text { AUDIT }\end{array}$ & $x$ & & & & & & & $x$ & & & & & & & & & & \\
\hline $\begin{array}{l}1963 \\
\text { FOURTH } \\
\text { AUDIT }\end{array}$ & & & & & & & $x$ & & $x$ & $x$ & & $x$ & & & & & & $x$ \\
\hline $\begin{array}{l}1965 \\
\text { FIFTH } \\
\text { AUDIT }\end{array}$ & & $x$ & & . & & & & & & $x$ & $x$ & & $x$ & $x$ & $x$ & & & \\
\hline $\begin{array}{l}1968 \\
\text { SIXTH } \\
\text { AUDIT }\end{array}$ & $x$ & & & $x$ & $x$ & & & & & & & & $x$ & $\left|\begin{array}{c}R \\
\text { BAND }\end{array}\right|$ & & $\begin{array}{c}\mathrm{R} \\
\text { BANQ }\end{array}$ & & \\
\hline
\end{tabular}


Viscosity \pm 0.25 percent

Specific gravity \pm 0.02 percent

Adjustment of 1 to 1 lever arm

Adjustment of 50 to 1 lever arm

Electronic counter for elapsed time measurement

Electronic counter for frequency and total count measurements

The one hundred (fifty pairs) measurements reported for the model $16 \mathrm{H}$ turbine flowmeters are plotted on figure 2 in accordance with Youden techniques. Values shown are relaive to the NBS pair, which fixes the origin. The measurements made by any one labortory are uniquely coded. There has been no effort, however, to identify the individual measurments by flowmeter frequency. Three of the fifty points fall outside the enclosed figure which represents \pm 0.15 percent from NBS values. This figure could be shifted to encompass all except one point.

The data received from one laboratory differed from NBS values by 3 percent. Review of this data indicated that an error had been made in specific gravity because an incorrect conversion factor had been used. This laboratory, which was immediately notified of these findings, subsequently provided corrected data which is coded c on figure 2.

Using the same plotting techniques as above, the eighty (forty pairs) measurements reported for the AN-8-4 flowmeter are recorded on figure 3 . These flowmeters were routed to laboratories in the following order: $\mathrm{O}, \mathrm{NBS},+$ and $\oplus$. Since measurements coded $O$ and $\oplus$ were performed by the

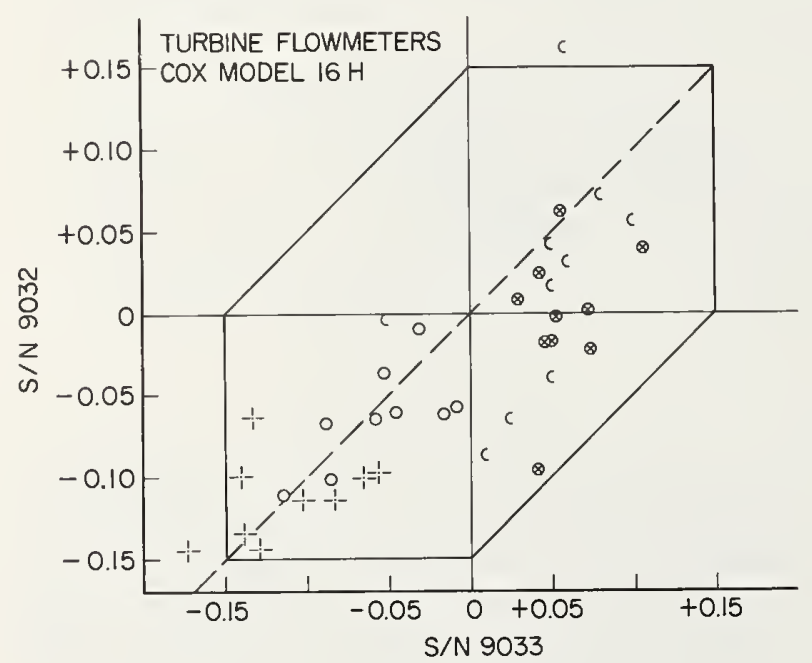

same laboratory, and the last two groups of measurements for turbine meters serial No. 9030 are somewhat lower than the first two groups of measurements, it is possible that the characteristics of the turbine meter changed during the audit. The check on this possibility the turbine meter is being resubmitted to the NBS for a second calibration. It is expected that the results of this recalibration will be available prior to convening the audit symposium.

This audit information which has not yet been completely analyzed will be discussed at the next symposium. To date the audit has uncovered a computational error and possibly a faulty transfer standard.

Review of other audit reports reveals that many problems are due to computation errors, wrong conversion factors, transposition of numbers, etc.

\section{Summary}

The VALUES of the Interservice Audit Program are many. As in any measurement comparison program, Interservice Audit participants can determine how well they are doing in relation to NBS and other laboratories. In addition the mutual assistance provided each of the laboratories in resolving measurement differences is beneficial in reducing the time required before corrective action can be taken by individual laboratories. A major part of the program is the audit symposium which affords some opportunity for training, and permits the discussion of measurement problems directly by the technical personnel involved.

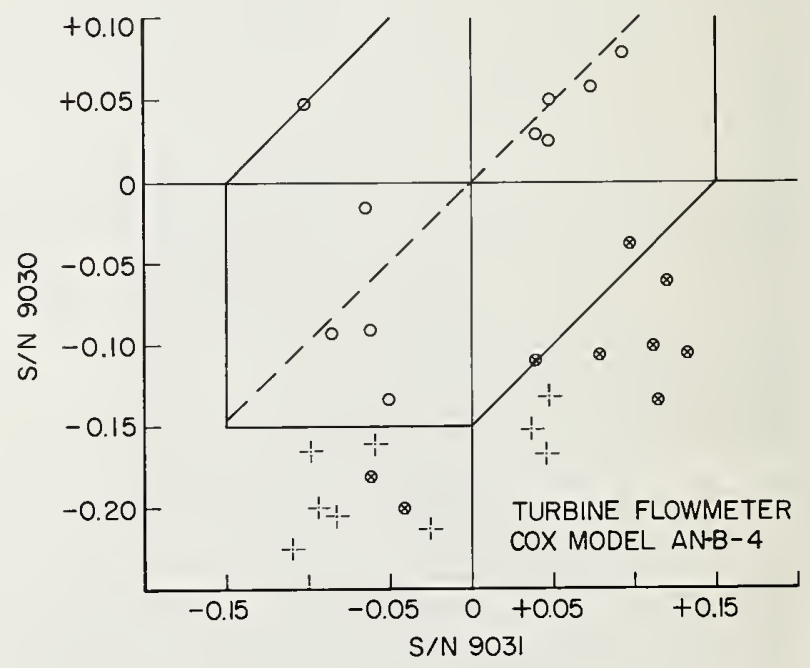


NCSL 68

\title{
SESSION 7: THE MANAGEMENT OF EQUIPMENT AND DATA
}

\author{
Chairman: J. C. Shackelford
}

LTV Electrosystems, Incorporated, Dallas, Texas 75222

\section{AN INFORMATION SYSTEM FOR STANDARDS LABORATORIES}

\author{
Wilbur J. Anson
}

\begin{abstract}
Manager, Radio Standards and Measurements Information Center, Radio Standards Engineering Division, National Bureau of Standards, Boulder, Colorado 80302

The Radio Standards and Measurements Information Center is being established to help solve measurement problems by collecting, anałyzing, and disseminating measurement know-how applicable to standards and measurement techniques from $30 \mathrm{kHz}$ through the millimeter-wave frequencies. The objectives, services, and techniques of the Center are described. Feedback is solicited as to the kind of information and services likely to be most useful.
\end{abstract}

\section{Introduction}

John F. Kennedy once pointed out that if all 50,000 years of mankind's recorded history were compressed into one century, then airplanes, radio, and TV would have been developed last month and we would be certain to reach the moon before midnight tonight!

With such rapid progress has come a mass of information. According to the Brooks Institute of Santa Barbara, the technical information generated during he last three years is equivalent in volume to that generated during the entire 19th Century. Current estimates indicate that more than a million significant documents, journal articles, technical reports, etc., are produced each year, worldwide, in science and technology. Even just the portion of technology concerned with measurement know-how-standards and measurement techniques and related instrumentation-contain a tremendous volume of knowledge.

We at NBS attempt to assist industry, universities, and other government agencies in coping with technological advances by developing standards and measurement techniques and offering calibration services so that the technical community can interface with the national standards. But repeatedly, on trips that $I$ and others have taken, we are told that in addition to standards and calibrations, engineers and scientists need to know how to use these standards-how to make the most of the calibrations we provide-now to set up, use, and evaluate measurement systems. These people would like to get authoritative and timely measurement know-how-not just documents, not just standards, and not just calibrations; although each serves a function.

That is why we have started a specialized technical information analysis center on radio standards and measurements. The goal is that the center will provide specialized bibliographies, survey articles, and state-of-the-art reviews, as well as assistance in answering specific technical questions and assistance in program planning. However, since an information center is a user-oriented activity and the gestation period is long, interaction with potential users is particularly important while the center is in the formative stage. In that way the subjects and services most needed can be pinpointed and, as a result, less time and money will be spent to make the center maximally useful. Therefore, I am inviting and encouraging your comments about the information and services most wanted from our Radio Standards and Measurements Information Center.

\section{Objectives of the Radio Standards and Measurements Information Center}

The mission of the Center is to help solve measurement problems by selectively assembling, analyzing, and disseminating information applicable to radio standards and measurements in the frequency range from $30 \mathrm{kHz}$ through the millimeterwave frequencies. The principal emphasis is upon standards and measurement techniques for various electrical quantities in that frequency range. Among the electrical quantities covered are power, voltage, current, impedance, noise, $\mathrm{Q}$, attenuation, field strength, and phase shift. Coverage may be 
extended to the sub-millimeter wave and the far infrared region wherein generation and detection devices, properties of materials, and new components would also be included.

\section{Services of the Radio Standards and Measurements Information Center}

Current Awareness List: The current awareness listings are by-products of the systematic examination of current technical journals. Articles within the scope of the information center aro identified, and those sufficiently relevant are procured and processed for the information files of the center. As a part of this process it is relatively easy to make a list of current articles and send these regularly to subscribers. Presently our current awareness list appears as a regular feature of the IEEE Instrumentation and Measurement Group's Newsletter every two months, but within six months an expanded version will be offered as a bi-weekly service.

Technical Cousultation: Because the center is part of the Radio Standards Engineering Division, it can contact specialists or arrange for direct consultation as appropriate in order to answer questions. Of course, as the information file of the center grows, many of the routine questions can be answered promptly from the files and thus spare the Division's technical staff for the knotty questions and for their own research.

File Searches: When the center's information file has grown to the point that it represents a fairly substantial and comprehensive collection in some of its subject areas, then rapid file searches can be made to provide references or substantive answers to technical questions. The capability for such searching is based upon (1) the content of each document being coded in detail, and (2) the use of quick-response search equipment. We have the equipment and techniques now, but it will be from one to three years before the information file is large enough for comprehensive searching. If money were available for the necessary personnel, the time scale could be shortened to less than a year.

Custom Searches and Surveys: Surveys of technical activity around the country or special literature searches on contract provide a useful service as well as adding significantly to the information file. The end product can be tailored to suit the need of the customer and may be in any of the following forms:
Bibliography
Annotated bibliography (descriptive)
Annotated bibliography (comparative or critical)
Bibliography with documents collected and bound
Survey paper
State-of-the-art review

Special-purpose article (such as a "how to do it" article for the general engineer rather than for the measurement specialist. The criteria for such articles are discussed later).

Special-Purpose Articles. The production of technical surveys, state-of-the-art reviews, and other special purpose articles is one of the main functions of specialized technical information analysis centers.

Dr. Alvin Wineberg, Director of the Oak Ridge National Laboratory said in his report "Science, Government, and Information" published by the President's Science Advisory Committee in 1963:

Scholarly reviews, articles, and critical bibliographies also play an important part in easing the information crisis. They serve the special needs of both the established workers in a field and the graduate student entering the field, as well as the general needs of the nonspecialist. Review writing is a task worthy of the deepest minds, able to recast, critically analyze, synthesize, and illuminate large bodies of results. The relation of the reviewer to the existing but widely scattered bits of knowledge resembles the relation of the theorist to available pieces of experimental information.

Surveys and state-of-the-art reviews have always been an important NBS product; hence, in a sense, the information center adds nothing new to the product line of the Radio Standards Engineering Division. However, a goal of the center is to make it easier for the Division's technical staff to prepare comprehensive reviews for publication. Also, as necessary to produce special surveys, studies, or reviews, the center will contract with specialists outside of NBS.

In addition to the traditional reviews and surveys, I sense a need for articles especially written for the general engineer rather than for the measurement specialist-for articles that bridge the gap between those written for the measurement specialist and the procedures written for the calibration technician. We at NBS usually must develop measurement techniques and standards for the greatest accuracy. In contrast, the engineer and scientist in industry and other agencies usually must consider trade-offs between parameters such as reliability, dependability, cost, user knowledge required, maintenance required, and equipment required. Not all of these parameters could bo fully covered in the series of articles that I visualize, but at least measurement techniques could be outlined and critically compared in such a way that the general engineer, pressed for time, could more efficiently select the methods to be studied further.

My experience in industry and NBS suggests that a blending of the specialized knowledge of 
the NBS measurement specialist with the experience and know-how of those outside NBS could produce valuable "Metrology Guides." Some of the guides would contain a comparison of techniques, and would consider some of the parameters just mentioned; others would be tailor-made to specific measurement problems. I am developing the criteria and a sample for the "Metrology Guides" series so as to determine whether the guides would meet customer needs well enough to secure financial support.

\section{Techniques and Equipment for Storage and Retrieval}

The Peek-a-Boo Filing System: 'This system was chosen because it has adequate capacity for several years, is self-contained, is browsable, and uses the coordinate-term retrieval approach.

The Peek-a-boo system is an optical-coincidence search method, in which a few of many cardseach peppered with holes-are stacked together and light shines through the holes that line up. Each card represents a word or phrase that could describe a document; each hole represents a number which in turn identifies a document-and the few cards stacked together represent a selection of words or phrases that fit the question being asked. Holes that then coincide and let light shine through identify documents that are described by all the words and phrases of that particular stack of cards.

This ability of the system to coordinate terms (words and phrases) give great flexibility to the way in which the collection is searched. For example, some questions may be best answered by searching for a combination of technical terms; other questions yield to a combination of document descriptors such as year of publication, kind of document (trip report, NBS report, etc.), plus a few technical content descriptors.

About 30,00 references are the maximum that can be stored in the system without awkward manipulation of cards. Eventually, therefore, we will likely use computer techniques. To ease any further changeover wo are adhering to conventional standards and practices as much as possible.

Of course, the computer could have been used from the beginning, but certain advantages of the Peek-a-boo prevailed. Since the Peek-a-boo system is self-contained, there is no standing in line to use the computer. No specialized programming knowledge is needed, and therefore anyone can use the system with just a few minutes of instruction.

Tape-Controlled Typewriter: A tape-controlled typewriter will contain a memory bank of bibliographic citations. Use of this unit and the optical coincidence search equipment will make it easy to prepare specialized bibliographies, whether for current awareness lists, for special publication, or in answer to questions.
Index: In the index we use a controlled vocabulary to restrict the size of the vocabulary and yet allow for some natural growth. Care has been taken to arrange the index for easy use, because it is anticipated that others in addition to information center personnel will use the index to locate documents in our files.

\section{Approach}

Former Deputy Assistant Secretary of Commerce Chalmers Sherwin defined a specialized technical information center in terms of its function ". . . to collect, critically evaluate, skillfully compress, and creatively organize all of the significant world-wide scientific and technical literature in a particular subject area for its more efficient utilization in science, technology, industry, and the government."

In his report "Science, Government, and Information," Dr. Alvin Weinberg said that

... a specialized information center makes its business to know everything that is being published in a special field such as nuclear spectroscopy or the thermal physical properties of chemical compounds. It collates and reviews the data and provides its subscribers with regularly issued compilations, critical reviews, specialized bibliographies, and other such tools.

"Specialized information centers, to be fully effective, must be operated in closest possible contact with working scientists and engineers in the field. The most successful centers are an intrinsic part of science and technology. The centers not only disseminate and retrieve information; they create new information.... Making a discriminating selection of data, as was done in preparing the International Critical Tables, requires scientific insight of the highest order, and it itself is an essential scientific activity."

These are good definitions of what an ideal information center should be; but no system is any better than it proves to be in operation. However, this establishes a goal for the Radio Standards and Measurements Information Center.

"He Who Moves Mountains Begins by Carrying Away Pebbles": In general, our approach is to work towards a carefully defined goal by completing individual tasks having useful by-products. The by-products also provide feedback to check the reasonableness of the approach before we are committed too strongly to a particular direction.

For example, much of the value of any specialized technical information center is based upon a comprehensive collection of documents that have been coded in such a way that they can be easily 
and rapidly retrieved to answer technical questions. The building of such a collection takes considerable time and effort. If one were to collect in all subject areas at the same time, it would be years before enough of a collection existed for any meaningful searches to be made. Therefore, we are collecting in small areas with specific end products in mind. For example, we are now collecting information on power, attenuation, phase shift, and impedance standards and measurement techniques published between January 1966 and December 1968. This particular collection is aimed at helping Division members in preparing URSI reports, but its usefulness will be multiplied by becoming part of the center's deeply indexed information file.
It would be more efficient and more generally useful if we could work in all of our subject areas at the same time. Accordingly, we are actively seeking contracts for custom work that would add rapidly to the information file. Now that we have the equipment and techniques, progress is almost directly proportional to the available personnel and that is mainly a function of available money.

\section{Conclusion}

Now is the time to shape the Center to your needs. So I repeat my invitation to the readers of this article to communicate with me and let me know what information and services would be most useful. 


\title{
ADMINISTRATIVE PROBLEMS IN THE INTRODUCTION OF AN AUTOMATIC MEASURING SYSTEM
}

\author{
George W. Pentico \\ Senior Staff Engineer, Western Electric Co., Inc, Lee's Summit, Missouri 65800

\begin{abstract}
A number of administrative problems connected with the introduction of automatic measuring systems in the manufacturing plant are discussed and the decisions made in a particular situation are described
\end{abstract}

\section{Introduction}

The Kansas City Works of the Western Electric Company, Manufacturing and Supply Unit of the Bell System, located at Lee's Summit, Missouri, concentrates its activities in two rather diverse areas. One is the manufacture of electron devices such as vacuum tubes, transistors, semiconductor diodes, thermocouples, varistors, switchboard lamps, etc. The other is the manufacture of carrier telephone equipment, both wire-line and radio. The testing problems presented by these diverse fields are of course quite different, but they share certain common problems. Among these are :

1. The everpressing problem of the high cost of testing.

2. The large number of measurements to be made.

3. Perennial demands for improved accuracy and precision.

4. Scarcity of skilled personnel and the high cost of training them.

5 . The high cost and the time required to collect data and analyze it to monitor process control and acceptability of product.

6 . Necessity of periodic calibration of test equipment and the cost of doing it.

I am sure that the problems listed have a familiar ring, for they are certainly not confined to the Western Electric Company or to the electronic manufacturing industry.

For some time we have been introducing automatic test sets in an effort to solve some of the problems posed above. Until recently most of these had been in the electron devices shop in the area of testing diodes, transistors, and switchboard lamps. In most cases, the logic was hard-wired or patch-board wired. The sets were relatively unsophisticated, single-purpose sets. In the wired equipment shops, automatic test sets were limited primarily to continuity testing or testing or relay circuits. Again, they were relatively unsophisticated, usually with patch-board wiring, although a few used punched paper tape programming. In most cases, data was not collected except during trouble periods. Experience with these sets has been encouraging in general; testing costs have been reduced and rate of testing increased.

A new generation of test sets is now appearing in the shop. Computers are being introduced as the control element, and programming is by "software", rather than by wiring. The flexibility of the test set is increased but so is its complexity, and a number of new problems are introduced in the administrative and operating areas. This paper discusses some of the problems encountered and the decisions made in a particular situation.

We were faced with the requirement to provide a transmission-measuring test set with improved insertion-loss measuring accuracy, and the capability to measure phase, in the frequency range of $50 \mathrm{MHz}$ to $90 \mathrm{MHz}$. Insertion loss in $\mathrm{dB}$ is defined as $10 \log \mathrm{P}_{1} / \mathrm{P}_{2}$, as shown in $\mathrm{A}$ and $\mathrm{B}$ of figure 1. After surveying commercial instruments and in-company designs available, we decided to build the Programmed 'Transmission Measuring Test Set shown in figure 2, which was developed by the Measurements Group at the Bell Telephone Laboratories. The capabilities of the test set are shown in table 1 and a simplified block diagram in figure 3. Building this test set and arranging to place it in operation in the manufacturing shop forced us to make decisions in a number of associated areas.

\section{Advantages}

In considering a proposal for the introduction of an automatic measuring system, both the advantages and disadvantages should be considered. The relative importance of various aspects of the situation will, of course, depend upon the particular circumstances. Automatic systems will usually make individual measurements much more quickly than manual ones. As an example, in the set we have built, the system balances within $0.01 \mathrm{~dB}$ in not more than three iterations, starting with 30 
dB unbalance. At frequencies above $2 \mathrm{KHz}$, this is accomplished in 0.10 seconds. The increased speed of measurement can be used to test more items in the same length of time; thus, reducing test time for each item, or it can be used to make more tests on the same number of items. For example, the frequency characteristic of a filter or amplifier can be checked at more frequencies than is feasible with manual operation. If the test system is fully utilized, the net cost per data point will be reduced despite the increase in total cost. It has been estimated that the cost per data point for the automatic system will be reduced to about one percent of that of a manually operated system.

It is usually possible to improve both accuracy and precision of an automatic test set over that obtained by a manual test set. Several factors contribute to this improvement:

1. Elimination of operator mistakes.

2. Elimination of operator bias in reading measurements. It is well known that most people tend to read instruments consistently high or low.

3. Reduction of effects of noise by using the average of several separate measurements. With this automatic test set, it is feasible to use the average of 16 to 32 measurements without noticeable delay in obtaining results, if results are typed out on a teletypewriter. The time required to do this with manual operation is usually prohibitive.

4. Reduction of the effects of drift, since the operating cycle is very short.

The automatic operation of the system reduces the requirements of skill to a minimum, and consequently minimizes the problems of training the operator. This is not an unalloyed blessing, as will be noted later. However, it does reduce the problems encountered with operator turnover, since training periods are reduced. As we all know, it takes a great deal of training and much practice to develop a skilled tester with good judgement.

With a computer-controlled system, it is possible to write programs which will check the operation of the system with a minimum of help from the operator. This is true both of the computer itself and the overall system and allows the introduction of standardized periodic checking of the operating condition of the system, with a minimum of effort by either the operator or the maintenance personnel. If the expected output is not obtained, maintenance work can then be done.

Test results can be made available in several forms from an automatic test set. Punched cards, paper tape, magnetic tape, teletype or line printers, or direct transmission to data processing equipment are of course all available. If enough memory capacity is available in the controlling computer, the data processing can be accomplished locally. Such processing can take any form desired. In the particular test set which we have built, the data typed out is the average of $8,16,32$, $64,128,256$, or 512 separate measurements as selected. The standard deviation of the group of measurements is also typed out. Much more sophisticated treatment of the data is possible; and it is even possible to have the machine plot frequency distributions or other curves. One piece of optional equipment not shown in the photograph is a pair of $\mathrm{X}-\mathrm{Y}$ plotters which will plot curves of the output data. The maximum plotting rate is about four points per second, which is limited by the slew rate of the plotters.

\section{Disadvantages}

Before we get carried away with optimism thinking that the introduction of automatic test sets will solve all our problems in measurements or testing, let us consider some of the penalties of introducing automatic systems.

One of the most overpowering ones at first glance is the large increases in all categories of cost : development and design, capital investment, maintenance, and the added one of programming. It takes some time to become accustomed to the approximate doubling in cost of the first two categories, and a thorough analysis should be made to make sure that the increase is justified. Of course, if a particular characteristic is required and that is the only way it can be obtained, there is no question. In our particular case the development work, much of the design work, and some of the programming had already been done by the Bell Telephone Laboratories. New designs of filters and equalizers which we were to manufacture required phase measurements. We had no test equipment which would measure phase. Requirements on previous items had been in terms of envelope delay distortion. This can be calculated from phase measurements, but the reverse cannot be done to the accuracy required. The cost of providing a manually-operated loss and phase measuling test set for the frequency range of 50 $\mathrm{MHz}$ to $90 \mathrm{MHz}$, with an accuracy of $0.03 \mathrm{~dB}$ for loss and 0.2 dgree for phase, was estimated to be about $\$ 100,000$. While this set would have been adequate for present requirements, it would have been outmoded in a few years. The automatic test set, at somewhat less than $t w i c e$ the cost, will provide the most accurate facility available at this time and will probably retain that status for about five years. In addition, its speed of operation is high enough that a good deal of the final testing performed on our other test sets can be transferred to it at a considerable savings in testing cost.

Another disadvantage in automatic test sets is that more highly skilled maintenance people are required. In addition to competence in the ordinary type of instrumentation, they must also become well versed in the operation of digital circuits. Since the system is more complex, it takes longer for the individual to achieve the intimate knowledge required for successful troubleshooting. This is true even with the availability of automatic checking programs. The maintenance 
man and engineer must become able to diagnose the ills from the syunptoms of a very complex system. In addition, both engineering and maintenance personnel must acquire familiarity with programming. Since the former will usually originate and prove-in the programs, they will need more proficiency than the maintenance people, but a certain minimun of competence will be required for efficient maintenance. It would, of course, be possible to contract for maintenance work on the computer portion of the system if a commercially available computer is used as the control element. We considered this approach but discarded it for two reasons. We were 500 miles from the supplier's nearest field office, and did not feel we could afford to have the system out of service for the length of time it would take to get service. Also, we felt that in order to do good maintenance work on the system, the person should be able to work on all parts of it. This attitude means that any person assigned to work on the system must become familiar with the entire system.

One of the penalties in the use of an automatic test system for some organizations would be the limitation in flexibility in use of test equipment. Some laboratories or testing organizations use temporary combinations of standard instruments for testing as the need arises. This reduces the capital investment involved, but requires assembly of test setups and verification that the combination operates properly, which can be quite time-consuming. Such a consideration did not apply in our situation, since for practically all production testing, we dedicate the test equipment to a particular permanent setup. For high volume production, this is of course necessary; but even for intermittent runs, we feel this pays off since the equipment is always there ready to operate with no assembly and a minimum of checking. We normally manufacture the same product or type of product over a period of many years.

While an automatic test set with a short operating cycle reduces the amount of test time required, by the same token it also results in the rapid acquisition of large amounts of faulty data if the system is not operating properly. Information concerning the standard deviation of the test results is valuable in monitoring the operation, since normally it should be very small and any increase is cause for suspicion. Quite frequent limited checks of the system will be necessary to monitor its operation.

One aspect of the introduction of such systems which usually receives very little consideration is their effect on worker motivation. Recent studies in this field have indicated that reducing the job content tends to lead to worker dissatisfaction, since it denies the worker the feeling of accomplishment, which derives from making a significant contribution toward some goal. Some companies have been experimenting with giving workers more responsibility and increasing the scope of a job. They have found that in certain circumstances at least this has resulted in increased productivity and more satisfaction on the part of the worker. Introduction of automatic systems in which the worker is reduced to the role of feeding a machine would seem to be a change in the wrong direction from this viewpoint. Perhaps, if automatic feeding of the machine can also be introduced and the worker given complete charge of the system operation including responsibility for troubleshooting, overall quality, scheduling, etc., it might help. Redesign of the product might be required to make this possible. It should certainly be considered in design of new product.

\section{Maintenance Considerations}

As already mentioned, with a computer-controlled system it is possible to write programs which will provide means of routine checking of the functioning of both the computer and the complete system. Some activity on the part of the maintenance personnel or the operator performing the tests is required. If marginal operation or a malfunction is indicated, maintenance work must be done. We have a policy of periodic checking of all test equipment to insure proper functioning. The interval used is based on engineering judgment concerning the complexity of the circuits involved, the reliability of the equipment, the margin between design capabilities and required performance, and experience. As a rule of thumb, we usually start out with six-month intervals, unless the responsible engineer feels that the equipment is unstable enough to require more frequent checks, or if little or no margin exists between the test set capabilities and the accuracy of the measurement required. If experience shows that few adjustments are required at the prescribed interval, it will be lengthened. On the other hand, if frequent troubles are reported between scheduled checks, the interval will be shortened. In the latter circumstances, the shop's inability to meet required tolerance on product is often the trigger for the unscheduled maintenance calls. It was decided to use the same routine on the computer section of the system and to check its operation periodically.

Because of the situation described earlier, it seemed best that maintenance of the whole system be done in-house and by the regular test set maintenance organization. The maintenance personnel must be trained in digital circuit operation and computer maintenance. It was helpful that some of these people had already been initiated into digital circuit operation to some extent, with the introduction of digital instruments such as counters and digital meters into the shop.

A choice of methods was available for accompplishing this training. The maintenance men could be sent to the supplier's school, or the maintenance supervisor could attend the school and train his 
people, or the responsible engineer could attend the maintenance school and conduct training sessions on his return. We chose the second course. In our company, the supervisor is traditionally responsible for training his people. Since the hourly-paid workers are more mobile than supervisors, both within the company and as regards to leaving the company, we believed that we had a better chance of recovering our investment in the training session at the supplier's plant if the supervisor were sent. If there were a change in maintenance persolnnel, the supervisor would be able to train the new ones. It was also felt that it was more appropriate for the supervisor to do this than an engineer. We did have an engineer in the Test Set Design organization attend the supplier's programming school. The engineer and two assistants who will do the planning for the shop operation of the system are quite familiar with computer programming. The maintenance supervisor who attended the maintenance school felt afterward that the experience would have been more valuable if he had attended the basic programming school first, since he had considerable difficulty in following the instructor. We had inquired if this were advisable when making the arrangements for his attendance. The reply had been that it was not necessary; that the class presentation would not assume familiarity with computers. Experience did not confirm this.

\section{System Utilization}

When a large capital investment is made in such a system, it seems obvious that there should be careful planning to insure maximum benefit from it. The Bell Laboratories personnel, based on experience with use of the developmental system, felt that to insure efficient use of the system, someone should be available who was thoroughly familiar with its capabilities and limitations. In addition, he should be well informed in the fundamentals and principles of transmission measurements. Our consultant on electrical measurements will take this responsibility.

As in all measurement fields, if the measurements are not made under the proper conditions, the results will not be valid. As an example, in making insertion-loss measurements to an accuracy of $0.001 \mathrm{~dB}$, the sum of the return losses at the measuring terminals of the system and the terminals of the device under test must be about 86 $\mathrm{dB}$ at both input and output connections. Unless this condition is satisfied, the accuracy of the measurement will be degraded, and if the person making the measurement is not aware of the requirement, he will ignore the error.

Someone should also schedule the use of the system, to avoid both idle periods and disappointment due to unavailability of the system when desired. In a laboratory situation, it may be wise to have the actual measurements performed by an individual assigned to operate the system, since he will become familiar with the normal operation and thus should be able to detect trouble symptoms. The time of professional people will not be consumed in performing what it is hoped will be a routine task. Such a procedure also simplifies multishift operation of the facility which should certainly be considered if one system does not have sufficient capacity to satisfy the demand.

With such a large investment, it is also desirable to strive for maximum flexibility of control in the system. Delegation of many of the control and logic functions of the system to the computer software rather than hard wiring or plug boards helps accomplish this objective. Programming is expensive, but in most cases the flexibility provided allows utilization of the system for more purposes than would otherwise be possible, or at least convenient. Needless to say, provision for this capability should be incorporated in the initial design of the system. Modifications are usually costly and the results often not as satisfactory as if the feature were included in the original construction.

Another feature which will enhance the convenience of operation and may be a necessity under certain conditions is provision for measurements at locations remote from the system. With our system, transmission measurements have been made at a distance of about 700 feet over connecting coaxial cables, with a degradation of accuracy of about ten to one, over a frequency range of about $0.1 \mathrm{MHz}$ to $20 \mathrm{MHz}$ for losses up to $70 \mathrm{~dB}$. Additional work will probably improve these results.

\section{Conclusions}

Based on our limited experience to date, we feel that the general philosophy which governed our decisions has been confirmed. For example, our decision to maintain the computer ourselves and have each person assigned to it capable of working on the complete system seems to be correct. In some types of trouble situations, there is considerable interaction between the computer and the test set. In such circumstances, it is necessary to be familiar with the complete system operation to locate the source of the trouble. We have already made minor modifications to some of the original proposals as further study indicated the advisability of doing so. We expect that future developments will confirm the wisdom of the decision to introduce additional and more complex automatic systems into our plant. Incidently, in the fabrication process we are also introducing more and more automatic punch presses, milling machines, drill presses, etc. Some of the problems connected with their introduction are very similar to those which have been discussed herein, such as maintenance and programming. 
Indeed, one might almost say that to resist this trend is to run the risk of obsolescence and subsequent failure of a business. With the continuing increase in labor costs, every effort must be made to reduce the labor content of product. Introduction of automatic systems seems to be one method of accomplishing this.

\section{Acknowledgments}

The author wishes to express appreciation to Mr. G. D. Hayne and his associates of the Bell Telephone Laboratories, Inc., for the time spent by them in discussing the design and operation of this system to enable him to gain an understanding of it.

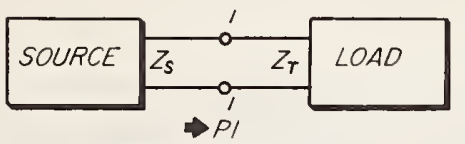

A-REFERENCE CONDITION

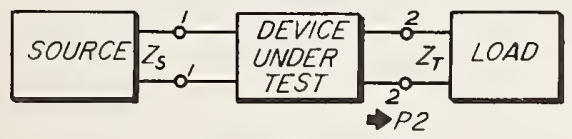

B - TEST CONDITION

FIgURE 1. Reference and test conditions for measuring insertion loss.

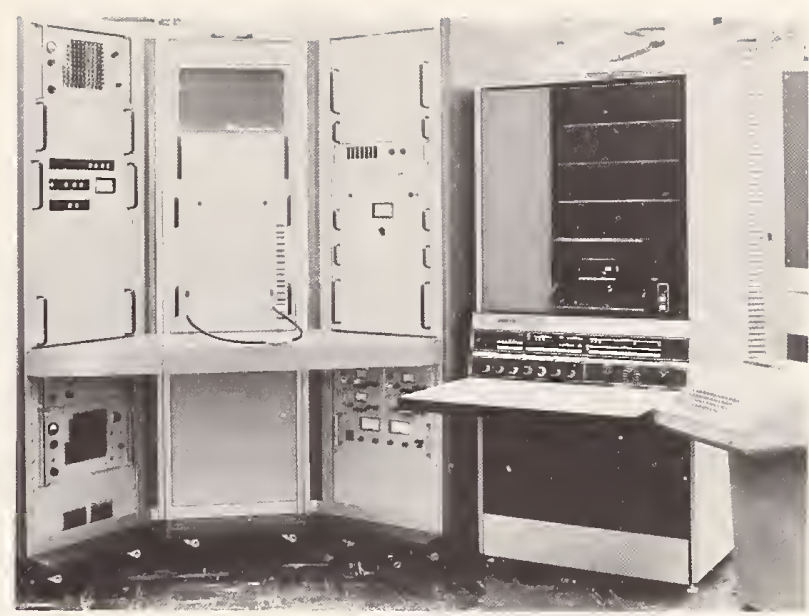

Figure 2. The programmed transmission measuring test set.

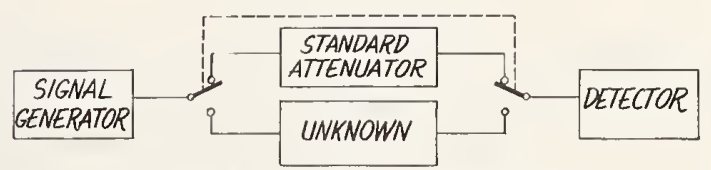

THE BASIC TRANSMISSION LOSS COMPARISON MEASURING SYSTEM

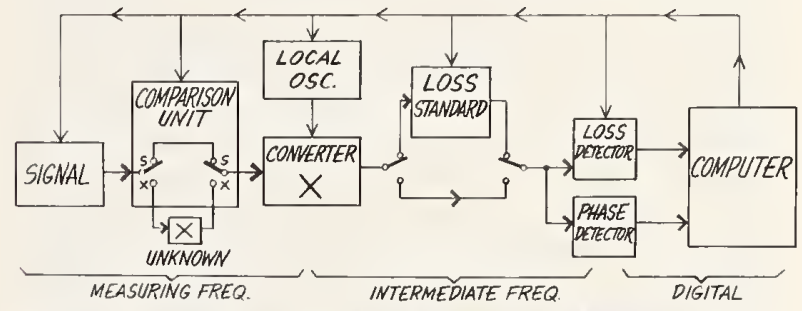

DOUBLE DETECTION TRANSMISSION MEASURING SET

Figure. 3. Block diagram.

TABLE 1. Test set capabilities

\begin{tabular}{|c|c|c|c|}
\hline & Range & Setability & Maximum Accuracy \\
\hline requency: & $50 \mathrm{~Hz}-250 \mathrm{MHz}$ & $0.01 \mathrm{~Hz}$ & 3 parts in $10^{8}$ \\
\hline gnal level: & -5 to $-50 \mathrm{dBm}$ & $5 \mathrm{~dB}$ & $\pm 2 \mathrm{~dB}$ \\
\hline ss : & $0-100 \mathrm{~dB}$ & $0.001 \mathrm{~dB}$ for loss (or gain) & $\pm 0.001 \mathrm{~dB}$ for less than $10 \mathrm{~dB}$ loss at 0.01 \\
\hline in: & $0-40 \mathrm{~dB}$ & less than $20 \mathrm{~dB}$ & $\begin{array}{l}\text { gain) }<40 \mathrm{~dB} \text {, increasing to } \pm 0.03 \mathrm{~dB} \text { at } \\
250 \mathrm{MHz}\end{array}$ \\
\hline ase: & $0-360^{\circ}$ & $0.01^{\circ}$ & $\begin{array}{l} \pm 0.01^{\circ} \text { for loss (or gain) }<40 \mathrm{~dB} \text {, increasing } \\
\text { to } \pm 0.18^{\circ} \text { at } 250 \mathrm{MHz}\end{array}$ \\
\hline ay: & & & $\begin{array}{l}55 / \Delta f \text { microseconds, where } \Delta \mathrm{f} \text { is selected by } \\
\text { engineer }\end{array}$ \\
\hline
\end{tabular}

Impedance

50 and $75 \mathrm{ohm}$, unbalanced 135 and 600 ohm, balanced and unbalanced

Plug-in impedances and highimpedance probes
Frequency Range

$50 \mathrm{~Hz}-250 \mathrm{MHz}$

$50 \mathrm{~Hz}-3 \mathrm{MHz}$

$50 \mathrm{~Hz}-20 \mathrm{MHz}$ 


\title{
PROCESSING TECHNICAL AND ADMINISTRATIVE DATA WITHIN THE STANDARDS LABORATORY
}

\author{
L. Darling \\ Supervisor Measurement Standards, Sperry Rand Corporation, Univac Data Processing Division, \\ Utica, New York 1350
}

\begin{abstract}
An operating system in its broad routine aspects is described, emphasizing its managerial necessity, and its numerous capabilities, and offering guidelines for development of one's own system.
\end{abstract}

\section{Introduction}

This paper includes the description of a reasonably complete but non-complex real data-handling system which has been dubbed the "Tool Calibration Report." I suggest the desirability of providing a skeptical cost-conscious higher management with enough understandable information to convince them why your facility is really needed, why it is so large and expensive, and why you need to expand. The paper considers the numerous capabilities which are partly a function of the basic datahandling design, your imagination, the extent of your computer system, and the expansion of usage as experience reveals its potentials. Some generalized discussion of our system follows to provide guidance for developing your own system. A final section mentions other data-handling considerations within or concerning the laboratory.

\section{An Instrument Control System}

Our current completely functional system is designed to perform numerous semi-technical functions required to maintain control of precision standards, tools and equipment, and to provide associated management data. This system is capable of effectively producing a profit; if it does not it is improperly designed, perhaps not even required.

This effective profit comes in the form of providing needed functions or data not practically possible with a hand-operated system. It produces a higher volume of necessary information,- -quicker, with less effort,-covers more areas,-integrates some data and gives directions based on accumulated data. It also makes it possible to disseminate necessary information to the proper areas in an easily understandable form. To do the latter, it reports by exception, giving only that data required, thus avoiding confusion. Management data is available by direct reports for both laboratory and higher management. A flexible design was de- sired, but here we missed the boat. Our views were too narrow when the system was developed. We can obtain all the data contained in any printout combination, but major changes in the type of program which the system can accomplish are limited.

Most reports in our system hinge around the word "calibration." Now at first glance this may lead one to confuse our scheme with the familiar instrument recall system. This function is a notable and active one, but it is not the single major factor in "control."

The system to be detailed is a compromise between feast and famine. It is presently operative using a simple card-controlled form of data processing in a very small computer system. Our new and yet unproven system utilizes a medium-tolarge computer, producing more data with an improved format, and requires much less input effort.

Our system contains seven major subsystems with fourteen associated sections. The first sub-system is Instrument Recall, which consists of a "Calibrations Due Report" package with a printout segregated by location, and a corresponding preprinted mailing sticker for attaching to an intra-factory mailing envelope. Its purpose is to provide a simple means for each affected department to obtain a listing of equipment due for recertification. It also provides Quality Control with a policing device.

Now that we have all this equipment on its way to the laboratory, provisions better be made to handle the work. This is accomplished by the next sub-system, Laboratory Instrument Work Load Control, which includes a "Calibration Work Load Report". This contains the same items as the "Calibrations Due Report" package, but the format changes. It is condensed, and tools (i.e., instruments) are listed in tool number order to allow laboratory supervision to schedule the work according to priorities and to the man assigned each job. An interpreter-card deck, from which these two reports were generated, is supplied in tool 
number order. These cards are called "Update Cards" and contain only that data subject to normal change, thus providing a verifying guide for the user. They are used by laboratory personnel to keep track of their time, to list the class of calibration and to update the indicated data, such as the new due-date. Tool number order is compatible with our historical and calibration files as well as with all other factory records on each instrument. We also receive a "Tool Calibrations Due Report," which lists all the instruments in the system in order of due date. This shows a long-term picture of work and allows adjustments in scheduling to be made in advance.

Lest things get out of hand and we miss something, we have the convenient System Master Reports. Each of these three contains all the data in the master deck, but the printout sequence changes on each, to best serve the required purposes. The "Weekly Tool Calibration Master Listing by Tool Number Order" keeps the laboratory up-to-date. The "Quarterly Tool Calibration Master Listing by Category Order" is also sublisted by manufacturer, then model designation. This allows inventory control of spare parts, and permits tracking failures of specific made and model of equipment. A great deal of semi-technical and management data may be extracted from this very useful listing. The "Quarterly Tool Calibration Master Listing by Location" is useful for audit, budget and similar functions. These reports have endless possibilities of usage.

Everyone knows that the efficiency of a laboratory and its technical personnel is questionable and cannot be defined anyway! However, we decided in our ignorance to generate a sub-system for laboratory time and classification efficiency. The "Calibration Time Report" shows how many items were calibrated by each person, and the number of items and hours he required above the alloted (goal) time. It will show over a period of time, a person who is not running with the average. Can you picture the manager's face when he finds out you have a "Weekly Hour Breakdown by Operator Report" showing the hours per type of work (Administrative, Technical, Repairs and Miscellaneous Routine Calibrations) and time used at each level of calibration. To show departmental loading for accounting purposes the "Calibration Time by Location Report" is included. This also shows by location the number of items dependent upon the laboratory for service.

Knowing that no one can attain perfection, we have the next sub-system, Error Check. The "Update Listing, Tool Number Order" is a printout of the "Update Cards" of completed work of the previous week. This may be scanned for keypunch input-data or processing errors. Equipment loading trends are also detectable. The "Tool Calibration Card Control Report" assures that the correct number of cards are in the master deck.
The Data Processing Procedures sub-system has a set of "Run Instructions" provided by the Management Systems (Programming) Department. They also retain all "Update Cards" and "Master Decks" for six months. This permits easy error correction without loss of the master data.

The final sub-system, the largest, is called Special Data Reports. This allows a print-out of any or all of the data in the master deck, with the information ordered in any desired sequence or sub-sequence. We can obtain anything from total manpower requirements for the year, to level of calibration procedures of certain equipment, or the number of failures in brand $\mathrm{X}$.

\section{Design of Your System}

To develop your own system, think practically, and don't allow unqualified prejudgment to scare you off. The immediate impression of the potential complexities of an Instrument Control System, or perhaps the computer language which could be involved, must not bias you! Iook at your total goal, define one item at a time, and then let the computer programmer go to work. You can avoid a major problem by designing your system to be as flexible as possible. This will allow for the inevitable changes, as your knowledge of the need increases. (A beginner will not really know what is needed in specific terms.) Do not allow this virtue of flexibility to continually change your routine operations or reporting format. Such changes should be undertaken only when enough significant improvements can be anticipated. Constant change breeds misunderstanding.

In terminology, we run into the technically correct terms, versus those whose usages are commonly understood. A careful compromise will update others' thinking, without loss of understanding. Technically correct changes can be made gradually in the format during a system updating or modification. We must be able to communicate with data processing programmers or we will never get a system. Repeating a necessary condition: Think practically, look at your needs one item at a time, and define them so $Y O U$ can understand them. At the risk of being childish, commit all of this to writing. As you well know, that which was so clear in your mind becomes next to impossible to write down so it makes sense. However, herein lies the key to the communications link between the programmer, yourself, and the users.

Do not confine your system to its so-called technical aspects, those which you are most used to dealing with, but include management-type data! Make this tool work for you by providing educational information and capabilities. Set down a simple example of the potentials of managerial and educational aspects. A simple total of the yearly calibration hours supplies you and higher management with data concerning a portion of your laboratory personnel requirements. It pro- 
vides the seldom available, factual justification usually only hypothesized. Another point to keep in mind is that paper is cheaper than mistakes caused by overly complex, misunderstood, multiusage forms. However, a giant paper mill is just as self-destructive.

A summary of some things we consider as desirable in a control system:

1. It must accomplish the necessary tasks effectively.

2. It must show an effective profit.

3. It must use language understood by all recipients.

4. It must be flexible enough to change with the times and to fill unexpected needs.

5. It must have all unnecessary data removed from any report.

6. It must be able to supply all data available within practical limits.

7. It must limit input-output paper to practical numbers, and in a practical form for each user.

8. It must contain enough management data to result in an effective overall control system.

\section{Management Data}

I have already expressed a number of management-oriented ideas, but a few additional points should be reviewed. A quick look at higher management quite often discloses a man who takes both an accounting and a production viewpoint. You and I are quite apt to retire into our technically oriented shell and think only along these narrow lines. Under these conditions we cannot supply the necessary justifying data, or speak accurately or adequately in terms that are understood by others. In other words we haven't done our job. We probably don't really know our job if we don't have a good control system, since we must operate by "guesstimate" rather than facts.

Yes! It is our job to supply the required information to higher management, which needs to understand and thus justify the laboratory up the next rung of the ladder. Consider-we are the experts in our field, higher management is not. They therefore, must have information translated from technical to monitorial and production terms in order to understand and thus add support to our facility. Here again two-way education is the keynote to success. Higher management can be guided by obvious needs, government regulations, or corrective action in problem areas, but our information provides another major guidance. General management people can make our system work as a simple tool for them. We must approach the user (this includes those who should use but don't) with the suggestion that management has given him a tool to assure him that our laboratories supply the calibrations he needs for successful production. With this weapon at his command, we will have his cooperation and have less trouble doing the type of job we see as necessary. Production department demands for more and better calibrations, coupled with good business practices in our laboratories, should give us all the higher management support needed.

\section{A Coordinated Data System}

It has been noted that we require a data file on every precision instrument and standard to maintain control. This historical file contains the usual recalibration readings and repair activities along with a precisely defined data-collection procedure. This constitutes a carefully devised data system which has produced information capable of being statistically analyzed. The results of the data analyses are returned to the original system to provide corrective adjustments. In other words the data-collection procedure for each instrument must be in a true state of definable process control. This condition is mandatory before one can establish if an instrument is in a state of control. I must point out that experience shows that many laboratories only think they can produce valid answers, or calibrate within a definable range, or really define the limits of the device they have calibrated. It might shock you to know how much we depend on well-known laboratories-who are giving us answers generated from conditions which are not in a state of control.

Another important factor is the statistical analysis of the data, and its subsequent end usage. The overall problem is not simple and could deal with such complexities as error-combining procedures. However, less complex action can help most situations by looking at and defining individual parameters. Calibration parameters and intervals may be adjusted and new control limits may be established thru proper use of the analyzed data. The big point is, that most of us don't really know what our true condition is, and therefore it can not be defined or corrected.

Our laboratory uses a mixture of data collecting, handling, and processing media. Special forms are used where the ease of data collection or the next stage of processing may be facilitated, or human error can be reduced. We use desk calculators, small-scale computers, and large-scale computers to operate upon technical and scientific data. Here we all must face some compromises. We can obtain a small calculator at low initial cost, but we must do most of the data processing with the calculator handling one event at a time, and time is costly. There is also a high error probability, due to the human tendency to make mistakes. Computers have high initial costs and require programming, although once the program is written, costs per activity drop markedly. Oh yes, we need to communicate with the programmer, and it takes him time to develop a program. A possible approach to programming is to use a format which consists of sub-routines which may be inserted into many over-all programs without the cost of re-writing them. 


\section{Conclusion}

The previous paragraphs show a bias toward the need for CONTROL of technical and administrative data. The bias remains when suggesting some form of data processing. Developing definitely prescribed data systems will remove many of the questionable technical and administrative conditions which exist in most laboratories. Statistical methods provide one of the more effective tools to obtain over-all control. A detailed description of our complete system, with twelve illustrations, is contained in an Appendix* which may help get you started on a control system of your owll.

* Available upon request to the NCSI secretariat, \% National Bureau of Standards, Washlngton. D.C. 20234. 


\title{
IS THERE A FIGURE OF MERIT FOR THE MEASUREMENT PROCESS?
}

\author{
Loebe Julie
}

\author{
President, Julie Research Laboratories, Inc., 211 West 61st Street, New York, New York 10000
}

\begin{abstract}
This paper examines the hardware, software, and operator characteristics of a measurment facility and attempts to establish approximate value analysis guidelines for measurements as a system or process.
\end{abstract}

In the light of recent discussions of measurement "efficiency, effectivity, and productivity," it would be desirable to treat a measurement and calibration laboratory as a machine or processor, if by so doing we could apply quantitative measures and concepts, relating to efficiency, that are useful elsewhere. Let us then attempt to describe such a measurement processor as follows:

(1) Consider the entire process facility to encompass all of the measurement plant, test apparatus, and other stationary equipment. Also part of the processor are its personnel and its software facilities, including procedures, routines, test forms and other standard documents.

(2) The facility described processes an input work flow which consists of all devices submitted for test, calibration and/or adjustment.

(3) The input work flow may be of varying complexity ranging from components, sub-assemblies or instruments to complete systems.

(4) The work output consists of the submitted devices after processing, which may include classification into acceptable and rejected categories, or grading into many fine-structured classes of performance, or complete detailed testing (and/or adjustment) accompanied by software output in the form of certificates, reports, graphs and other data on device performance.

In spite of the fact that the measurement system handles an extremely varied work flow, it does permit quantitative measures of performance or efficiency. Efficiency for a conventional production process is characterized in terms of speed-quantity of work flow per hour of operator/machine time-related to the produotion facility cost (including operator) expressed per hour of operator/ machine time. Efficiency evaluation for varied production processes also takes into consideration the difference in quality levels of work being performed. Thus, there are different speed and cost performance quotas tabulated for the different quality levels of the process. This paper attempts a tentative appraisal of the parameters of measurement in terms of process performance, and to indicate definitions of work flow, speed, cost and quality of measurement in enough detail to suggest practical and useful concepts and guidelines for the measurement manager.

Effective measurement speed " $S$ "-In order to be usable in efficiency calculations, we must relate the definition of effective measurement speed to the concept of total operator/machine time required to achieve fully reliable, fully traceable, and fully reported measurements. Typically, large amounts of process time are consumed in maintenance, check measurements, data logging and data correction. Because of the considerable time spent not on direct dial readings but on establishing the validity of and correcting and reporting data, effective overall measurement speed is typically two to ten times lower than the speed of simple, direct, unchecked and unreported testing. Although the term speed is conversationally used in quantitative speed comparisons, it is customary to give units of time " $T$ " per measurement

$$
S=1 / T
$$

Direct test time "t" - the time required to make a simple direct, test observation without checking or reporting.

Test time multiplier " $M$ " - total measurement time divided by direct test time. This multiplier increases measurement cost proportionately, usually by a large factor.

$$
M=\frac{T}{t}
$$

Effective work-flow rate " $W "$-expressed as measurements performed or devices tested per hour of operator/machine total time. $W=1 / T$ Thus, $W$ and $S$ are numerically identical.

Facility cost rate " $F$ "-related to the total purchase cost of the facility, its depreciation and maintenance cost and the operator cost (depending on skill grade) including training costs. Expressed per hour of total operator/machine time.

Measurement cost rate " $C$ " - the effective cost of making a measurement or testing a device. 


$$
C=\frac{F}{W}=\frac{F}{S}=F T=F M t
$$

Measurement accuracy " $A$ "- this is perhaps the most significant measure of measurement quality and is widely used in an intuitive sense. It is not easily defined and will be used here in terms of its inverse-total limit of error.

$$
A=\frac{1}{T \cdot L \cdot E .}
$$

Presumably, based on this small number of definitions, we should be able to make simple performance, efficiency, or effectiveness comparisons between systems.

To do so it is first necessary to chose a figure of merit expression which weighs the various factors in a way which makes sense for our particular system requirement.

$$
f=\text { function of }(S, M, t, F)
$$

For example, in cases where measurement back$\log$ is overwhelming, measurement managers may wish to maximize speed regardless of cost; or where budget restrictions are excessive, to minimize facility cost rate; or where overall department efficiency is the paramount consideration, to minimize measurement cost rate. In any case, those factors which are of maximum importance are given weight 1 and those of minimum importance are given minimum weight (approaching zero). The most difficult maximization problem is that of minimizing overall measurement cost rate because this requires giving significant weight to the three competing factors- $F, M, t$-and carefully balancing system elements for maximum cost effectiveness simultaneously.

An analysis of these three cost-rate factors shows that they themselves are functions of many individual equipment design factors which directly affect measurement cost effectiveness. The effect and individual significance of these factors will be discussed in the remainder of this paper.

a. Equipment Initial Cost. This factor is usually considered as a major parameter of the buying decision. Most manufacturers provide a clear statement of the initial cost of their equipment.

b. Useful Life Including Probabitity of Design Obsolescence. This represents a hidden part of equipment cost and is usually not specified by either manufacturer or user in a very satisfactory way. Since the real impact of equipment cost is on a per year or rather on a per measurement-hour basis, equipment cost is not known unless useful life is accurately estimated. It is important to emphasize, since much calibration instrumentation becomes unuseful because of design obsolescence ather than by wearing out, that considerable shough should be given to the possibility that an instrument of a particular design and at a particu- lar accuracy limit will not be useful over en vugh years.

c. Equipment Versatitity (Useabitity). This is also a major factor of effective equipment cost because of the very low use factor of most calibration equipment. For example, a highly specialized piece of equipment costing $\$ 5,000$ and with a useful life of two years and with a usability of 100 hours per year has an effective cost of $\$ 25$ per hour of use. A slightly more expensive but more versatile equipment costing $\$ 6,000$ with a two-year useful life and with a usability of 300 hours per year has an effective equipment cost of $\$ 10$ per hour. The second instruments has 2.5 times the cost effectiveness of the first because of its greater usability.

d. Cost of Accessory and Auxitiary Catibration Equipment. This cost factor is usually not specified at the time of purchase, but may become painfully apparent at the end of the first calibration interval for the test instrument. 'The information is generally available as part of the manufacturer's instruction book and it is not at all unusual to find accessory and auxiliary equipment required for calibration that is several times as expensive as the instrument itself. Thus, a very-low-cost instrument performing the same function as the instruments described in (c) might have an initial cost of $\$ 2,000$, a useful life of two years and a useability of 100 hours per year with an effective cost of $\$ 10$ per hour. However, this instrument might also require $\$ 8,000$ worth of auxiliary calibration equipment of relatively low useability. If 10 percent of the cost of the auxiliary calibration equipment must be charged to the support of the test instrument, there is an additional $\$ 4.00$ an hour of cost for auxiliary calibration equipment. Labor costs for calibration must be added to this. See (h) and (i).

e. Cost of Installation, including Environment Control. This measurement system cost factor is usually not itemized as part of the equipment initial cost, although, like auxiliary calibration equipment cost, it can multiply effective cost many times. Thus, equipment which has been designed for use in carefully controlled environments may require special air conditioning, special humidity and other special environmental controls to operate within specifications. Although such carefully controlled environments may be available at the time new equipment is designed into an existing measurement system, this extra cost burden should not be neglected. If installation cost and environment control cost are considered in the initial stages of the design of a measurement facility, equipments may be selected all of which are relatively insensitive to environment. The savings achieved in plant structure and control represent a permanent "edge" in measurement cost effectiveness.

f. Equipment Accuracy. This refers to the ability of the test equipment to deliver measurements at various levels of quality. While some version of accuracy is generally specified by the manufac- 
turer, it is becoming increasingly difficult to determine the total limit of error. Where only error fragments or error statistics are given, it may be necessary to do the work of a legal statistician in order to determine equipment accuracy. Also, there is frequently confusion about whether the accuracy specified results from a direct reading or is that obtained after time-consuming operator corrections for the "systematic" instrument errors. Since highest measurement efficiency requires that measurements be performed at high test speeds, measurement efficiency drops if operator correction of data is needed.

g. Direct Test Speed. This refers to the time required for a simple direct measurement or test without check measurements, traceability, data correction or data logging. Large efficiency differences in direct test speed are possible between different design classes of instruments, generally as a function of detector response time and the detector sensitivity to overload. Where high-speed detectors are used which are insensitive to overload, a measurement can be made at the maximum speed at which operator can turn dials. Thus, in a direct speed test between measurement system A using a sensitive optical galvanometer and measurement system B using a high-speed overload-protected galvanometer of suitable design, a six-dial measurement may require two minutes for equipment $\mathrm{A}$ but only ten seconds for equipment $\mathrm{B}$ - a range of 12 to 1 . There may, however, be significant differences in the additional operator time required to verify the measurement. See $(h)$ and (i).

h. Confidence Level, Reliability, Verifiability. These characteristics of measurement equipment have a major influence on measurement efficiency but are not usually specified in a useable quantitative way. Instruments which are outstanding permit personnel to function in highly confident manner, spending maximum time on output measurements rather than on check measurements or data manipulations. Such certainty is highest for optimally simple equipment which is direct reading without correction, easily self-calibrating with fixed-point National Bureau of Standards references, maximally accurate and maximally stable. An outstanding example is an instrument like the electronic frequency counter, which functions as an optimal ratio instrument (time is subdivided), driven by a highly perfected and stable standardizeable source (crystal clock) and standardized against a small number of National Bureau of Standards frequency-standard reference points to establish traceability.

i. Operating Costs (Labor) for Correction, Restandardization, Recalibration, Retrimming and Maintenance. In evaluating equipments for measurement speed performance, total measurement time must be determined. Total Measurement Time, which we have already determined as the product of Direct Test Time and Test Time Mul- tiplier, may also be considered as the sum of Direct Test Time and Parasitic Time. The Test Time Multiplier may vary from slightly more than 1 , for high certainty instruments, to 10 or more for high parasitic-time instruments requiring frequent correction, restandardization, retrimming, recalibration or other maintenance. There is a wide variation between instruments otherwise equal in performance with respect to the ratio of operator time spent on direct test to time spent on instrument restandardization and checking. The effect is that of many small items and is cumulative. As a minor example, in precise potentiometric work an instrument designed to use storage batteries and without independent standardizing dials may require two minutes out of every ten to be spent on restandardizing working current, whereas a better designed potentiometer may need only one restandardization per day, taking only 30 seconds. Obviously, with regard to this one minor parasitic factor alone, output efficiency would be 20 percent higher for the latter instrument.

j. Direct and Indirect Cost of Periodic Outside Recertification. Traceability of the measurement process requires periodic validation back to $\mathrm{Na}$ tional Bureau of Standards reference levels of accuracy. Many classes of measurement instruments are recertified by direct submission of the entire instrument to a higher echelon laboratory. An instrument with 100 hours of useability and costing $\$ 150$ for the annual recertification fee and $\$ 50$ for handling charges has an additional direct cost of $\$ 2$ an hour for recertification. In addition, if the instrument is out of operation for such maintenance for two months out of every year, this $16 \%$ downtime represents an extra indirect cost.

It should be noted that an even more serious indirect cost is sometimes incurred when additional back-up instrumentation must be purchased and maintained in order to do the job of this instrument while it is being recertified. Under such conditions, excess measurement cost can exceed $100 \%$.

This problem has been attacked by the design of classes of instruments which use ratio techniques in an optimal way to permit simple, fast and completely autonomous recertification of instruments by the operator. In such ratio-type systems, National Bureau of Standards calibration of a laboratory's basic standards (frequency, resistance, voltage) is often sufficient to establish traceability of measurements. Instrument recertification costs, instrument downtime and instrument duplication are all eliminated.

k. Operator Prerequisite Technical Education;

1. Additional Training Time Required for Operators;

m. Availability and Cost of Continuing Education and Training Programs for Operators.

The effective hourly labor cost of measurement is highly variable, depending on the skill class of the operator or operators required and on the investment in specialized training required to make 
and keep them competent in the use of the measurement equipment. Where measurement equipment requires highly skilled operators for operation or maintenance, there is a danger not only of excessive measurement cost but of a partial or complete shutdown of the measurement process in the event of continued personnel shortages or excessive personnel turnover.

Assuming a situation of medium shortages where operators are available for training but must turn over their instrument assignments on the average of once a year, there may be a significant difference in cost between two classes of equipment. If four weeks of training is required on equipment $\mathrm{A}$, which has only 100 hours per year of useability, as opposed to one week on more versatile equipment $B$, which has 200 hours per year of useability, equipment $\mathrm{A}$ has an excess operator training cost of $160 \%$ whereas equipment $\mathrm{B}$ has an excess operator training cost of $20 \%$. In addition, if equipment $\mathrm{A}$ requires an operator with two years more of college or technical education than equipment $\mathrm{B}$, there may also be an hourly rate cost differential of more than twenty percent.

n. Availability of Suitable Class of Operators to Undergo Training. The rapid growth of measurements has led to the development of an educational gap in measurements and to a general shortage of trained or trainable measurement operators. Even if materials and training programs are made available for the training of operators on classes of equipment, there may be no practical or economical way in which to keep the measurement process going if student operators of requisite quality and background are not available to enter training. Recognition of this serious problem has led to the design and use of simpler "everyman" types of measurement equipment so that process continuation can be guaranteed under the worst conditions of personnel shortage.

A more recent attack on the growing operator shortage problem has been by the addition of automatability features to measurement instrumentation in order to simplify and save labor (See (r).)

o. Availability and Cost of Materials Required for Continued Use of Equipment; and

p. Availability and Cost of Valid Operating Procedures.

There may be appreciable cost differences between two designs of measurement systems depending on the cost of materials required for continued operation and the availability of prefabricated and simple, fast and efficient operating procedures. Operating procedures may represent a very significant cost item if efficient ones are not available cheaply. For example, if an equipment with 100 hours of useability and a useful life of two years requires two weeks per year of operator time for generating, debugging and documenting its test procedures, this represents an extra labor cost of 40 percent. To this should be added extra costs for production and publication of the procedures.

q. Appearance. This is the only factor that has no direct connection with measurement efficiency. However, attractive appearance of a facility is used in "selling" measurement service to prospective customers who stress appearance as opposed to performance as a figure-of-merit.

r. Automatability. As in other processesmanufacturing, for example, or clerical paperwork processes-the measurement process may soon reach the point where workload volume quotas, workload variety, or unit cost quotas may go beyond the limits that can be reached, even with the highest figure-of-merit manual operations, by skilled operators, or where such operators are not available in sufficient numbers for the given workload.

During the transition from a manual to an automatic or semi-automatic measurement era, the most efficient measurement facility will be one that is optimal in the manual mode and that is adapted for early, gradual conversion to semi-automatic and automatic operation.

Automatic features which may be considered are:
1. Data Logging
2. Data Storage
3. Data Playback
4. Programmed Testing
5. Computer Analysis
6. Computer Control
7. Automatic Balancing.

It certainly is too early for measurement superautomation incorporating all of the above because of technical problems, because of the size of the investment that would be required, and because of the practical questions that must be raised about the reliability and maintainability of the automation devices themselves. Some automation is technically and economically practical for consideration at this time and should be discussed briefly.

Data logging is presently feasible for automatic entry of data to printed tape or typed documents, eliminating time-consuming manual writing and transcribing of numbers by the operator. Simultaneously, the data may be entered and stored on punched tape or cards. Once stored, such data may be played back automatically to the test dials of a suitably designed measurement instrument, eliminating large amounts of operator dial setting time doing repetitive programmed tests of components or instruments. Also, once stored, the data can be played automatically from tape or cards into a standard computer for correction, averaging, determination of standard deviations or for even more sophisticated analysis and automatic printout of data, graphs and reports.

Conversion of a measurement facility to automation may be attempted on an instrument-by- 
instrument basis. This, however, leads to duplicacation of expensive interface and input/output data processing devices so that the cost of such an approach to automation may reach astronomical proportions. In addition, once such a facility is established, the training, calibration and maintenance burden of such large numbers of specialized machines may raise rather than lower manpower costs.

An opposite approach to the development of an automated facility is through the design of a large single automatic machine for measurements somewhat along the lines of the giant super-computers now in use. This is also extremely expensive approach and may be equally impractical from a technical, operational, training and maintenance point of view. Thus, in converting to automatic measurement, careful evaluation of all the cost, performance and maintenance factors must be made to avoid alternatives which may prove to be excessively expensive or unproductive.

\section{Summary}

Measurement equipment, facilities, and procedures have been examined as part of a work-flow system or process and many factors of the process figure-of-merit have been examined.

The quality and quantity of measurement work performed is describable in terms of elementary definitions of accuracy, speed, direct test time, test time multiplier, effective work-flow rate, facility cost rate and measurement cost rate. Any of these factors or a suitable combination of them can be used to give a quantitative figure-of-merit for measurement process efficiency.

Eighteen equipment figure-of-merit factors have been listed and their influence on measurement process performance and cost effectiveness discussed.

\section{Conclusions}

By applying process efficiency concepts to measurement performance, it is possible to see where changes in facilities and procedures will improve accuracy, speed, output and efficiency and lower costs.

Most of the factors responsible for low process efficiency have to do with low equipment or procedure accuracy, low effective speed, low equipment versatility, and high effective equipment cost.
Effective equipment costs are many times higher than initial costs because of hidden installation, operation, training and maintenance costs.

Effective equipment costs are also unnecessarily high because of specialized design which decreases usability, and premature obsolescence as a result of accuracy or speed limitations or nonadaptability to changing workload requirements.

Low process efficiency can also be related to the low ration of effective operator test time to total time.

In the same way that production processes have been made more efficient by providing operators with more efficient equipment and procedures, there is a possibility for a 2 to 10 times improvement in measurement process efficiency by similar improvements.

Process improvements can be evaluated quantitatively. A study is available which shows a figure-of-merit analysis for measurement speed and measurement accuracy versus measurement cost and evaluates the effect of improvements in those factors on overall measurement efficiency. ${ }^{1}$

Efficiency can be raised significantly if many time-consuming and repetitive parasitic operations now being performed can be simplified or eliminated, and if unnecessary investment in specialized (low useability) or high-maintenance machines-that is those with a large burden of of installation, recalibration, restandardization, retrimming correction, recertification and obsolescence costs-are eliminated.

In the same way that production processes have been made móre efficient by providing operators with practical labor-saving devices, it may be desirable to make a major improvement in measurement process efficiency by doing mechanically those many time-consuming and repetitive operations now done manually.

Automatable precision measurement equipment may be added to the measurement process in order to make it possible to adapt existing standard computer and automatic data processing hardware for mechanization of the routine repetitive parts of the measurement process. By so doing, there can be a gradual reduction in the present burden on the operator of manual entry of test results, manual setting of instrument dials to predetermined values, and manual manipulation of raw data to correct and convert it in a form suitable for final test reports.

1 "A Proposed Value Analysis for Measurements," Notes on the Julie Ratiometic Method of Measurement, pp. 16-19. 


\title{
TOTAL INSTRUMENT CONTROL
}

\author{
L. M. Auxier and L. A. Micco \\ Beckman Instruments, Inc. \\ Fullerton, California
}

\begin{abstract}
The maximum utilization of capital goods is used as a technique to control the purchase, use, and retirement of instruments. This responsibility has been assigned to the Corporate Reliability Engineering Department, which performs these functions through its Instrument Library. A description of the operation, including a manual Porta-Punch system for controlling the loan of instruments, will be presented; and a review of the growth and costs associated with this program also will be given.
\end{abstract}

\section{Discussion}

The concept of maximum utilization of company assets is not new. Industrial engineers have attempted to minimize capital expenditures for tools, molds and machines for many years. Added impetus was given this cost-saving method after War War II when commercial markets began to expand rapidly. At first, large sums of capital monies were spent to modernize and expand facilities to meet the ever growing demands of the economy. However, as this phase peaked out, and it became evident that economies must be effected, the idea of maximum utilization of existing facilities and resources became more appealing to management. This technique has proven to be one of the best methods for controlling capital spending without materially restraining the requirements of the operating divisions. Although this may sound like a paradox, believe me, it is not. However, it does require careful planning and central control of capital spending, plus availability and maintenance of a good stock of popular items. These must be coupled with a frequent physical inventory. The inventory is necessary to locate bootlegged or lost items, to permit quick retirement of instruments which require excessive repair, and to obtain information concerning change in emphasis of items being used. Above all, this program requires the backing of top management and an effective organization to implement it. The result is control of capital goods from the cradle to the grave.

This maximum utilization technique was first initiated at Beckman over ten years ago. The initial area attacked was that of machine tools, jigs, and fixtures. All capital items in the Corporation were brought under the cognizance of the Vice President of Manufacturing and under the direct responsibility of the Corporate Director of Industrial Engineering.
About this time, the question was asked, as I am sure it has been asked many times before and since, "How can we better utilize the electronic instruments which are beginning to pile up in our inventories? Why does every engineer and technician want his own pet instrument and refuse to share it with his neighbor?" The Beckman Instrument Library grew from an analysis of these and similar questions-it is a department devoted to the total control and maximum utilization of electronic instruments.

Before I proceed further, let me say that this system could not have been initiated without the whole-hearted support of management from the top down to the line supervisors. Nor could it have been successful without the proper attitude on the part of the people involved in the Instrument Library, as well as the confidence placed in these people by the personnel in the departments using the service.

Before detailing the operation of the Instrument Library, an outline of the structure and responsibilities of this group is in order. One year prior to the initiation of the Instrument Library, a Reliability Engineering Department had been formed at the Corporate level to evaluate components and instruments of the various Beckman Divisions before they were released to Production. Since calibrated test instruments are vital to the development and production of reliable instruments, it was decided that the Instrument Library would be associated with this Corporate Department. It has remained in this Department ever since.

The responsibilities which were initially assigned to the Instrument Library, as well as those subsequently assumed by the group, are as follows:

1. Assemble, evaluate, and formulate a yearly capital appropriations budget, covering the instrument requirements for all the Fullerton Divisions. 
2. Audit and implement the procedure for the purchase of items of the capital appropriations budget throughout the year.

3. Advise Corporate Industrial Engineering of the availability of instruments in surplus, the advisability of purchasing certain instrument types for standardization purposes, and whether or not a divisional instrument purchase request should come under the control of the Instrument Library.

4. Operate a loan-pool service for the benefit of the Divisions located at Fullerton. Make available, to outlying Divisions, instruments for shortterm loan; these usually are special-purpose instruments.

5. Maintain a facility capable of calibrating as many instrument types as is economically feasible, including an efficient recall system for these instruments.

6 . In conjunction with the preceeding responsibility $(\# 5)$, conduct a maintenace program to ensure reliable operation of the instruments between calibration periods.

7. As a matter of expediency and better control, operate an electrical metrology laboratory as an integral part of the Instrument Library.

8. Make available to the Fullerton Divisions a mechanical calibration facility. (Accomplished just during the past year, with the installation of a laminar-flow semi-clean room.)

9. Supervise a surplus pool of instruments for the entire Corporation, receiving units declared surplus by any and all Divisions.

10. Actively audit the reliability of the instruments in the loan pool. When data dictate, initiate a retirement proposal to remove defective, obsolete and/or little-used equipment from the Corporate files.

11. Conduct an inventory of all electrical test instruments in the Fullerton location in conjunction with the Corporate inventory conducted every four years.

When the Instrument Library was chartered, it was required to have a balanced budget. This was accomplished by placing a rental fee on the instruments borrowed. This fee reflects the depreciation of the instrument, the cost of calibration, and an estimated cost for maintenance. The revenue obtained from these rentals was added to the money received for calibration and maintenance of instruments not owned by the Instrument Library, for mechanical repair and calibration, and for primary calibration. The total income essentially balances the cost of the operation which includes salaries, rent for space, depreciation of instruments, and cost of parts. This type of funding has proved more equitable than any type of allocation back to the Divisions.

Until just recently, the procedure for recall of instruments, for the checkout of instruments, and for the billing of charges, was performed manually. Forms were developed for this purpose and data were reduced monthly on a hand calculator.
It was not practical to computerize for the few thousand instruments involved. It still isn't. However, with the help of the Corporate Data Processing Department, a "Manual/Computer System" was developed. All information associated with the instrument is stored in a 360 computer disc. This bank of data forms the basis for the recall system. The heart of the system is the IBM PortaPunch. All pertinent data for an instrument transaction is punched manually and simultaneously into two identical cards. One is filed in the Instrument Library while the other is sent to the computer to up-date the location information in the computer disc. When the instrument is returned, the filed card is punched with the return date, and sent to the computer. The computer stores information from all transaction cards until the 20th of the month, when it summarizes the charges by departments. For repair and calibration services performed on instruments not belonging to the Instrument Library, a single card is punched. This card also is used to document charges for supplies (such as chart paper) which are purchased through these facilities. The total charges for each department are printed out by the computer and forwarded to Corporate Accounting at the end of each month.

The present Instrument Library group includes a supervisor who is a measurement standards engineer, a clerk-typist, two expeditors to pick up and deliver instruments, four technicians, including a lead man performing secondary calibrations and maintenance on instruments, a mechanical metrologist, a mechanical technician, and an electronic metrologist, who assists in the calibration and maintenance when he is not performing primary electrical calibrations.

The inventory of instruments in the loan pool is presently at 3,000 (2,000 of which are on calibration), and an additional 1,000 are calibrated and maintained for other departments. Mechanical calibrations are performed on 1,000 devices. Electrical certifications are issued on 325 instruments. An indication of the volume of instruments handled is given by the total transactions conducted per month-currently 600. This figure includes only the pickup and return of rentals. There are also 2,000 instruments which are considered "permanent" loan, i.e., they have been loaned to the same individual for more than six months. Adding to these rentals the income from work performed on instruments owned by other departments, the operation currently grosses approximately $\$ 30,000$ per month.

It is interesting to see the growth of the facility over the past seven years (fig. 1). The graph shows the increase in total instruments being controlled and calibrated by this group, the average cost of maintaining an instrument per year (without labor, which gives an indication of the improvement in the instruments under the maintenance 
program) and the total man-months expended in the operation. The cross-hatched part of the bar graph includes times of personnel actively working on the calibration and maintenance program while the clear portion indicates the time spent on the nontechnical functions, such as pickup, delivery, and filing. Although this analysis is by no means complete, it has been used effectively by management as a guide to the cost and efficiency of the operation.

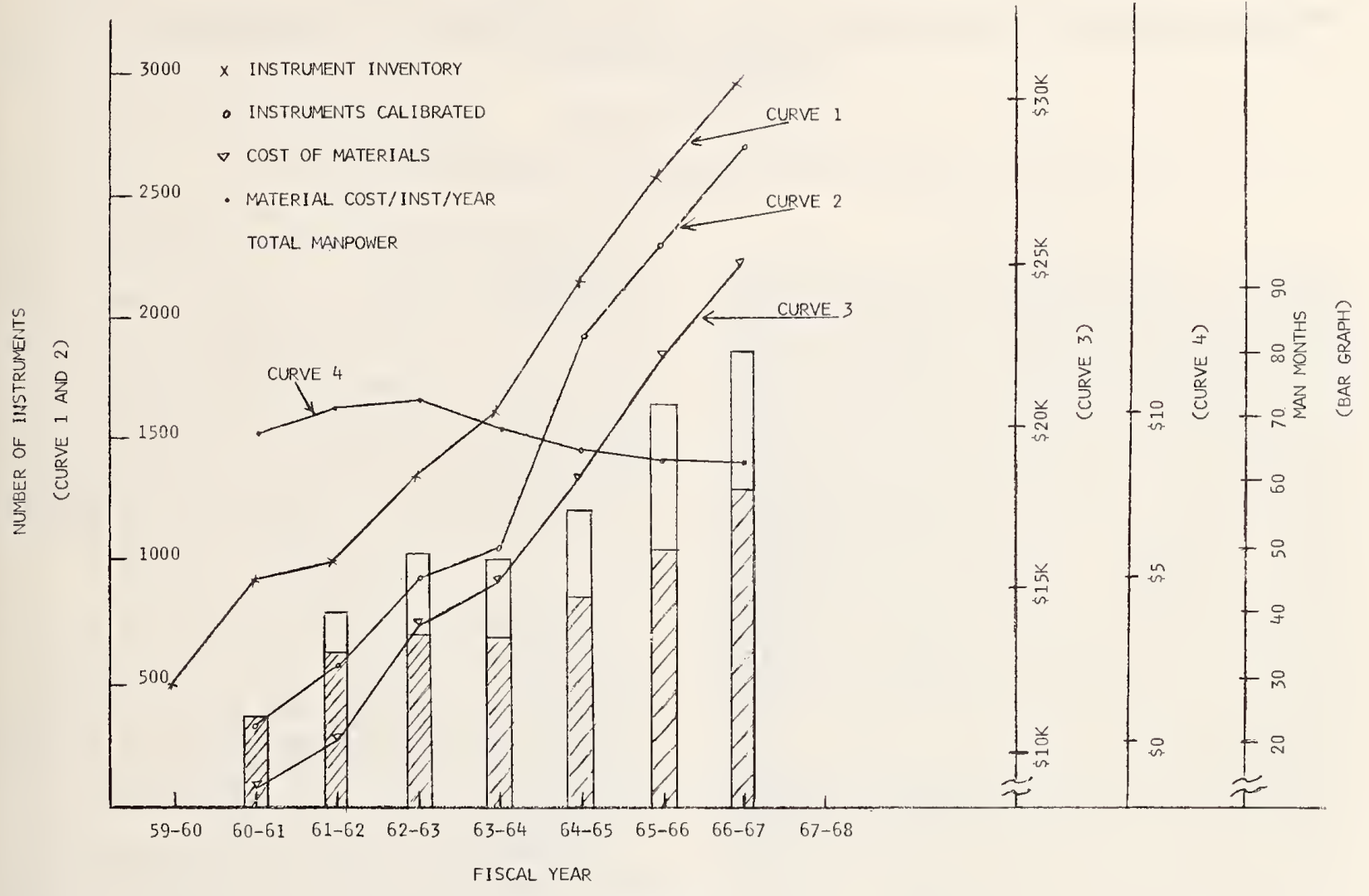

Figure 1. 


\title{
MANAGEMENT MEASUREMENT TECHNIQUES FOR CALIBRATION LABORATORIES
}

\author{
E. J. Arsenault \\ General Electric Company, Re-Entry Systems, Philadelphia, Pennsylvania 19104
}

\section{Introduction}

For years, management has applied the terms productivity, efficiency, effectiveness, and unit cost to assist them in the operation of their departments. Great success has been obtained by organizations dealing with high volume products for the consumer market. Standards have been established that can be employed by many companies to evaluate their own product line against that of their competitors. When these measurements are applied to complex technical activities such as that in a calibration laboratory, serious difficulties are encountered. The usual production standards cannot be used. Furthermore, there is a reluctance on the part of technical personnel to develop techniques that could rate them on such things as efficiency, productivity, etc.

Technical programs must be managed and evaluated against some form of standards. The failure of management to recognize this can result in a high-cost operation, with no way of assessing the value of the program. A calibration program had been established in 1957 at Re-Entry Systems. In 1962 , the program was reviewed to evaluate its contribution to the department. It became apparent that, because there was a lack of established standards, a management evaluation was impossible. The program had been in opertion for five years, and yet there was no way to answer these basic questions :

- Are the laboratories operating at a high efficiency?

- Is the quality level in the calibration program improving, or what level is being maintained?

- Do the laboratories operate at the same or better efficiency with the advent of newer, more complex equipment?

- What are the factors which influence the quality and reliability of a calibration program?

- How much analysis of the data obtained is being utilized?

A comprehensive program was established to achieve the following objectives:

- Establish a data analysis system to obtain maximum value for the calibration program.

- Develop measurement criteria.
- Identify standards to be maintained for a calibration program.

- Compare costs against other internal as well as external laboratories providing the same service.

This report describes that program and some of the experience gained in its application at ReEntry Systems. We believe we have achieved the following results:

1. Measurements of efficiency, productivity, effectiveness; economical limits, and the level of quality have been successfully applied for the past four years.

2. Standards have been established for all measurements, and for each type of calibration laboratory.

3. Effective programs for optimum calibration intervals and equipment replacement have been instituted.

After the experience of the past five years, we conclude that:

1. Laboratories of various technical disciplines can be measured and evaluated equitably through the establishment of a complexity rating system.

2. Operational failures and maintenance costs are the greatest contributing factors for low efficiency in operation of a calibration laboratory.

3. Cost per unit of productivity is an accurate measurement of operational cost for a calibration program.

\section{Productivity}

The standard employed to measure productivity in most laboratories is usually the number of instruments calibrated over a period of time. Although this old stand-by provides a representation of productivity, it has become greatly diluted with the advent of more sophisticated instrumentation. Really, to begin to define the true product of a laboratory, manager must first identifiy what he actually produces. Analysis will reveal that the only tangible evidence of laboratory productivity is its calibration record. Therefore, the true prodnct of a laboratory is calibration data.

Everyone agrees that the difference between instruments is in their technical complexity. Calibrating a voltmeter, as compared to an oscilloscope, which is a great deal more complex and 
requires a higher level of technical personnel and equipment to calibrate, cannot be given the same productivity rating. To develop a measurement of productivity requires that a criteria be established for the complexity rating of all instruments serviced. Some of the elements to consider in this complexity rating are:

- Technical level of personnel required

- Type and number of standards required for calibration capabilities (a fixed installation versus one that has to have a special lash-up)

- Extent of calibration procedures

- Number of data points obtained

- Normal or average time expected to perform calibration

The system for establishing the complexity rating should be kept simple. At Re-Entry Systems, ratings of $3,10,20,30$, and 50 have been assigned. $\mathrm{A}$ micrometer is rated a 3 and an oscilloscope is given a 50, for example. A rather complete list of complexity ratings is given in A ppendix C.

Since calibration data is the true product of the laboratories, the unit of complexity should then be related to that. Re-Entry Systems has established the Unit of Calibration Data (UCD) as the simplest unit of productivity, and one unit of complexity would be equivalent to one UCD.

\section{Efficiency}

Efficiency is assumed proportional to productivity per hour (UCD/hr). We must then establish a reference point for average output. We will assume tht average output is equivalent to 50 percent efficiency, and then assume a straight-line relation between them, as in figure 1. At Re-Entry Systems, we set 10 UDC's per hour $=50$ percent efficiency. Assuming total productivity of 10,450 UCD and a total calibration time of 940 hours, we get 11.1 $\mathrm{UCD} / \mathrm{hr}$, and proportionally $50 \times 11.1 / 10=56 \mathrm{per}$ cent overall efficiency.

Caution should be exercised and a well-known average of productivity determined before establishing average efficiency rating as 50 percent.

\section{Effectiveness}

Effectiveness is defined as the ratio of actual time expended to the potential time available. Suppose a technician is assigned 40 hours a week to perform calibration, and a review of calibration records submitted by him indicates that a total of 32 hours has been accounted for. The ratio $32 / 40=$ 80 percent effectiveness. This technique can be administered if a laboratory records its labor time through a voucher system.

\section{Maintenance Productivity}

We have discussed how to measure the productivity of calibration effort. However, when applying this technique to the maintenance area, we en-

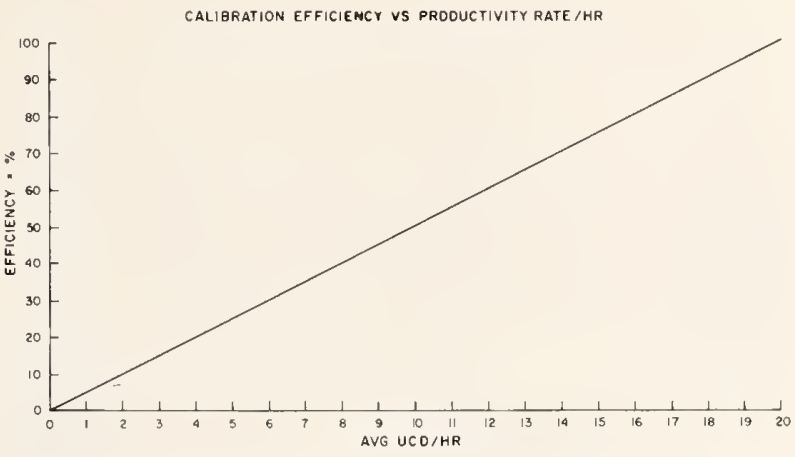

FIG. 1. Assigned relation of efficiency to UCD's per hour.

counter a problem which is unique. First of all, maintenance must be separated from calibration. If not, it will seriously affect the validity of the calibration productivity measurement. Since maintenance cannot be accurately predicted, there is a temptation to establish an average $\mathrm{UCD} / \mathrm{hr}$. However, a flat rate cannot be established as this would not take into account efficiency. Our approach has been to assume that the technician's productivity, efficiency, and effectiveness in maintenance effort is the same as that applied to calibration. For example: an oscilloscope has a complexity rating of 50 UCD's, and a technician required 3 hours to calibrate the instrument. In addition, he applied 2 hours to maintenance. What is his productivity? Calibration productivity rate per hour equals total UCD's per calibration total hours $=50 / 3=16.6$ $\mathrm{UCD} / \mathrm{hr}$. (This is equivalent to an efficiency rating of 83 percent). Maintenance productivity would then be $16.6 \times 2=33 \mathrm{UCD}$, and total productivity $=50+33=83$ UCD.

\section{Operational Costs}

The definition of operational cost is the labor and material expended to produce a product, plus operational overhead expenses. Since the product of a calibration laboratory is data, represented by the UCD as the unit of productivity. Therefore, the cost/UCD can serve as an excellent measure of the operational costs of a calibration program:

$$
\frac{\text { Cost of operation }+ \text { profit }}{\text { Productivity in UCD }}=\text { Cost } / \text { UCD. }
$$

If for a period of one month, productivity was 3500 UCD's, and the cost of operation was $\$ 3,255$, then $\$ 3,255 / 3500=\$ 0.93 /$ UCD. (Most calibration laboratories have a parent operation, so that a profit is usually omitted in calculating the cost of operation.)

The breadth of definition of operational charges is the key to obtaining an accurate cost/UCD. The best suggestion is to be as factual as possible in listing all overheads. Plotting the cost/UCD along 


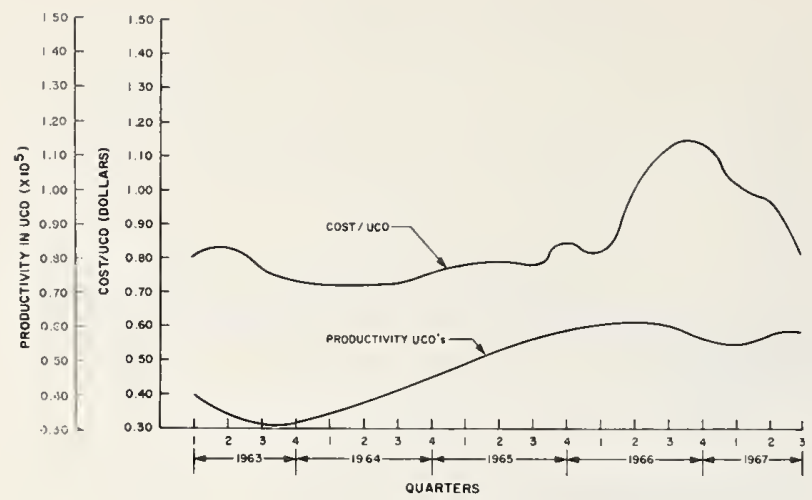

FIG. 2. History of productivity and costs.

with the productivity level, as in figure 2 , will provide a management tool which measures the cost of operation regardless of the changes in the levels of productivity.

\section{Optimum Calibration Cycles}

Our study has shown that calibration intervals are the outstanding factor which influences manpower, capability, facilities, cost of operation, even the extent of an organization's inventory. The whole calibration program revolves about this cycle; it controls the level of quality and the total cost. Open up the average calibration interval by 10 percent, and manpower, operating costs, facilities, etc. (assuming the inventory constant) will drop accordingly. Close the calibration cycle by the same degree, and costs will go up.

It is most important to establish some reference for the assignment of calibration intervals for each family of instruments. In the past, many calibration cycles were established based on tradition. Consideration must be given to determine effect of age, use, and other which may cause deterioration to quality. The techniques employed by the Standards and Calibration Laboratories is based on a statistical probability approach developed in 1964. A very simple system of calculation is used, using the recorded average failure rate (failure per item per year, or FIY) for any group of (say 25) instruments with data available for a year or more. Constants derived from a Poisson distribution table for confidence levels of 99,95 , 90 and 85 percent are multiplied by a known FIY to determine a mean demand rate (MDR) i.e. the expected demand for calibration (or maintenance) service, in pieces per year. Normally, the Standards and Calibration Laboratories have striven to maintain a confidence level of 85 to 95 percent. The value for an optimum calibration cycle in months is the quotient $12 / \mathrm{MDR}$, and a plot of such values is shown in figure 3. As long as the FIY does not alter significantly, we can assume we are operating on the optimum curve.

\section{Economical Limits}

The problem of identifying the economical limits of servicing by the calibration laboratory has always been a challenge to management. The laboratory is concerned with the cost of maintaining an instrument. The user's views are more concerned with employing equipment which has the greatest depenability and will encounter minimum down-time. Both these requirements must be met, and quality and reliability have been established as the measurement parameters for economical limit. The prime requisite to this measurement is a standard definition for both quality failures and reliability failures, such as the one employed by Re-Entry Systems (Appendix B). The next step is to select a level of confidence adequate to maintain quality and reliability. In figure 3 , it will be noted that the optimum calibration cycle differs very little for confidence levels from 90 to 99 percent.

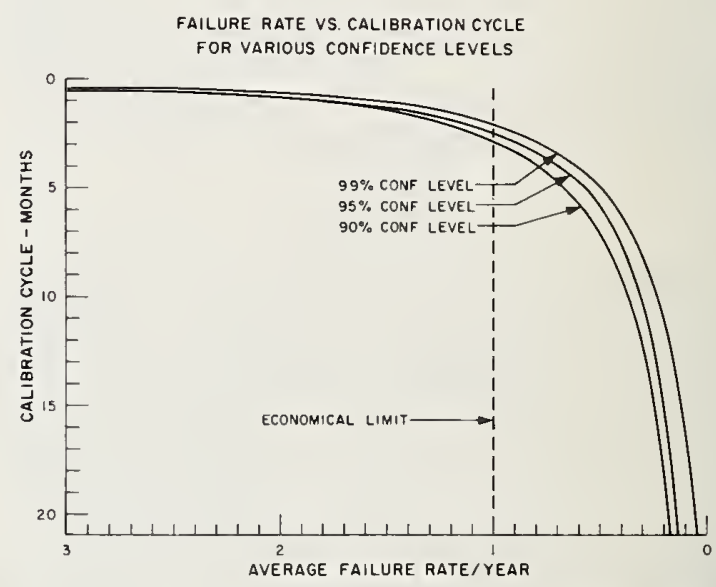

FIG. 3. Optimum calibration cycle based on average failure rate, at various confidence levels.

In figure 4 , the 95 percent curve of figure 3 appears with the legend "Quality Level." Its terminus at about 3 months sets the economical limit for supplying calibration/maintenance service on any group of instruments having a quality failure rate as high as one per year. A similar (dashed) curve shows about one month as the economical limit for a group having a reliability failure rate as high as two per year.

Employing this technique, along with several years of experience, enabled the Standards and Calibration Laboratories to establish the following economical/limits to continued servicing of a family of instruments:

- One quality failure per year

- Tro reliability failures per year

- A combination of quality and reliability failures exceeding 3 . 


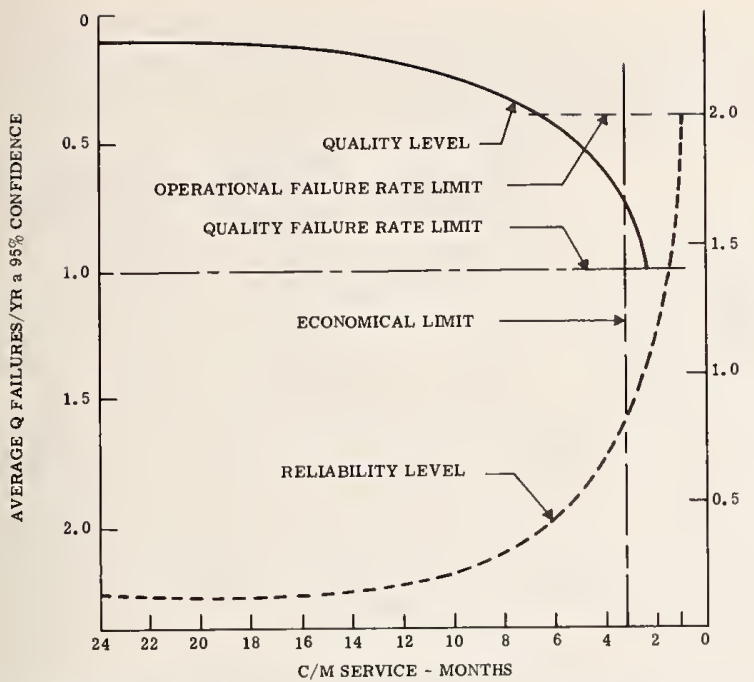

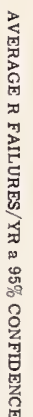

FIG. 4. Economical limit of calibration and maintenance interval based on quality level and reliability level.

The last action was to limit labor and material expenditures to 25 percent of the first cost value of any instrument. No repairs were permitted until investigations were completed to determine the real need for such expenditures. When approval was obtained to perform repairs, the expense funding was considered to be a capital investment and was so treated.

\section{"Quality-Rating” of a Calibration Program}

An important management tool is to be able to adequately rate the "quality" of a calibration program. This must be accomplished for not only monitoring the level of quality, but to identify which parameters are causing the greatest effect.

First, the establishment of the parameters to be measured is required. Those selected are the ones which most affect the quality of the program. At Re-Entery System, the following parameters have been established:

\section{Parameter Monitored}

Quality failures of instrument family

Operational failures of instrument family

Instruments received "over-due" for Control calibration (by 60 days)

The percentage of over-due calibration instruments was computed as follows for instruments which were found to be still in specification, and plotted as in figure 5 :

"Q" $\mathrm{Q} "$ Quality rating in percent $=100 \mathrm{Y} / \mathrm{X}$

$X=$ Number of instruments (total serviced)

$\mathrm{Y}=$ Number of instruments in specs on schedule A variation of this can be applied to compute a Zero Defects rating (fig. 5) :

$\mathrm{Z}$ D percent $=100(\mathrm{~A}+\mathrm{B}+\mathrm{C}) /(\mathrm{X}+\mathrm{Y})$
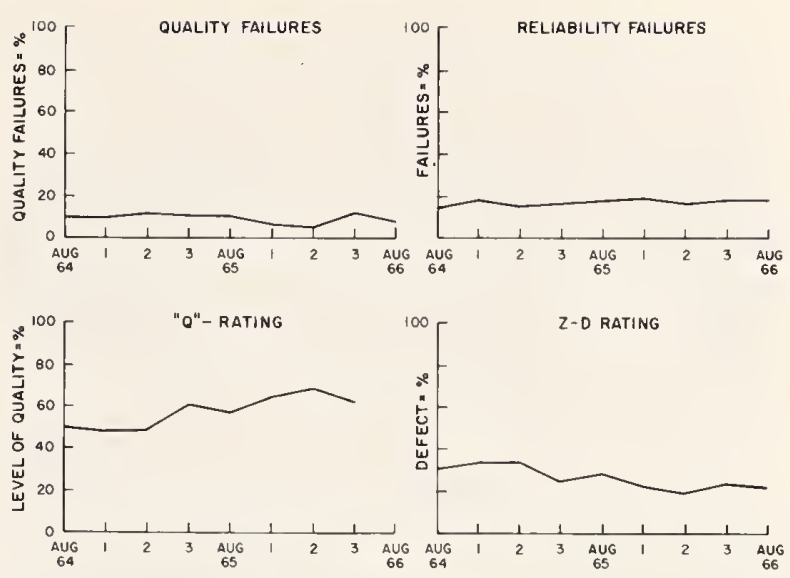

FIG. 5. Quality rating and zero-defects rating on calibration program.

$A=$ Number of instruments out of specs

$\mathrm{B}=$ Number of instruments over-due calibration $\mathrm{C}=$ Number of instruments having operational failures

Note that if all defects are eliminated, then the numerator becomes zero and the defects rating is 0 percent, and if all instruments have defects, the defects rating is 100 percent. In either technique, all five parameters are monitored to allow determination of those most influential.

\section{Application Results}

The UCD as a unit of productivity has been employed very successfully to measure output among technicians, regardless of the area of calibration in which they work. The results (see fig. 6 covering 21 technicians for a six-month period) indicate that a top-grade technician can consistently operate at 75 percent efficiency in electronic calibration. In a dimensional laboratory the average technician operates at 35 percent efficiency. First reaction might be that the rating is not equitable between electronic and dimensional areas. However, note that in the dimensional laboratory the amount of administrative work relative to actual calibration work is proportionately higher.

An interesting comparison is that of productivity and efficiency in the Standards Laboratory and the Calibration Laboratory. With similar equipment the Calibration Laboratory performs at 65 percent efficiency, while the Standards Laboratory operates at 50 percent. Consider that the Standards Laboratory is not high-volume oriented, and usually has to make a complete new set-up prior to performing a job. Because of the higher order of accuracy, consideration of environmental conditions, stability of readings, calculation of data, etc. that are required, they are necessarily less efficient than the Calibration Laboratory. 
Average effectiveness of our technicians ranged between 65 and 85 percent. Investigation revealed that the lower effectiveness ratings were due to handling unique or special jobs which were unscheduled and required much preparation without any advance notice. A lack of good documentation of time of the technicians was a problem. It was necessary to establish separate job numbers for miscellaneous tasks performed by technicians (clean-up, filing, sorting, spare parts, etc.) in order to accurately record calibration labor.

One of the most interesting trend indicators is the cost per unit of productivity (fig. 2). In 1963, the laboratories output averaged 34,200 UCD's/ month at an operating cost of $\$ 0.78 / \mathrm{UCD}$. In 1964 , an increase in productivity by 12 percent was accomplished which reduced cost/UCD by 5 percent. A major contribution to this improvement was the Selected Calibration Program (SCP) which was established. SCP allowed only instruments which were "clean," not "dogs," to be processed. Since this was accomplished during austere times, manpower was numerically low but consisted of the most experienced technicians. The result was high productivity per. hour at minimum cost. The following year, a further increase in productivity of 8 percent was obtained; however, the cost/UCD increased by 20 percent. Analysis revealed that with increased expenses for material, contract services, and additional non-productive personnel (engineers, clerks, supervisors) effectiveness dropped, especially while new personnel were being trained by experienced technicians. A 44 percent increase in maintenance services was caused by the elimination of SCP. The laboratory was now servicing any and all instruments and therefore were encountering more "dogs." Over the same period, an increase of overtime also contributed to the increased cost of productivity.

Productivity and efficiency measurements were compared among technicians. Additional measurements of maintenance and set-up time were in-

STANDARDS AND CALIBRATION LABORATORIES EFFECTIVENESS AND COMPLEXITY LAST HALF 1963

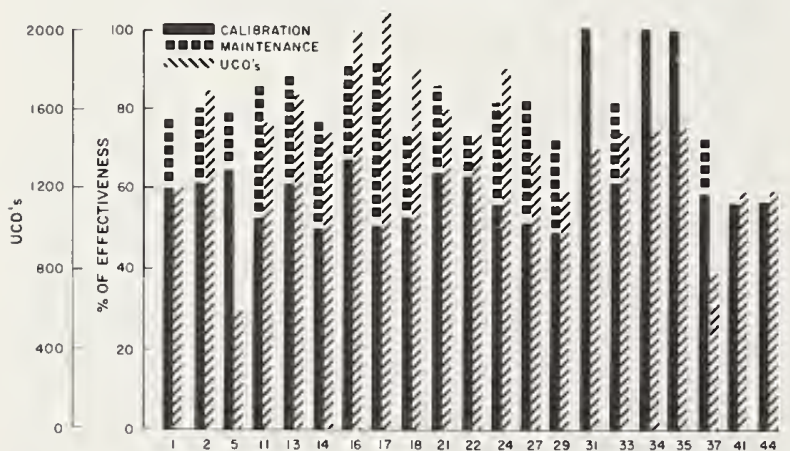

FIG. 6. Comparison of effectiveness of technicians in Standards Laboratory. Electronic Calibration Laboratory, and Dimensional Laboratory. cluded. After three years of monitoring data, the several laboratories established the averages indicated below (fig. 6).

$\begin{array}{llll} & \begin{array}{l}\text { Standards } \\ \text { Laboratory }\end{array} & \begin{array}{c}\text { Electronic } \\ \text { Calibration } \\ \text { Laboratory }\end{array} & \begin{array}{c}\text { Dimensional } \\ \text { Laboratory }\end{array} \\ \text { Efficiency } & 50 \% & 65 \% & 35 \% \\ \text { Productivity } & 10 \mathrm{UCD} & 13 \mathrm{UCD} & 7 \text { UCD } \\ \text { Rate/Hr } & & 20 \% & 0.5 \% \\ \text { Maintenance } & 5 \% & 10 \% & \\ \text { Set-up Time } & 15 \% & 75 \% & 95 \% \\ \text { Effectiveness } & 85 \% & & \end{array}$

These averages represent a reliable standard to rate both technicians and individual laboratories.

Whenever possible, the calibration interval is established with a confidence level of 95 percent. The average failure rate of a family of instruments is monitored monthly. Should this figure exceed one, then a detailed investigation is conducted to determine the cause of this increase. Experience has shown us that the increase in failure rate of any family is due to only 15 to 25 percent of the instruments within that family, but accounts for 40 to 60 percent of the failures. Further evaluation positively shows that through replacement of this minority group, average failure rate of the entire family will be lowered to such an extent that the optimum calibration cycle can be increased by 25 to 50 percent.

The program for optimum calibration cycles was developed in 1964 by the Standards and Calibration Laboratories. Since the inception of this program, we have gained sufficient experience to recognize that when quality failure averages exceed one per year, regardless of the desired confidence level, the cost is prohibitively high compared to the small gains in quality shown in figure 3 . Up to now, we have identified the desired quality level of our test equipment; however, no attempt has been made to identify the reliability level. Since 1964, we have monitored the trend of operational test equipment failures in Re-Entry Systems. This trend has increased from a base of 13 percent in 1964 to a rate of 18 percent (figure $5)$. If we consider that the number of instruments serviced by the laboratories in 1966 as compared to 1964 has increased by 52 percent, the rise in operational failures takes on even further significance.

Because of this trend, it became necessary to establish an optimum curve for reliability. Since the Poisson distribution table of Appendix A was really composed of constants for the reliability of electronic components, we employed the same techniques for a reliability curve as we had for a quality curve. Again, relying on the experience we had gained over the past few years, we established a reliability failure rate of 2 per year as a limit that any family or individual instrument should encounter.

The last consideration for economical limitation was the combination of quality and reliability fail- 
ures. This limitation was established by selecting points on the quality and reliability curve at which the slope became relatively steep. The reliability and quality curves are presented in figure 4, and a compromise economical limit is marked.

Our initial experience with applying this statistical technique for calibration intervals, revealed that we had an unbalanced distribution of quality in the calibration program. There were a large number of instruments which were being "over" calibrated and a substantial number "under" calibrated. This unbalanced distribution of quality was corrected by proper adjustments in calibration intervals based on data from the previous two years. The overall average calibration cycle increased 11 percent without any increase in cost of operation.

A concentrated effort was applied to the families of instruments which exhibited higher $Q$ \& $R$ failure rates. The results of this effort produced an equipment replacement program designed to remove individual instruments which had been identified as exceeding economical limits. This was administered by placing these items on their own calibration cycle. Continued applications of these techniques have produced an average calibration interval 23 percent longer than existed prior to the adoption of this program. Most important, the level of quality maintained on instruments has been improved. A good example of "over" calibrating was in the dimensional area: after four years of statistical analysis, the present average of calibration intervals is 40 percent longer than it was. It is now standard procedure that any instrument which has quality and reliability failures above limits for two years in a row is automatically placed on the replacement list.

Many companies have established calibration programs to meet the requirements of military specifications. These programs represent a substantial initial investment as well as a considerable amount of money to maintain. A technique for management to evaluate performance becomes a necessity.

The " $Q$ "-rating for a calibration program has been in existence for the past three years at ReEntry Systems. Figure 5 displays a 2-year record. The rating is monitored monthly, and semi-annual reports are issued to higher management. The reports identify the areas which must be emphasized to improve the effectiveness of the calibration program. The present goal for Re-Entry Systems is to obtain an average " $Q$ "-rating of 80 percent. To achieve this, quality and reliability failures of less than 15 percent must be maintained while the "over-due" instruments must be less than 5 percent. This, in turn, requires that the equipment replacement program has to be 90 percent effective so as to eliminate instruments exceeding economical limits from the active listing.

\section{Summary}

The use of the measurements described has supplied management with sufficient information to determine when any deviations from established standards occur. The cost of maintaining this system is minimal, and only during initial set-up are any substantial costs encountered. These measurements should be implemented for a period of at least one year prior to any attempt to establish standards.

Experience has shown that all these measurements are interacting. To rely on only one or two would be misleading. If for example, standards of 75 percent efficiency and 90 percent effectiveness were established and achieved, we might assume that the goal had been met. However, maintenance effort must not be overlooked; simultaneously, it might have increased to 50 percent, an alarming level which could not be detected by measurement of either efficiency or effectiveness. The same can be said about set-up time, an area in our operation too important to be ignored. Therefore all four parameters are monitored, and established levels for each are employed to measure overall performance.

The complexity rating becomes the basis for charging all customers for services rendered by the Calibration Laboratory. All costs can be quoted on a firm price based on the cost/UCD. This approach is more accurate than charging by estimated labor hours. Also, the responsibility to provide services within the price quoted motivates the laboratory to operate within accepted efficiency levels.

Appendix A. Table of Poisson Distributions for Selecting Optimum Calibration Cycles

\begin{tabular}{ccccc}
\hline $\begin{array}{c}\text { Failures* } \\
\text { per item } \\
\text { per year }\end{array}$ & $\begin{array}{c}C \\
\text { for } 99 \\
\text { percent }\end{array}$ & $\begin{array}{c}C \\
\text { for } 95 \\
\text { percent }\end{array}$ & $\begin{array}{c}C \\
\text { for } 90 \\
\text { percent }\end{array}$ & $\begin{array}{c}C \\
\text { for } 85 \\
\text { percent }\end{array}$ \\
\hline & & & & \\
0 & 4.6 & 3.0 & 2.3 & 1.9 \\
1 & 6.7 & 4.7 & 3.9 & 3.4 \\
2 & 8.4 & 6.3 & 5.4 & 4.8 \\
3 & 10.7 & 7.7 & 6.6 & 6.1 \\
4 & 11.7 & 9.0 & 8.0 & 7.3 \\
5 & 13.9 & 10.6 & 9.1 & 8.5 \\
& & & & \\
6 & 14.6 & 12.0 & 10.6 & 9.7 \\
7 & 16.0 & 13.0 & 11.8 & 10.9 \\
8 & 17.6 & 14.6 & 13.0 & 12.1 \\
9 & 18.9 & 16.0 & 14.8 & 13.3 \\
10 & 20.2 & 17.0 & 15.2 & 14.4 \\
& & & & \\
11 & 21.5 & 18.0 & 16.6 & 15.6 \\
12 & 22.9 & 19.5 & 17.8 & 16.7 \\
13 & 24.2 & 21.0 & 18.8 & 17.9 \\
14 & 25.2 & 22.0 & 20.2 & 19.0 \\
15 & 26.8 & 23.0 & 21.0 & 20.1 \\
& & & & \\
\hline
\end{tabular}

*In selecting the proper constant, any FIY from zero to 1 should use the constants listed under the failure rate of 1 . For any failure rate greater than 1 , but not exceeding 2 , we use the line of constants listed under failure rate 2 , and so on. 


\section{Appendix B. Determination of Specification/Operational Equipment Failure}

\section{Purpose}

To establish responsibility and guidelines for classification of equipment performance at time of receipt for calibration/maintenance servicing. Standardization of classification interpretation is required to normalize failure data used as inputs to a statistical determination of an optimum calibration cycle.

\section{Criteria}

For purposes of this procedure, two conditions will be considered for interpretation:

(a) Specification compliance ("In" or "Out")

(b) Operational performance ("In" or "Out")

The criterion for "Out of Specification" classification is that the instrument as received will not produce quality data, for those parameters it is intended to measure, with the accuracy set forth in the manufacturer's specifications. This determination is to be made prior to any adjustments.

The criteria for "Operational Failure" classification are that a significant circuit function of the instrument will not perform, or the instrument cannot be properly set up to make measurements, or the instrument has mechanically failed.

Operational failure does not necessarily constitute specification failure. If, after restoration of proper operation through component replacement, the instrument is found to comply with performance specifications without calibration adjustment other than optimizing the replaced component in a circuit, then the instrument has operationally failed, but is still maintaining specifications.

If a component has failed in an accuracy-determining network, then the "Specification Compliance" classification shall be discounted in selecting a new calibration cycle. Similarly, if an instrument is received which has been misused, (input network burned out, etc.), or abused, (obvious rough handling, improper ventilation, etc.) it shall not be considered for rating as to operational or specification performance.

Failure of minor components such as fuses or indicators, which fail due to factors not circuit-induced, shall not be cause for rating the instrument as operationally failed. The minor failure should be remedied, and the instrument considered as a submission for normal calibration servicing.

\section{Responsibilities and Procedure}

Each laboratory supervisor will designate one technician whó will be responsible for the review and rating of historical records generated by that laboratory. Another technician performing the calibration/maintenance action will record pertinent "before calibration" data prior to adjustment procedure. He will then proceed with making all calibration adjustments to optimum nominal, unless otherwise instructed, after which he is to complete all blocks of the Calibration-Maintenance Report, with the exception of specification compliance and operational performance, and forward his records to the designated reviewing technician. Based on interpretation of the records, in the context of the philosophy discussed earlier, the reviewing technician will annotate these ratings.

The reviewing technician should establish a notebook listing pertinent factors for each category and type of instrument reviewed, as follows:

(a) Significant parameters and checks which are considered indicative of data quality from the instrument under test and are determinant in "Specification Compliance" rating.

(b) Checks which if found with specification limits do not call for adjustment.

(c) Checks where the adjustment should be on the high or low side, to account for predicted drift rate and direction.

(d) Information on the aging and maintenance characteristics of the instrument, including specific techniques which have been successfully (or unsuccessfully) employed.

The information collected in this fashion will be used to formulate instructions on adjustments and rating factors for use in future historical records. The immediate laboratory supervisor is responsible for implementation and sustaining this procedure, and rendering assistance in interpretation of rating. The Standards \& Measurements Engineering Group will render assistance in data analysis and determinations of adjustments criteria.

\section{Appendix C. Complexity Rating of Instruments}

\section{Type of Instrument}

Micrometer (all sizes)

Dial Indicator

Caliper

Temperature Controller

Multi-meter

Sub-carrier Amp.

Power Supply

Xtal Oscillator

D.C. Amplifier

Plug IN TEA K

Voltmeter DP-2

Voltmeter 320

Voltmeter DV40

VTVM $400 \mathrm{HR}$

Accelerometers (all)

Divider $80 \mathrm{~A}-5$

Test Panel

Voltmeter 451-R

Oscillator 140-A

Pressure Gauge (Heise)

Pressure Gauge (Wallace \& Tiernan)

Scale (Toledo) 2151

Scale 0-2600GR

Voltmeter 7200-A

$$
\text { Rating (U.C.D.'s) }
$$

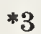

*3 $* 3$

*Or 5 , convenience of calculation.

\section{Type of Instrument}

Voltmeter $6200-\mathrm{A}$

Counter 524-B

Signal Generator 202-G

Vibrationmeter N499

Bridge 1650-A

Resistor 8315

Pulse Generator PG-32

Signal Generator 606-A

Power Meter 431-B

Oscilloscope TEA (All models)

Analyzer SS-500

Sweep Oscillator 692-B

Recorder Oscillograph

Wave Amplifier 277-B

Attenuator

Indicator $415-\mathrm{B}$

Beam Osc. 132-A

Function Generator 203-A

Vacuum Gauge M34-7R

B \& K Exciter 1028

Shock Amplifier 2718

D.C. Voltmeter DP11

Volt/Ohm Milliammeter 269

Power Supply LE104FM

Pressure Gauge

Digital Voltmeter 5400
Rating (U.C.D.'s)

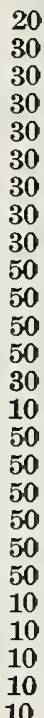


Appendix C. Complexity Rating of Instruments-Continued

Type of Instrument

Capacitor Decade 219K

$\mathrm{X}-\mathrm{Y}$ Recorder 135AM

Test Oscillator 650A

EPUT timer 7350

Wavemeter 2335-4

Frequency Meter 802B

Logarithmic Converter $60 \mathrm{D}$

Wide-Band Preamp. $\mathrm{H}$
Rating (U.C.D.'s)

20

20

20

20

20

30

20

20
Type of Instrument

Attenuator $350 \mathrm{~B}$

Temperature Controller

Pressure Transducer 607L

Electronic Counter 524C

V.H.F. Signal Gen. 608D

Oscilloscope 531

Oscilloscope 547

Accessory Module 030
Rating (U.C.D.'s)

20

20

20

30

30

30

50

50 


\title{
DETECTING ECONOMIC OBSOLESCENCE IN MEASUREMENT EQUIPMENT
}

\author{
C. R. Duda \\ McDonnell-Douglas Astronautics Company, Santa Monica, California 90406
}

\begin{abstract}
This report outlines two methods to determine optimum replacement age for individual test and measuring instruments, based on operation at minimum cost rates: The first method requires accumulation of the combined cost of calibration, maintenance, and repair from the date of equipment purchase. The second method requires only a relatively short sample of the existing service-cost rate. By assuming a logarithmic growth of service costs, one can reasonably predict when the equipment will reach-or perhaps has reached-a point when replacement on an economic basis should be considered. This method provides advantages both in forecasting probable equipment replacement dates, and in locating economically obsolete equipment within an established inventory.
\end{abstract}

\section{Introduction}

The existence of obsolete laboratory and test equipment within a company is undesirable but often undetected. Commonly, obsolescence is associated with equipment that has outlived its usefulness, and has become neglected and antiquated. A more subtle form of obsolescence, however, may affect equipment still in everyday useequipment that exhibits every sign of continued service and well being. This form of obsolescence, economic in origin, can unnecessarily drain a company of thousands of dollars yearly. A method uncovering this waste is described in this report. But first let us examine technological obsolescence-the more obvious form caused by advances in equipment technology.

\section{Technological Obsolescence}

The application of new and better manufacturing methods and processes leads to new and better equipment. Existing equipment, in comparison, has lower capability, which gradually results in lower utilization. A measure of technological obsolescence would concern itself with decreasing capability and lower utilization of equipment. As a partial solution to this problem, equipment suffering from decreasing utilization can be reassigned to a more appropriate area. The "obsolete" instrument in a research laboratory may be ideally suited to the needs of a testing laboratory.

To solve such utilization problems, many companies have set up centralized equipment management areas to assign, deploy, and purchase equipment. Despite initial success in forestalling technological obsolescence by transferring equipment, normal aging processes must eventually provide cause to consider replacement. At this point, perhaps, the point of initial obsolescence has long since passed, due to unsuspected economic reasons.

\section{The Patterns of Cost}

The true cost of equipment is measured not by acquisition cost alone, but also by the service charges accumulated during its lifetime. These service charges include calibration, maintenance, and repair of the equipment. Customarily, such costs are treated in bulk, perhaps in the form of average figures, and seldom are regarded as a relevant characteristic of individual equipment. Yet individual service cost is the key factor in the determination of equipment obsolescence.

A typical instrument might exhibit the economic pattern indicated in figure 1 . Costs begin with the purchase price of the unit and thereafter start to climb with an upward curvature as services charges are incurred. A line through the origin tangent to this curve represents the minimum-cost rate as equipment ages or is replaced. When the equipment is new, service is apt to be minimal. But as components age and parts begin to wear, repairs are encountered. Replacement of components may be followed in time with replacement of entire assemblies. As costs increase the curve begins to climb at a steeper rate. In addition, calibration will need to be performed more often, and may take longer. This is caused by the fact that the instrument was purchased to meet certain performance specifications, such as accuracy and precision, which must be maintained. When unobserved, service costs may silently grow and pass the point when a replacement unit should he considered. Eventually of course, "repair" may involve a complete overhaul, or require parts that are no longer available, and the unit may then be replaced. By this time (the dashed part on the cost curve) the point of eco- 
nomic obsolescence, where the minimum-cost line is tangent to the initial curve, may have long since passed, causing unnecessary expense. The object in detection of obsolescence is to operate at the lowest cost rate possible. This minimum-cost rate may be thought of as the lowest possible monthly charge during the life of the equipment, considering the cost of both acquisition and service. At the tangent point the equipment becomes economically obsolete. Let us see why this is true.

First, note that at this point the cycle can be repeated with no change in the minimum-cost rate. That is, when the same purchase price and servicecharge rate the curve for the replacement unit will return to the minimum-cost line. Since there is no option to operate below this line-short of uncovering a way to reduce either purchase or service costs-replacement does not alter the established rate.

Now let us consider the effect of replacement, whether by plan or neglect, at a time different from the proposed replacement point. Too early a replacement, before the optimum time (point $\mathrm{E}$ in fig. 1) evidently results in a higher cost rate. This might occur when equipment is replaced at scheduled predetermined intervals. In this case, premature replacement results in a loss represented by the difference between the actual curve and the minimum-cost line.

A more common failure-late replacement after the economically optimum replacement point $(\mathrm{L}$ in fig. 1) results in a loss which is the difference between the actual curve and the minimum-cost line. One factor which seemingly encourages late replacement is the assumption that the longer one delays replacement, the more is saved of the replacement budget. The fallacy, of course, is in disregarding the fact that the required service costs to accomplish these savings exceeds the savings and contributes to an overall loss.

By observing the economy of individual instruments, losses otherwise undetected may be found and corrected. Timely replacement not only saves money, but new equipment becomes available sooner for use.

\section{Accounting for Cost}

To determine economic obsolescence points for equipment, the essential information requirements are acquisition and service costs, and the dates associated with these costs. Often, service costs within a company are expressed in accounting figures that do not necessarily reflect true costs for our purpose. The service costs of interest can be thought of as those costs which would immediately cease upon removal of a particular instrument from the inventory. Obviously, the cost of service and replacement parts would cease. But, unless an extensive program was involved, many overhead costs-such as floor space, lighting, and depreciation of existing equipment-would remain. Mind-

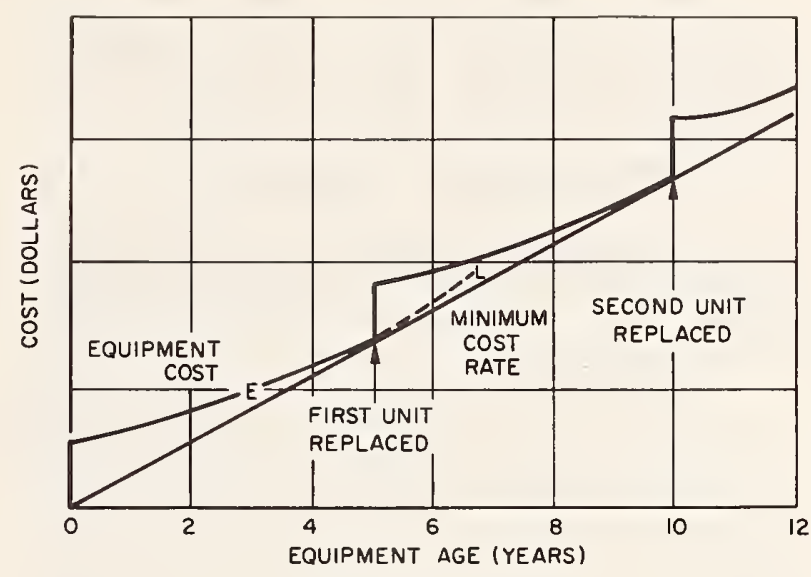

Figure 1.

ful that readily available accounting figures do not necessarily comprise valid service costs, we offer two methods to consider for determining obsolescence. These methods are presented in the following paragraphs.

\section{Obsolescence-Method I}

For a small amount of equipment, simple plotting of cost vs. age will suffice. Starting with the acquisition cost, each successive service cost is added and entered at the appropriate date. Figure 2 shows the plot at year 3 , with the cost-rate line drawn through the end point. Eventually a point of tangency is reached (at year 5 in fig. 1); that is when an instrument becomes economically obsolete. This method has several disadvantages. If previous records of service costs are not available, the method can be applied only to yet-to-bepurchased equipment for which such costs can be accumulated. Furthermore, data must then be collected until this new equipment is found to be absolete. Meanwhile, little can be done to forecast

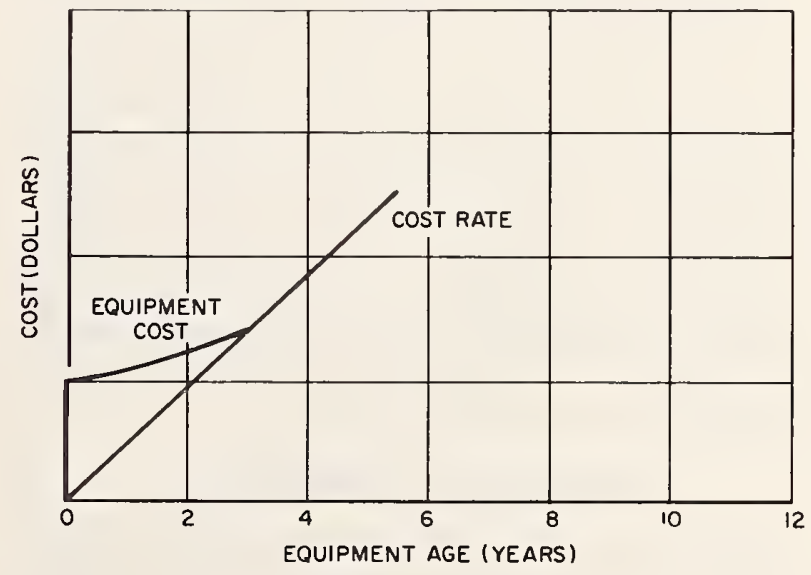

Figure 2. 
when obsolescence will occur. To solve these problems, the following alternate technique has been developed.

\section{Obsolescence-Method II}

This method differs from Method I only in that the shape of the cost curve is anticipated, allowing use of cost data collected anytime during the equipment lifetime. The assumed shape of the cost curve is logarithmic, because this is the naturally occurring form for many growth and aging processes; furthermore this shape lends itself readily to either graphical or computer solutions. Again the acquisition cost and its associated date are necessary. Suppose that subsequent service costs and dates are converted to a cost rate. Next, a logarithmic curve is chosen, begining at the purchase cost and conforming to the observed cost rate found to be in effect. This procedure generates the equipment cost curve from the limited information available.

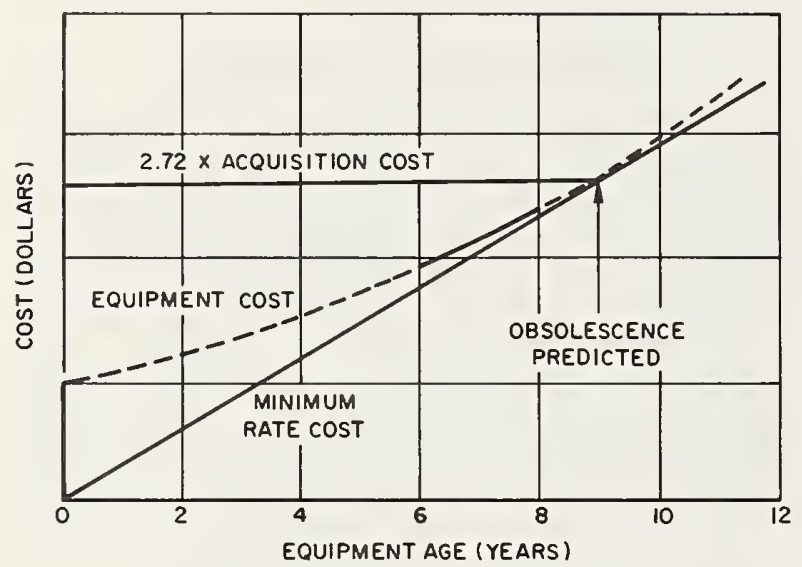

Figure 3.

Once this is done, it can be shown (see Appendix) that obsolescence will occur when the cumulative costs reach a value equal to 2.72 times the acquisition cost, figure 3 . The minimum cost rate is also shown for comparison with the techniques previously discussed. The advantages of this method are the ability to determine when obsolescence has occurred and the ability to forecast the event. These advantages are applicable to new and old equipment alike, since data may be collected anytime during equipment lifetime, even if obsolescence has already occurred.

\section{Successive Predictions}

By producing a series of obsolescence predictions as each new service cost is available, a check can be made on the assumption of logarithmic growth of equipment cost. In some cases, each successive prediction of obsolescence will be longer than the last, meaning service costs are not increasing at the rate anticipated; equipment with no appreciable wear will lead to this situation. Or the opposite case may be encountered. In either case, more data is necessary to improve the accuracy of prediction than in the deal case where successive predictions remain the same.

Figure 4 shows the results of successive predictions of obsolescence age for an electronic counter manufactured by a well-know firm. This unit had been in service for eight years before data was taken. The first prediction, 17 years, has no real significance. As more data became available, predictions became generally stable. At ten years, the obsolescence age and the actual age of the unit coincided and the counter was removed from service.

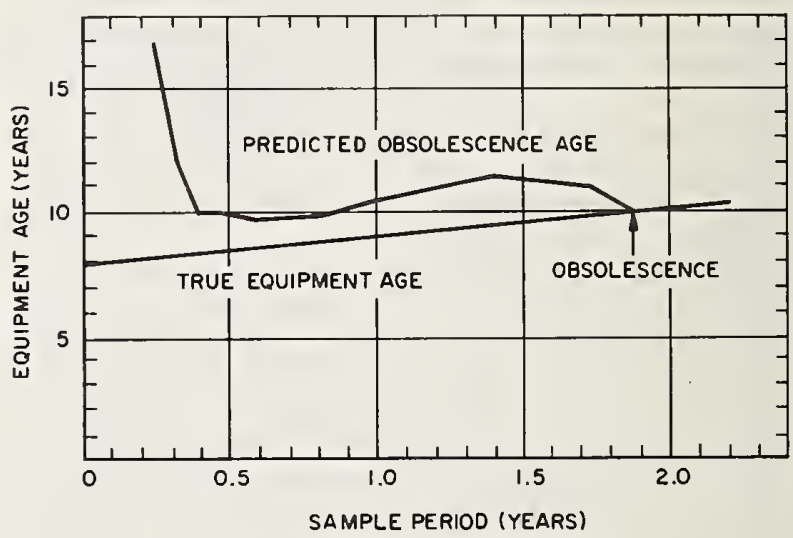

Figure 4.

Obsolescence detection can be used to economically remove equipment from an inventory for replacement. The predictive capabality can be used to forecast the replacement budget required to some extent. Additionally, this capability can be used as a basis for procurement of equipment having a better probability of long, economical life. In this application it is essential that the utilization of competitive equipment be nearly equivalent. Equality of maintenance or calibration procedures is also important, since any factor which may minimize service will contribute to a longer economic life.

\section{Conclusion}

The retirement age for various types of equipment can be neither arbitrarily fixed nor arbitrarily ignored. The effect of not knowing when equipment is economically obsolete is almost certainly a loss. And a loss need not always be obvious 
to become significant. Perhaps the following example will best illustrate this point. Suppose we have an instrument purchased for $\$ 1000$, economically obsolete in eight years, with a minimum-cost rate of $\$ 340$ per year. If this fact were not detected an additional two years might pass before replacement, but by this time nearly $\$ 100$ has been spent on services not needed. This loss is 10 percent of the replacement cost. In a large company where the replacement budget may exceed a million dol- lars, such losses could approach a significant $\$ 100,000$.

Admittedly many factors have not been discussed, such an inflation, taxes, depreciation, and such. Also, the fact that there can be many factors to consider before replacement of equipment is fully justified. Nevertheless, a signal when such decisions are necessary, based on the economics of service costs, can be a valuable tool in the management of equipment.

\section{Appendix. Logarithmic Obsolescence Analysis (Method II)}

In order to reconstruct and extrapolate cost curves when only limited cost data is available, service charges are assumed to describe a logarithmic curve. Therefore, equipment costs, $Y$, can be represented by the equation

$$
Y_{1}=b e^{a x}
$$

where $b$ is the acquisition cost (purchase price plus preliminary service), $e$ is the natural logarithmic base, $a$ is the service cost factor, and $x$ is the age of equipment.

The minimum-cost rate is defined as a straight line tangent to the cost curve and has the equation

$$
Y_{2}=m x
$$

where $m$ is the slope.

At the obsolescence point, where the cost curve and the minimum cost rate line are tangent, the two costs and the two slopes are equal:

and

$$
Y_{1}=Y_{2}
$$

$$
\frac{d Y_{1}}{d x}=m
$$

Differentiating eq (1), we find

$$
\frac{d Y_{1}}{d x}=a b e^{a x} .
$$

Combining the previous equations yields the following obsolescence point relationships:

$$
m=\frac{d Y_{1}}{d x}=a b e^{a x}=a Y_{1}=a Y_{2}=a m x
$$

and thus from the first and last terms

$$
a x=1 \text {. }
$$

Equation (7) shows that $x$, the age of equipment at obsolescence, is merely the reciprocal of the service cost factor, $a$. To solve for this factor, eq (5) can be used. For this application $d Y_{1}$ is the incremental service costs, $d x$ is the time interval involved, and $x$ is the average age of the equipment during the data period.

Since factor $a$ appears twice as an unknown, there is no direct solution. Graphical techniques require locating $b$, the acquisition cost, at $x=0$. From this point a straight line can be drawn on semilog paper so that the observed cost rate during the data period is correct at the appropriate value of $x$. From eq (6) and (7), substitution shows that at obsolescence

$$
Y_{1}=b e,
$$

or, the equipment cost is 2.72 times the acquisition cost. From this value, the graph can be read directly to obtain $x$, the obsolescent age.

Computer solution to this problem can be done by iteration. An approximate value is assigned to one of the $a^{\prime}$ 's in eq (5) and the solution is found for the resulting value of the other $a$. Then, these two values of $a$ are averaged and used as the new approximate value for one $a$. This process is continued until the $a$ 's are found equal, which of course solves the equation. The reciprocal of the final value of $a$ is the obsolescent age.

Because costs seldom occur ideally, some deviation between successive estimates of obsolescent ages should be expected as additional service cost data are entered. To better observe the trends toward or away from logarithmic cost accumulation, smoothing of the obsolescence age predictions may be desired. One method of doing this is by averaging each pair of original obsoclescence ages, averaging each pair of averaged points, and replaceing the original values with these points. 


\title{
CALIBRATION DATA COLLECTION AND UTILIZATION
}

\author{
Wayne L. Bates
}

Head, Analytical Studies Staff, Metrology Engineering Center, Naval Plant Representative, Pomona, California 91766

This paper discusses the various data elements related to the calibration function and their use in reports, studies, and management control systems.

\section{Introduction}

The a great extent the true product of the Standards or Calibration Laboratory is data. From it we get measured values whose accuracies are traceable to the National Bureau of Standards (NBS), product quality assurance, control of the calibration system, and a measure of the effectiveness of the calibration process. No effort is made in this paper to discuss the analysis process. Information on analysis techniques may be found in the bibliography.

\section{Types of Data Systems}

Following are three basic types of data systems currently in use:
1. Manual Systems-All control and variables data are entered on a report form, such as shown in figure 1, by the calibration technician. These reports may be filed, retrieved and summarized by hand. They are easily modified to meet individual measurement needs. The principal cost in maintaining such a system is in the man-hours expended in hand tabulation and summarization of the data. Manual systems are normally limited to approximately 3000 test instrument calibrations per year.

2. Conventional Punched Card Data Processing Systems (EAM)-Selected information on the report form is keypunched on cards. These cards may then be sorted in most any sequence and the punched information printed directly on a tabu-

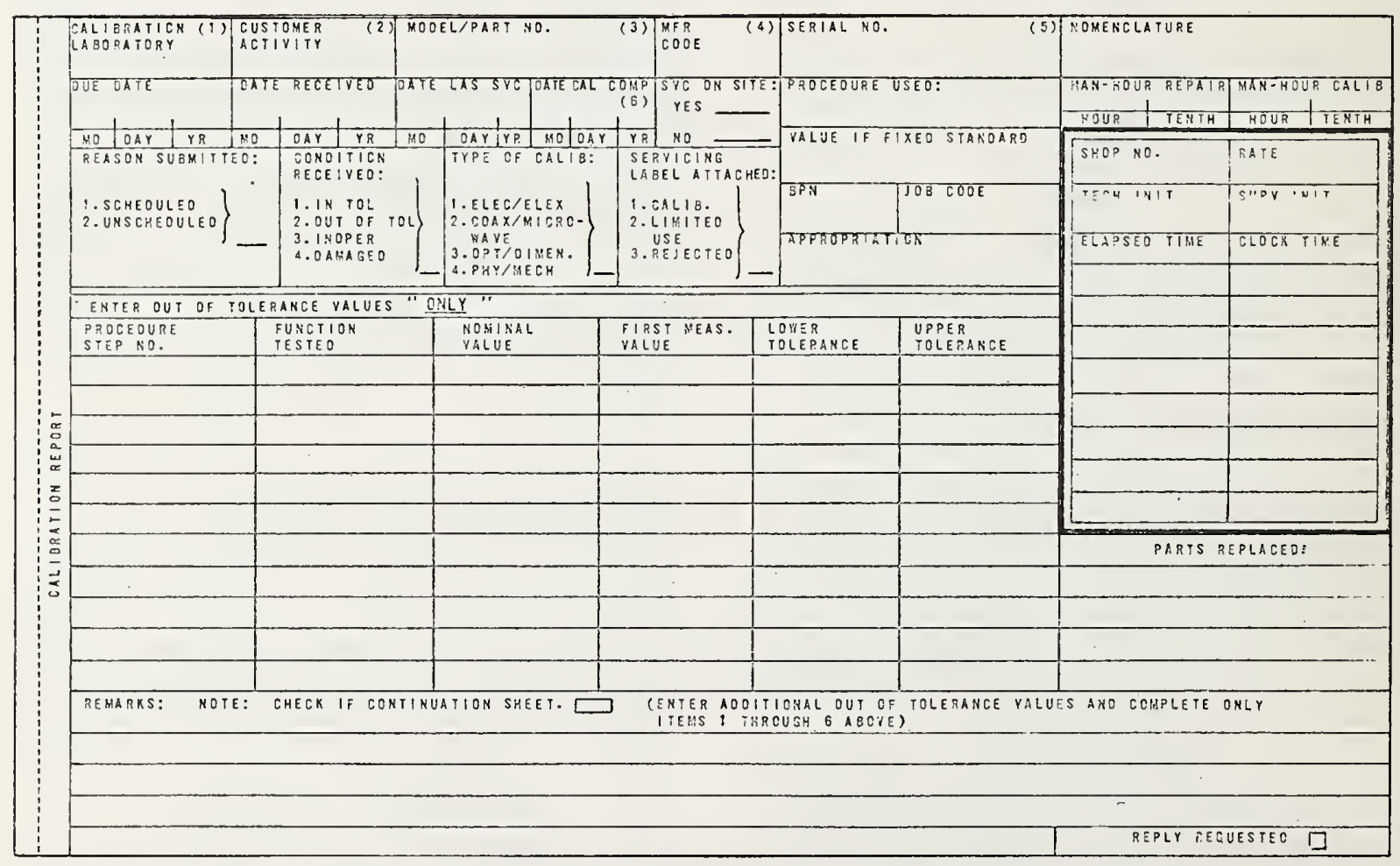

Frgure 1. Calibration report form. 
lated format. Data accumulation is simplified, but computations other than addition and subtraction must be performed manually. In order to perform a meaningful sort the information usually is limited to a single card of 80 characters. The cost of operating such a system with three readouts is less than $\$ 0.50$ per test instrument. This system is usually used by laboratories with workloads of between 2000 and 20,000 test instrument calibrations per year.

3. Magnetic Tape Systems-As with the previous system, cards are punched from selected information on the report form. This information is transferred to magnetic tape which can then be used in a high-speed scientific computer. Here the information for a single test instrument is not limited to one card and the computer can perform an unlimited amount of computational tasks such as adding, subtracting, multiplying, dividing, averaging, extracting roots, testing chi-square, etc.
Programming, set-up, and machine time usually restrict the use of magnetic tape systems to laboratories performing at least 10,000 test instrument calibrations per year. The cost of a typical magnetic tape system is approximately $\$ 1.50$ per test instrument.

\section{Design of the Calibration Report Form}

In designing a report format, such as the one shown in figure 1, prime consideration should be given to the use of data elements in reports, evaluations, or management controls. Figure 2 is a table relating the uses of data to the data elements themselves. The figure (1) shown in the table signifies a data element required for the use noted. A (2) denotes a useful but not necessary element, and a (3) indicates the element is not required for the corresponding use.
Calibration Lab code

Customer activity or location code

Model number

Manufacturer code

Serial (or inventory) number

Nomenclature

Next due date

Date received

Date last serviced

Date calibration completed

Service on site

Procedure used

Man-hours to calibrate

Man-hours to repair

Reason submitted

Condition received

Type of calibration

Label type (condition returned)

In-tolerance variables data

Out-of-tolerance variables data

Parts replaced

Costs of parts replaced

Hourly cost rate

Replacement cost

NBS traceability

Utilization hours
Use of data

\begin{tabular}{|c|c|c|c|c|c|c|c|c|c|}
\hline 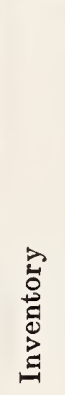 & 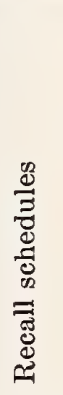 & 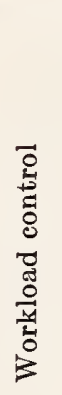 & 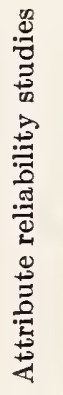 & 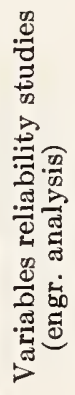 & 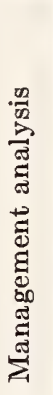 & 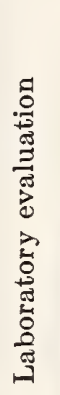 & 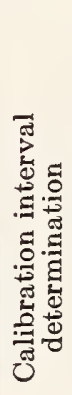 & 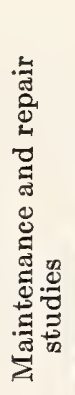 & 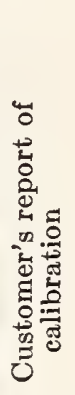 \\
\hline 3 & 1 & 1 & ? & 3 & 1 & 1 & 2 & & \\
\hline 1 & 1 & $\begin{array}{l}1 \\
3\end{array}$ & 2 & $\begin{array}{l}\mathbf{2} \\
2\end{array}$ & 1 & 1 & $\begin{array}{l}0 \\
2\end{array}$ & $\begin{array}{l}3 \\
1\end{array}$ & \\
\hline 1 & 1 & 1 & 1 & 1 & 2 & 1 & 1 & 1 & \\
\hline 1 & 1 & 1 & 1 & 1 & 2 & 1 & 1 & 1 & \\
\hline 1 & 1 & 1 & 3 & 2 & 3 & 3 & 2 & 1 & \\
\hline 2 & 3 & 3 & 3 & 3 & 2 & 3 & 3 & 3 & \\
\hline 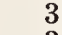 & 1 & 1 & 3 & 3 & 3 & 3 & 1 & 1 & \\
\hline 3 & 2 & 1 & 1 & 1 & 1 & $\frac{1}{2}$ & 1 & 1 & 3 \\
\hline $\begin{array}{l}3 \\
3\end{array}$ & $\begin{array}{l}1 \\
1\end{array}$ & $\begin{array}{l}3 \\
1\end{array}$ & $\begin{array}{l}1 \\
1\end{array}$ & 1 & $\begin{array}{l}2 \\
1\end{array}$ & $\begin{array}{l}2 \\
1\end{array}$ & 1 & $\begin{array}{l}1 \\
1\end{array}$ & \\
\hline 0 & 3 & 1 & 2 & 2 & 1 & 1 & 1 & 1 & \\
\hline 3 & 3 & 2 & $\mathbf{1}$ & 1 & 3 & 1 & 1 & 3 & \\
\hline 3 & 3 & 1 & 3 & 3 & 1 & 1 & $\begin{array}{l}3 \\
2\end{array}$ & 3 & \\
\hline 3 & 3 & 1 & 3 & 3 & 1 & $\frac{1}{2}$ & $\begin{array}{l}3 \\
1\end{array}$ & 1 & \\
\hline $\begin{array}{l}3 \\
3\end{array}$ & 1 & 1 & 1 & 1 & 1 & $\begin{array}{l}3 \\
2\end{array}$ & 1 & 1 & \\
\hline 1 & 3 & 1 & 1 & 1 & 1 & 1 & 1 & 1 & 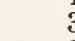 \\
\hline 3 & 3 & 3 & 1 & 1 & 1 & 1 & 1 & 1 & \\
\hline 3 & 3 & 3 & 3 & 2 & 3 & 3 & 2 & 2 & \\
\hline 3 & 3 & 3 & 3 & 1 & 3 & 3 & 2 & 2 & \\
\hline 3 & 3 & 3 & 1 & 1 & 2 & 3 & 3 & 1 & \\
\hline 3 & 3 & 3 & 3 & 3 & 1 & 2 & 3 & 1 & \\
\hline 3 & 3 & 3 & 3 & 3 & 1 & 1 & 3 & 2 & \\
\hline 1 & $\begin{array}{l}3 \\
3\end{array}$ & $\begin{array}{l}3 \\
2\end{array}$ & 3 & $\begin{array}{l}3 \\
3\end{array}$ & 1 & 3 & $\begin{array}{r}3 \\
3\end{array}$ & $\begin{array}{l}1 \\
3\end{array}$ & \\
\hline 3 & 3 & 3 & $\begin{array}{l}5 \\
2\end{array}$ & 2 & 2 & 3 & 2 & 2 & \\
\hline
\end{tabular}

1-Required; 2-useful; 3-not required. 


\section{Bibliography}

(1) Dyke, F. and Taylor, K., "Methods for Retrieving and Correlating Technical Data," (a manual) American Society for Testing and Materials (ASTM).

(2) Vondracek, J., "Data Collection, Utilization and Analysis Subcommittee Report," Proceedings of the 1966 Standards Laboratory Conference, NBS Miscellaneous Publication 291.

(3) Smith, N. D., "Maintenance Scheduling By Sequential Testing," Instruments \& Control Systems, August 1966 .

(4) Ku, H. H., "Statistical Concepts in Metrology," Ch. 2 in Handbook of Industrial Metrology, PrenticeHall, New York, 1967.
(5) Youden, W. J., "How to Evaluate Accuracy," and Connor, W. S., "How to Evaluate Precision," Materials Research \& Standards, Vol. 1, No. 4, April 1961

(6) McGuire, J. E., "An Electronic Data Processing Program for Establishing Calibration Intervals," 1965 ISA Conference, Preprint number 42.3-3-65.

(7) Hager, C. L., "Confidence Intervals and Calibration Uncertainty," ISA Journal, April 1966.

(8) Moss, C. E. Jr., "Assigning Calibration Intervals," Instruments \& Control Systems, January 1966.

(9) Natrella, M. G., "Experimental Statistics," NBS Handbook 91.

(10) Hagerty, R. J., "Measurement Limits for Optimizing Production," Measurement \& Data, March-April 1967. 


\title{
SESSION 8: THE MANAGEMENT OF VALUABLE MEASUREMENTS
}

\author{
Chairman: A. J. Woodington
}

General Dynamics/Convair, San Diego, California 92112

\section{VALUE ENGINEERING TECHNIQUES- A WAY OF MANAGING VALUABLE MEASUREMENTS}

\author{
Phil I. Harr \\ Corporate Director, Reliability, Quality Control, Value Control, General Dynamics, New York, N.Y. 10014
}

Today's social, economic, and political environments place tremendous pressures on manager, engineer, and shop worker alike to achieve high product quality, as well as outstanding performance-and at lower costs than ever before. These pressures have become so intense that we are faced with a major crisis in the development of the whole industrial process if we are to prosper or indeed even to survive. Fortunately there have been evolving, over a period of years, a number of management systems, practices, or disciplines which have been designed to assure the quality of our products while maintaining or reducing costs and improving delivery schedules. The control of measurement tools and equipment is one of the most important of these management systems.

Accuracy of measurements is vital to any industrial process. The performance and high quality of many of today's complex products and systems are evidence of the progress in measurements techniques in industry. Such accomplishments would not have been possible without a corresponding rapid growth in our capability to measure accurately and consistently. However, project management at every level in government and industry must carefully plan for the measurement tasks involved in all phases of the product life cycle, if we are to assure that quality is built into and maintained in our products. Careful selection and clear specification of such tasks, even at the stage of requests for proposals, is of critical importance to the operational success of components as well as systems. The metrology specialist must participate in all phases of the development and identification of the measurement tasks involved in the support of product quality (fig. 1).

How can we best make logical decisions concerning the measurement control tasks to be implemented on a particular project or program? I believe that value engineering techniques are now

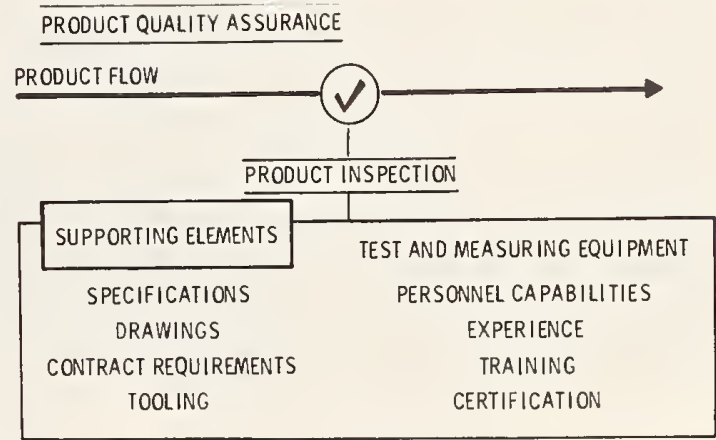

Figure 1. Support for product quality.

developed to the point where they can be valuable management tools in making such decisions. This is true not only in the development of the original plan but also in the dynamics of its day-to-day use. Have the answers really been provided for such questions as:

What parameters and tolerances must be measured?

What parameters and tolerances would it be desirable to measure?

What is the environment for each measurement?

Are the measurement procedures available?

Are trained measurement personnel available?

Is the proper measurement equipment available?

Is the proper measurement equipment support available?

Will the answers to the above questions provide the measurements in the most economical manner consistent with performance requirements?

To manage valuable measurements it is necessary to have a measurement control program. I shall discuss a program with nine major elements, as diagrammed in figure 2. 


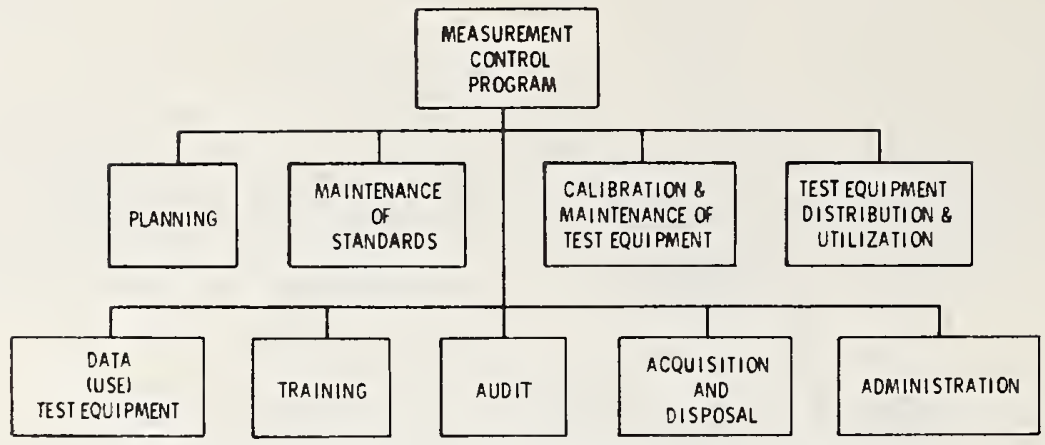

FIGURE 2. Elements of a measurement control program.

\section{Planning}

This element covers measurement considerations from the conception of the program through feasibility, development, production, delivery to user, and period of use by the procuring organization. Throughout the program a few questions must be answered-Is the measurement necessary? Can it be accomplished in the controlling environment? Is it being done at minimum cost while meeting specifications? It cannot be overemphasized that decisions made in the feasibility and development phases can commit the production and user phases to an expensive measurement process.

\section{Administration}

Every program has certain administrative procedures to provide continuity and to define the action required at known interfaces between groups. The type of organization to be used in the execution of the measurement control program must be determined. Although a single organization may be desirable in some cases, it is not necessary for the accomplishment of the program. Participation of many groups helps to promote understanding and cooperation in the execution of the program.

\section{Maintenance of Standards}

The complexity of many products has resulted in sub-assemblies being produced in many different manufacturing plants. To avoid assembly problems, all measurement equipment must be calibrated with standards that can trace their accuracies to an acceptable common standard. In this country, the National Bureau of Standards normally is in possession of such a common standard.

To prevent unnecessary tolerance degradation, a review of the optimum number of calibration echelons from NBS to the product must be made. Of course a cost study is included in the review.

\section{Calibration and Maintenance of Test and Measuring Equipment}

Here we must give consideration to calibration procedures and techniques, types and quantities of calibartion standards and auxiliary equipment required, calibration laboratory environment required, and skill levels and quantity of personnel required. This provides a challenge for value engineering techniques. The separation of calibration from maintenance of test and measuring equipment is not recommended, because of the additional time required for each task, and the duplication of personnel and measurement equipment.

\section{Test Equipment Distribution and Utilization}

For effective utilization of measuring equipment, it must be distributed among using personnel so as to be conveniently available to the maximum number. Since recalibration is a necessity, some system must be established for returning test equipment to the calibration laboratory, or for calibration "in place." This system normally includes location records as well as issue records. From such records, the quantity of equipment required as well as most cost-effective distribution can be ascertained. Let me stress the point that equipment-using personnel will tend to "hoard" equipment rather than share it, unless the equipment is easily available. The "hoarding" process is rather costly.

\section{Use Data on Test Equipment}

A definition of the end use of data is required to maximize their value and minimize their amount. Some uses to be considered are: failure rate, effect of failures on product, level of difficulty to maintain, skill level required to use, length of calibration interval, and economical disposition. 
The techniques of acquiring and presenting the data must be considered. Should they be manual, semi-automatic, or fully automatic? The quantity of measurement equipment and the availability of data-processing equipment are two governing factors.

\section{Training of User Personnel}

The importance of training the user of measurement equipment in the proper application and use of the equipment cannot be exaggerated. I am sure that most of you can give examples of measurement data that were invalid because of misapplication or improper operation. But how many times did you identify the cost to repeat the measurements? To date, very few places are available to teach the application, use, and calibration of measuring equipment, even though manufacturers provide some information on their equipment. Making visible the cost of repeating measurements will indicate the cost effectiveness of adequate user training. Those places where it is impossible, or at least very costly to repeat a measurement, must be clearly identified and handled accordingly. Every user should be made fully aware of the important management decisions which will be based on his measurements.

\section{Audit of Measurement Control Program}

Although some method of determining the compliance to the defined control program is required, the audit techniques should be studied to see whether the desired results are achieved with minimum costs and annoyance to program personnel.
Some audit techniques can cause passive resistance to compliance with the control program.

\section{Acquisition and Disposal of Test Equipment}

Although this is being discussed last, it is very important to the success of the program. In the acquisition phase, some points to consider are: type of equipment required for the measurements, ease of use, ease of calibration and maintenance, availability of parts, reliability, and user acceptability. The disposal process is emphasized because cost of ownership will continue if the equipment is kept available for use after it has served its purpose. The program must make visible to management all test and measuring equipment which is inactive for any reason. Such devices must be removed from the calibration and maintenance cycle and disposed of as surplus, if further need has not been clearly identified.

Although nine elements are listed, it is readily apparent that they cannot be considered independently. The extent of interdependence is subject to the degree of centralization of the measurement control program. Some of the advantages resulting from a centralization as indicated in figure 3 are standardized nomenclature; catalog of test equipment available and its location; early determination of requirements; preferred test equipment listings; standardization of spare parts; standardization of calibration procedures; reduced training requirements; reduced calibration effort; improved quality of measurements; joint procurement cost reductions; optimized calibration intervals.

FLWW - MEASUREMENT CONTROL

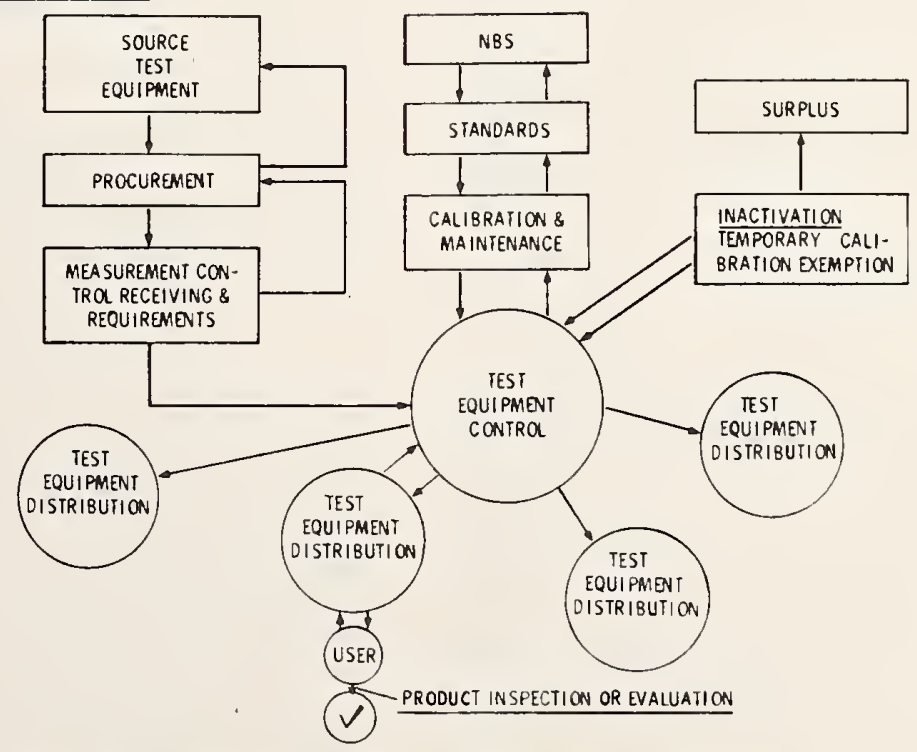

Figure 3. Centralizing a measurement control program. 
Here are a few of the results from our five-year Measurement Control Program, utilizing various combinations of the task elements discussed:

1. Availability of the measuring equipment within the company. Over this period the identified equipment increased threefold with a resulting increase in utilization, and reduction in procurement costs (fig. 4).

\section{TEST AND MEASUREMENT EQUI PMENT ACTIVITY}

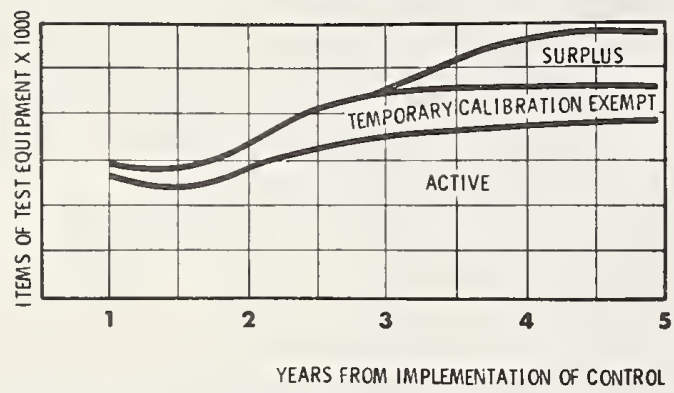

FIgURe 4. Results in equipment availability.

2. Manpower requirements for the calibration effort dropped approximately 50 percent (fig. 5).

3. Measurement equipment maintenance material costs were reduced by more than 40 percent (fig. 6).

4. Other savings were realized, but methods to define them are not currently available.

In summary, a Measurement Control Program is being recognized at all levels of management as

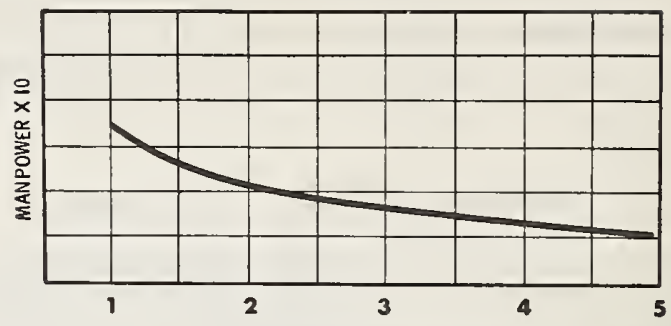

YEARS FROM IMPLEMENTATION OF CONTROL

Figure 5. Results in calibration manpower.

EQUIPMENT MAINTENANCE MATERIAL COSTS

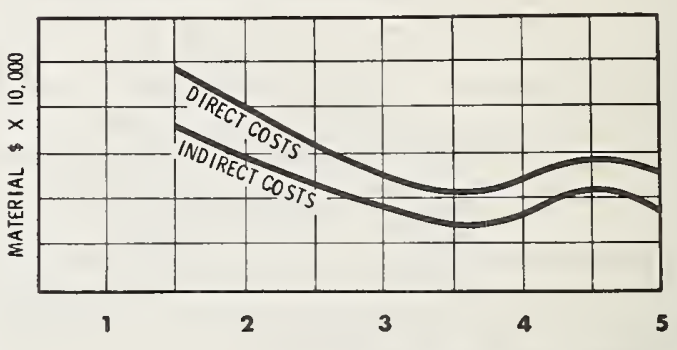

YEARS FROM IMPLEMENTATION OF CONTROL

FIGURE 6. Results in maintenance material costs.

a way to provide high-quality measurements at minimum cost for a given product or project. To achieve this goal, value engineering techniques should be applied to all elements of the Measurement Control Program. 


\title{
GOVERNMENT'S VIEW OF CONTRACTOR'S MANAGEMENT OF VALUABLE MEASUREMENTS
}

\author{
H. B. Berkowitz
}

\begin{abstract}
Chief, Quality Engineering Applications Branch, Quality Assurance Engineering Division, HQ DSA Contract Administration Services, Cameron Station, Alexandria, Virginia 22314
\end{abstract}

\begin{abstract}
During contract performance, contractors normally generate numerous types and varied amounts of valuable measurements. The purpose of this paper is to provide an insight into the why, when, where, what, and how DCAS reacts to a contractor's management control of his measurements. Recognition is given to the Department of Defense Contract Administration Services Plant Cognizance Program Objectives specified in DoD Instruction 4105.59 ( ref. 1 ).
\end{abstract}

\section{Introduction}

A contractor's management of valuable measurements is of interest and concern to the Government. The word "Government" as used herein refers to the Defense Contract Administration Services, commonly known as DCAS. The Government's interest can be expressed by the following five key questions:

1. Why is the Government interested in the way contractors manage?

2. What are the advantages to the Government for efficient contractor's management?

3. How can the Government benefit from a dynamic organization for contractor's management?

4. When and to what degree should the Government ascertain the efficacy of a contractor's management?

5 . Where and to what extent should the Government assess contractor's management controls?

The purpose of this paper is to discuss these questions and propose suitable answers. The views expressed herein represent those of the Department of Defense in general and the Defense Contract Administration Services in particular.

\section{Key Phrases}

The following definitions are furnished to assure the party-line concept between Government and industry in consideration of this paper :

1. Valuable Measurements-Those physical and functional characteristics, such as dimensions, hardness, tensile strength, weight, percentage of chemical impurity, etc., essential to be made and recorded and which are determined to be of considerable use, value, service, or importance.

a. Physical Characteristics-Quantitative and qualitative expressions of material features, such as composition, dimensions, finishes, form, fit, and their respective tolerances. b. Functional Characteristics-Quantitative parameters of performance, operations, and logistics, and their respective tolerances. Functional characteristics include such performance parameters as range, speed, reliability, maintainability, lethality, safety.

2. Contractor's Management-Direction provided by a contractor for accomplishing an enterprise through the planning, organizing, coordinating, and controlling of its human and material resources toward the attainment of a predetermined objective.

3. Government's View-The regard, reaction, recognition, or consideration of the Government (e.g., How does the Government respond or react or what recognition does the Government give?).

4. Defense Contract Administration Services (DCAS) - An organizational entity of DSA, comprised of a headquarters staff and a field organization of geographic and plant components, established to provide uniform administration services for DoD contracts with private industry.

\section{Measurements-Reliable versus Valuable}

1. Valuable measurements are generally considered to be reliable, but reliable measurements are not necessarily valuable. Reliable measurenents are those derived from devices whose accuracy is traceable to a known standard. Data resulting from measurements are one of the contractual endor by-products, and the bases for a course of action, whether hardware or software is involved. We can safely state that valuable data are those which are reliable, whether they result in acceptance, rejection, or a condition of indecision. In one contractual situation, hardware could be the direct produot, with test or inspection data as the supporting by-product. In a contractual R\&D situation where 
no hardware is involved, test or inspection data could be the direct product.

2. Contractors usually strive to develop valuable data but sometimes it is difficult to separate the wheat from the chaff. Contractor-recorded inspection, test, and performance data generally include a wealth of valuable information. However, we must continuously resassess the values initially assigned in light of economics, criticality, and specific needs. Detailed review of such data as programs advance often shows that the data originally thought most valuable are really not worth too much.

\section{Responsibilities of the Contractor}

1. The contractor is responsible for carrying out his obligations as set forth in the terms and conditions of the contract and in the applicable specification.

2. The contractor is responsible for controlling product quality and for offering to the Government for acceptance only those supplies that conform to contract requirements and, when required, maintaining and furnishing substantiating evidence of this conformance. With this end in view, the quality of a contractor's product depends to a large degree on the effectiveness of the contractor's control over his manufacturing processes, and his inspection and testing operations.

3 . The contractor is responsible for instituting such controls over quality as may be necessary to insure that the product he produces conforms to the consumers' quality requirements. Equally important, the contractor is obligated to substantiate the quality of his product by objective, verifiable evidence. Thus a contractor ordinarily sells not only supplies, but also evidence that the product offered to the consumer was properly fabricated and subjected to an effective inspection.

4. It is this objective, verifiable evidence (the valuable measurements) that is the contractual byproduct which places confidence and integrity in the contractor's decision-makers and in the consumer's eyes. Notwithstanding the product disposition status, a condition of "customer satisfaction" usually results.

\section{Responsibilities of Government}

1. The Government purchasing activity is responsible for establishing contractual quality requirements.

2. The Government is responsible for determining (a) the type and extent of Government procurement quality actions and (b) whether or not the contractual requirements have in fact been met before acceptance of supplies.

3. The purchasing activity must communicate these requirements in writing to the contractor. These requirements are of two kinds, and therefore two types of specifications must be prepared: (a) product specifications that specify the particular quality characteristics to which the product must conform (e.g., hardness), and the examinations and tests by which the conformance is to be assured, and (b) systems specifications which identify certain environmental requirements (e.g., calibration capabilities) that provide for the quality control the contractor should exercise.

4. It is incumbent on the Government to exercise sufficient surveillance over the contractor's program to assure that effective controls are in fact established and maintained pursuant to contract terms. The amount (severity) of this surveillance is appropriately a function of the effectiveness of the contractor's controls and the demonstrated quality of the product-permitting a minimum of surveillance when a contractor is demonstrably reliable.

5. Essentially, contractual responsibility must be emphasized. The Government will reward the quality contractor through less surveillance effort, and penalize a poor contractor through increased surveillance and administrative actions.

\section{Goals in Product Quality}

To determine whether measurement information is valuable for solving a specific problem, we must ask whether it meets the requirements set by the problem. Large quantities of undiscovered defectives could create production difficulties at users' facilities. When they are disclosed at the consuming plants, the user is forced to establish a full acceptance inspection and to retest delivered articles and component parts, which is a wasteful practice.

In the relationship of quality to measurement information, three things must be recognized:

1. Measurements constitute an important part of all work whose quality has a direct effect on the product quality.

2. The capability of measuring processes for insuring product quality rests on their reliability (e.g., the probability that measurements will provide information whose accuracy corresponds to the requirements of the specific problem).

3. It is essential to establish conditions which fully eliminate the possibility of obtaining measurements which are either incorrect or lack the accuracy needed for a specific problem.

\section{Valuable Data Management}

1. Contractors are responsible for the control of product quality. The relevant records of contractors' findings constitute the objective evidence for decision-making and form a part of the contractor's quality data bank. This bank generally includes, but is not limited to, the following types of information:

a. Data developed as a result of contractually required examinations and tests of products. 
b. Results of inspections which are selfimposed in order to meet production standards.

c. Records of rejected items or nonconforming characteristics.

d. Records maintained to control various processes.

e. Records developed through a material review system.

2. Although data are collected independently by the Government in the course of assuring that adequate controls are in fact exercised by the contractor, the Government normally evaluates the data in the contractor's quality data bank for currency, accuracy, reliability, repetitious deficiencies, comparison of contractor versus Government findings, the timeliness and effectiveness of corrective actions, and the extent of the contractor's analysis and use of his data.

3. It is essential that a determination be made as to whether the data were obtained through use of measuring and testing devices having an accuracy traceable to known standards. Once this is established, the contractor's inspection data take on a new property-that of valuable measurements.

4. Control of the accuracy of measuring and testing equipment is such an important element of a contractor's quality program or inspection system that the Department of Defense has considered it advisable to expand on those parts of MIL-Q-9858A (ref. 2) and MIL-I-45208A (ref. 3) pertaining specifically to calibration. This additional detail has been provided in a separate specification, MIL-C-45662A (ref. 4).

5. Contractors' records form a basis of action by both the contractor and the Government. Recordkeeping for the records' sake serves no useful purpose, but record-keeping as a tool for management will preclude many embarrassing situations. Valuable data cost money to obtain, and we should make effective use of them.

\section{Contractor's Management of Valuable Measurements}

1. For purposes of discussion, contractor's management actions on measurements will be assessed in terms of their contribution to the five basic DoD objectives prescribed in DoD Instruction 4105.59: field

a. Improved management of contracts in the

b. Provision of more uniform and timely support to buying activities and program managers by Government field representatives.

c. Minimized duplication of effort.

d. Decreased operating costs.

e. Reduced Government controls over industry.

2. Why is the Government interested in the way a contractor manages? What are the advantages to the Government of efficient contractor's man- agement? How can the Government benefit from a dynamic organization of contractor's management? When and to what degree should the Government ascertain the efficacy of contractor's management? Where and to what extent should the Government assess contractor's management controls? Answers to these questions follow.

a. Where effective contractor's management exists, it will decrease the Government's operating costs through avoiding the repetition of inspections that the contractor should have performed. It should also reduce the contractor's costs. Where ineffective contractor's management exists, it will necessitate additional costs due to the Government inspections required.

b. Where contractor management assumes a full contractural responsibilities, it will reduce Government controls over industry through checking less material less often. This disengagement will prevail as long as the contractor demonstrates control, and will permit concentration of Government manpower on problems and trends.

c. Effective contractor's management will result in greater flexibility of operation through improved contractor-Government rapport, and will encourage Government disengagement. Ineffective contractor's management may result in bad product and will call for increased administrative action by the Government.

\section{Conclusions}

1. Customer satisfaction is the end result of satisfactory contract performance. Effective contractor's management of valuable measurements can lead to many beneficial results-decreased costs being the most significant-and yet provide the desired satisfaction. It also enables the Government to realize cost reductions with no degradation of product quality or loss in performance effectiveness.

2. I wish I could compute the cost effectiveness of valuable measurements management. I believe that suitable economic data are not readily available, and techniques for obtaining the data are inadequate.

3. A better environment exists today for innovation and improvement in our decision-making and our management controls over valuable measurements. We've made progress but we are far from our goals.

\section{References}

(1) DoD Instruction 4105.59, Department of Defense Contract Administration Services Plant Cognizance Program, October 13, 1964.

(2) MIL-Q-9858A, Quality Program Requirements, December 16, 1963.

(3) MIL-I-45208A, Inspection System Requirements, December 16, 1963.

(4) MIL-C-45662A, Calibration System Requirements, February 9, 1962. 


\title{
SOME DEVELOPMENTS IN THE MANAGEMENT OF STANDARDS ACTIVITIES IN THE NBS INSTITUTE FOR BASIC STANDARDS
}

\author{
B. W. Birmingham
}

\begin{abstract}
Deputy Director, IBS/Boulder, National Bureau of Standards, Boulder, Colorado 80302
The traditional responsibility of the. NBS Institute for Basic Standards has been to provide the central basis of the U.S. system of physical measurement. Recently, in response to pleas for stronger efforts to meet thẻ Nation's measurement needs, we have broadened our objectives to include central national leadership of the measurement system. We have looked rather carefully at many of the Nation's measurement problems and already are working toward solutions of some of them. We are improving our information and data services to standards laboratories and are working on better methods for measuring the performance of standards laboratories (the accuracy of their outputs). We have established a new Office of Measurement Services in IBS Washington to help improve our services and the relevance of our programs to national needs. All NBS units in Boulder are now under a single management which also is giving strong attention to improved services and program relevance. Through direct contacts with key organizations, through a system of advisory panels, we are strengthening our basis for effective program decisions. These efforts already have received favorable recognition by several echelons of our higher management.
\end{abstract}

\section{Introduction}

This afternoon I shall bring you up to date on some recent plans and policy developments in the NBS Institute for Basic Standards (IBS) and on some recent organizational changes. In doing so I shall be speaking not only for myself, but also for Dr. Ernest Ambler, Director of IBS, who had a prior engagement and could not be in Boulder this week.

First, I want to discuss the primary responsibility of IBS and to show how it is being broadened with the aim of providing leadership for the National Measurement System. Then, as illustrations of our efforts in the leadership area, I shall point out some of the current problems of the measurement system and some of our work in response to these problems. Finally, I shall describe some organizational arrangements that we have made recently to help us in the decision-making process.

\section{Broadening the Responsibility of IBS}

For many years a primary responsibility of IBS has been to provide the central basis for the U.S. system of physical measurement, to coordinate this system with that of other nations, and to provide essential services leading to an accurate and uniform system of measurement within the nation. In fulfilling this role, the main outputs of IBS are valid measurement methods, calibrated standards, and evaluated data. These functions and these outputs, no doubt, are quite familiar to you. Within the past two or three years our concepts of the IBS role and objectives have under- gone some significant changes which I would like to discuss with you today.

At the 1966 Standards Laboratory Conference R. D. Huntoon described the concept of a National Measurement System [1], including the "central core" role played by NBS, the work of many other measurement laboratories, and the everyday measurements made by millions of our citizens. My discussion will be based on this system concept.

Despite the obvious importance of measurement, the measurement system is not working as well as it should. Writers have spoken of a "measurement pinch" or "measurement gap" which has slowed the pace of American technological progress. They have spoken of our declining measurement posture and feel the costs of this decline are staggering although impossible to evaluate accurately. They have made strong pleas for steps to meet the measurement needs of the country on a timely basis, with the cooperative action of various national groups and with NBS spearheading and coordinating the effort.

Thus there emerges a broader role for IBS than merely providing the central basis for the measurement system. The broader role we are asked to play is that of providing central national leadership of the system.

Leadership of the system implies studying and understanding the system, evaluating its effectiveness and its deficiencies, and initiating corrective and innovative action where needed. In other words, we are requested to look more broadly and deeply into the measurement system and to do all we can to make it more effective. 
Leadership of the system also implies responsibility for its effective operation. However, NBS has no formal regulatory authority and must depend upon voluntary acceptance of its leadership and its recommendations. Such acceptance can be based only on recognized competence.

\section{IBS Work on Some Important Measure- ment Problems}

In efforts to provide the leadership expected of IBS, we already have looked rather carefully at many of the problems of the measurement system and are working toward solutions of some of the most important of these.

To understand these, let us review three types of measurement information with which we deal. The types are:

1. Information on how to measure; for example, papers on measurement techniques and error analysis, critical review papers, and measurement system studies.

2. Quantitative information (data) ; for example, pressure and temperature fixed points, values of physical constants, and the properties of materials.

3. Information provided through formal calibration of standards and instruments; for example, gage blocks, resistance thermometers, and atomic clocks.

The first two types of information are distributed through publications, conferences, etc., not primarily through the hierarchcy of calibration laboratories. Formal calibrations of instruments and standards, on the other hand, are distributed largely through the calibration hierarchy.

With these facts in mind, let us now summarize some of the current problems of the measurement system.

One problem we encounter repeatedly is the lack of adequate information on how to measure. In widely separated locations, laboratory personnel have told us, in essence, "We have good measuring" equipment and standards. What we especially need is better information on how to use them."

A rather general complaint is that calibration services often are not available at NBS when needed. As a result, makeshift procedures have been necessary in industry; for example, shipping a guided missile back and forth between the factory and the launching site to resolve measurement discrepancies, or sending engineers and calorimeters back and forth between the east coast and the west coast to reconcile disagreements between a radar systems manufacturer and a klystron manufacturer. Such makeshifts eventually may achieve measurement agreement, but they are time-consuming and expensive.

We find that the quality of standards of calibration laboratories is spotty. Some companies make no effort to establish a measurement capa- bility until they have a contract which requires it, while others attempt to maintain capabilities approaching the state-of-the-art for the fields in which they work. Since stable equipment and continuity of experience are necessary to make accurate measurements, laboratories of the former type often have difficulty in meeting their company's measurement needs. We find that private calibration laboratories face a number of problems. First, it is difficult to build a staff and facilities for high quality measurement work. Second, there is a potential conflict of interest between the need for profit and the painstaking work required for high measurement accuracy. Third, the private laboratory does not have formal responsibility for accuracy or for continuity and uniformity of service. As a result there is a tendency to avoid the services offered by such laboratories, particularly newer ones that have not yet established their reputations. Some agencies are unwilling to buy services until they have adequate evidence of quality.

The solutions to some of these problems should take account of certain obvious trends. With our rapid growth in population and with a gross national product which has an increasing technological content, mole and more measurements of greater accuracy certainly will have to be made. Greater demands will be made on all types of standards laboratories. Therefore, the problems of providing information on measurements and of devising means for measuring the performance of standards laboratories will become still more critical. I want to describe some of our efforts toward the solution of these problems.

A recent example of IBS response to the need for more information on how to measure is the Radio Standards and Measurements Information Center in Boulder, which Mr. Anson already has discussed. As he pointed out, this Center is generating current awareness lists, ordinary or annotated bibliographies, survey papers, state-ofthe-art reviews, and special purpose articles, in the field of electromagnetic measurements.

Other examples are groups which have been functioning for some years such as the Cryogenic Data Center, which similarly serves the low temperature field, and the JILA Information Analysis Center (in the Joint Institute for Laboratory Astrophysics), which serves primarily the needs of plasma physicists and astrophysicists.

One cannot get reliable data without good measurement techniques, and good measurement techniques are rare. As a result, published data often are wrong. All of these Centers emphasize critical review and analysis of measurement techniques. In this way they are able to recognize the meaningful data in the literature and to evaluate it. Such evaluated data often are called Reference Data. They serve as reliable bases for the verification of scientific theories, for design purposes, and as ready-made calibrations. 
We are working on improved methods for determining the accuracy of our own outputs, and these methods may also be useful to other laboratries. One of our goals is to provide detailed statements of errors for our calibration efforts. These are to include (1) more information on what we do when we make a calibration, and (2) more detailed analysis of the uncertainties we assign. We already have made significant progress:

(a) We have completed a 3-year study of our force calibrations, eliminating some sources of error and devising more meaningful ways of presenting the calibration results.

(b) We have established a formal review process for verification of the accuracy of services from the Electronic Calibration Center before they are announced. This review gives us a clearer picture of the sources of error and points out additional work that would be effective in improving the services.

(c) We have completed a systematic study of errors present in the radio-frequency calibration provided by the IBS laboratories here in Boulder. A detailed report on this work is now in preparation and will be issued as an NBS Technical Note.

We also are working directly with other laboratories on programs to help them improve the accuracy of their outputs. One of these is a new approach to mass calibration developed recently in IBS. The basic approach is of very great importance because it is applicable to the dissemination of other types of standards. Some of you are familiar with this "pilot" program. [2] As I recall, some seventeen laboratories are participating in it. A pair of kilogram mass standards (and some auxiliary weights) recently calibrated by IBS are shipped to the participating laboratory. That laboratory uses its own equipment and operators, in its own environment, to compare its mass standards with the NBS standards. We specify the comparison procedures and a computer program for calculating the results. The program yields the masses of the laboratory's standards, large and small, and the uncertainties to be assigned to each. It extracts all useful information from the data and provides a statistical evaluation of the measurement process of the laboratory. Some of this information simply could not be obtained by sending standards to IBS for calibration.

This general approach is applicable to other types of calibrations. Of course, other factors not important in mass calibration must be taken into account. However, the procedure used is designed to reveal the precision and accuracy actually being atained, whatever the sources of error in the measurement process.

Another new approach to calibration is a comparator system for radio standards, based on an Air Force suggestion. The work was supported by the Air Force. The strength of this system lies in its redundancy. In the version just completed special standards of power, impedance, voltage, and current are used. The interrelationships among these quantities provide a double redundancy which permits a check on systematic changes in the standards in addition to information on precision. There is practically no chance that a standard can drift beyond predetermined and acceptable limits without the drift being detected. The system has the potential of avoiding the use of arbitrarily set recalibration intervals and will enable the laboratory personnel to know that their standards are in calibration immediately before and/or after using them.

Traditionally, IBS has been concerned primarily with the central core of the measurement system. The two new approaches just described are examples of our broadened range of interest. In the pilot program for mass calibrations we are concerned with the output accuracy of top-level government and industrial standards laboratories. In the radio standards comparator we are helping to improve the output of military base calibration laboratories. These approaches provide the sort of objective evidence needed to demonstrate the precision and accuracy delivered by a standards laboratory. There is need, of course, for objective methods of demonstrating performance for other measurement quantities.

In addition, we are engaged in a study of the radio frequency calibration system of the Department of Defense, funded by the DoD Calibration Coordinating Group. This study covers the whole gamut of the calibration hierarchy and extends our interests to the production line and the field site. So you see that our active interest covers every echelon of the measurement system.

Such a broad view of the measurement system is necessary if we are to provide effective solutions to measurement problems. Investments by IBS in increased accuracy may be of little value unless adequate means are available for distributing the improvements to the ultimate users.

\section{Office of Measurement Services}

I would like to tell you about some recent organizational changes in IBS which, we hope, will increase our effectiveness--first, some changes made in Washington.

A few weeks ago, Dr. Ambler received approval to establish a new Office of Measurement Services as a part of the IBS Director's Office. Acting Chief of the new office is Mr. Joseph Cameron, formerly Chief of the Statistical Engineering Section. The purpose of the office is to improve the internal management of our calibration efforts and to make our services more effective.

I shall not devote much time to the internal operations of the new office but will simply say that it should provide management information and a management overview which will permit us to make better policy decisions and to develop 
smoother operational procedures. It will provide information on how operations are proceeding, as compared to our plans, so that corrections can be made promptly when needed. The technical responsibility for calibration services remains, of course, in the technical divisions. The office is expected to improve in many ways our services to our customers and, more broadly, to improve the relevance of our programs to national needs.

The functions of the office are:

(a) to cooperate with the technical divisions in gathering information and evaluating national calibration needs;

(b) to assist in planning for new IBS services and in phasing out old services when there are desirable alternatives;

(c) to spearhead and coordinate efforts to develop more effective documentation procedures which should be more meaningful to users of our services;

(d) to help achieve proper balance among the various types of services offered by IBS, including calibrations, interlaboratory measurement agreement programs, handbooks, and seminars; and

(e) to sponsor or carry out studies of the measurement system. We expect that the work of this office will lead, for example, to studies similar to our study of the DoD radio frequency calibration system but for other segments of the measurement system. Also, this work should lead to approaches equivalent to the mass pilot program or the radio standards comparator but for other measurement quantities.

\section{IBS Boulder Operations}

I would like to turn now to IBS Boulder operations to illustrate some of the management techniques used by IBS.

My job at IBS Boulder is unique in some respects. Here, both the technical divisions and the service divisions report to me. By contrast, in Washington, the service divisions report at the NBS level to an Associate Director or to the Deputy Director. The arrangement in Boulder complicates the management problem, but it provides an opportunity to couple the service divisions more directly with the technical divisions and make the overall program more effective.

I work in close cooperation with the Director of IBS to develop policy and to manage the Boulder operation in harmony with IBS Washington. Also, I work with the responsible officials at the NBS level to maintain reasonable consistency of operation between the Boulder support divisions and the corresponding divisions in Washington.

Here is how we work at keeping our program up to date. One of my staff offices is the Office of Program Development and Evaluation. This office contributes very strongly toward (a) gathering the data we need for management purposes, (b) analyzing these data and developing program plans, and (c) telling the IBS story.
For an organization to perform effectively, its management and the people in it must understand and agree upon their role. Such agreement can only be based on accurate information about what is going on. Therefore we must have up-to-date information on our fiscal situation, our manpower, and our facilities. We collect and analyze such information and supply it to our operating divisions. We must also know what is going on in the outside world that is relevant to our activities. We encourage the divisions to maintain extensive liaison with other organizations, and we supplement their work with efforts of our own. We collect long-range planning information from other major organizations and state-of-the-art forecasts closely related to our work.

Central leadership can be provided only through proper program analysis and planning. Having collected our data, we then work with the technical divisions to identify major issues and problems, to design and carry out program studies for sharpening our understanding, to develop long-range goals for IBS Boulder, and to devise programs for meeting measurement needs.

We have several program studies underway and are about to start more. We have contributed to state-of-the-art forecasts closely related to our fields of interest. We are continuing our efforts to clarify our mission and goals and are working out improved descriptions of our program structure and our outputs. These must be representative of what we do, and they must be understandable, both to the public and to our higher levels of management.

A specific goal of this office has been to develop an "output center" with displays showing the major outputs of our divisions. Such a center provides graphic displays which give visitors a quick grasp of our overall program. This center is still in the fledgling stage.

Our work is incomplete until our story is told. We have the know-how and the facilities for producing effective visual presentations to major visitors, to the devision advisory panels, and to management during program reviews of each division. Our prime interest is in helping speakers say what ought to be said, with maximum clarity and impact.

Now I would like to tell you a little more about our program evaluation and development process; in other words, about how we make program decisions. First, let me point out how we draw upon our own staff, through a series of program reviews. We devote approximately one day to the work of each division. The division chief and other key personnel of the division summarize their total program and report in detail on areas of specific interest. At the conclusion of the review, Dr. Ambler and I give confidential evaluations of the work to the division chief and make suggestions on priorities and program emphasis. We make formal program decisions near the beginning of the fiscal year, when funds are allocated. 
Second, let me describe our system of advisory panels, which meet in the fall and winter. Each division has its own panel, which meets with the division for two or three days to review and discuss its work and then submits its comments and recommendations to Dr. Ambler. The chairmen of the division panels collectively form an IBS advisory panel, which meets later in the year to provide coordinated advice to IBS. Finally, the IBS advisory panel meets with a "visiting committee" which advises the Secretary of Commerce on NBS. The members of the advisory panels are experts chosen from representative groups in government, industry, and the universities and who are directly involved with the subject matter of the division. Thus, the panels provide a formal, systematic method of supplying us with information for planning programs and for assessing their effectiveness.

Thus, you can see that through direct contacts with key organizations, maintained at many levels within IBS, through formal management reviews in which the key members of our staff are heard, and through our system of advisory panels, we have a good basis for effective program decisions. We still are far from perfection, but I would like you to know that some of our efforts have been received favorably by our higher management. You surely are aware of the Planning, Programming, and Budgeting (PPB) System which originated in $\mathrm{DoD}$ and now is being applied widely throughout government. The PPB efforts of NBS have been based largely on the concept of the National Measurement System developed by Huntoon. This approach has led to improved understanding and support of our programs within the Department of Commerce, the Bureau of the Budget, and (we believe) the Congress.

I am convinced that NBS receives recognition and support according to its response to the $\mathrm{Na}$ - tion's measurement needs and its effectiveness in making this response known to the Congress. I believe that our management approach in IBS gives us a firm foundation on which to build further success for NBS and further service to the Nation.

\section{Summary}

To summarize, I have shown that:

(1) IBS provides the central basis for the measurement system and also has accepted responsibility for central national leadership of the system.

(2) We are aware of many of the problems of the measurement system and are actively working toward solutions.

(3) We have established an Office of Measurement Services in Gaithersburg, to strengthen and to improve the effectiveness of our services.

(4) We have brought all NBS Boulder operations under a single management which is dedicated to improving the relevance of our programs to national needs.

I hope that during the coming months we can improve our effectiveness in support of the measurement system and, more specifically, that we can increase our usefulness to members of the $\mathrm{Na}$ tional Conference of Standards Laboratories, who form a very important part of this system.

\section{References}

[1] Huntoon, R. D., The Measurement System of the United States, NCSL 66, Proceedings of the 1966 Standards Laboratory Conference, Natl. Bureau of Standards Misc. Publication 291, issued July 13, 1967.

[2] Pontius, P. E., Measurement Philosophy of the Pilot Program for Mass Calibration, Natl. Bureau of Standards Tech. Note 288, issued May 6, 1966.

[3] Pontius, P. E., and J. M. Cameron, Realistic Uncertainties and the Mass Measurement Process, Natl. Bureau of Standards Monograph 103, issued August 15, 1967. 


\title{
WEAPON SYSTEM USER MANAGEMENT OF MEASUREMENTS
}

\author{
Ray Y. Bailey \\ Deputy Chief, Air Force Calibration and Metrology Division, Newark Air Force Station, Ohio 43055
}

The Air Force has a system of managing measurement requirements which was initially established in 1958. This system requires the producer of weapon systems to provide technical data on all measurement requirements and the list of equipments which are proposed for making these measurements.

\section{Introduction}

In 1958, the Air Force realized the requirement to provide management of measurement requirements being generated by new weapon systems developed for introduction into the Air Force operational inventory. The Thor missile system was selected to be the first weapon to be evaluated for true measurement requirements. An item-by-item review was made of all the subsystems to determine true measurement requirements. As a result of this review, formats were established and contractual documents were written to cover calibration requirements in the development and production of all future weapon systems.

\section{Calibration Requirements Summary}

The measurement requirements of a weapon system are identified in a four-part document known as a Calibration Requirements Summary (fig. 1). The requirement for preparing such a summary is levied upon the contractor by Military Specification MIL-Q-9858, which is a part of the contract.

The first of the four parts, Operational Equipment, identifies the part of the weapon to be measured. After the identification of the component or subsystem are columns listing the range, accuracy, operating parameters, number per squadron, and calibration item.

The second part, Peculiar Measuring Equipment, lists all special test or measuring equipment specifically designed to support this system. Here again are listed specification ranges and accuracies along with the quantity information. The item is here identified with the measurement requirement in the first part, usually by in-line presentation on the form.

The third part, Precision Measuring Equipment, lists the common test equipment used to test or measure the items of the first two categories.
The fourth part, Calibration Equipment, covers the standards and measuring equipment used by the calibration organization to support the other categories.

\section{Management Data}

From this display of the measurement requirements of the weapon system, several other actions are generated :

1. A determination is made by the Air Force of the suitability of the proposed equipment to meet the measurement needs. The equipment should not be unnecessarily sophisticated but it must meet the accuracy requirement of the item being tested.

2. A decision is made as to the capabilities of the Air Force calibration system to support the measurement requirements.

3. New calibration equipment requirements are identified and procurement actions initiated.

4. Training requirements on new measurement systems and equipments are identified and added to the established training courses. Workloads which must be supported at the operating location are identified to provide justification for manpower requirements.

5 . The capabilities of the higher echelon standards laboratories are reviewed to determine if the new measurement standards or equipments can be calibrated. This may involve a requirement for new or improved calibration services from the NBS.

The Calibration Requirement Summary is then published as an Air Force Technical Order for field use in support of the operational weapon system.

\section{Conclusions}

The Air Force considers the management of measurements a vital part of weapon system operation and maintenance. The Calibration Requirements Summary is the medium used to determine the management actions. The organization responsible for accomplishing these management actions is the Air Force Calibration and Metrology Division, Newark Air Force Station, Newark Ohio. 


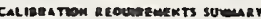

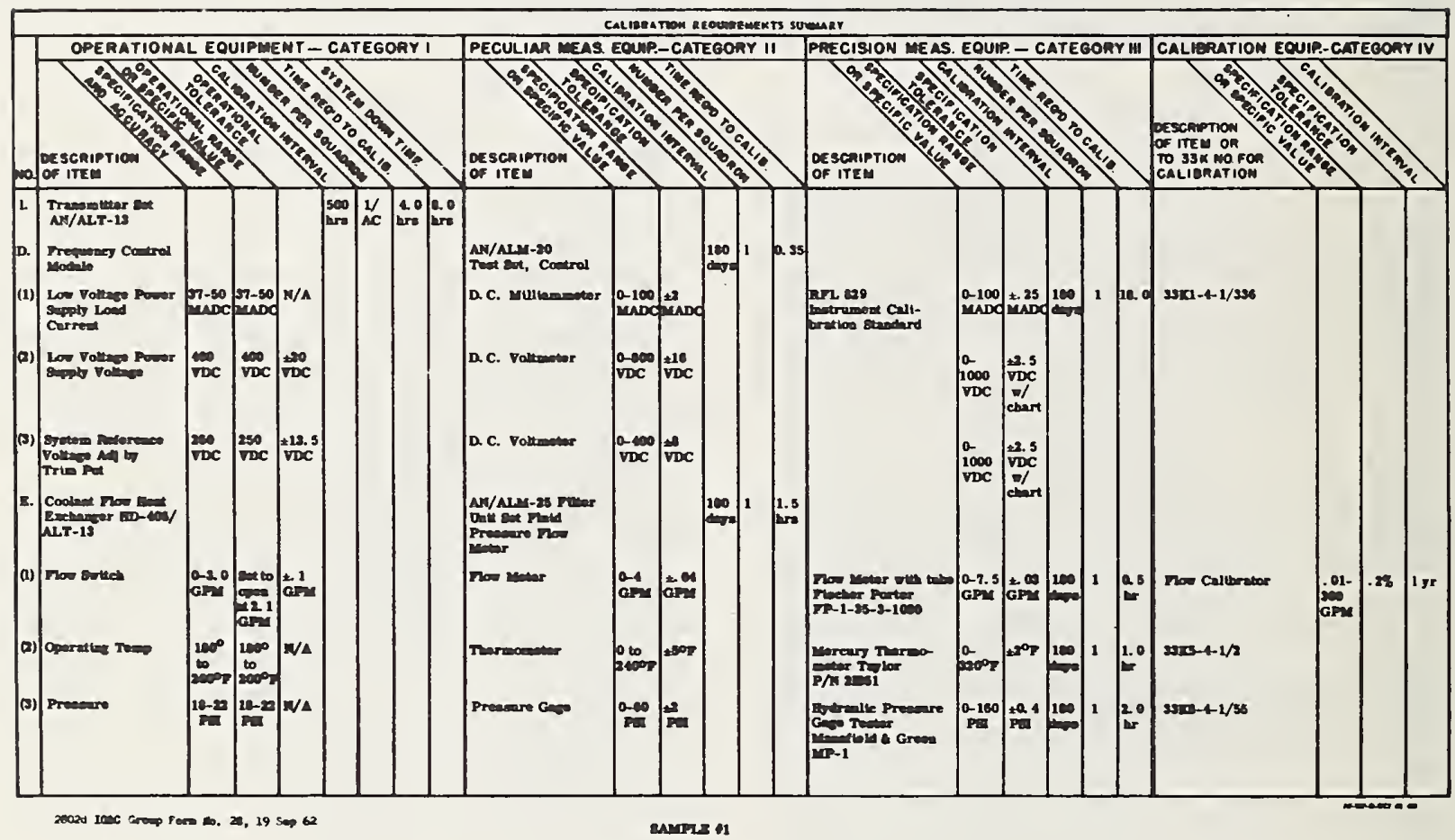




\title{
NATIONAL CONFERENCE OF STANDARDS LABORATORIES REPORT OF THE CHAIRMAN $1967-68$
}

\author{
C. E. White
}

Arco/MSD

\section{Management and General Activity}

The transition from operating year 1966-67 to the year 1967-68 was facilitated by the Chairman's re-election to office. First meeting of the Board of Directors was held on November 3,1968 at Boston in conjunction with the Northeast Electronic Research Engineering meetings sponsored annually by the New England Sections of the Institute of Electrical and Electronic Engineers. A report of the Board meeting and also of the two Workshops (Measurement Agreement Comparisons and Community Affairs for Standards Personnel) was contained in the December 1967 issue of the NCSL Newsletter (67-4). Officers and Board Members are listed in Attachment A to this report.

Other official meeting activities of NCSL included (a) Workshops on Jan. 24-26, 1968 and a Board Meeting on Jan 25, at Anaheim, California; (b) the NCSL 1968 Standards Laboratory Conference on Aug. 26-29, 1968, Board Meetings on Aug. 25 and Aug. 28, and the Delegates Assembly on Aug. 28, all at the NBS Boulder Laboratories in Colorado.

The Anaheim Workshops covered problem areas such as Information for Standards Laboratories, Recommended Practices, Workload Control, Production and Calibration Data, Calibration Procedures, Procurement Regulations, Measurement Agreement, and publication policies of the Standards Laboratory Directory. Details are contained in NCSL Newsletter 68-1, March 1968.

The biennial Standards Laboratory Conference featured numerous papers relating to "Making Valuable Measurements" and was reported in detail in the September, 1968 Newsletter (68-3). High spots were an opening address by Dr. A. V. Astin, Director of NBS, the luncheon speech by J. L. Sloop of NASA-Washington which stressed the role of measurement standards in society's environment and behavior, and eight papers from interested overseas activities. The Delegates Assembly conducted the annual election of officers, with H. W. Lance moving into the chairmanship.
Division of committee activities into four categories was maintained again this year with $J$. L. Hayes monitoring the "Operational" activities, E. J. Arsenault watching the "Activities" programs, H. W. Lance overseeing the work of the "Laboratory Management/Administration" committees, and O. L. Linebrink coordinating the work of the "Laboratory Technical Information/Support" activities. Personnel involved in NCSL committee activities are listed in Attachment B to this report.

An activity not covered by committee reports, is that centered around the idea of a "National Measurements Standards Week", originally conceived by Past Chairman Van de Houten in 1966. By action of the Board at Anaheim, in January 1968 the NCSL Chairman was given permission once again to interest Congress and the President in such an idea. Several meetings were arranged with a representative of the Speaker of the U.S. House of Representatives to establish an approach. At the conclusion of the meetings, the Chairman withdrew from this approach and arranged to present the idea to the Scientific Apparatus Makers Association (SAMA) with headquarters in Washington, D.C. The incoming President of SAMA, Nathan Cohn, was receptive to the plan in general, and during a meeting in September 1968 it was agreed that SAMA would coordinate the entire idea with the National Society of Professional Engineers (NSPE). This organization, with a sophistication in matters of this type far superior to that of NCSL or SAMA, presently is considering the theme as one suitable for a future National Engineers Week and will discuss the matter in subsequent meetings.

\section{NCSL Committee Activity}

A-1. Organization Committee. Prepared, and had accepted by the Board, a policy for handling requests for calibration procedures originating from non-United States members. Preliminary work was done toward control of financial liability 
of NCSL officers, and establishing procedures for NCSL meetings.

A-2. Nomination Committee. Reported a slate of officers for ballot at the Delegates Assembly; conducted the election on Aug. 28.

A-3/D-2. Finance/Audit Committees. Conducted the annual audit of the Treasurer's books; provided for temporary transition of Treasurer's duties from D. I. Hervig to J. R. Van de Houten; established a separate Calibration Procedures Library checking account; prepared an operating budget for 1967-68 and a preliminary budget for 1968-69; arranged to update and to increase liability amount covered by officer's' bonding policy; made an inconclusive survey of the position of NCSL with regards to the IRS; submitted suggested standardized reporting format for use by Treasurer.

A-4/D-1. Activities/Program Committees. Planned for and conducted workshop sessions at Boston on Nov. 2-3, 1967 and at Anaheim on Jan. 26-27, 1968; planned and coordinated functioning of 1968 Standards Laboratory Conference at Boulder on Aug. 26-29, 1968; planned for precision measurement seminar at Orange, California on Oct. 7-9, 1968.

A-5. Newsletter Committee. Published regular quarterly issues and distributed approximately 850 copies of each issue. Conducted cost study of typical issue to prepare for shift to commercial handling, if required in future. Total page issue for operating year was 222 pages.

A-6. Information Committee. Participated actively in sessions at the 1968 SLC and at the Anaheim Workshops; prepared and published in the Newsletter (June 1968) a bibliography on "Measurement Statistics".

A-7. Directory Committee. Distributed the 1967 edition in November, 1967 ; prepared and distributed the 1968 supplement in August 1968 at the 1968 SLC.

A-8. National Requirements Committee. Reorganizational changes within NBS, and the unexpected death of Sponsor's Delegate Dr. M. B. Wallenstein, prevented any effective work.

A-9. Recommended Practices Committee. The first tentative practice, approved for distribution, did not reach the members due to the chairman's change in position and location. A second practice in draft form on preparation of calibration procedures was distributed for review and comment in August 1968 at the 1968 SLC.

B-1. Workload Control Committee. Reorganization of the committee membership in this period was completed too late to accomplish more than some data accumulation resulting from a workshop at Anaheim. It is anticipated that a draft of a recommended practice for recall systems and intervals will be prepared during 1968-69.

B-2. Personnel Development Committee. Changes in position and location of several committee members effectively prevented any forward progress. No report has been received of future activity planning.

B-3/4/5/6. Measurements Standards Laboratory Committee. This committee actively participated in the Anaheim Workshops, and prepared a summary of a questionnaire distributed in 1967. Future activity appears to be based upon the theme of quality assurance methods to be employed in measurement laboratories.

B-7. Procurement Regulations Committee. During the 1968 SLC, the committee chairman displayed a coordinate index to military specifications concerned with calibration.

C-1/2/3/4. Criteria for Standards Committee. This committee was inactive and unmanned during 1967-68.

C-5. Measurement Agreement Comparison Committee. Actively participated in the Boston Workshops, Nov. 3, 1967 and at Anaheim, in order to receive direction for the 1968-69 program; questionnaires were directed to all $1965-66$ participants in the MAC program; committee meetings were held at Gaithersburg and Boulder during which decisions were made regarding operating practices for MAC and the possibility of techniques for comparison other than that presently employed, also the initiation of recommended practices for national and for inter-company programs.

C-6. Calibration Procedures Library Committee. During 1967-68, the committee established a basis for handling requests for procedures from U.S. and non-U.S. members. Steps also were taken to solicit offers from interested activities to take over physical control of the library, permitting NCSL activity to be expended in the direction of higher quality and common format of the reports, plus a reduction of redundancy. The library was closed by action of the Board until after Jan. 1, 1969 to permit a constructive review of material already assembled, to prepare for shipment of the library to another location, and to establish a recommended practice for writing procedures. The committee was extremely active during this year and participated directly in both the Anaheim Workshops and the 1968 SIC.

C-7. Statistical Procedures Committee. Although not participating in any of the year's programs, it is understood that the committee has prepared a definition glossary and a tentative statistical procedure for intercomparison of standard cells.

\section{Liaison Activity}

Active liaison was maintained with the USASI Committee $C-100$ (Electrical Standards) through NCSL representative K. Koep (Weston Instruments); with the IEEE G-IM Technical Subcommittee on Pulse Techniques through D. Antonucci (Grumman Aircraft); with the Precision Measurements Association through the services of P. Painchaud (E-H Research), D. 
Brungart (Teledyne) and R. Emst (NAR). In addition, correspondence bearing upon matters of related interests was exchanged with J. G. Cameron (Canadian Department of National Defence), L. D. Lawrence (American Society for Quality Control), F. McGinnis and L. Wilson (Aerospace Industries Association), O. L. Linebrink (Instrument Society of America), W. G. Amey (Scientific Apparatus Makers Association), H. E. Barnett and A. H. A. Wynn (British Calibration Service), and N. L. Lock (E.I.D.-British Ministry of Aviation).

A surprising number of other overseas organizations continued to maintain contact with NCSL. These included but were not limited to:

Working party on Instrument Behavior (WIB), Delft-Holland

Dutch Service of Weights and Measures, 's-Gravenhage-Holland

National Electrotechnical Institute, TurinItaly

Research Institute of National Defence, Stockholm-Sweden

Royal Academy of Engineering Sciences, Stockholm-Sweden

Directorate of Weights and Measures, New Delhi-India
National Physical Laboratory, New DelhiIndia

National Association of Testing Authorities, Chatswood-N.S.W.-Australia

Defence Standards Laboratory, Ascot ValeVictoria-Australia

Institute for Industrial Research and Standards, Dublin-Ireland

\section{Statistics}

The growth of our organization has been maintained steadily during the past few years and does not appear to be reaching a plateau in membership. As of September 30, 1968, membership was held by 203 organizations. A listing of member organizations is presented as Attachment $\mathrm{C}$ to this report.

The financial health of the organization continues to be satisfactory. The Treasurel's statement as of September 30, 1968 showed a balance of $\$ 34,612.52$ reflecting in part a larger-than-normal receipt of dues resulting from a billing for 18 months dues, in order to establish the new fiscal year. Outstanding are charges to be incurred for printing of the Proceedings of the 1968 Standards Laboratory Conference, and other unpaid costs incurred at the Conference, and for the Orange Seminar publicity mailings. 

